\title{
TECHNOLOGY-SUPPORTED REFLECTION: TOWARDS BRIDGING THE GAP BETWEEN THEORY AND PRACTICE IN TEACHER EDUCATION
}

Abdullah Almodaires 
DOCTORAL COMMITTEE

Chairman: $\quad$ Prof. dr.S. Dijkstra - University of Twente

Promoter: $\quad$ Prof. dr. ir. P. Verhagen - University of Twente

Assistant promoter: $\quad$ Dr. P. H. G. Fisser - University of Twente

Members: $\quad$ Prof. dr. J. M. Pieters - University of Twente

Prof. dr. J. F. M. Letschert - University of Twente

Prof. Dr. P. R. J. Simons - University of Utrecht

Prof. Dr. J. J. Beishuizen - Free University Amsterdam

Prof. dr. W. A. J. M. Kuiper - University of Utrecht

Dr. E. van den Berg · University of Twente

Almodaires, Abdullah Abdulaziz

Technology-supported reflection: Towards bridging the gap between theory and practice in teacher education

Thesis University of Twente, Enschede.

ISBN 978-90-365-2828-3

DOI $10.3990 / 1.9789036528283$

Layout: Sandra Schele

Press: PrintPartners Ipskamp - Enschede

(C) Copyright, 2009, Abdullah Abdulaziz Almodaires

All rights reserved. No part of this book may be produced in any form: by print, photocopy, microfilm, or any other means without written permission from the author. 
TECHNOLOGY-SUPPORTED REFLECTION:

TOWARDS BRIDGING THE GAP BETWEEN

THEORY AND PRACTICE IN TEACHER EDUCATION

\section{DISSERTATION}

to obtain

the degree of doctor at the University of Twente

on the authority of the rector magnificus

prof. dr. H. Brinksma

on account of the decision of the graduation committee

to be publicly defended

on Wednesday the $24^{\text {th }}$ of June 2009 at 15.00

by

Abdullah Abdulaziz Almodaires

born on the $15^{\text {th }}$ of August 1973

in Kuwait, Kuwait 
Promoters:

Assistant promoter
Prof. dr. ir. P.W. Verhagen

Dr. P.H.G. Fisser

This dissertation has been approved by the promoter and assistant promoter. 


\section{TABLE OF CONTENTS}

\section{TEACHER PREPARATION AND THE GAP BETWEEN THEORY AND}

PRACTICE

1.1 Teacher education 1

1.2 Teacher education in Kuwait 2

$\begin{array}{ll}1.3 \text { Problem statement } & 7\end{array}$

1.4 Aim of the research 9

$\begin{array}{ll}1.5 \text { Research questions } & 10\end{array}$

$\begin{array}{ll}1.6 & \text { Research overview } \\ \end{array}$

2 THE REFLECTIVE PRACTICE APPROACH 15

$\begin{array}{lll}2.1 & \text { Learning and the notion of reflection } & 17\end{array}$

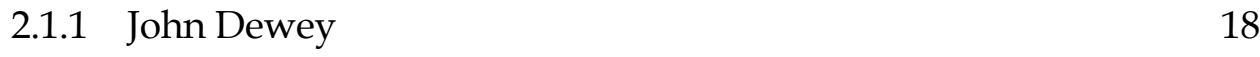

2.1.2 Donald Schön 20

2.2 Reflection Models 21

2.2.1 Boud, Keogh and Walker 21

2.2.2 Korthagen 24

$\begin{array}{lll}2.3 & \text { Difficulties in practicing reflection } & 27\end{array}$

2.4 Discussion 31

3 ICT-SUPPORTED REFLECTION

3.1 Video use in teacher education 36

3.2 Offline video-based learning environments 40

3.3 Online video-based learning environments 42

$\begin{array}{lll}3.4 & \text { Discussion } & 47\end{array}$

3.4.1 ICT-supported reflection $\quad 47$

3.4.2 Difficulties in practicing reflection supported by an online video-based learning environment 49 
4 Methodology OF THE RESEARCH: ACTION RESEARCH

4.1 Methodological framework for addressing the research questions 51

4.2 Rationale for choice of research methodology 53

4.3 Action Research methodology 56

4.3.1 Overview of action research 56

4.3.2 Process of action research 57

4.3.3 Data collection methods in action research 59

4.4 The research questions in data collection context 60

4.4.1 Data concerning the reflective practice approach (RQ1) 60

4.4.2 Data concerning the online video-based learning environments (RQ2) 61

4.4.3 Data concerning the opportunities of utilizing the reflective practice in teacher education program in Kuwait (RQ3) 61

4.4.4 Data concerning the difficulties in practicing the reflection (RQ4) 62

4.4.5 Data concerning the effectiveness of the online environment (RQ5) 62

4.4.6 Data concerning the reflection's influence on the learning achievement and on the gap between theory and practice (RQ6) 63

4.5 Overview of the data collection instruments 64

4.5.1 Literature review $\quad 64$

4.5.2 Documents analysis $\quad 64$

$\begin{array}{lll}4.5 .3 & \text { Questionnaires } & 65\end{array}$

4.5.4 Interviews 66

$\begin{array}{lll}4.6 & \text { Summary } & 67\end{array}$

5 DESIGN OF THE EXPERIMENTAL FIELD STUDY 69

5.1 Context of the field experiment 70

5.1.1 The College of Basic Education in PAAET 71

5.1.2 ICT infrastructure in the College of Basic Education 73

5.1.3 Field training in the College of Basic Education 76

5.1.3.1 English Language department (prospective teachers) 77

5.1.3.2 Educational Technology department (prospective trainers) $\quad 79$

5.1.4 Conclusion 
$\begin{array}{lll}5.2 & \text { Participants } & 82\end{array}$

5.2.1 Computers and the Internet, experience, and skills 83

5.2.2 Digital video cameras, experience, and skills 85

5.2.3 Channels of communication, availability, and efficiency 86

5.2.4 Reflective practice, knowledge, experience, and practice 87

$\begin{array}{lll}5.2 .5 & \text { Discussion } & 89\end{array}$

$\begin{array}{lll}5.3 & \text { Method and procedure } & 91\end{array}$

5.3.1 Stage one: the preparation stage 92

5.3.2 Stage two: the experimental stage 94

5.3.3 Stage three: the data collection stage 98

5.3.4 Schedule of the experiment 98

5.4 Materials 99

5.4.1 A generic model for practicing reflection 100

5.4.2 The online video-based learning environment 104

5.4.2.1 V-class for supervisors 106

5.4.2.2 V-class for participants 109

5.5 Data collection instruments for the field experiment 113

5.5.1 Difficulties Questionnaire 113

5.5.2 Effectiveness Questionnaire 116

$\begin{array}{lll}\text { 5.5.3 Achievement Questionnaire } & 117\end{array}$

$\begin{array}{ll}\text { 5.5.4 Interviews } & 119\end{array}$

$\begin{array}{lll}\text { 5.5.4.1 Supervisors interview } & 119\end{array}$

5.5.4.2 Group 2 and 4 interview $\quad 120$

5.5.4.3 Group 1 and 3 interview 121

$\begin{array}{lll}5.6 & \text { Summary } & 123\end{array}$

6 DIFFICULTIES IN PRACTICING REFLECTION 125

$\begin{array}{lll}6.1 & \text { Difficulties questionnaire } & 126\end{array}$

6.1.1 Difficulties related to the activities of recording 126

6.1.2 Difficulties related to the activities of description 128

6.1.3 Difficulties related to the activities of self-reflection 129

6.1.4 Difficulties related to the activities of peer-reflection 129

6.1.5 Difficulties related to the activities of finding alternatives 130

6.1.6 Summary of the results of the Difficulties Questionnaire 131

$\begin{array}{ll}6.2 & \text { Participants' interview } \\ & 133\end{array}$ 
$\begin{array}{lll}6.3 & \text { Discussion } & 137\end{array}$

$\begin{array}{lll}\text { 6.3.1 Results comparison } & 137\end{array}$

6.3.2 Difficulties in practicing the activities of reflection 139

6.3.2.1 Personal and social barriers 140

6.3.2.2 Knowledge and skills barriers 141

6.3.2.3 Technical and organizational barriers 143

7 FACILITATING REFLECTION: EFFECTIVENESS OF THE V-CLASS $\begin{array}{ll}\text { ENVIRONMENT } & 145\end{array}$

$\begin{array}{lll}7.1 & \text { Effectiveness questionnaire } & 146\end{array}$

7.1.1 The usability of the V-class environment 146

7.1.2 The usefulness of the V-class environment 148

7.1.3 Summary of the results of the Effectiveness

Questionnaire 149

$\begin{array}{lll}7.2 & \text { Participants' interview } & 149\end{array}$

$\begin{array}{lll}7.3 & \text { Discussion } & 152\end{array}$

7.3.1 Results comparison 152

7.3.2 Effectiveness of the V-class environment 153

8 REFLECTION AND LEARNING ACHIEVEMENT $\quad 155$

$\begin{array}{lll}8.1 & \text { Achievement questionnaire } & 155\end{array}$

8.1.1 Effect on connecting theory and practice 156

8.1.2 Effect on mastering the practiced competences 157

8.1.3 Summary of the results of the Achievement

Questionnaire 158

$\begin{array}{ll}\text { 8.2 Participants' interview } & 158\end{array}$

$\begin{array}{ll}\text { 8.2.1 General questions } & 159\end{array}$

8.2.2 The pedagogical influence of the reflection activities 163

8.2.3 Additional questions (Group 1 and 3) 165

$\begin{array}{ll}\text { 8.2.4 Summary } & 169\end{array}$

$\begin{array}{lll}8.3 & \text { Supervisors' interview } & 170\end{array}$

$\begin{array}{ll}\text { 8.3.1 General questions } & 171\end{array}$

8.3.2 The influence of reflection on the field training 172

8.3.3 The influence of reflection on the gap between theory

$\begin{array}{ll}\text { 8.3.4 Summary } & 176\end{array}$ 
$\begin{array}{lll}8.4 & \text { Discussion } & 176\end{array}$

$\begin{array}{lll}\text { 8.4.1 Results comparison } & 177\end{array}$

$\begin{array}{lll}\text { 8.4.2 Reflection and learning } & 178\end{array}$

9 GENERAL DISCUSSION

$\begin{array}{lll}9.1 & \text { Revisiting the experiment's findings } & 185\end{array}$

9.1.1 Discussion related to the difficulties (RQ4) 186

9.1.2 Discussion related to the effectiveness (RQ5) 187

9.1.3 Discussion related to the achievement (RQ6) 189

9.2 Reflection and the gap between theory and practice 190

9.3 Conceptual and practical contributions of the study 192

$\begin{array}{ll}9.4 & \text { Limitations of the study } \\ & 193\end{array}$

9.4.1 Possible novelty effect 193

9.4.2 The trustworthiness of the self reporting findings 194

$\begin{array}{ll}\text { 9.4.3 Sample's constraints } & 195\end{array}$

9.5 Recommendations for further researches 195

$\begin{array}{ll}9.6 \text { Concluding remarks } & 196\end{array}$

$\begin{array}{ll}\text { REFERENCES } & 197\end{array}$

$\begin{array}{lr}\text { ENGLISH SUMMARY } & 207\end{array}$

APPENDICES

Appendix 1: The Background Questionnaire 223

Appendix 2: Field training evaluation form $\quad 231$

Appendix 3: Results of the Background Questionnaire 235

Appendix 4: Main functionalities in the supervisors' V-class

environment 241

Appendix 5: Main components of the participants' module page in the V-class environment 247

Appendix 6: Guidelines for supervisors' interview 253

Appendix 7: Guidelines for students' interviews (G 2\&4) 255

Appendix 8: Guidelines for students' interviews (G 1\&3) 257

Appendix 9: Results of the Difficulties Questionnaire 259

Appendix 10: Results of the Effectiveness Questionnaire 261

Appendix 11: Results of the Achievement Questionnaire 263 


\section{LIST OF FIGURES AND TABLES}

\section{FIGURES}

2.1 Kantian Epistemology of Reflection 18

2.2 Model of reflection in the learning process 23

2.3 The ALACT model 25

2.4 Concretizing questions for stage 2 of the ALACT model 25

3.1 Understanding Teaching learning environment 41

3.2 Making Weighty Decisions learning environment 42

3.3 Modules window in DiViDU leaning environment 45

4.1 Action research model 58

$\begin{array}{lll}5.1 & \text { PAAET's structure } & 73\end{array}$

5.2 The reflective practice model 103

$\begin{array}{lll}5.3 & \text { The V-class environment } & 105\end{array}$

5.4 Flowchart of the structure of the supervisor's environment 106

5.5 Supervisors' main page in the V-class environment 109

5.6 Flowchart of the structure of the participants' environment 110

5.7 Participants' main page in the V-class environment 112

\section{TABLES}

4.1 Case Studies and Action Research 55

5.1 ICT infrastructure matrix $\quad 75$

5.2 Field training requirements for English language teachers 78

5.3 Field training requirements for Educational technologists 81

5.4 Computers and Internet background's questions 84

5.5 Digital video cameras background's questions 85

5.6 Availability and efficiency of the channels of communication's $\begin{array}{ll}\text { questions } & 86\end{array}$

5.7 Knowledge and experiences of the reflective practice's questions $\quad 88$

5.8 The main activities in the introduction session 93

5.9 The main activities in the workshop 94 
5.10 The arrangement of the competences within the experiment

5.11 The main activities in the group's reflection session 98

5.12 Groups' activities 99

5.13 The Difficulties Questionnaire 115

5.14 The usability of the environment 116

5.15 The usefulness of the environment 117

5.16 The Achievement Questionnaire 18

5.17 Interview for the Supervisors $\quad 120$

5.18 Interview for the participants of group $2 \& 4 \quad 121$

5.19 Interview for the participants of group $1 \& 3 \quad 122$

5.20 Summary to the main design and organization issues in the $\begin{array}{ll}\text { experiment } & 123\end{array}$

6.1 Difficulties related to the activities of recording 127

6.2 Difficulties related to the activities of description 128

6.3 Difficulties related to the activities of self-reflection 129

6.4 Difficulties related to the activities of peer-reflection 130

6.5 Difficulties related to the activities of finding alternatives 131

6.6 Participants' responses on the difficulties questions of the $\begin{array}{ll}\text { interview } & 135\end{array}$

6.7 Summary to the difficulties from practicing reflection in the field $\begin{array}{ll}\text { training in Kuwait } & 139\end{array}$

7.1 The usability of the V-class environment 147

7.2 The usefulness of the V-class environment 148

7.3 Participants' responses to the questions of the fourth part of the $\begin{array}{ll}\text { interview } & 151\end{array}$

8.1 The effect of the reflection in connecting theory to practice 156

8.2 The effect of the reflection in mastering the required competences 157

8.3 Participants' response to the first question of this section 160

8.4 Participants' response to the second question of this section 161

8.5 Participants' response to the third question of this section 162

8.6 Participants' response to the questions of this section 164

8.7 Participants' responses on the additional questions of the first $\begin{array}{ll}\text { section of the interview } & 166\end{array}$

8.8 Participants' response to the first three questions in the additional $\begin{array}{ll}\text { section of the interview for Groups } 1 \text { and } 3 & 168\end{array}$

8.9 Participants' response to questions four and five in the additional section of the interview for Groups 1 and 3 
8.10 Supervisors' response to the questions of the first section of the interview

8.11 Supervisors' response to the questions of the second section of the interview

8.12 Supervisors' response on the questions of the third section of the interview 


\section{CHAPTER 1}

\section{Teacher preparation and the gap between theory and practice}

The ability to convert theoretical knowledge into practical behavior is a common obstacle facing new, just graduated employees in most professions. To overcome this obstacle, educational institutes are offering some kind of field training courses that allow their students to practice and gain experience in a real professional situation. In some professional training institutes, such as teacher education and nursing institutes, these courses are usually mandatory requirements for completing the program. The goal of the field training is to give the students the opportunity to apply their theoretical knowledge, under experienced supervision, in a real professional context.

Teacher education programs are one of the main educational programs that use field training. Field training in this kind of program supports the period of transition between the initial training of prospective teachers and their entry into professional life as fully qualified teachers (European Commission, 2002). Regarding this transition, many educators, for instance Buckingham (2005), Smith (2000), Stigler and Hiebert (1999) and Schön (1987) warn about a gap between the theoretical knowledge that is acquired from the educational program and the practical skills that are required at the schools. This gap is also found in the teacher education programs in Kuwait (AlDeeb, 1997). The poor performance of the field training in developing prospective teachers' competences is presented as an important factor that is causing this gap in teacher education in Kuwait (Hasan, 2001). Improving the performance of the field training in these programs could lead to reducing the gap between theory and practice. This study attempts to improve the field training in the teacher education programs in Kuwait through the facilitation of the reflective practice approach supported by ICT applications among prospective teachers. 
In this chapter, an overview of this research will be given. Section 1.1 will present a general overview of the development of teacher education programs over the years and the role of field training in these programs. An introduction to the teacher education programs in Kuwait and the arrangement of field training in these programs will be described in section 1.2. Section 1.3 will introduce the problem that drives the research and section 1.4 will state the aim of the research. The research questions based on the aim of the research will then be formulated in section 1.5. Section 1.6 will conclude this chapter with an overview of this research and an overview of the following chapters.

\subsection{TEACHER EDUCATION}

Teacher education is an educational program that aims to prepare prospective teachers to work in schools. The first formal teacher education program was established in France in the second half of the seventeenth century, precisely in 1681 when the Christian Brothers opened the "école normale" ("The New-York Times," 1890, p.8). The term "Normal school", which is the translation of "école normale", was used for a long time to describe the field of teacher education. It is now considered an archaic term in most countries and has been replaced with teacher training or teacher education schools. Following the French, the first school for teacher education in Germany was opened in Berlin in the 1740s. The first school for teacher education in the United States, however, was opened in the 1820s. At the end of the nineteenth century in France and Germany alone, there were about three hundred schools for teacher education ("The New-York Times," 1890, p.8). Today, teacher education schools are an essential part of the higher education system in almost all countries.

The organization of teacher education programs has gone through several stages since the beginning in the seventeenth century. In the early days, there was no dominant form for the organization of teacher education programs. However, in a number of cases the organization of the program took the form of an organized meeting between experienced and prospective teachers for a couple of weeks to discuss teaching-related issues. In other cases, prospective teachers had to attend a local school board meeting to demonstrate their moral character and abilities. The first major turn in the organization of teacher education was in the nineteenth century. At that time, prospective teachers were required to pass a

qualification exam that usually included several topics such as spelling, 
grammar, and history as well as a demonstration of some basic teaching skills. Another shift was in the twentieth century when increasingly teacher education schools were expanded into colleges and institutes (Ravitch, 2002). Currently, the program of teacher education requires from three and up to seven years of study and practice, and as a result, the graduate usually obtains a bachelors or masters degree in the profession of teaching.

With the development of teacher education programs, the complexity of organizing these programs has increased particularly with respect to the curriculum's components and the delivery strategies. Even though the curriculum of teacher education programs varies between one program and another, two main components can be distinguished among the majority of teacher education programs. They are as follows:

- General component: in this component, the focus is on the development of students' knowledge regarding the content-area of their specialty, and

- Professional component: the focus here is on developing students' knowledge and skills regarding the profession of teaching. Subjects such as sociology, psychology, and teaching methods in addition to field training in schools are provided (European Commission, 2002).

To deliver these components, either the so-called concurrent model or the consecutive model is commonly used based on the policy of the college. Moreover, in some programs, a combination of these two models is applied. On the one hand, the strategy of the concurrent model is to apply the professional component at the same time as the general component from the beginning of the program. The consecutive model strategy, on the other hand, is to apply the professional component in a second phase of the program after completing all or most of the courses in the general component (European Commission, 2005).

Field training as a part of the professional component takes place at an early stage when the program is implementing the concurrent model while field training comes in a later stage when the program is following the consecutive model. In these types of field training, prospective teachers are supervised by a coach from the work place and assessed by their instructor from the educational institute. However, the engagement of the field training during the study program, whether based on the concurrent model or the consecutive model, is relatively short and unremunerated (European Commission, 2002).

Many teacher education colleges recently extended their program's structure to 
include a final phase that usually occurs after the completion of both the general and the professional components of the program. The final 'on-the-job' qualifying phase is intensive field training that aims to facilitate the transition from the study environment to the real professional environment and to ensure the quality of the prospective teachers. The final 'on-the-job' qualifying phase has been used in teacher education programs of some countries like Germany and France since the 1970s. In other countries such as the Netherlands and the United Kingdom, the implementation of this phase was utilized at the end of the 1990s. Providing this kind of training phase in the end of the teacher education program is also taking place increasingly in many other countries (European Commission, 2002). The duration of this phase usually takes one or two years in schools where prospective teachers practice their performance under the supervision of a qualified coach. Prospective teachers, at the end of this phase and by satisfying certain evaluation criteria, become fully qualified teachers (European Commission, 2002).

An interesting implementation strategy for utilizing field training in teacher education programs can be found in the Netherlands. In this strategy, prospective teachers practice the field training regularly at the same time they acquire the general and professional knowledge. Prospective teachers for elementary schools in the Netherlands practice field training from the beginning of the program until the end aiming to connect what they learn in the program into a real teaching practice in the schools (Blijleven, 2005).

The gap between theory and practice in teacher education programs is a major factor that triggers this increased attention to the importance of field training and the variation of the implementation strategies. An effective field training that can connect the theories that have been learned into the practice of teaching is assumed to reduce this gap.

The development of teacher education programs and the role of field training in these programs were presented in this section. In order to put the Kuwaiti situation in context, the development of teacher education programs in Kuwait and the arrangement of field training in these programs will be described in the next section. 


\subsection{TEACHER EDUCATION IN KUWAIT}

The College of Education in Kuwait University and the College of Basic Education in the Public Authority for Applied Education and Training (PAAET) are the only educational colleges offering a program for teacher education in Kuwait. The College of Education in Kuwait University was established in 1980 after being a department in the College of Art since the establishment of Kuwait University in 1966 (AlThuwaini, 2003). The College of Basic Education in PAAET was established in 1986 as a college with four years programs; however, since 1949 this college has existed as a teacher institute that offers a diploma in teacher education following a two-year program (AlHamad, Behbahani, \& AlShargawi, 1995). Both Kuwait University and PAAET are governmental organizations, which explains the similarity in the goals and the organization of their teacher education program. Nevertheless, while the aim of the College of Education in Kuwait University is to prepare teachers for all schools levels (kindergarten, elementary, intermediate, and secondary); the aim of the College of Basic Education in PAAET is to prepare teachers for kindergarten and elementary school only.

The study program in both colleges consists of four years that are divided into eight semesters. Students spend the first seven semesters in the college learning theoretical knowledge while the last semester is devoted to the field training in schools. Both colleges also share a general goal, which is to educate and train teachers who are able to fulfill the demands and needs of the Kuwaiti's labor market (Hasan, 2001). In order to achieve this goal, the curriculum of teacher education includes three main components: a cultural preparation component, an academic preparation component, and a professional (vocational) preparation component (AbuZaina, Hassan \& AlJazzar, 1990). They are defined as follows:

- The cultural component of the program focuses on the development of students' knowledge in the fields of philosophy and social science with respect to the culture in Kuwait.

- The academic component of the program introduces the students to the contentarea in the field of their specialization together with the principles for teaching these specific subjects, for instance mathematics, language, religion and so on.

- The professional or vocational component focuses on several topics that are related to the practice of teaching such as teaching methods, evaluation and assessment, curriculum, and field training. 
In the College of Basic Education, these three components were allocated in a way that the cultural component covers $38 \%$ of the study program and the academic component covers $32 \%$ of the study program while the professional component covers $30 \%$ of the study program (Hasan, 2001).

To deliver these components, both teacher education programs in Kuwait are using the consecutive model of delivery. The load of the three components in the program is divided all through the eight semesters. In the first seven semesters, the focus of the program is on delivering the theoretical components without any kind of field training. After passing all the theoretical components, prospective teachers will be qualified to attend the field training in the last semester of the program.

AlDeeb (1997) conducted a comparison study between teacher education programs in Kuwait and similar programs in Japan, Germany, the United Kingdom, and the United States. Concerning the field training, he found that while other programs require one year of practical field training after graduation, the programs in Kuwait do not include this requirement. Even 12 years after this study, the programs in Kuwait still do not include this requirement while other programs like those in the Netherlands have developed to allow prospective teachers to practice field training from the beginning until the end of their program.

Field training, however, is a compulsory requirement in the teacher education programs in Kuwait. The office responsible for arranging the field training activities for all departments within the college is the 'Field Training Center', which can be found in both teacher education colleges in Kuwait. The field training center describes their mission as to produce qualified teachers who have the knowledge and skills that allow them to practice the profession of teaching successfully. To accomplish this mission, three main objectives for the field training were identified as follows:

- To prepare the prospective teachers vocationally in the field of their expertise,

- To give prospective teachers the opportunity to practice their competences and to deal with real professional situations, and

- To help prospective teachers develop their skills and performance and take responsibility for their actions (Kuwait University, 2007). 
In order to fulfill the mission and objectives of the field training center, the following aspects are presented as the responsibility of this center in relation to the prospective teachers as described on their website (Kuwait University, 2007):

- To determine the objectives of the field training,

- To supervise the implementation and the development of the field training,

- To plan the field training based on the college's strategies and goals,

- To distribute prospective teachers in schools based on their specialties, and

- To facilitate prospective teachers' needs of the educational technologies equipment.

The field training takes place in the last semester of the teacher education program and covers about $10 \%$ of the duration of the program. Prospective teachers must prove that they acquired the needed knowledge and skills by completing all courses in the program in order to attend the field training. During the field training, an internal coach from the school and an external supervisor from the educational program will be assigned to supervise the trainees' progress and to assess their performance. Each of the trainees will work in the field training on developing their performance and competences in a different school separately from their peers.

This separation, in fact, is causing a communication problem among prospective teachers during the field training, consequently preventing them from sharing and reflecting on each other's experiences. And it is this sharing and reflecting that seems to be very important in the learning process, because learning through reflection plays a significant role in building a bridge between theory and practice (Schön, 1987). In order to identify the specific problem that drives this research, the next section will discuss the importance of the reflection activities as well as the separation problem that is preventing this reflection among prospective teachers in field training in the teacher education programs in Kuwait.

\subsection{Problem STATEMENT}

Many educators emphasize the effectiveness of the reflective practice approach in developing prospective teachers' competences (See for instance Korthagen \& Kessels, 1999; Loughran, 2002; Newhouse, Lane \& Brown, 2007; Richert, 2005; Schön, 1987). Reflective practice or reflection is described by Schön (1987) as a 
vital component of the learning process. Farrell (1995b, p.95) defines reflection as "an activity or process in which experience is recalled, considered and evaluated in relation to a broader purpose". This approach is recommended by many researchers as an effective method to support teachers' move from routine actions in their teaching into more considered cognitive actions (Farrell, 1995a; Vallance, 2006; Vallance, 2008). Accordingly, reflective practice can be found today in many teacher education programs worldwide as a valued record of teaching practice (Murphy, 2003; Vallance, 2008). Prospective teachers in these programs are encouraged to reflect on their performance in order to transfer the theories that have been learned during the program into the practice of teaching in schools.

Furthermore, based on social-constructivism, learning from each other's experiences and reflecting on these experiences are also considered a significant component in developing learners' knowledge. In social-constructivism theory, learners gain their view of reality and construct knowledge through socially mediated processing (Warrick, 2001). Vygotsky (1978) argued that, with help and supervision from adults or peers, students can grasp advanced knowledge that cannot be gained independently. Therefore, in addition to the added value from reflecting on one's own experience, peer-reflection as a social mediated process extends the potential and the effectiveness of the reflection approach and provides more in depth reflection to the experience. Moreover, Kulk, Janssen, Gielis and Scheringa (2005) presented the isolation of prospective teachers from their peers during field training as a major problem that limits their range of behaviors within the profession. The exchange of experiences and the reflection on these experiences among prospective teachers, therefore, are expected to expand their perception of the range of behaviors within the same context.

Based on these advantages of the reflective practice approach, it can be proposed that incorporating the activities of reflection in the field training in teacher education programs in Kuwait appears to improve the performance of the field training. Accordingly, this incorporating appears to bridge or at least to reduce the gap between theory and practice in these programs. However, several barriers are likely to intervene in the utilization of the reflective practice approach in teacher education programs in Kuwait.

A major barrier relates to the complexity of recalling the different details in an experience in order to describe and analyze this experience. This barrier has been highlighted in several research studies as a major difficulty holding down the 
potential of the reflection approach and is also described sometimes as a major weakness in this approach (Boud, Keogh \& Walker, 1985; Mackintosh, 1998). A second barrier is related to the arrangement of the field training in the teacher education programs in Kuwait specifically where each prospective teacher performs his or her task alone in a different school. This arrangement is isolating these trainees from each other with almost no channel of communication. It is considered another major obstacle for the utilization of particularly the peerreflection activities in the field training. Thirdly, introducing a completely new pedagogical approach is expected to bring along with it some complexities. This also applies to the implementation of the reflective practice approach in the teacher education programs in Kuwait. Therefore, in order to implement this approach effectively, these barriers need to be taken into account.

\subsection{AIM OF THE RESEARCH}

The description in Section 1.3 shows potential for the reflective practice approach to bridge the gap between theory and practice in teacher education. Yet, several barriers were presented as obstacles toward the implementation of this approach. Therefore, in order for prospective teachers to reflect on their own experiences effectively, they need first to be able to clearly recall these experiences. Furthermore, for prospective teachers to practice the peer-reflection activities they also need to have access to their peers' experiences and be able to observe their peers' behaviors in similar situations. The practice of a new approach also requires some kind of support and guidance. Thus, this research attempts to find a solution to overcome these barriers in order to reduce the gap between theory and practice in the teacher education through the utilization of the reflective practice approach.

Providing prospective teachers with tools that have the ability to facilitate the recalling of the experienced activities and to strengthen the channels of communication among prospective teachers is assumed to support the implementation of the reflective practice approach. Today's classrooms are full of different kinds of technology equipment and applications that provide effective solutions for many educational problems. The field training component in teacher education could also make use of this technology to overcome the recalling of the experiences and the communication barriers. In fact, several attempts have already been made in the last decade to use technology for improving the performance of field training (Kulk et al., 2005; Newhouse et al., 2007). 
Particularly, the use of video applications in an online learning environment in teacher education programs was tested on several occasions and it showed promising impact and potential use for the field training (Kulk et al., 2005; Newhouse et al., 2007). For example, Kulk et al. (2005) evaluated the use of video in an online task-based learning environment during the Digital Video for Digital University (DiViDU) project. They stated interesting functionalities of such environment for field training in their evaluation. Furthermore, the Third International Mathematics and Science Study-Repeat (TIMSS-R) Video Study, which results in the development of the LessonLab online learning platform, is another successful example of the use of video in teacher education (Hiebert, Gallimore, Garnier et al., 2003). Examples of the use of video applications in online environments in education will be described in more detail in Chapter 3.

The use of video in an online learning environment in both examples and many others that will be presented in Chapter 3 shows significant opportunities into the context of our research. For instance, recording the performance on video will allow prospective teachers to watch their performance, which will facilitate the self-reflection activities. Furthermore, through the recorded video prospective teachers will be able to demonstrate objectively their performance to their peers, facilitating peer reflection. Moreover, with respect to the separation of the prospective teachers during the field training, the use of the online learning

environment will provide them with communication channels that support the exchange of experiences and the reflection activities. Based on those expected opportunities of the online video-based learning environments for our research, the aim of this research is formulated as follows:

To reduce the gap between theory and practice in the teacher education programs in Kuwait by the utilization of the reflective practice approach in the field training supported by an online video-based learning environment.

\subsection{RESEARCH QUESTIONS}

Based upon the aim of the research that has been described in the previous section, a general question has been developed that serves as the overall question for this research: 
Does the use of the reflective practice approach supported by an online videobased learning environment in field training in teacher education programs have pedagogical advantages in reducing the gap between theory and practice?

This overall research question is studied in the case of the Kuwait teacher education programs by six more focused questions that are formulated to cover all aspects within this question. The first of these questions is investigating the reflective practice approach that is used in teacher education and the benefits from using this approach for the field training. This question is expressed as follows:

RQ1: What is meant by the reflective practice and how has it been used as an educational approach?

Moreover, a second research question is formulated to understand the potential of ICT in general and the online video-based learning environments in particular for supporting the practice of reflection in teacher education and is stated as follows:

$R Q 2:$ What are the opportunities of ICT for supporting the reflective practice approach in teacher education?

These two research questions will be addressed by studying the literature regarding the reflective practice approach and the employment of video technology in education in general and through the Internet in particular. The third question is concerned with the management of the teacher education program in Kuwait and the role of the field training in this program. This question is formulated as follows:

RQ3: What are the opportunities for using the reflective practice approach and an online video-based learning environment in field training in the teacher education programs in Kuwait?

Documents related to the organization of the teacher education program and the involvement of the field training in this program in the College of Basic Education in PAAET in Kuwait will be analyzed. Furthermore, investigation into the ICT infrastructure and the background of the students in this college will also be conducted. This should provide adequate information in answering this question. 
Finally, the last three research questions are focused on the effect of using the reflective practice approach and the online environment to facilitate this reflection on the teacher education program in Kuwait and are formulated as follows:

RQ4: What are the difficulties that prospective teachers and trainers encounter by utilizing the reflective practice approach supported by an online video-based learning environment in field training in the teacher education programs in Kuwait?

RQ5: Will the use of an online video-based learning environment provide adequate support to facilitate the practice of reflection among prospective teachers in field training in the teacher education programs in Kuwait?

RQ6: Will the use of reflection supported by an online video-based learning environment in field training facilitate the learning process and improve learners' achievement in the teacher education programs in Kuwait?

A field-based scientific experiment will be conducted in this research to provide the answers for these last three questions.

\subsection{RESEARCH OVERVIEW}

An overview of this research was presented in this chapter. In Chapter 2, the result of a literature review regarding the reflective practice approach in learning will be conducted. The implementation of this approach in education will be studied to clarify the benefits of such an educational approach. Furthermore, the difficulties that may be encountered by practicing reflection will also be discussed. RQ1 will be investigated in that chapter. Through the literature chapter 3 will further investigate the opportunities of ICT for teacher education. The opportunities of using online video-based learning environments in the field training will be particularly investigated in this chapter in order to address the second research question. This chapter will also discuss several examples of using online video-based learning environments in teacher education programs. An answer for RQ2 will be presented in this chapter based on the discussed information. Later, chapter 4 will describe the methodology that will be used in this research. 
The design of an experimental field study to evaluate the effects from using the reflective practice approach and the online video-based learning environment on field training in the teacher education programs in Kuwait will be explained in Chapter 5. This chapter will also present a preliminary investigation including document analysis and a background questionnaire in order to understand the main characteristics of the teacher education programs in Kuwait, the role of field training and the knowledge and skills of the learners in this program. This information will be used to formulate an answer for RQ3 as well as to support the design of the field experiment. The findings from the field experiment will be discussed in Chapter 6, 7, and 8 with respect to RQ4, RQ5, and RQ6. Chapter 9 will discuss the overall research question based on the answers to the six research questions throughout this dissertation and will conclude this research. 


\section{CHAPTER 2 The reflective practice approach}

A general definition for the reflective practice is described by Leijen, Lam, Simons and Wildschut (2008) as "a cognitive process carried out in order to learn from experiences through individual inquiry and collaboration with others" (p.224). Biggs (1999) describes the activities of reflection by comparing the professional practice of reflection with a mirror's reflection: the mirror reflects an exact replica of the object in front of it while the reflection in professional practice offers what might be an improvement of the original. The competence behind the concept of reflective practice or reflective teaching has been considered an important competence among the educators and the researchers in the field of teacher education since the beginning of the 1980s (Korthagen, 1993). Stein (2000) describes the process of reflection as blending the experience with the theoretical and the technical learning in order to create alternatives in the knowledge, the behavior, or the insight of the practitioner. Educators such as Schön (1987) and Calderhead (1989) state that the competence of reflection is essential for teachers to learn from their experience. Furthermore, Procee (2006) rates the reflective practice as one of the most promising innovations in education. Today, reflection is indeed one of the essential goals in many teacher education programs (Newman, 1996; Korthagen \& Vasalos, 2005).

The concept of reflection, however, is considered by some educators to be an ambiguous and misused concept when it comes to the practice of reflection (Griffiths, 2000; Kinsella, 2003; Procee, 2006). For example, Mackintosh (1998) and Procee (2006) criticize the different, and sometimes contradictory, interpretation of the meaning of reflection in education especially among the most influential reflection schools: the pragmatist school of Dewey and his followers on the one hand and the school of critical social theory that follows Habermas' work on the other. One of the arguments in this regard is stated by Mackintosh (1998): "reflection has no clear or universal definition, an uncertain framework for implementation,

and is of unproven benefit" (p.553). In fact, the practice of reflection has been 
criticized, sometimes, even among some of the defenders of it. For example, Boud and Walker (1998), assert "While we are sympathetic to the focus on learning through experience in reflective practice and committed to the inclusion of reflective processes and theorizing about reflection within professional courses, we believe that there are now many examples of poor educational practices being implemented under the guise and rhetoric of reflection" (p.191). However, such criticisms-differences in interpreting the meaning of reflection or differences in implementing reflection-could be associated with the conflict between those two major schools that advocate for reflection. Mackintosh (1998) argues that the pragmatist school of Dewey and the school of critical social theory are identifying different concepts and thought processes with similar names.

On the one hand, the school of critical social theory or as it is called informally, the Frankfurt school, describes critical reflection as opening up a horizon of liberation by taking a critical stance towards the repressive actual situation (Procee, 2006). It assumes that, by questioning the existing assumptions, values, and perspectives of people's actions, decisions, and judgments, the practitioners liberate themselves from their habitual ways of thinking and acting (Procee, 2006; Leijen et al., 2008). Mezirow (1981), based on Habermas work, developed the term "perspective transformation" that focuses on the functions of reification and reflectivity. He believed that perspective's transformation is only possible through critical reconsideration of one's own perspectives and orientations (Mezirow, 1981). Mezirow (1981), therefore, distinguished between seven stages of reflectivity. They are reflectivity, affective reflectivity, discriminant reflectivity, judgmental reflectivity, conceptual reflectivity, psychic reflectivity, and theoretical reflectivity.

On the other hand, Dewey's pragmatic school underlines the conscious thought of one's action as opposed to trial and error instead of emphasizing the critical position of individuals and groups in relation to the actual situation as it is in the school of critical social theory (Leijen et al., 2008). Furthermore, Dewey sees the process of reflection on one uniform level while reflectivity in the school of critical social theory as presented by Mezirow (1981) is divided into several stages (Mackintosh, 1998). Our research will follow Dewey's pragmatic school. Therefore, Dewey's concept of reflection will be further clarified later in this chapter to understand how this approach has been used in education. 
The process of reflection will be also described in this chapter based on two reflection models that are developed by Boud, Keogh \& Walker (1985) and Korthagen (1985) based on Dewey's principles. Furthermore, difficulties that have been encountered by practicing reflection in previous research will also be discussed in this chapter. The study of these topics is expected to help create an implementation strategy for using the reflective practice approach in the field training in the teacher education programs in Kuwait. The chapter starts with general background information about the notion of reflection and the roots of this approach in Section 2.1. Two well-known reflection models and strategies that are commonly used for implementing this approach will be explained in Section 2.2 and some of the difficulties that have been encountered in previous research regarding the practice of reflection will be discussed in Section 2.3. The results of this chapter are then used to answer the first research question:

RQ1: What is meant by the reflective practice and how has it been used as an educational approach?

This will be presented in Section 2.4.

\subsection{LEARNING AND THE NOTION OF REFLECTION}

Beyond the physical phenomenon of reflection in a mirror, reflection as a term has a long history tracing back to Greek philosophers such as Aristotle where he discusses reflection as practical judgment and moral action in his Ethics (Grundy \& Kemmis, 1982). This may be understood as thinking about something that happened to us in the past to make sense of it and to judge the experience relative to the cognitive and moral position of the self. Procee (2006) introduces the ideas of the eighteenth-century philosopher Immanuel Kant and his distinction between understanding and judgment as a better approach for understanding reflection. In his "First Introduction" in the Critique of Judgment (1790), Kant stated as presented in Procee (2006), "to reflect is to compare and to hold together given presentations either with other presentations or one's cognitive power, in reference to a concept that this activity makes possible" (p.237). Practically, Kant's view of reflection can be understood as a process of three parts, which are understanding (rules and concepts), judgment (determinative and reflective judgment), and experience (domains in reality). The determinative judgment connects understanding with experience while the reflective judgment connects the experience back to the 
understood, which facilitates learning (Procee, 2006). This “Kantian's Epistemology of Reflection" is demonstrated by Procee (2006) in figure 2.1.

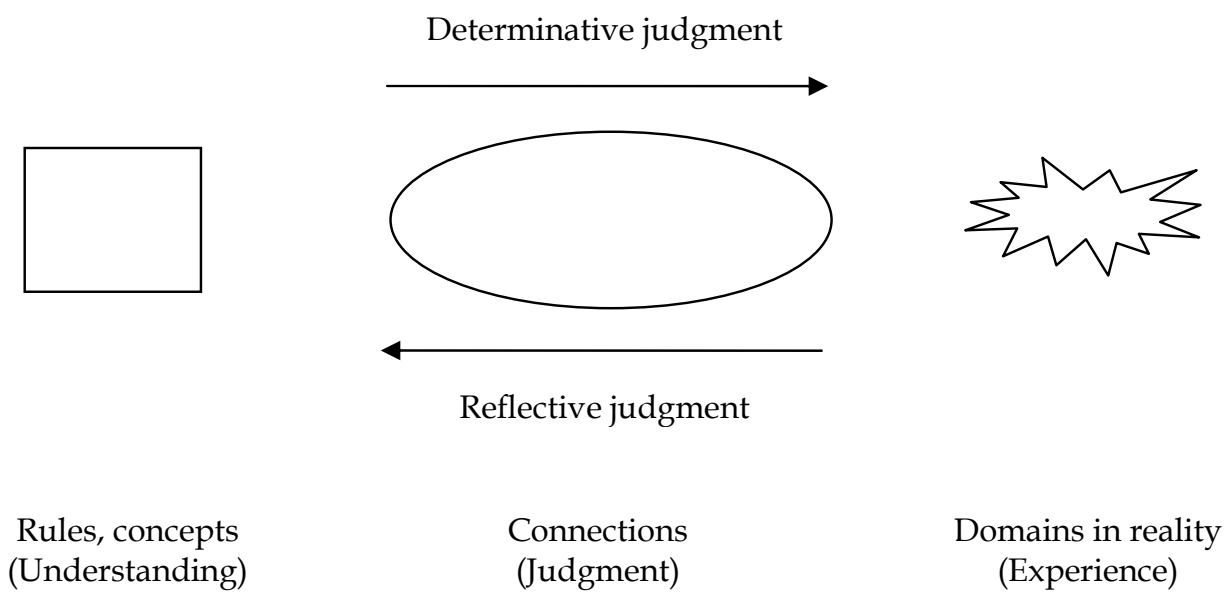

Figure 2.1 Kantian Epistemology of Reflection (Procee, 2006, p.248)

The influence of Kantian's epistemology of reflection can be seen in the work of most educators today. Furthermore, this epistemology as Procee (2006) describes it provides a straightforward explanation of the practice of reflection. Based on this epistemology, reflection can be seen as the relationship between understanding and experience. This relationship, in fact, can be recognized in most of the reflection notions today. In the next sections, the notions of two educators whom led the practice of reflection as an educational approach are presented.

\subsubsection{John Dewey}

The notion of reflection was there for a long time and was influenced by different notions, in addition to those previously mentioned, such as the selfinspection of Descartes and the criticism of instrumental rationality by Horkheimer and Andorno (Bengtsson, 1995; Idalovichi, 2003; Fendler, 2003; Bengtsson, 2003; Procee, 2006). Even though the term reflection is used sometimes differently as it has been discussed in the introduction of this chapter, the credit for utilizing reflection in education goes mainly to John Dewey $(1910 ; 1933)$ as the inspirer of most of the reflection applications in education today. For example, the works of influential educators such as Kolb (1984), Schön (1983; 1987), Korthagen (1985), and many others educators were essentially based upon Dewey's thinking about thought. 
Learning, according to Dewey, occurs by either trial and error where it will be limited to the specific problem at hand, or by the reflective activities that connects different parts of the experience, creating a perception of relationships. Dewey (1933) labeled these two types of learning as routine action that is guided by tradition and authority, and reflective action that entails "active, persistent and careful consideration of any belief or supposed form of knowledge in the light of the grounds that support it and the further conclusions to which it tends" (p.9). He considers the reflection activities as a loop of learning where the experience and the perception of relationships feed each other back and forth in a continuous process. Dewey's explanation of the process of the reflection activities as a loop of learning is in line with Kantian's epistemology of reflection, where a similar relationship can be found between understanding and experience. Therefore, Dewey's reflective action can be seen as an elaboration of Kantians' explanation of the process of reflection.

For educational practice, Dewey rejected the idea that reflection can be provided for teachers as a series of steps or procedures. He argued that reflection is a holistic way of learning that integrates attitudes and skills, which cannot be neatly packaged into a set of techniques for teachers to use, because it includes more than just logical problem-solving processes; it also involves intuition, emotion, and passion (Zeichner \& Liston, 1996). Nevertheless, he identified three attitudes that are required from the practitioner for the reflective action: Open-mindedness, Responsibility, and Wholeheartedness.

Open-mindedness is described by Dewey (1933) as an "active desire to listen to more sides than one; to give heed to the facts from whatever source they come; to give full attention to alternative possibilities; and to recognize the possibility of error even in the beliefs that are dearest to us" (p.29). Responsibility requires careful consideration of the consequences of intended actions (Zeichner, 1982). Finally, the attitude of open-mindedness and responsibility must be the major focus of the reflective teacher and that is what Dewey meant by the attitude of wholeheartedness. Quoting from Dewey, Zeichner (1982) argued that by obtaining these three attitudes together with the required skills for inquiry, the quality of reflection "emancipates us from merely impulsive and merely routine activity. Put in positive terms, thinking enables us to direct our actions with foresight and to plan according to ends in view or purposes of which we are aware... It enables us to know what we are about when we act" (Dewey, 1933, p.17). One of the well known educators who 
elaborated on Dewey's notion of reflection is Schön (1983; 1987). The main contribution of Schön on reflection is discussed in the next section.

\subsubsection{Donald Schön}

Donald Schön $(1983 ; 1987)$, who based his notion of reflection on Dewey's work, became one of the most influential authors about the practice of reflection in education. Being against technical-rationality, Schön argues that technicalrationality fails to resolve the dilemma of rigor versus relevance confronting professionals and he proposes a new epistemology where the knowledge inherent in practice is to be understood as artful doing (Usher, Bryant \& Johnston, 1997).

A distinguished figure in Schön's work in this area is his notion of "reflection-inaction" and "reflection-on-action". Reflection-in-action is explained as thinking on our feet while the situation is unfolding. In such practice the practitioner recalls previous experiences, enters these into the inner feeling and attends the theories in use in order to create an understanding that leads his action as the situation develops (Smith, 2001). Reflection-on-action, on the other hand, is to recall afterwards the situation and the actions, or in this case the reflection-inaction, in order to understand the reasons behind the actions. The practitioner's repertoire of images, ideas, examples, and actions are considered here as the key aspect in this practice. For Schön (1983), this repertoire is central to reflective thought because "When a practitioner makes sense of a situation he perceives to be unique, he sees it as something already present in his repertoire. To see this site as that one is not to subsume the first under a familiar category or rule. It is, rather, to see the unfamiliar, unique situation as both similar to and different from the familiar one, without at first being able to say similar or different with respect to what. The familiar situation functions as a precedent, or a metaphor, or... an exemplar for the unfamiliar one" (p.138). The basic cycle of Schön's approach, the iteration of "reflection-inaction" and "reflection-on-action", can be seen as an elaboration of Kantian's epistemology of reflection and Dewey's reflective action. This cycle makes the notion of reflection a robust concept for judging experience.

In order to develop a concrete approach for applying reflection in this research, two well-known reflection models that focus the principles of Dewey's school of reflection on practical application in educational setting will be presented in the next section. 


\subsection{REFLECTION MODELS}

Most of the processes that lead to reflective thinking share common activities and attitudes although different educators may describe them differently. This section, therefore, will present and discuss two perspectives and cyclical processes that have been proposed by two influential educators for the implementation of the reflective practice approach. The choice of these models among others was based on their initial background, which is mainly based on Dewey's (1910; 933) work and accordingly Kantian's epistemology of reflection. Furthermore, other reasons for selecting these two models were their influence on different educational programs around the globe as well as their variation in the number of stages that they proposed in order to utilize the reflective practice approach.

Even though different educators share similar grounds, many of them proposed different number of stages for practicing reflection. For example, the well-known learning cycle that is described by Kolb (1984) consists of four major stages: the concrete experience stage, the observation and reflection stage, the forming abstract concepts stage, and the stage of testing in a new situation. Another example of a reflection model can be seen in Korthagen's works (1985). His model includes five major stages: action, looking back on the action, awareness of essential aspects, creating alternative methods of action, and trail. Interestingly, even though Kolb and Korthagen differ in their practical approach to reflection, they both developed their models with inspiration from Dewey's notion of reflection. In fact, the number of stages can vary from a simple model that consists of just one or two stages into a model that involves many details and several stages. However, these models mostly share the same goal and similar key characteristics. A common characteristic of most reflection models is that they involve a cycle where the stage of testing leads to refined and modified action (mostly the last stage) that is also the first stage for a new cycle.

The following two sections will discuss the perspectives and the models for utilizing the reflective practice approach of two well-known educators in this field, namely David Boud and Fred Korthagen.

\subsubsection{Boud, Keogh and Walker}

In 1985, Boud, Keogh and Walker edited a book entitled Reflection: Turning experience into learning. The book introduces and discusses the concept of 
reflection by several authors and from different perspectives. In this book, Boud and his co-editors describe a model that promotes reflection in learning. They focus on emotion, a factor they claim has been ignored in other reflection models such as the learning cycle described by Kolb and Fry (1975) and the reflection model of the British Further Education Curriculum and Development Unit (FEU). Boud et al. (1985), therefore, introduce emotion as an important factor in the reflection process. They argue that Kolb's learning cycle does not help in the understanding the elements of reflection even though they admit that his scheme is useful for planning the learning activities and examining the learners' involvement in these activities (Boud et al., 1985).

While Boud et al. (1985) think of reflection as an activity of recalling, thinking deeply, and evaluating the experience, they consider reflection in learning as " $a$ generic term describing intellectual and affective activities in which individuals engage to explore their experiences in order to lead to new understandings and applications" (p.19). Similar to Dewey's "state of doubt" (1933) and Boyd and Fales's "inner discomfort" (1983), Boud et al. (1985) consider one's own dissatisfaction or discomfort with an existing situation as impetus to reflective thinking. Furthermore, they add the positive state such as a successful experience as another impetus to reflection. They argue that the personal affective is a more frequent stimulus of reflection than the activities that are planned by others. Based on this emphasis on the emotions they introduced a new model of reflection in the learning process consisting of two main components: the experience that the learners go through, and the reflective activity on this experience. The experience here refers to the total response of a person at the time or immediately after a situation or event (Boud et al., 1985). Figure 2.2 presents their model of reflection where an obvious emphasis on a cycle between the experience and the reflection process can be seen while the product of this cycle is presented in the outcomes. Arguing that, "the characteristics and aspirations of the learners are the most important factors in the learning process", Boud et al. (1985, p.21) emphasize the knowledge background of the learners and the fact that different learners react to a situation differently based on their backgrounds. Drawing heavily on the realm of feeling, they highlighted the behavior, the ideas, and the feeling as the totality of the experiences of learning. These three elements are presented in the experience part of Figure 2.2. 


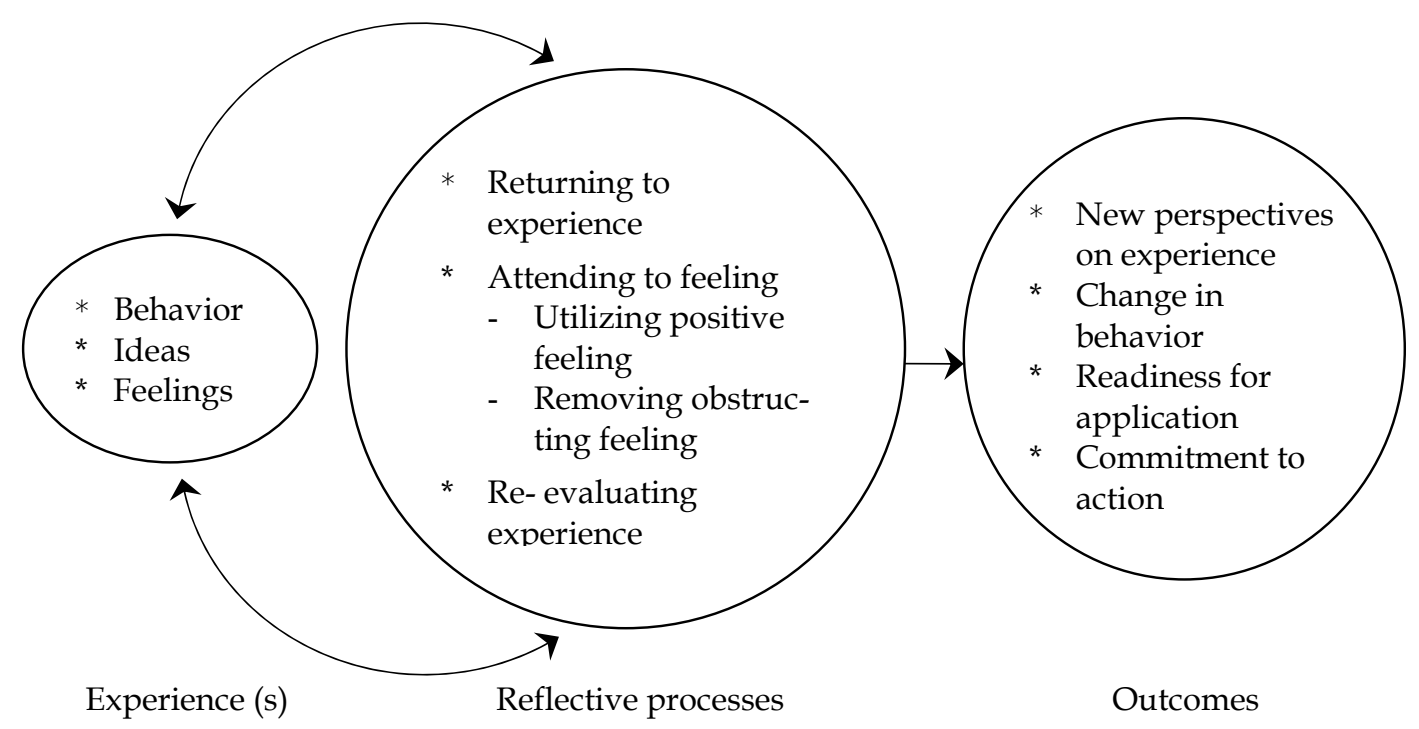

Figure 2.2 Model of reflection in the learning process (Boud, Keogh \& Walker, 1985)

The central activities are presented in the reflection processes where they distinguish between three types of activities or stages. The first stage (Returning to experience) serves the purpose of recalling the experience or as Boud et al. (1985) put it "recollection of the salient events", which can be done by, for example, putting it in a paper or describing it to others. Important in this stage is that the practitioner commit to merely describing the experience without any judgment that may dismiss some of the experience's features. The second stage (Attending to feeling) focuses on treating two types of feelings: positive and obstructing feelings. On the one hand, the positive feelings supposedly stimulate the practitioner's persistence in challenging situations as well as clarify the events; therefore, the practitioner must work on utilizing these feelings. The obstructing feelings, on the other hand, may create different kinds of barriers that cloud a rational consideration of the events. The practitioner, therefore, must remove the obstructing feelings by, for example, expressing them openly or in writing (Boud et al., 1985; Rainer, 1980). The third stage in the reflection process (Re-evaluating experience) must follow the previous two stages even though it may be attempted by the practitioner to conduct this stage immediately after the experience, which may cause losing valuable features of the experience. Boud et al. (1985) suggest four elements that need to be considered in this stage. They are association, integration, validation, and appropriation. In order to re-evaluate the experience, it should be associated with the pre-existing knowledge and feelings that are relevant to this experience. The association is considered an important element of 
the learning process. Finding relationships between the data in order to place them in a new category is the goal of the integration activity. Tools such as concept mapping and Venn diagrams are useful for this integration activity. Validating the outcomes of these ideas and feelings is the third activity suggested by Boud et al. (1985) and finally they refer to knowledge's ownership as the appropriation where the practitioners regard these ideas and feelings as their own.

The outcomes of the reflection processes may be demonstrated as new perspectives on the experience, changes in the behavior, readiness for application, or commitment to action. The elements of integration, validation, and appropriation that are conducted in the processes of reflection are considered an outcome as well (Boud et al., 1985). The reflection model that is proposed by Boud et al. (1985) could be seen as a straightforward procedure. In reality, however, it could be difficult to distinguish the stages or the steps in this model from each other. This model will be discussed further in relationship to other reflection models in Section 2.4 of this chapter.

\subsubsection{Korthagen}

Another influential contributor to the practice of reflection is Korthagen. Korthagen's (1985) works on the practice of reflection is widely used in many countries, especially in the Netherlands, as a basis for systematic reflection in teacher education (Korthagen \& Vasalos, 2005). Although Korthagen (1985) is convinced that people reflect on their experiences by nature, he assumes that systematic reflection is different from what teachers are accustomed to do. Therefore, he introduces a model of reflection that consists of five stages: action, looking back on action, awareness of essential aspects, creating alternative methods of action, and trial. This model, which is called ALACT, was originally developed to be used in teacher education programs; however, other educational program such as nursing education is also making use of the ALACT model today. Figure 2.3 presents the ALACT reflection model. 


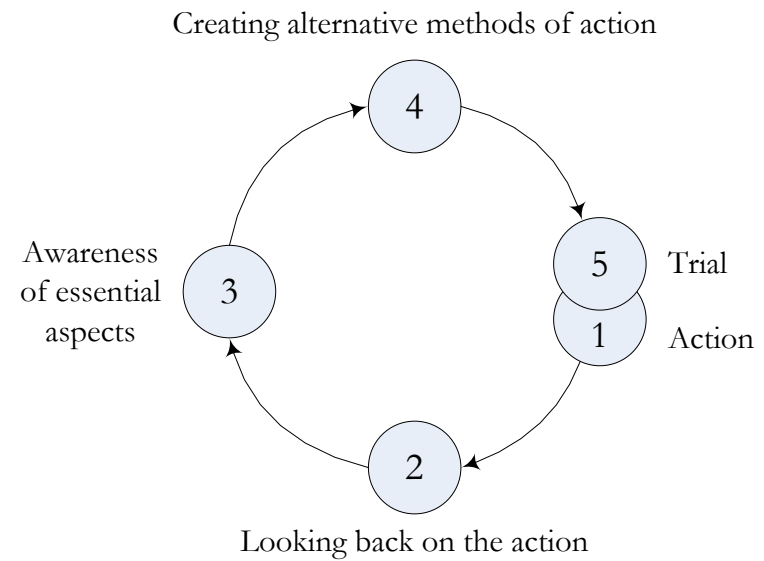

Figure 2.3 The ALACT model (Korthagen, 1985)

Similar to other reflection models, ALACT presents the reflection process as a continuous cycle where the first stage "action" and the last stage "trial" are overlapping. The cycle starts with real practice in the classroom. Later in the second stage, the practitioner thinks of what has been done during the class in order to clarify the situation. Korthagen and Kessels (1999) proposed the questions that are presented in Figure 2.4 in order to help promoting concreteness in the reflection process at this stage.

1. What did I want?
$\begin{array}{ll}\text { 2. What did I do? } & \text { 6. What do I think the students wanted? } \\ \text { 3. What did I think? } & \text { 7. What do I think the students thought? } \\ \text { 4. How did I feel? } & \text { 8. How do I think the students felt? }\end{array}$

Figure 2.4 Concretizing questions for stage 2 of the ALACT model (Korthagen \& Kessels, 1999)

By answering these questions, the practitioner reaches a clear understanding of the essential aspects of the process during the class, which brings the reflection to the third stage (Korthagen, Kessels, Koster, Lagerwerf \& Wubbels, 2001). In the "awareness of essential aspects" stage, the practitioner makes a connection between the answers of the questions from the previous stage. Furthermore, it is important in this stage that the practitioners are aware of the problem or the advantage of this experience and how it is affecting them personally. The involvement of some of the theoretical elements may be useful at this stage (Korthagen et al., 2001). After being aware of the situation from different angles, the practitioner, in the fourth stage, creates alternatives that are assumed to 
improve the situation. Comparing the advantages and disadvantages of each of these alternatives is another task in this stage aiming to reach a level of contentment that a specific alternative could be the best solution for the problem at hand. Trying out the alternative is the goal of the last stage as well as being the first stage of a new cycle (Korthagen \& Kessels, 1999).

In addition to identifying the role of the practitioner in this model, Korthagen and Vasalos (2005) define the role of the supervisor in the process of reflection, as well. Even though the emphasis in the reflection process is always on the practitioner, they specify several activities for the supervisor they assume will help the practitioner go successfully through the different stages of the reflection process. The supervisor may help the practitioner in finding or identifying useful experiences in the first stage. Discussing the questions in Figure 2.4 with the practitioner as well as showing acceptance and understanding of the practitioner's behavior and feelings will help the practitioner go through the second stage. Involving theoretical discussion in the third stage may help the practitioner make the connection between the information at hand. The supervisor may also play a useful role in discussing the alternatives and their advantages and disadvantages in the fourth stage, and in continuing the learning process in the last stage (Korthagen \& Vasalos, 2005).

Korthagen (1992) argues that most program descriptions of reflection are rather general and lack detailed information about the activities that promote reflection. Therefore, he proposed and tested four techniques, namely the "wall", "columns", "repertory grid", and "arrows", to be used in teacher education seminars that were assumed to encourage prospective teachers to reflect on their teaching practice. The wall technique aims to promote reflection on the relationships between different educational goals or values while the columns technique aims further to promote reflection on the relationships between educational goals and actual teaching behavior. From Kelly's (1955) technique for inquiry into the constructs people use when dealing with their environment, Korthagen (1992) designed the repertory grid technique that involves relationship between teacher behavior and pupil characteristics as perceived by the prospective teacher. It is assumed that this technique helps in understanding the way that a prospective teacher's behavior is shaped by subjective perceptions of pupils. The last technique proposed by Korthagen is the arrows, which is an integration of the wall and the repertory grid techniques to correspond to the relationship among goals and pupil characteristics as perceived by the prospective teacher and teaching strategies. In the conclusion of this study, 
Korthagen (1992) stated that the four techniques were useful and helped prospective teachers make their knowledge explicit.

Korthagen (1993) also discusses reflection on non-rational processes. Based on many educators, much of the everyday classroom teaching relies on non-rational teacher behavior (Carter, 1990; Clark \& Yinger, 1979). Schön (1987) described this non-rational behavior as "knowing-in-action" where rational analysis plays no role at the exact moment of action. Korthagen (1993), therefore, proposed several techniques that can help prospective teachers become aware of their non-rational processes and reflect on it. Metaphor, which is described by Lakoff and Jonson (1980) as "understanding and experiencing one kind of thing in term of another" (p.5), is one of these techniques where prospective teachers describe their practice metaphorically. Other techniques that the prospective teachers may use are expressing themselves by drawing and painting a picture of their practice, or even by taking photographs, instead of using words as in the metaphor technique (Korthagen, 1993). The idea is that prospective teachers should use whatever means they prefer in order to gain an awareness of the non-rational processes and accordingly to reflect on these processes. Korthagen (1993) argues that, in order to reflect effectively on the practice of teaching, both the reflection on the rational analysis and the non-rational processes are required.

Two models of reflection have been discussed in this section. This discussion together with the discussion of the notion of reflection that have been presented in the previous sections in this chapter will be used in section 2.4 in order to formulate an answer to the first question in this research. Furthermore, this discussion will be further elaborated later in the design of the field experiment in this research in Chapter 5 in order to build a generic reflection model for the field experiment in this research.

\subsection{DIFFICULTIES IN PRACTICING REFLECTION}

The increased importance of acquiring the competence of reflection among higher education students and specifically prospective teachers was discussed previously in this chapter. The literature reviewed shows an emphasis in the higher education programs on developing students' ability to reflect on their experiences (Schön, 1987; Calderhead, 1989; Korthagen \& Vasalos, 2005; Procee, 2006; Leijen et al., 2008). Consequently, an increase of the implementation of the 
reflection approach can be seen not only in teacher education programs but also in other educational programs such as nursing education and dance education. Recognizing that practicing reflection is a challenging activity for practitioners, different types of difficulties have been reported by several researchers regarding the practice of reflection (Mackintosh, 1998; Platzer, Blake \& Ashford, 2000; Leijen, 2008).

In a study by Platzer et al. (2000) concerning the use of reflective group-work, they reported several barriers that caused difficulties in practicing reflection. The result of this study shows that an influential barrier that affects the practice of reflection and causes different kinds of difficulties is the educational, socialization, and cultural background of the practitioners. Practitioners, who have been taught previously by a traditional learning style or work in a relatively strict environment, found it particularly difficult to critically comment or reflect on their experience. Another barrier related to the social and cultural background of the practitioners as well is the emotional factor where practitioners feel vulnerable and exposed. The shame of being seen by their peers and supervisors as lacking the necessary knowledge about aspects of their practice and the fear of being exposed to potential criticism and judgment by others and by themselves, keeps them from opening up and practicing the reflection in a group setting. Furthermore, the effect of the commitment or an individual's resistance to share learning with other members in the group, is another barrier that causes difficulties in practicing group reflection. This barrier is actually the factor that causes a two-way affect as if "an individual who was open to learning from experience could be prevented from doing so by other group members. Conversely, the commitment to shared learning could enhance opportunities for individuals whether or not they were initially committed themselves" (Platzer et al., 2000, p.1003). They also found that sometimes the behavior of an individual practitioner, by being dominant or passive, may prevent others in the group from participating in the reflection activities and make them feel uncomfortable.

Similar difficulties to those reported in the previous study of Platzer et al. (2000) can be found in several studies about reflection. For example, the findings regarding the effect of traditional education are consistent with Mountford's and Rogers' (1996) findings where the practitioners did not value personal knowledge and their role in the construction of expert knowledge. Furthermore, the fear of criticism and judgment is also discussed in Wade (1994). Based on a study he concluded that a major difficulty with examining discussion as a tool for critical 
reflection is "the fear that ideas will be judged as unworthy or that comments will be openly criticized by either the teacher or other classmates" (Wade, 1994, p.240). Wade (1994) also drew attention to the effect of the behavior of an individual on the other members in the group. Furthermore, a negative experience in the discussion that was commonly agreed upon among the practitioners in this study is the criticism or undervaluing of practitioners' ideas (Wade, 1994).

In a recent study on the use of reflection in dance education, Leijen (2008) described several types of difficulties that have been pointed out by the practitioners. Leijen (2008) categorized these difficulties into four types that correspond to those reported in other studies. The first category concerns general difficulties and deals with problems related to emotions and verbalizing ideas. The second category focuses on difficulties in describing experiences. Difficulties in evaluating experiences are the third category and this category deals with problems related to the lack of competences of evaluation. The last category that Leijen (2008) proposed deals with difficulties in relating to multiple perspectives.

In the general difficulties, Leijen (2008) found that dealing with emotional and personal matter and verbalizing ideas were two problems encountered by the majority of the practitioners. The practitioners found it difficult to express themselves in words and to voice personal issues in order to reflect on their own development. In the second category, the discrepancy between doing and awareness and the insufficient observation of the experiences are presented as difficulties in describing experiences. Leijen (2008) found differences between what the practitioners think or feel about what to do in a specific practice and what they really did in that practice. The practitioners were also unable to notice many details of their experiences. In the third category, the lack of criteria for evaluation and the devaluing of their own personal knowledge were the difficulties expressed by the practitioners in evaluating the experiences. The practitioners were waiting for a supervisor's feedback instead of self evaluation. The practitioners also focused mainly on negative aspects of their practice and ignored the positive ones. In the last category-difficulties in relating to multiple perspectives - the practitioners were faced with difficulties in finding alternatives for their practice and in pointing out the weaknesses in the practice of others (Leijen, 2008).

It can be concluded based on the findings of these studies, in addition to similar findings in many other studies (Argyris \& Schön, 1974; Miller, Tomlinson \& Jones, 1994; Drake \& Dart, 1995; Chung, Mak \& Paul, 1995; Mackintosh, 1998; 
Eraut, 2000; Stein, 2000), that the barriers causing the difficulties concerning the practice of reflection are widely reported. However, the difficulties that are strongly influencing the practice of reflection and specifically the ability of description and evaluation as two major activities for reflection can be categorized into two main barriers.

The first influential barrier to effective reflection that was presented in many studies is the practitioners' personality and emotions as well as their ability to describe their experience. On the one hand, practitioners usually tend to avoid confrontation with their supervisor or peers about their ideas and their implicitly held knowledge (Drake \& Dart, 1995; Stein, 2000). On the other hand, even when the practitioners are willing to share and discuss with others, they may face difficulties in verbalizing their ideas and describing their actions. That can be caused by a lack of vocabulary (Chung, Mak \& Paul, 1995), unawareness of their actions (Eraut, 2000), or the use of uncommunicative types of theories and knowledge, which are described by Argyris and Schön (1974) as the "theories-in-use".

The second commonly mentioned barrier to effective reflection is the ability and willingness of the practitioners to rely on their own knowledge and experiences and use it to evaluate their performance (Mountford \& Rogers, 1996; Leijen, 2008). Instead, practitioners usually wait for the correction and the feedback from their supervisor. Leijen (2008) connected this ability with what Dewey (1933) describes as "directness" where the practitioner should "trust the validity of their experiences without spending a lot of time worrying about the judgments of others" (Leijen, 2008, p.101). This ability can be extended to the evaluation of others' experiences and the ability of relating to multiple perspectives. One of the reasons that prevents the practitioners from practicing the evaluation is the fear of poor grades (Richardson \& Maltby, 1995). The use of practitioners' evaluation by the supervisor as a tool for assessment may result in some hesitation among the practitioners about what should be included in this evaluation. Furthermore, it may also limit the truth in this evaluation and lead the practitioners to write what they believe others wish to read (Mackintosh, 1998). Another reason for this barrier is practitioners' lack of confidence in of their personal knowledge (Mountford \& Rogers, 1996) and the feeling of vulnerability and exposure (Platzer et al., 2000).

Even though the difficulties and the barriers that have been discussed in this section showed diversity in their nature, a general classification of these difficulties may come handy for the investigation of this research. The difficulties' 
classification that has been presented by Leijen (2008) includes the majority of these difficulties. Therefore, a modified version of this classification will be developed in Chapter 3 in order to sort out the different types of difficulties for the design of the field experiment in this research.

\subsection{DISCUSSION}

This chapter was driven by the first question in this research concerning the meaning of the reflective practice and the implementation of this concept in education. Therefore, a discussion of the information presented previously in this chapter in order to provide a sufficient answer to this question will be given in this section.

Dewey's notion of reflection that is discussed in Section 2.1.1 shows similarity with Kantian's epistemology of reflection presented in Figure 2.1 Dewey's relationship between perception and experience can be seen as an elaboration of Kant's relationship between understanding and experience. In fact, most of the existing notions of reflection can be seen as a development or elaboration of this relationship such as Schön's relationship between reflection-in-action and reflection-on-action that is discussed in 2.1.2. Hinett (2002) asserts, in this regard, that only through reflection can the experience become understanding. Reflection based on this interpretation plays the role of continually connecting practitioners' understanding with their experiences and connecting their experiences back to their prior knowledge in order to facilitate learning.

Looking into the reflective practice from this perspective reveals the core of the reflection notion as building a bridge between practitioners' knowledge and their experiences, therefore, connecting theory and practice. The focus of the reflection activities is on directing the thoughts of the practitioners toward questioning their experience. 'What did they do?', 'how did they do it?', 'what went well and what didn't?', 'what should have been done?', are questions that are assumed will create a relationship between practitioners' knowledge and their experience (Korthagen \& Kessels, 1999; Hinett, 2002). To better understand the notion of reflection, a broad description of reflection activities with consideration of the essence of most of the different notions of reflection could be useful here. The reflection activities in most of these notions can be generically described as a process where the 
practitioners look back consciously into their experience, think about and question this experience in light of their prior knowledge, and judge their action in this experience in order to develop an alternative knowledge and action.

In the educational context, reflection is increasingly implemented in teacher education programs supported by common contentment among many educators and researchers in the field of teacher education towards the importance of acquiring the reflective competence by teachers (Dewey, 1933; Kolb, 1984; Boud et al., 1985; Schön, 1987; Calderhead, 1989; Zeichner \& Liston, 1996; Korthagen \& Vasalos, 2005). In an educational sense, Race (2002) claims "the act of reflecting is one which causes us to make sense of what we've learned, why we learned it, and how that particular increment of learning took place. Moreover, reflection is about linking one increment of learning to the wider perspective of learning - heading towards seeing the bigger picture" (p.2). Today, a shared goal among most teacher education programs is to ensure that prospective teachers have the ability to reflect on their practice and to improve their teaching skills as they teach. Actually, the use of reflection in education is not only limited to teacher education as reflection is applied today in many other specialties like nursing education (Mountford \& Rogers, 1996; Platzer et al., 2000), dance education (Warburton, 2004; Leijen, 2008), and legal education (Schrag \& Meltsner, 1998; Allen, 2007).

However, even though the common understanding among educators toward the core of the reflection notion has resulted in formulating similar goals as discussed above, different strategies and models for practicing the reflective activities can be found in the field of education. The differentiation among these strategies and models could be presented by the level of generalization or elaboration in the model. For example, the process of reflection based on Boud et al. (1985) consists of only two stages while Korthagen (1985) suggests five stages in practicing reflection. Furthermore, the differentiation could be also presented by the emphasis on specific aspects in practicing reflection. Kolb's (1984) reflection model, for example, relies mainly on the concrete experiences whereas the Boud et al. (1985) reflection model focuses heavily on the emotions as the major aspect in reflection.

The reason for this variation is that the development of these different reflection models is mostly influenced by different factors that shaped the focus of the implementation and the stages of the models. Some of the important factors that may determine the design and the implementation of the activities of the 
reflection are the level of learners' awareness, the social influence of the society, or the type of program delivery in the specific education program. Yet, three components commonly exist in the majority of these models, which are the importance of practitioner's prior knowledge and background, the importance of conscious observation of the experience and the emphasis on a cyclical and continuous process. These components are, in fact, in line with the core of the notion of reflection, which focuses on the relationship between the experience and the understanding. Using these three components for developing a generic model of reflection that takes into account practitioners' characteristics and the social and organizational aspects in a specific educational program will presumably increase the opportunity of successful implementation of reflective practice. Therefore, these three components will be used later in the design stage of this research to develop a generic model of reflection that may best suit the situation in Kuwait considering the characteristics of Kuwait's teacher education programs and the level of awareness about the reflective practice among the learners in Kuwait.

In addition to the notions and the processes of reflection, the difficulties that have been encountered by practicing the reflection activities were also discussed in this chapter. This discussion of the difficulties will be elaborated further in the design of the field experiment for this research in order to develop an instrument for investigating the difficulties that may face the Kuwaiti practitioners. However, attention should be paid here to the difficulties that have been reported concerning specifically the description activities such as the difficulties in verbalizing ideas (Chung et al., 1995), the discrepancy between doing and awareness (Eraut, 2000; Leijen, 2008), and the difficulty in describing the actions that resulted from utilizing the "theories-in-use" (Argyris \& Schön, 1974). Korthagen (1993) also referred to the description's difficulties as a major barrier for reflecting on the non-rational processes of practitioners' practice. He argues that the non-rational processes are difficult to communicate.

Description plays a critical role in practicing the reflection and the description difficulties often affect other activities in the practice of reflection, and not only the description as a separate activity. Major activities such as the self or group reflection on the experience or the development of alternatives are, in fact, built in and dependent entirely on the quality of the provided description. The reflective practice is criticized because of the dependence on only the practitioner's perspective of the events (Newell, 1992) as well as the expected effect of distortion 
of hindsight bias on the quality of practitioners' description (Reece Jones, 1995). Mackintosh (1998) argues that "Reflection, with its emphasis on individual perspectives of events, their interpretation and their analysis, excludes all other viewpoints" (p.556). It is, indeed, without clear, accurate, and unbiased description of the experience, that the practitioners and their supervisors would not be able to reflect meaningfully on the experience or to develop useful alternatives for the actions.

Language, whether spoken or written, is used today in most of the educational programs that adopt reflection as the means of communication or the vehicle for delivering the experience to others. The underlying assumption is that through language practitioners can express their observation to themselves, to other practitioners, or to their supervisors. Evidently, based on the described difficulties and criticisms, using language as the only tool for communicating and explaining the experience to the self as well as to others shows limitations. The practice of reflection needs other and more effective means of communication that can provide those involved in the reflective practice with realistic, truthful and unbiased description to the experiences.

Information and Communication Technology (ICT) offers many types of equipment and applications that support the education process. The practice of reflection could also make use of some of the technological aids to overcome the difficulties in practicing the description activities. ICT, in fact, may offers tools that go beyond solving a specific problem in practicing reflection into providing applications that improve the outcomes from practicing reflection in general. The next chapter, therefore, will investigate the opportunities of ICT for practicing the reflection. 


\section{CHAPTER 3}

\section{ICT-supported reflection}

The term Information and Communication Technology (ICT) is rather a broad term that is mostly associated within the context of education, medicine, and libraries. Blurton (1999) describes ICT as "a diverse set of technological tools and resources used to communicate, and to create, disseminate, store, and manage information" (p.46). Understanding the opportunities of ICT for supporting the practice of reflection in teacher education is a major goal in our research. Therefore, the second question in this research, presented in Section 1.5, is formulated as follows:

RQ2: What are the opportunities of ICT for supporting the reflective practice in teacher education?

A starting point for answering this question lies on the condition that to be used ICT applications must facilitate reflecting on concrete teaching behavior of prospective teachers. Video would be a first choice to serve that purpose. However, the term ICT in education today is commonly connected with the use of computers and the Internet (Tinio, 2003). The history of ICT shows rather a considerable variety of tools that have been used in education. A great deal of examination concerning the usefulness of ICT tools such as telephone, radio, video, film, and television in education can be found in the literature (De Korte, 1967; Cuban, 1986; Blurton, 1999). For example, radio and television have been used for over forty years as tools for open and distance learning (Cuban, 1986; Potashnik \& Capper, 1998). Despite this long tradition Tinio (2003) argues that enthusiasm among educators towards many of these tools such as video and television has faded over time because of several obstacles in relation to the accessibility and the expenses of these tools in comparison with print materials.

In relation to the use of video in education, Santagata, Zannoni and Stigler (2007) assert that educators recently have shown new interest in the use of video for teacher education. This interest can be associated with the development of digital 
forms of media that provide promising interventions and great advantages for using video in education (Blurton, 1999). Digital recording techniques are useful for capturing the complexity of the classroom and they also allow random access to this material (Schrader et al., 2003). This interest can also be related to online applications that are provided through the Internet. Online environments are offering several tools that facilitate video delivery and exchange, accordingly providing valuable means of communication and accessibility for prospective teachers and their supervisors. The advantages of these new technologies, in fact, revived the enthusiasm among educators towards the implementation of video in education and expanded the usefulness of video specifically in teacher education.

In this chapter, an overview regarding the contribution of video applications to the field of teacher education and the development of these applications is discussed in Section 3.1. Several examples of using video-based learning environments both offline (Section 3.2) and online (Section 3.3) are discussed in this chapter in order to give an understanding of the implementation of such environments as educational tools in teacher education. It is assumed these environments will highlight the opportunities of using video applications in combination with other ICT applications. Discussion of the outcome of this chapter is presented in Section 3.4 to address RQ2.

\subsection{VIDEO USE IN TEACHER EDUCATION}

The use of video applications in teacher education has a long and successful history and goes back to the 1960s (McCurry, 2000; Sherin, 2004; Santagata et al., 2007). An early example of the use of video in teacher education can be found in the development of the "microteaching" method at Stanford University in the late 1960s (Allen, 1966; Allen \& Ryan, 1969). In this method, video was used to allow new teachers to observe a model of teaching that demonstrates a specific skill. Furthermore, video was also used in this method for facilitating the supervisor's feedback. In spite of the positive results in many studies towards the effectiveness of microteaching as a method that facilitates the acquisition of new teaching techniques (Ward, 1970; Acheson \& Zigler, 1971; Limbacher, 1971), the popularity of microteaching methodology decreased during the 1970s. Some of the major obstacles faced in the practice of this

method were the expenses and the accessibility of video given the video technology of those days (Santagata et al., 2007). 
Video today, however, is used intensively with the case-study methodology in teacher education. Even though the use of video is now considered an essential part of case studies, the case-study method was originally developed as a textbased method. Merseth (1994) describes a case-study as "a descriptive research document, often presented in narrative form, that is based on a real-life situation or event. It attempts to convey a balanced, multi-dimensional representation of the content, participants and reality of the situation" (p.16). Case-study methodology in teacher education is assumed to create a bridge between theory and practice by bringing the complexities of the classroom into the focus of prospective teachers in an engaging, more demanding, and stimulating way (Shulman, 1992; Cannings \& Talley, 2002). This method is used in teacher education as an exemplar for the practice of teaching in the classroom as well as a tool to facilitate analysis and assimilation of differing perspectives (Merseth, 1994; Cannings \& Talley, 2002). Accordingly, the use of video is varied based on the goal of the practice. However, a common contentment among educators toward the usefulness of using video applications in teacher education can be found in the literature (Van den Berg, 2001; Cannings \& Talley, 2002; Schrader et al., 2003; Moreno \& Valdez, 2007).

Several advantages of video technologies can be found in studies that focus on the use of video in teacher education. Wang and Hartley (2003), for example, found that video cases show more promising results regarding the development of the knowledge and skills of observation in comparison with written cases. Another study by Sherin and Van Es (2005) concluded that using video caused a significant shift among prospective teachers from providing literal descriptions of classroom events to focused reflections on issues of teaching and learning. Furthermore, Santagata et al. (2007) discuss several possibilities and advantages of using video in teacher education. Among these possibilities, video is considered a useful tool that allows prospective teachers to connect the knowledge they acquired during their courses to the classroom context. In addition, video also allows the development of a shared language among prospective teachers for describing and discussing classroom practice by providing them with a common set of experiences. Seago (2004) asserts that norms for discourse regarding teaching are developed through the discussion of video in teacher education which leads prospective teachers to use precise ways to talk about teaching practice.

It can be seen from the literature that the use of video in teacher education is mostly utilized for the purpose of providing prospective teachers with realistic examples of specific behaviors (Cannings \& Talley, 2002; Schrader et al., 2003; 
Moreno \& Valdez, 2007). A recent new trend of utilizing video can be found in teacher education with emphasis on the use of video for reflective practice (Holodick, Scappaticci \& Drazdowski, 1999; McCurry, 2000; Santagata et al., 2007; Stockero, 2008). Santagata et al. (2007) argue that the role of video in teacher education has progressed in the last few years from "being a means to expose preservice teachers to specific behaviors to be imitated to a tool for the development of teachers' professional judgment" (p.126). Santagata et al. (2007) assert that video allows for a depth of reflection and analysis that is not possible during live observations. Slowing down the process of teaching using the functionality of random access where video can be played over and over is a significant tool for facilitating deep reflection and analysis (Schrader et al., 2003; Santagata et al., 2007). In a similar context, McCurry (2000) describes five advantages from video that should be considered when using video with prospective teachers, which are as follows:

- Authenticity: video recorded for the purposes of modeling behavior for any type of further analysis should be collected in real environments. Even though simulations have some utility their unauthentic nature will always be a distraction,

- Digital video data: possibility for demonstrating performance or for assessment. Data need to be collected in authentic environments and edited into "exemplary moments" based on critical judgment about one's development and performance,

- Shared communication of feedback: sharing observations to confirm or refute assumptions and ascribed meaning to action,

- Contextualization of the data: focusing less on the individual's behavior in isolation and more on the observed practice in real setting, and

- Participatory video production for reflective practice and practitioner inquiry: the development of practitioners' knowledge with prospective teachers can be improved through video production (p.10).

Regarding the practice of reflection, using video is not only a useful tool for gathering information about the self in authentic practical settings (McCurry, 2000), but using for facilitating the different activities in the process of reflection. As it was discussed in Chapter 2, the quality of description is considered as a major difficulty with the practice of reflection because it affects as well the activities of self-reflection, peers-reflection, and the search for alternatives for the actions. Today, the digital form of video provides opportunities for the 
practitioners to not only record their practice but also to edit the recorded material into exemplary moments (McCurry, 2000) in order to demonstrate their performance more accurately. It is assumed that these functionalities of video will improve the quality of description, accordingly to improve the practice of other activities of reflection.

Next to video other technologies are also available today to provide facilitation for exchanging knowledge and materials, which may support the different activities of reflection as well. Actually, the potential and the effectiveness of video for reflection are supposed to be increased by the use of video supported by other ICT applications. The history of ICT shows that a combination of more than one type of technology is assumed to increase the potential of these tools (Tinio, 2003). Barron and Goldman (1994) suggest in this regard that "from our own experience in using integrated media with pre-service teachers, and from similar research and development efforts at other institutions, we are encouraged about the use and potential of such materials in preparing teachers for the challenges of the classroom" (p.104). The Kothmale Community Radio Internet, for example, uses radio broadcasts and computer and Internet technologies to facilitate the sharing of information thus providing educational opportunities in a rural community in Sri Lanka (Taghioff, 2001).

In education, many of the ICT applications have grown from being used as an individual tool to being included in systems that consist of several tools as a package or an environment that is dedicated to specific educational purposes. The use of video applications as a part of such learning environments, which is mostly considered the core of the environment, is increasingly utilized in teacher education. These kinds of video-based learning environments are usually delivered for the users through CD-ROM, DVD-ROM or by being installed on the hard-disk drive (HDD) of the computer (Schrader et al., 2003). With the advancement of the Internet as an effective delivery system in the last few years, many of these video-based learning environments are designed to be delivered through the Internet. In the next sections, the opportunities of using video supported by other ICT applications in a learning environment for the practice of reflection in teacher education are discussed. Examples of the use of video as a part of learning environments in both offline (Section 3.2) and online (Section 3.3) settings are distinguished. 


\subsection{OFFLINE VIDEO-BASED LEARNING ENVIRONMENTS}

The development of the mobile storage devices that have the ability to accommodate large amounts of data on the 1980s "CD-ROM" and later on the 1990s "DVD" made the exchange of information and materials more accessible. These storage devices have the capability to accommodate large amounts of different kinds of data such as text, graphics, audio, video, and other data formats. In the field of education, the advantages of these storage devices are used intensively by the educators to deliver different learning environments.

An example of an offline delivered learning environment in teacher education that includes video applications is the "Understanding Teaching: Implementing the NCTM Professional standards for teaching mathematics" learning environment. This environment was developed by the Association for Supervision and Curriculum Development (ASCD) at Arizona State University in 1997 and was delivered via four CD-ROMs. The interface of the environment demonstrates a real-world classroom environment for prospective teachers. Several types of materials are included in this environment such as video of classroom practice, expert audio commentary, 3D graphics, and animations. Figure 3.1 presents the "Understanding Teaching" learning environment (Cannings \& Talley, 2002).

The aim of this environment is to provide prospective mathematic teachers with observational experience that models the National Council of Teachers of Mathematics (NCTM) Professional Teaching Standards in order to help them recognize, understand, and explain the NCTM standards for teaching mathematics (Cannings \& Talley, 2002). According to the authors of this

environment, these materials comprise "an interactive multimedia professional development seminar on CD-ROM designed to help the user understand the Professional Standards for Teaching Mathematics recommended by the National Council of Teachers of Mathematics (NCTM)" (Teacher Education Material website, 1995). The environment also facilitates both individual and collaboration practices. 


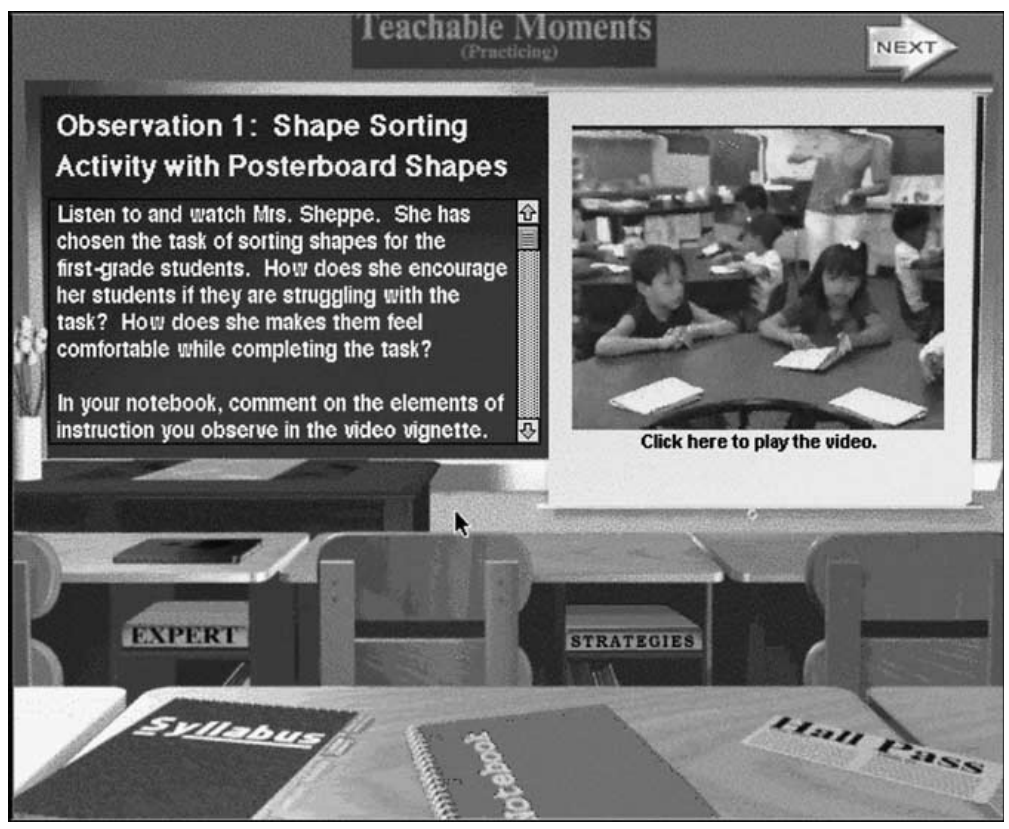

Figure 3.1 Understanding Teaching learning environment (Cannings \& Talley, 2002)

Another example of the integration of video with other ICT tools in a learning environment that is delivered via CD-ROM is the "Making Weighty Decisions" multimedia case learning environment. The "Making Weighty Decisions" learning environment was designed at Syracuse University in 1999 with the aim to facilitate prospective teachers to understand the complexity of the classroom. This multimedia case environment also aims to improve the observation competence of prospective teachers through their ability to reflect on their own practice. By demonstrating specific aspects of an eighth-grade mathematics lesson implemented in a real classroom, prospective teachers are encouraged to discuss, analyze, and understand those aspects together with their supervisor (Cannings \& Talley, 2002). This environment includes edited video material, teacher reflection, lesson plans, and seating charts.

Even though the offline learning environments are still widely used in education, more attention is given today to the possibilities of the Internet delivering such learning environments. In 2000, for example, a new online-based version of the "Making Weighty Decisions" learning environment was developed (Doerr, Bowers, Masingila \& McClain, 2000). The major goal of this new version was to increase the effectiveness of this learning environment via the facilities if the Internet. Figure 3.2 presents the "Making Weighty Decisions" learning environment (Doerr et al., 2000). Other advanced examples of the online video-based learning 
environments are discussed in the next section in order to understand the advantages that come from such practice.

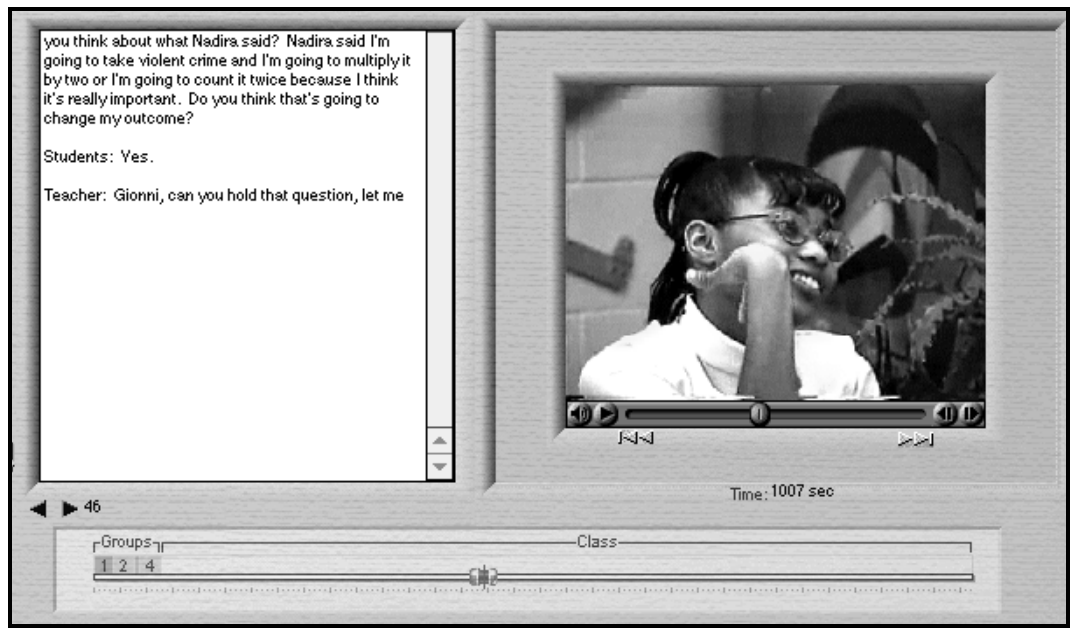

Figure 3.2 Making Weighty Decisions learning environment (Doerr et al., 2000)

\subsection{ONLINE VIDEO-BASED LEARNING ENVIRONMENTS}

Today, with the Internet being the predominant delivery system of information, many of the educational packages and environments are being provided online. Using a combination of ICT applications in online learning environments shows useful implementations for teacher education. Online learning environments are relatively new systems introduced for education around the mid-1990s as a response to the need for a practical way for faculty members to use the web. These online environments have become widely available in education since 1997 (Lamberson \& Lamb, 2003; Ullman \& Rabinowitz, 2004). Although the rapid evolvement of the online learning environments makes it difficult to pin down what exactly they represent (Morgan, 2003), many definitions for these environments can be found. For example, Becta (2004) described the online virtual learning environment as "a software tool which brings together in an integrated environment, a range of resources that enable learners and staff to interact online, and includes content delivery and tracking" (p. 1). A more general definition of these environments is presented by Currier, Brown and Ekmekioglu (2001) as "tools which support e-learning through provision and integration of web-based materials" (p.1). In general, the online learning environments can be seen as a set of teaching and learning tools designed to enhance students' learning experience by including computers and the Internet in the learning process (Ferl, 2006). Among other 
functionalities, most online learning environments facilitate communication, group work, material exchange, assessment, and links to remote resources.

A major advantage of the online environments as asserted by Cannings and Talley (2002) is that the participants will have convenient and cost-effective access to different ICT tools without any restraints with respect to time and place. Kovalchick, Hrabe, Julian, and Kinzie (1999, p.145) presented three significant capabilities of the Internet for delivering multimedia cases as follows:

- The ability to simulate real-world complexities,

- The ability to use multiple media in case presentations, and

- The ability to use hyperlink/hypertext navigation features.

Moreover, with the development of the digital video format and more recently the streaming video format, more attention is being given by researchers and educators to the use of video as part of online learning environments to support teacher education. Several studies conducted in the last few years have attempted to investigate the effectiveness of using online video-based learning environments for teacher education (Cannings \& Talley, 2002; Schrader et al., 2003; Nemirovsky \& Galvis, 2004; Kulk et al., 2005; Eilam \& Poyas, 2006; Leijen et al., 2008).

For example, in a study of the effectiveness of video and the Internet for overcoming the complexity of the classroom, Eilam and Poyas (2006) designed an intervention that aims to achieve the following:

- Promote novices' awareness of classroom complexity to reduce their possible reductive bias and to increase their cognitive flexibility,

- Advance novices' ability to identify cognitive aspects of implicit, concurrent teaching - learning processes and their interrelations, and

- Enhance novices' capacity to apply and relate theoretical knowledge to specific classroom episodes (p.339).

During this experiment, the participants are provided with several types of materials and resources through an Internet site to facilitate their understanding of the situation. For each unit, the participants are provided with a video of the actual classroom lesson, a written transcript of the lesson scenario, information about the characteristics of the students in this lesson, and information about the school and the curriculum and the learning materials that have been used in this 
lesson such as the textbook or the worksheets. Furthermore, a discussion forum to facilitate online dialogue among the participants and their supervisor, videoand audio-recorded interviews with experts and links to external resources such as the university library are also provided in each unit. In order to engage the participants, three tasks are assigned to them to encourage description, interpretation, and evaluation activities.

Based on the results of this study Eilam and Poyas (2006) concluded that their intervention contributed to the promotion of all three targeted aspects of novices' learning for teaching. However, some limitations of this video- and Internetbased intervention are also highlighted by the authors in this study. One of the major limitations that they describe is the lack of participants' knowledge and skills that are required for analyzing video and for working with the Internet site.

Another example that presents innovative use of an online video-based learning environment in teacher education and specifically in the field training can be found in the Digital Video for the Digital University "DiViDU" project. In 2004, the project "DiViDU" was launched in a co-operation between ten universities and colleges in the Netherlands (Kulk et al., 2005). The main goal of this project was to develop innovative learning activities that support and enhance field training in teacher education programs. Three modules were developed for this goal, which are an analysis module, a reflection module, and an assessment module. To support the implementation of these modules, video is used within an online video-based learning environment. The use of video in this project differs depending on the goal of each module.

The aim of the analysis module is to demonstrate professional behavior of experienced teachers in practical situations. The video is used in this module to provide the participants with real classroom teaching examples, which is assumed to trigger the discussion about the how to behave in a professional situation. Participants are assumed to develop the competences of observation, prediction, comparison, making links to theory, and one's own actions in a professional situation through this module. In the reflection module, the aim is to develop systematically the reflective skills of the participants. The video is used in this module to capture participants' actions during their practice of teaching to make their performance in the classroom available for themselves, their peers, and their supervisors. The five steps in Korthagen's model of reflection that have 
been discussed in Chapter 2 are used in this module to facilitate participants' reflection on their performance. The aim of the assessment module is to allow the participants to demonstrate their teaching competences. The video is used in this module together with text to help the participants in composing a coherent story that shows progress in their professional behavior (Kulk et al., 2005; Admiraal, Janssen, \& Pijls, 2007). Figure 3.3 shows the navigation window that provides access to the three modules in the DiViDU environment.

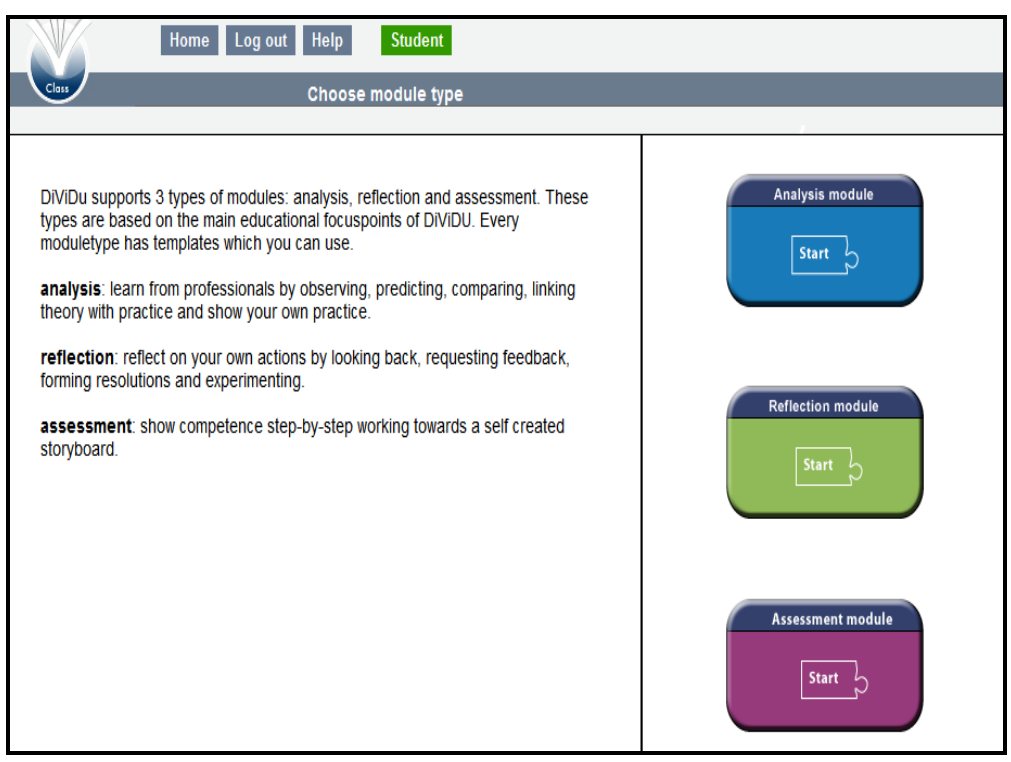

Figure 3.3 Modules window in DiViDU leaning environment

In 2005, the DiViDU learning environment was tested in six pilot studies and revealed promising implications for field training in teacher education (Kulk et al., 2005). One of the advantages described by Kulk et al. (2005) with respect to the use of video in their study is that the participants "pointed out that they learned from observing and interpreting their own behavior, something which is immediately lost in real life or which may even have been invisible in real life" (p.7). Furthermore, learning with the DiViDU environment is described by the participants as a very motivating and effective way of learning (Bimmel \& Janssen, 2004). However, several difficulties are reported that have been encountered by the participants for learning with the DiViDU environment. Most of these difficulties are related to the equipment and the knowledge and the skills that are needed to learn through this environment. In 2007, and because of the promising results of the DiViDU environment, four case studies were conducted using this environment to facilitate the use of web-based video (Admiraal, Janssen, Pijls, \& Gielis, 2008). The 
cases in this study are part of a larger study with more cases where the web-based video has been used as part of a student file or portfolio. In these files, students gather all information and materials about their professional learning during a 1 or 2 years course programme including video clips, literature, reflections, feedback, narratives, and more materials. Students integrate the video clips in their files into a narrative of a process of learning and teaching which also includes peer feedback, teacher feedback, reflections, literature, assessments, and course materials. The researchers presented a positive viewpoint towards the value of web-based video in this study even though no clear conclusion was asserted. However, they suggested that in order to get more insight and an overall picture of the value of web-based video in the transfer between learning and practice they would need to analyze the cases with students filling in more details (Admiraal et al., 2008).

Many other online environments have been found recently that support learning and have been specifically developed to facilitate reflective practice such as SenseMaker (Quintana, Shin, Norris \& Soloway, 2006), Case Application Suite (Kolodner, 2006), and Campus Productivity Kit that was developed by filemaker software (www.filemaker.com/cpkpr). However, the online video-based learning environment "DiViDU" was selected to be used later in our research as a tool in an experimental field study to facilitate the reflective practice. The main reason for selecting DiViDU for our field experiment is the strong emphasis in this environment on the use of video to facilitate reflection while the role of the other functionalities in the environment is to support specifically the use of video. This emphasis on the use of video corresponds to the vision and requirement of the online environment for the field experiment of this research. Another reason is related to the use of streaming video technology to deliver and to exchange video fragments in the DiViDU environment, which are assumed to help overcoming some of the problems concerning Internet connection speed and downloading the materials. Moreover, even though most of the environments provide diversity of tools and applications, DiViDU provides almost the exact tools and applications that are needed to complete the activities in our field experiment. Other reasons for selecting the DiViDU environment for the field experiment are related to the ease of use and the simple organization of the environment's interface. Therefore, Chapter 5 will present elaborative discussion and description of the functionalities of the DiViDU environment in relation to the field experiment. 


\subsection{DISCUSSION}

In this chapter, several opportunities of ICT for supporting the practice of reflection in teacher education were presented and a discussion of this information was meant to shed light on these opportunities with respect to the context of our research. Therefore, this section will discuss the information that has been presented in this chapter in order to formulate an answer to RQ2 in relation to the opportunities of ICT for supporting the reflective practice approach in teacher education (3.4.1). Furthermore, discussion of the expected difficulties from practicing reflection supported by an online video-based learning environment in Kuwait is also presented in this section (3.4.2).

\subsubsection{ICT-supported reflection}

Among many ICT applications that have been used in education, the history of educational video revealed a recognizable benefit of this application in teacher education. Nevertheless, several obstacles that are related mostly to the accessibility and the expenses of video prevented the optimal use of this application in teacher education in the past. However, the development of the role of video in recent years that has been discussed in Section 3.1 shows strong potential for a new functionality of video in teacher education that can effectively support the practice of reflection. Video can now be used during reflection as a tool that allows practitioners to capture the complexity of the classroom during their own teaching in order to reflect on the self and on other practitioners. It is assumed that this new functionality of video will overcome some of the major difficulties in practicing reflection that relate to the description activities. As a consequence, the use of video to facilitate the description activities is assumed to influence and to improve the major activities of reflection such as self-reflection, peer-reflection, and finding alternatives.

The potential of this new video functionality has become attainable by the fact that the advancement of technologies such as computers, the Internet, and the new digital and streaming video formats has provided promising solutions for the obstacles that faced video use in the past. Furthermore, the current trend of grouping several ICT applications in one learning environment instead of using each of these applications separately shows an increase of the effectiveness of these environments. These developments in the last few years have led to several attempts to examine the use of video as a part of learning environments that are 
accessible through the use of computers and the Internet (Cannings \& Talley, 2002; Schrader et al., 2003; Kulk et al., 2005; Eilam \& Poyas, 2006; Admiraal et al., 2008; Leijen, Lam, Wildschut, Simons \& Admiraal, 2009). The implications of some of these attempts discussed in Sections 3.2 and 3.3 illustrate promising opportunities for online video-based learning environments for the support of the reflective practice in particular and for teacher education in general.

In order to support the practice of reflection effectively via online video-based learning environments, consideration should be given to essential applications to be included in these environments. Generally, the number of applications in an environment differs from one environment to another based on their purpose. For example, as shown in Section 3.3, the website of Eilam and Poyas (2006) provides many tools and applications to the users while other environments may offer only the essential applications. Nevertheless, the use of computers and video and Internet applications are considered as the essential components that are always integrated into the main parts of any online video-based learning environment. Other applications that may contribute to the functionality of these environments vary from applications for communication such as a chat room or a discussion forum, applications for exchanging materials, or software applications for playing and manipulating the recorded materials. Cannings and Talley (2002), for example, specify four factors that they assume increases the effectiveness of the environment:

1. An engaging tool interface: the environment should encourage ongoing observation, dialogue, and reflection through tools such as teacher reflection, peer reflection, and participants' reflection journals,

2. An ongoing communication system: the environment should support the communication among the participants to engage them in reflective dialogue through tools such as discussion forums or chat rooms,

3. Contextual clues for viewing: the environment should include tools that allow the delivery of background information about the school, students, and classroom activities of the presented video, and

4. Access to additional resources: the environment should provide the possibility of access to other materials such as links, references, and articles that are related to the presented video case (p.365).

The information in this chapter leads to the formulation of a positive answer to RQ2 where it shows real opportunities of ICT for supporting the reflective practice particularly through the use of online video-based learning 
environments. Yet, this information also highlights the importance of understanding the requirements that come with using ICT applications. Hence, in order to practice reflection using an online video-based learning environment effectively, the requirements of the main applications in these environments must be accounted for.

In order to cover these requirements, four main factors may play a significant role in determining the usability and the usefulness of an application. The ability of the environment's infrastructure to accommodate an application and the availability of the needed equipment for operating this application are two major factors in this regard. Furthermore, users are encouraged to acquire two types of competences in order to operate any kind of applications effectively. First, users should have at least basic knowledge about issues like the purpose, the functionalities, the strengths, and the weaknesses of the application that they will use. Second, users should also have the necessary skills that allow them to operate this application accurately. These four factors are also valid to the three major applications in the online video-based learning environments: computers, video, and the Internet.

Therefore, considering that an experimental field study concerning the practice of reflection in an online video-based learning environment will be conducted in Kuwait later in this research, these four factors will be investigated beforehand. In Chapter 5, a document analysis will be conducted in order to understand the ICT infrastructure in the College of Basic Education in PAAET in Kuwait including the availability of the needed equipment. In addition, investigation into the knowledge and background of the participants in our intended field experiment regarding computers, video, and the Internet will be conducted in the same chapter.

\subsubsection{Difficulties in practicing reflection supported by an online video-based learning environment}

The difficulties that have been encountered in previous studies from practicing reflection as an educational approach were discussed in Chapter 2. Furthermore, the difficulties that are expected to come along from using ICT applications and specifically from using online video-based learning environments were also presented in this chapter. The attempt of this section, therefore, is to classify the expected difficulties that may occur from practicing reflection through an online video-based learning environment in Kuwait. Accordingly, this classification will 
be used later to collect the data concerning the difficulties in practicing reflection in Kuwait.

Many kinds of difficulties were found in the literature in Chapter 2 regarding the practice of reflection as well as some attempts in classifying these difficulties. For example, the barriers that are described by Platzer et al. (2000) that relate to the educational, socialization, and cultural background of the participants. Furthermore, Leijen (2008) also classified the reflection difficulties into four categories: general difficulties, difficulties in describing experiences, difficulties in evaluating experiences, and difficulties in relating to multiple perspectives. The classification of Leijen (2008) is, in fact, a good basis for building our classification as it covers most of the difficulties that have been described in the literature. Moreover, accommodating a new technology application is expected to bring along with it other kinds of difficulties as they were presented in this chapter. Thus, it is significant to anticipate the difficulties that may be encountered by using the different technology applications and to include these difficulties as a category in our classification.

The information presented in this chapter shows that the use of an online videobased learning environment to support reflection will introduce and require additional and relatively new activities to the practice of reflection. Most of these activities are related to the video application and specifically to the recording, editing, and uploading of the video fragments. A preliminary investigation in Chapter 5 will investigate learners' knowledge and skills in relation to the use of digital video. A new category of reflection difficulties for this purpose is introduced here. Based on the presented information in this chapter and the discussion of the reflection difficulties in Chapter 2, especially the work of Leijen (2008), a classification that consists of five types of categories will be used in this research:

- Difficulties related to recording,

- Difficulties related to description,

- Difficulties related to self-reflection,

- Difficulties related to peer-reflection, and

- Difficulties related to finding alternatives.

The design of the field experiment and the data collection instruments in Chapter 5 will follow this classification. 


\section{CHAPTER 4}

\section{Methodology of the research: Action Research}

This chapter discusses the methodology of the study behind this dissertation and the rationale behind the choice for the Action Research methodology. Section 4.1 describes the methodologies that are used to address the different research questions. Section 4.2 discusses the research philosophy and the rationale for the choice of research methodology. This section also discusses the main steps in scientific research and their utilization in this study. An overview of the methodology of Action Research as the method for this study is provided in Section 4.3. The type of information that is required to answer the different questions in this research is discussed in Section 4.4, and in Section 4.5 the instruments for collecting this information are explained. The chapter concludes with a summary in Section 4.6.

\subsection{METHODOLOGICAL FRAMEWORK FOR ADDRESSING THE RESEARCH QUESTIONS}

The aim of this research as stated in Section 1.4 is to investigate the opportunities of using an online video-based learning environment to provide adequate channels of communication that facilitate the reflective practice among prospective teachers and trainers during field training. This is assumed to help reduce the gap between theory and practice in the teacher education programs in Kuwait. This aim is used as the basis for the overall question for this research in Section 1.5:

Can the use of the reflective practice approach supported by an online videobased learning environment in field training in the teacher education programs in Kuwait reduce the gap between the theory and practice in this program?

In order to provide an adequate amount of evidence to answer this main research question, six questions that are more specific were formulated. The nature of 
these questions differs in a way that requires different methodologies for collecting and analyzing the data for each question. The main methods for investigating these questions are a literature study, document analysis, and an experimental field study.

The first two specific questions (RQ1 and RQ2) were dealt with in Chapters 2 and 3. The first question focuses on the reflective practice approach while the second question aims to understand the potential and the opportunities of the ICT applications in education for practicing reflection. The methodology used to address these two questions is reviewed based on literature that relates to the topics of the reflective practice approach in Chapter 2 and the use of ICT applications in education in Chapter 3.

Firstly and with respect to the reflective practice, it is found that the ultimate aim of the reflection notion is to connect the prior theoretical knowledge of the practitioners to their experience, thus, to build a bridge between theory and practice. Moreover, even though different models of reflection are proposed, they mostly share similar components that represent the core of this notion. The major components of a reflection model are the emphasis on a cyclical and continuous process, the importance of practitioner's prior background knowledge, and the importance of conscious observation of the experience. It is found also that the real influential factors, which determine the design of the reflection model, are the organization of the educational program and the characteristics of the learners in a specific educational program. Secondly, with relation to the possibilities of ICT application for reflection, it is found that the advancement of the ICT applications today provides teacher education with promising tools for supporting reflection. The examination of the online video-based learning environments specifically, where a combination of different ICT applications is provided, shows potential for supporting the reflective practice to overcome some of its difficulties. It is assumed that the activities of describing the experiences will be facilitated through the use of video supported by other ICT applications in such environments, which consequently will lead to improvement of the other activities in reflection.

Answering the previous two questions provided the research with applicable understanding of the use of reflective practice for teacher education and the opportunities of ICT and specifically the use of the online video-based learning environments for this purpose. A framework of context-related knowledge for 
this research, therefore, has been established through the answers of these two questions.

The third research question (RQ3) concerns the environment in which this research is taking place. Particularly, this question concerns the organization of the teacher education program in PAAET, the role of field training in this program, and the type of learners in this program. To address this question, documents from the College of Basic Education in PAAET regarding the organization of their program and the role of field training are analyzed and discussed in Chapter 5. Furthermore, background information that is collected through a questionnaire about the participants of an experimental field study regarding specific factors that may affect this study will be presented and discussed in the same chapter. More information about the design of the Background Questionnaire is provided in Section 4.5.3.

The last three research questions in this study (RQ4, RQ5, and RQ6) are formulated to gain understanding of the effect of reflective practice and the use of online video-based learning environments on the field training in the teacher education programs in Kuwait. Question 4 focuses on the expected difficulties from practicing the reflection while question 5 focuses on the effectiveness of the online video-based learning environment. The effect on learners' achievement from practicing reflection supported by video in an online environment is the focus of question 6. Evaluating the use of an online video-based learning environment that supports reflection in a real context in the field training in Kuwait is assumed to provide answers to these three questions. Therefore, the use of reflection in an online video-based learning environment is tested during an experimental field study in the teacher education in Kuwait to collect the required information for answering these questions. The discussion of the design of this field experiment will be presented in Chapter 5 and the results of this experiment will be discussed in Chapters 6, 7, and 8. The methodology that is applied in this research will be discussed in the next sections.

\subsection{RATIONALE FOR CHOICE OF RESEARCH METHODOLOGY}

Gathering, analyzing, and using the data about a phenomenon are the major steps in conducting scientific research (Davison, 1998). Nevertheless, two major research philosophies are known to conduct these steps in a contradicting way, which are the positivist and the interpretivist approaches (Galliers, 1991). Both of these 
research philosophies have long traditions and a history that goes back to the classical Greek times. The positivists believe that reality is stable and can be observed and described from an objective viewpoint (Levin, 1988). The interpretivists contradict this view and assert that reality can be fully understood only through the subjective interpretation and intervention of reality (Davison, 1998). The positivist paradigm was the dominant research philosophy in the scientific society for a long time (Hirschheim, 1985) while the interpretivist paradigm has recently become common in social sciences. Even though the major steps of these two research philosophies are usually conducted in a contradicting way, several research methodologies can be used with both philosophies.

Case study research is one of the research methodologies that can be used with both the positivist and the interpretivist approach. Looking at the approach of how to carry out our research, the similarity with the case study methodology can be recognized. Benbasat, Goldstein, and Mead (1987, p.370) assert, "A case study examines a phenomenon in its natural setting, employing multiple methods of data collection to gather information from one or a few entities (people, groups, or organizations). The boundaries of the phenomenon are not clearly evident at the outset of the research and no experimental control or manipulation is used". Christie, Rowe, Perry, and Chamard (2000) identify major activities that are involved in the main three steps in a case study. In the first step, the framework of the research is usually constructed through the literature review and pilot studies. The second step is used to confirm the conceptual framework of the research. This step also focuses on the case study and the research evaluation. Issue clarification is the last step of the research. In this step, the researcher discusses the finding, constructs theory, and makes the conclusion and recommendations (Christie et al., 2000). To describe these three steps briefly in relation to our research, the first three chapters in the dissertation present the first step where the problem, the goal, and the questions of this research were identified based on the literature in Chapter 1 to build a conceptual framework. Furthermore, Chapters 2 and 3 played the role of investigating the major factors of this research. The second step can be seen in this chapter together with Chapter 5 where the preliminary analysis and the design of the field experiment take place. The major analysis and the discussion, which belongs to both the second and the third steps, are conducted in Chapters 6, 7, and 8. Chapter 9 also serves the purpose of the third step and presents the theory construction through a discussion of the outcomes in order to build a solid conclusion with recommendations. 
Benbasat et al. (1987, p.370) describe three reasons that make the case study a viable research method:

1. It is necessary to study the phenomenon in its natural setting,

2. The researcher can ask "how" and "why" questions, so as to understand the nature and complexity of the processes taking place, and

3. Research is being conducted in an area where few, if any, previous studies have been undertaken.

Davison (1998) contends that the three reasons that (1987) make case study research viable according to Benbasat et al. are equally true for action research. Furthermore, he argues that action research is likely to include cases while a case study can certainly avoid using an action research approach (Davison, 1998). Several aspects related to the organization of our research suggest the suitability of action research methodology more than the case study approach. Two strong indicators for the use of action research methodology can be recognized here. The first indicator is if the researcher is working at the organization (PAAET) funding this research. The second indicator is if the aim of the research is to make a change and to improve the performance of this organization. Vreede (1995) highlights the major differences between case study and action research as it shows in Table 4.1.

Table 4.1 Case Studies and Action Research (Vreede, 1995)

\begin{tabular}{ll}
\hline Case Study & Action Research \\
\hline Researcher is observer & Researcher is active participant \\
\hline Exploratory, explanatory or descriptive & Prescriptive, intervening \\
\hline Focus on "How?" and "Why?" & Additional focus on "How to?" \\
\hline May be positivist or interpretivist & Usually interpretivist \\
\hline
\end{tabular}

Action research is known as inquiry or research within the context of focused efforts to improve the quality of an organization and its performance. Furthermore, the design and implementation of action research is typically done in collaboration between the researcher and the client. The participation of the researcher and the client in this research, as it will be explained later in Chapter 5, in addition to the embedded aim of the research to make a change and to improve the situation in the organization, also suggest the use of action research methodology. 


\subsection{ACTION RESEARCH METHODOLOGY}

Many researchers such as Kemmis and McTaggert (1988), Zuber-Skerrit (1992), and Holter and Schwartz-Barcott (1993) referred to Kurt Lewin as the originator of the term action research. Lewin (1948) states, "The research needed for social practice can best be characterized as research for social management or social engineering. It is a type of action-research, a comparative research on the conditions and effects of various forms of social action, and research leading to social action. Research that produces nothing but books will not suffice" (p.203). He argued that understanding and changing certain social practices requires the scientist to include practitioners from the real social world in all phases of inquiry (Masters, 1995). Other major contributors to this field are Trist, Collier and Lippitt (O'Brien, 2001; Masters, 1995).

\subsubsection{Overview of action research}

The description of $\mathrm{O}^{\prime}$ Brien (2001) refers to a general scenario for action research as "a group of people identifying a problem, do something to resolve it, see how successful their efforts were, and if not satisfied, try again". Though rather simple, this description covers the major phases in action research. In order to conduct a complete cycle of action research, the researcher needs to plan, act, observe, reflect, and repeat these phases if needed (Zuber-Skerrit, 1992). However, a more elaborative definition of action research is "a form of collective self-reflective inquiry undertaken by participants in social situations in order to improve the rationality and justice of their own social or educational practices, as well as their understanding of these practices and the situations in which these practices are carried out" (Kemmis \& McTaggert, 1988, p5). The emphasis on scientific study is the main characteristic that distinguishes action research from the daily problem solving activities or professional practice. In action research, the researcher studies the problem systematically and ensures the intervention is informed by theoretical considerations (O'Brien, 2001). Action research based on Rapoport (1970) aims to contribute both to the practical concerns of people in an immediate problematic situation and to the goals of social science by joint collaboration within a mutually acceptable ethical framework.

Considering that the aim of action research is to solve real problems, this type of research is used in real situations instead of contrived, experimental studies $\left(\mathrm{O}^{\prime} \mathrm{Brien}, 2001\right)$. In this way, theory informs practice and practice refines theory in a continuous transformation, which is one of the main principles of action research 
(Winter, 1989). This principle of "theory, practice, transformation" together with other principles such as "reflexive critique" and "collaborative resource handling" encourage the categorization of action research in the paradigm of praxis, which is neither positivist nor interpretive (Lather, 1986; Morley, 1991). The art of acting upon the conditions one faces in order to change them is what praxis is about (O'Brien, 2001). Nevertheless, action research also shares several perspectives with the interpretive paradigm particularly with respect to the use of the qualitative methodologies in this paradigm (Lather, 1986; Morley, 1991).

Furthermore, action research is characterized by minimally three requirements or conditions that incorporate the goals of improvement and involvement as presented by Grundy and Kemmis (1981):

1. The project takes as its subject-matter a social practice, regarding it as a strategic action susceptible to improvement,

2. The project proceeds through a spiral of cycles of planning, acting, observing and reflecting, with each of these activities being systematically and selfcritically implemented and interrelated, and

3. The project involves those responsible for the practice in each of the moments of the activity, widening participation in the project gradually to include others affected by the practice and maintaining collaborative control of the process (Grundy \& Kemmis, 1981).

\subsubsection{Process of action research}

Lewin (1946) proposed a basic approach of inquiry that comprised action cycles including analysis, fact-finding, conceptualization, planning, implementation, and evaluation (Sarac-Suzer, 2007). The process of action research aims to bring together theory and practice in order to solve a problem or to introduce an innovation in a systematic approach. This process usually includes identifying problems, analyzing problems, formulating ideas or hypotheses, gathering and interpreting data, implementing action, and evaluating the results of action (Taba \& Noel, 1957). Different scholars from these steps have created a variety of procedural models. The procedural model by Susman and Evered (1978), for example, consists of five stages aiming to provide a systematic approach of conducting action research. Figure 4.1 presents this model of action research from Susman and Evered (1978). 


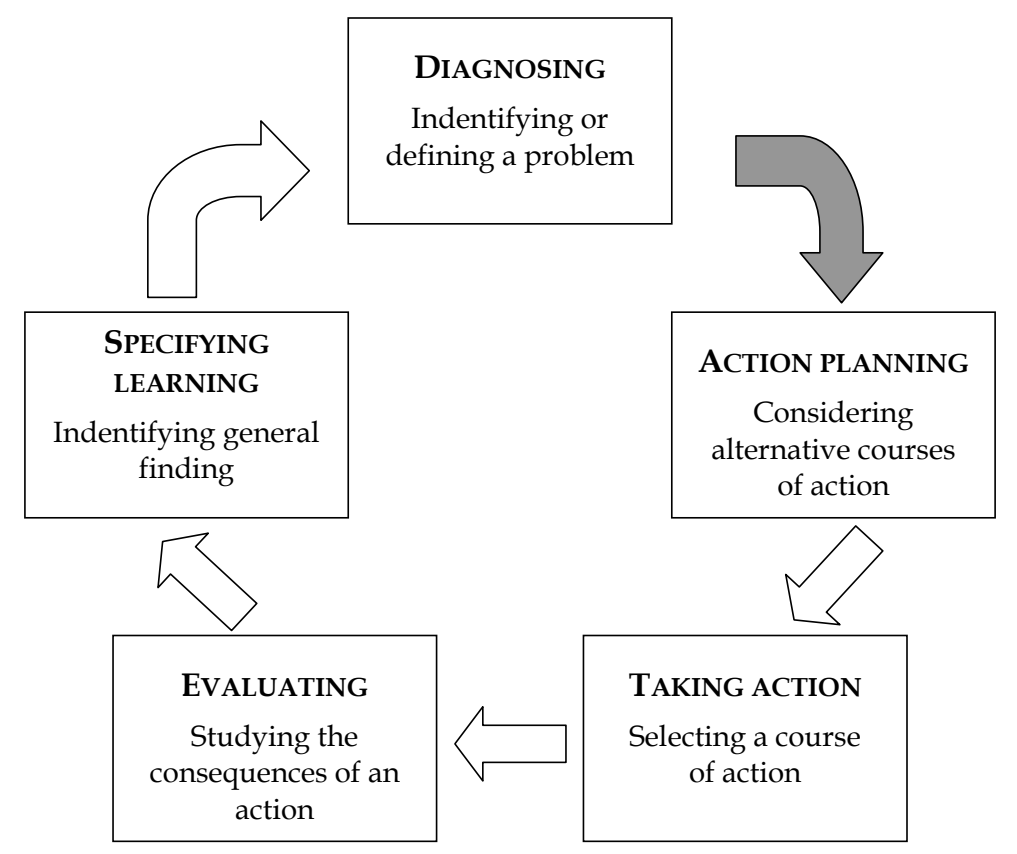

Figure 4.1 Action research model (Susman \& Evered, 1978)

In this model, diagnosing, action planning, action taking, evaluating, and specifying learning were presented as the main stages in conducting an action research project. Susman and Evered (1978) describe the activities involved in each of these five stages:

- The diagnosing stage involves the identification and definition of an improvement opportunity or a general problem to be solved in the client organization,

- The action planning stage involves the consideration of alternative courses of action to attain the improvement or solve the problem identified,

- The action taking stage involves the selection and realization of one of the courses of action considered in the previous stage,

- The evaluating stage involves the study of the outcomes of the selected course of action, and

- The specifying learning stage involves the study of the outcomes of the evaluating stage and, based on this study, knowledge building in the form of a model describing the situation being studied. 


\subsubsection{Data collection methods in action research}

A major strength of action research is the ability to process the data both qualitatively and quantitatively even though this type of research is classified as a qualitative approach (Miles \& Huberman, 1994; Winter, 2000). Considering that action research is more of a holistic approach for problem solving, several research methods for collecting data can be used. Some of these methods are document collection and analysis, participant observation recording, questionnaire survey, structured and unstructured interviews, and case studies (O'Brien, 2001).

As it has been discussed in Section 4.2, action research and case study research are treated as separate forms of research although they belong to the same family of methodologies (Benbasat et al., 1987). To some extent, the sources of data for the case studies can be used for action research (Strijker, 2004). Therefore, similar to a case study, several sources such as documentation, archival records, interviews, questionnaires, observation, and participant comment and reaction can provide significant data for analysis in action research (Stake, 1995; Yin, 1994). However, some of these sources might not be relevant for specific research; therefore, the choice of the sources should reflect the need of the study (Yin, 1994). Based on the relevance for our research, some of these sources are explained further:

- Documents and archival records: could be any kinds of materials such as letters, course information, reports, log files, or organizational records that can assist in confirming the evidence from other sources (Fisser, 2001),

- Interviews: two common types of interviews are the structured and the unstructured interview. While the structured interview has a fixed format and all questions should be prepared beforehand in one order, the unstructured interview has no specific format; however, the researcher should have key questions to lead the interview, and

- Questionnaires: A questionnaire is a set of written questions that calls for responses on the part of the client (Grinnel \& Williams, 1990). Questionnaires are useful tools for collecting appropriate data, making the data comparable and amenable for analysis, minimizing the bias in formulating and asking questions, and making these questions engaging and varied.

For this research, several instruments are used to collect the data to answer the different research questions. The relevance of the data for our research questions will be discussed in the next section in relation to the data collection methods that are explained in this section. 


\subsection{THE RESEARCH QUESTIONS IN DATA COLLECTION CONTEXT}

This research is driven by the six research questions extracted from the main research question. Depending on the nature of the question, these questions aim to clarify and to understand different kind of topics. Accordingly, this inquiry requires different types of information, which are collected using different methods and instruments.

As it has been discussed in Section 4.3.3, action research is considered a holistic approach to problem solving $\left(\mathrm{O}^{\prime}\right.$ Brien, 2001) and this characteristic allows for using a variety of research methods and instruments to collect and to analyze the data instead of a single method of collection and analysis. The main methods that are used in this research, therefore, are literature study, document analysis, and an experimental field study. The literature study is intensively used to answer the first and the second questions. The document analysis is used mainly to answer the third question while the experimental field study is used to answer the fourth, the fifth, and the sixth research question. Furthermore, based on the possibilities of data collection that are discussed in Section 4.3.3, the information is gathered for the different research questions using four different instruments: literature review, documents analysis, questionnaires, and interviews. The aim and the focus of the questions as well as the methods and instruments that are used to collect the required information for answering these questions are discussed in the next sections.

\subsubsection{Data concerning the reflective practice approach (RQ1)}

RQ1 concerns the reflective practice approach. Specifically, the question aims to understand the philosophy behind the reflective practice and how this approach may be used in teacher education programs. In order to find an answer to this question, a literature review was conducted in Chapter 2 to understand the theoretical perspectives behind reflection and the different schools that promote these approaches. Furthermore, in the same chapter, different reflection models from the literature were studied to determine a suitable implementation strategy for the reflection approach in this research. Finally, major difficulties about reflection that were encountered in previous studies were investigated to provide a solid basis for building the field experiment. 


\subsubsection{Data concerning the online video-based learning environments (RQ2)}

RQ2 concerns the online video-based learning environments. The focus of this question is on the opportunities of video applications for teacher education. The opportunities for using video applications in an online learning environment to support reflection in teacher education are precisely the major focus of this research question. Therefore, to find an answer to this question, the opportunities of video applications on the Internet are investigated by studying the literature of several topics in relation to video applications and online learning environments. Several examples that demonstrate the use of online video-based learning environment were also studied for the same purpose. This investigation is reported in Chapter 3 of this dissertation.

\subsubsection{Data concerning the opportunities of utilizing the reflective practice in teacher education programs in Kuwait (RQ3)}

RQ3 concerns the possible opportunities for utilizing the intervention of practicing the reflective approach via an online video-based environment in field training in the teacher education programs in Kuwait. To find an answer to this question, the discussion in Chapter 2 showed that it is significant to understand the organization of the teacher education programs in Kuwait and to identify the role of field training within these programs. Furthermore, the ICT infrastructure in the College of Basic Education is another important factor that influences the implementation of reflection though an online environment as it was discussed in Chapter 3. The significance of having a clear understanding of the background of the participants regarding several knowledge areas that are related strongly to the use of reflection and the online environment was also highlighted in Chapter 2.

Therefore, an analysis of the documents from the College of Basic Education in PAAET regarding the organization of their program and the role of the field training in this program is conducted in Chapter 5. Furthermore, data concerning the background of the participants collected via a questionnaire (Background Questionnaire) and presented in Chapter 5 is also used to understand the situation in this program and to arrive at an answer for RQ3 in this study. 


\subsubsection{Data concerning the difficulties in practicing the reflection (RQ4)}

The usefulness and the importance of the reflective practice approach for teacher education are demonstrated explicitly through the literature in Chapter 2. In the same chapter, however, several types of difficulties in practicing reflection are also discussed. Furthermore, difficulties that may emerge from practicing reflection via an online video-based environment are also discussed in Chapter 3. The relevance of the different types of difficulties for this research is discussed also in Chapter 3 and a specific categorization for these difficulties is presented.

RQ4 aims to investigate the presence of these difficulties in practicing reflection via an online video-based environment in the teacher education program in Kuwait. In order to answer this research question, an experimental field study is conducted in the teacher education programs in Kuwait that aims to collect information regarding the different types of difficulties. This information is collected at the end of this experiment through a questionnaire (Difficulties Questionnaire) and through interviews with the participants and their supervisors. The design of the field experiment, the Difficulties Questionnaire, and the interviews are discussed in Chapter 5. The results from this experiment are presented in Chapter 6 in order to answer this research question.

\subsubsection{Data concerning the effectiveness of the online environment (RQ5)}

The opportunities of the online video-based learning environments are investigated in Chapter 3. The results of this investigation illustrate promising potentials of such environments in providing prospective teachers and trainers with adequate channels of communication that can facilitate the practice of reflection during field training. RQ5, therefore, measures the effectiveness of the online video-based environment in facilitating the practice of reflection among prospective teachers and trainers in field training in Kuwait in relation to facilitating reflection.

In order to answer this question, information about the existing channels of communication in the field training and the satisfaction of prospective teachers and trainers with these channels is collected before the use of the environment. This information is collected through analyzing documents from the College of Basic Education in PAAET in relation to the organization and the structure of the field training in Chapter 5. Further, more information concerning the availability 
and the efficiency of the existing channels of communication is collected via the Background Questionnaire in the same chapter.

To determine the effectiveness of the environment in facilitating reflection, participants' satisfaction with the usability and the usefulness of the environment will be used as indicators. The usability is used here as a general term that reflects the enquiry toward the ease of use of this environment while the usefulness refers to the facilitation of the practice of reflection. After conducting the field experiment, information about participants' satisfaction is collected using a questionnaire (Effectiveness Questionnaire) and interviews with the participants. Furthermore, understanding supervisors' perspectives toward the usability and the usefulness of the environment is another indicator of the effectiveness of this environment. Interviews with the supervisors are also conducted after the experiment to collect this information. The design of the Effectiveness Questionnaire and the interviews is discussed in Chapter 5 and the results are presented in Chapter 7 in order to answer this research question.

\subsubsection{Data concerning the reflection's influence on the learning achievement and on the gap between theory and practice (RQ6)}

The major goal of this research is to reduce the gap between theory and practice in field training in the teacher education program in Kuwait. To fulfill this goal, it is proposed that, based on the literature, using the reflective practice approach via an online video-based learning environment would positively influence this gap. The use of reflection in an online video-based learning environment is tested during an experimental field study that is conducted in teacher education programs in Kuwait.

To determine if there is an influence from this intervention, RQ6 was formulated. To answer this question, information in relation to participants' perspective towards the influence of this intervention on connecting theory and practice and on their ability to master the practiced competences is one of the indicators. In addition, information about the performance of the participants with and without the intervention and their perspectives toward the practice of reflection is another indicator. Furthermore, the perspectives of their supervisors about the influence of the intervention on connecting theory and practice are a third indicator. 
The information for answering this research question is collected by two different instruments. A questionnaire (Achievement Questionnaire) is used to collect the information from the participants concerning their appreciation of the influence of reflection in relation to theories and to practice. Moreover, interviews with the participants and their supervisors are also conducted to collect information about the influence of using this intervention and the benefits from practicing the reflection approach in an online video-based learning environment. The design of the Achievement Questionnaire and the interviews is discussed in Chapter 5 and the results are presented in Chapter 8 in order to answer this research question.

\subsection{OVERVIEW OF THE DATA COLLECTION INSTRUMENTS}

To collect the required information that is able to provide answers to the questions of this research, four different instruments for data collectionliterature review, documents analysis, questionnaires, and interviews-are used. The following sections provide brief descriptions of the design, the components, and the purpose of these instruments. Some of the instruments, however, will be elaborated on later in Chapter 5.

\subsubsection{Literature review}

The literature review is used in this research continually as the research is conducted. However, the focus on the literature review, as it was described in Section 4.4.1, is mainly in the first three chapters of this dissertation. The literature study is used in Chapter 1 to build the theoretical framework for this research. Studying the literature regarding the reflective practice approach and the use of the online video-based learning environments for practicing reflection are the bases for Chapters 2 and 3 .

\subsubsection{Documents analysis}

The documents analysis is used mainly to investigate the situation in the College of Basic Education in PAAET in Kuwait. Documents concerning the teacher education program and the role of the field training in this program are analyzed

in Chapter 5 to understand how this program is organized and the importance of the field training in this program. This information together with the information from the Background Questionnaire in the same chapter is used to design the experimental field study and the reflective practice model. 


\subsubsection{Questionnaires}

The questionnaires are one of the main data collection instruments that have been used in this research. The aim of administering the questionnaires is to collect information both before and after conducting the field experiment. Four different questionnaires are used in this study: the Background Questionnaire, the Difficulties Questionnaire, the Effectiveness Questionnaire, and the Achievement Questionnaire.

The Background Questionnaire is used during the preliminary investigation before conducting the field experiment and aims to acquire insight into the knowledge and experience of the participants regarding several areas. At the end of the field experiment, information about the difficulties on practicing the reflection, the usability and usefulness of the online environment, and the effect of the reflection activities are collected via the other three questionnaires. The Difficulties Questionnaire aims to collect information about different types of difficulties that the participants may have encountered when carrying out the reflection activities. The Effectiveness Questionnaire aims to collect information about participants' perspective towards the usability and the usefulness of the online environment for carrying out the reflection activities. The Achievement Questionnaire aims to collect information about the effects of practicing the reflection activities on the participants' learning achievement. The design of the Difficulties, the Effectiveness, and the Achievement Questionnaires are presented in Chapter 5. However, the design of the Background Questionnaire that is used in the preliminary investigation is discussed here.

The Background Questionnaire as a preliminary data collection instrument aims to collect information that helps to create an understanding of the background of the participants in four different areas. The main sections in this questionnaire are as follows:

- Section A: Computers and \& the Internet: the questions in this section focus on collecting information related to participants' experience and skills regarding the use of computers and the Internet. The questions in this section are all closed-ended questions. However, several types of closed-ended questions are used. Questions 1 and 3 are Yes/No types of questions while questions 2, 5, 6 and 7 are multiple-choice. In addition, questions 4 and 8 are ordinal types of questions and the last two questions are Likert-scale questions, 
- Section B: Digital video cameras: the questions in this section focus on collecting information related to participants' experience and skills regarding the use of digital video cameras and the familiarity with this kind of equipment. This section is consisted of five Yes/No questions,

- Section C: Channels of communication: the questions in this section focus on collecting information related to the availability and efficiency of the existing channels of communication among prospective teachers and trainers during the field training. All questions in this section are closed-ended using Yes/No, multiple-choice, and ordinal types of questions except for the last question, which is an open-ended question, and

- Section D: Reflective practice: the questions in this section focus on collecting information related to participants' background regarding the practice of reflection. Five closed-ended Yes/No questions are presented in this section. For the complete version of the Background Questionnaire see Appendix 1.

The information collected from this questionnaire is presented and discussed in Chapter 5. The results of this discussion are used to confirm the answer to RQ3 and to support the design of the experimental field study and the reflective practice model in Chapter 5.

\subsubsection{Interviews}

As the field experiment is conducted, information is collected through unstructured interviews by talking to different individuals such as the participants, school coaches, supervisors, school principals, and employees in the field training unit. Furthermore, structured interviews with the supervisors as well as the participants are conducted at the end of the experiment. The aim of the interviews generally is to collect information that supports the collected responses from the different questionnaires. Furthermore, the interviews are assumed to provide opportunity to the participants to explain in more detail their experience in this experiment. The design of the different types of interviews is discussed in Chapter 5. 


\subsection{SUMMARY}

This chapter identified a framework for this research. The philosophy behind the positivist and the interpretivist schools was discussed in Section 4.2 to illuminate the differences between these two approaches in conducting the various steps of a scientific research. Furthermore, the characteristics of case study research as a methodology that is able to accommodate both the positivist and the interpretivist perspectives and the similarity of this method with Action Research methodology were also discussed. This discussion led to the choice of Action Research methodology as the suitable method for carrying out this research. An overview of Action Research methodology including the process and the data collection instruments in this type of research was then discussed in Section 4.3 with respect to the characteristics of our research. Specifying the research methodology for this study and the possibilities for collecting the data based on this method led to the discussion about suitable data collection methods and instruments in Sections 4.4 and 4.5.

Generally, the discussion in this chapter played the role of clarifying the conceptual framework for this research and setting up a framework for the following steps in this research. The next chapter will discuss major factors that are involved in the experimental field study. An investigation of the teacher education programs in Kuwait will be discussed in the next chapter in order to

support the design of the field experiment and the reflective practice model for this research. 


\section{CHAPTER 5 Design of the experimental field study}

Evidence from the literature review in Chapter 2 suggests the utilization of reflective practice activities in field training to reduce the gap between theory and practice. Moreover, the investigation of opportunities of ICT applications in Chapter 3 and the examples of using video applications, particularly in online learning environments, showed promising intervention options for utilizing the reflective practice activities in field training. It could be assumed accordingly that the use of video in an interactive online learning environment among prospective teachers and trainers in the field training will support the communication and facilitate the reflective practice, thereby reducing the gap between theory and practice.

The focus of the previous chapters is on constructing a conceptual framework for this research through the literature. The practical part of this research that will be based on this conceptual framework is presented in the rest of this dissertation. This chapter, therefore, presents the design of a field experiment to be conducted in the College of Basic Education in the Public Authority for Applied Education and Training (PAAET) in Kuwait. The aim of the experiment is to investigate the opportunity of using an online video-based learning environment to facilitate the reflective practice among prospective teachers and trainers in field training. PAAET is one of the main governmental institutes in Kuwait that offers a

program for teacher education. The educational program and the facilities of PAAET that form the context of the experiment have to be studied first to answer the third question in this research that is formulated in Section 1.5 as follows:

RQ3: What are the opportunities for using the reflective practice approach and the online video-based learning environment in field training in the teacher education programs in Kuwait? 
The preliminary investigation to answer this question is presented in this chapter in Section 5.1 together with Section 5.2; the collected information is discussed in Section 5.2.5. As described in chapter 4, the aim of the experiment in the so defined context is to collect data that are assumed to provide answers for questions 4, 5, and 6 of this research, which were presented in Section 1.5 as follows:

RQ4: What are the difficulties that prospective teachers and trainers encounter by utilizing the reflective practice approach supported by the online video-based learning environment in field training in the teacher education programs in Kuwait?

RQ5: Will the use of the online video-based learning environment provide adequate support to facilitate reflection among prospective teachers in field training in the teacher education programs in Kuwait?

RQ6: Will using the reflective practice approach supported by the online videobased learning environment in field training improve learners' achievement and help in reducing the gap between theory and practice in the teacher education programs in Kuwait?

The design of the field experiment in this chapter is described in terms of participants (Section 5.2), method and procedure (Section 5.3), and materials (Section 5.4). Moreover, the design of the data collection instruments for this experiment is described in Section 5.5. Section 5.6 will conclude this chapter with a summary of the main elements that have been discussed.

\subsection{CONTEXT OF THE FIELD EXPERIMENT}

In order to implement the reflective practice approach supported by an online video-based learning environment, the context and the conditions of this implementation must be investigated. Several conditions and requirements in

relation to both the reflective practice approach and the online video-based learning environments were discussed previously in Chapters 2 and 3. 
Chapter 2 discussed two crucial factors that influence the design of an effective model for practicing reflection. The first factor is the need for understanding the educational program. This factor is dealt with in this section by analyzing documents from PAAET and specifically from the College of Basic Education in this organization, which is expected to provide sufficient information about the organization of this program.

The requirements that come along from using ICT applications, which were discussed in Chapter 3, are a second set of factors to determine the viability of implementing the reflective practice supported by ICT application in a specific program. The ability of the ICT infrastructure, the availability of ICT equipment, and the knowledge and skills of the participants are all influential factors in this regard. Therefore, investigating the infrastructure of the College of Basic Education with relation to ICT implementation is supposed to provide useful information for designing the reflective practice model and the field experiment.

This section starts with a general overview of the College of Basic Education in PAAET (5.1.1) and discusses the status of ICT infrastructure in this college (5.1.2). This leads to the decision to involve the English Language and the Educational Technology departments in this research. The role of the field training courses in the English Language and the Educational Technology departments is then described in Section 5.1.3.

\subsubsection{The College of Basic Education in PAAET}

The Public Authority for Applied Education and Training (PAAET) is one of the governmental authorities in the State of Kuwait that was established in 1982 in order to manage the development of the workforce for governmental and business sectors in the State of Kuwait (PAAET, 2004). The Authority consists of four colleges and seven institutes that focus on different specialties for the work place. The colleges in PAAET are the College of Technology Studies, the College of Business Studies, the College of Health Science, and the College of Basic Education. The institutes in PAAET are the Electricity and Water Institute, the Telecommunication and Navigation Institute, the Vocational Training Institute, the Constructional Training Institute, the Nursing Training Institute, the Secretary Training institute, and the Industrial Training Institute. 
The College of Basic Education was established at the beginning of the 1960s as a teacher education institute that provides a two-year program to prepare prospective teachers for the intermediate schools in several subject-matter areas. In the 1986-87 academic year, however, the program was replaced with a fouryear program, and accordingly the name was changed into the present one. The main goal of this college is to supply the governmental schools in Kuwait with skilled teachers for the different subject-matter areas. Four main objectives were extracted from this goal as follows:

- Preparing skilled national workforce to teach in primary and kindergarten schools,

- Qualifying the national workforce in various specialties that are required by the Ministry of Education,

- Designing the educational goals based on the competences that are expected from the Ministry of Education, and

- Fostering a close link between the appropriate divisions of the Ministry of Education and the College of Basic Education (PAAET, 2004).

The college operates under the credit hour system, which requires the learner to complete successfully 130 credit points in order to graduate. The credits can be earned by passing the different courses in the program where each course counts for between two and three points and the field training at the end of the program counts for nine points. The majority of the learners attend the college after finishing high school as full-time learners. However, some of those who received their diploma before the 1986-87 year when the college was still operating as an institute are also attending the college as life-long learners to upgrade their diploma to bachelor's degree. The normal period of study in this college is four years divided into eight semesters where the learners spend seven semesters in the college and one semester in practical field training at the end of the study program in the schools.

The college consists of fifteen departments aiming to prepare prospective teachers for different specialties to reflect the needs of the schools, which are determined by the Ministry of Education. Two departments in this college are chosen for the experimental field study in this research: the English Language department and the Educational Technology department. Three main reasons led to the choice of these two departments for our field experiment. First is the difference in the nature of these two departments in practicing field training. 
Second is the difference in the role of the graduates from these two departments later in the workplace. More information about these two reasons and the differences of these two departments is presented later in Section 5.1.3. The third reason for choosing the Educational Technology department for our field experiment is related to the required ICT infrastructure and equipment for practicing reflection through an online video-based learning environment. This reason is explained in the next section in which a discussion of the infrastructure of the College of Basic Education in PAAET regarding ICT is presented. A general presentation of the structure of PAAET in relation to the chosen departments is presented in Figure 5.1.

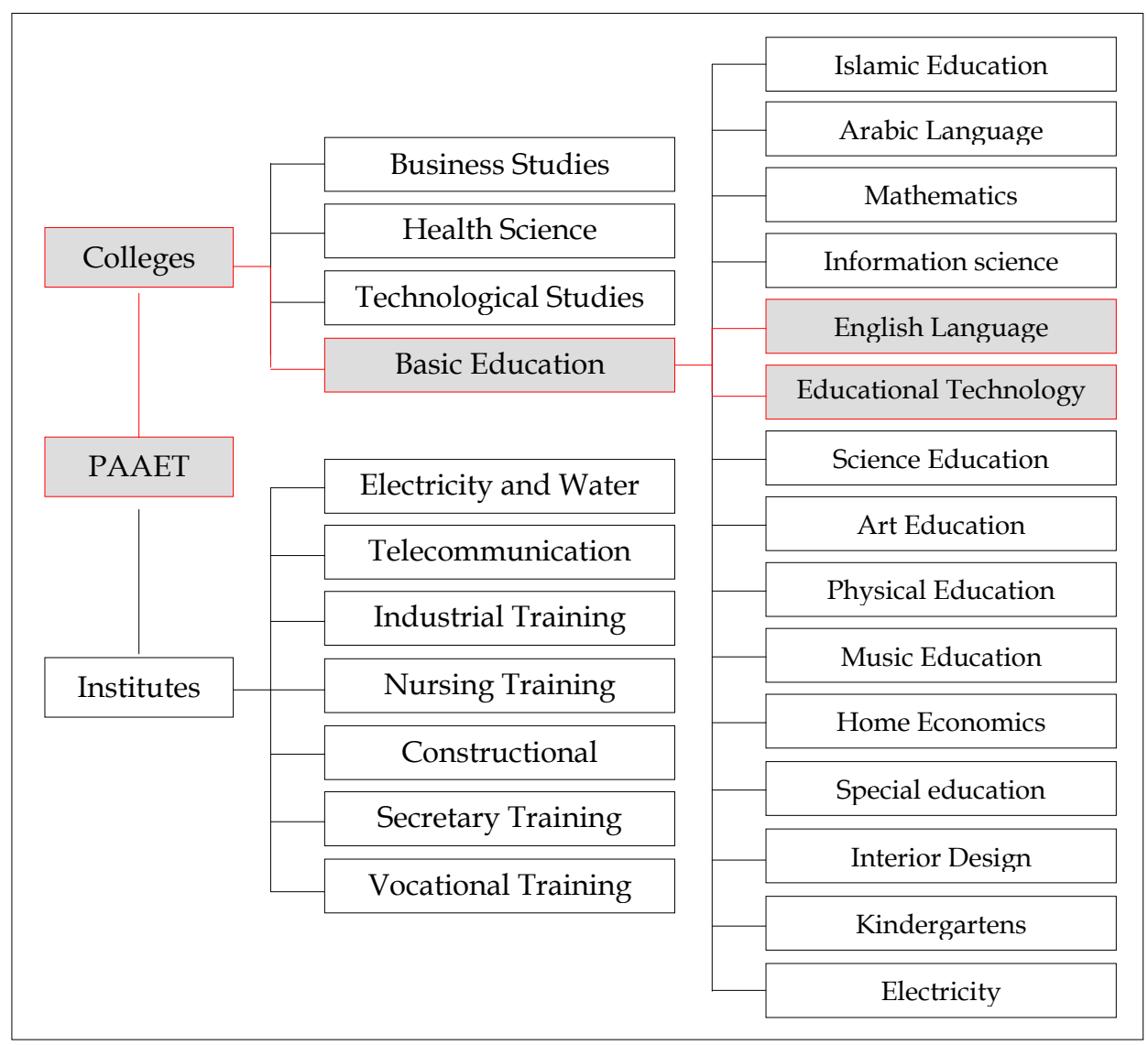

Figure 5.1 PAAET's structure

\subsubsection{ICT INFRASTRUCTURE IN THE COLLEGE OF BASIC EDUCATION}

In Chapter 3, the ICT infrastructure in an organization is described as an important factor that affects the usability and the usefulness of utilizing an ICT application. Therefore, an overview of the ICT infrastructure in PAAET and 
specifically in the two departments in the College of Basic Education is presented here in order to investigate the opportunities of implementing an online videobased learning environment in this college.

From the ICT planning matrix that is described by the National Center for Technology in Education (NCTE, 2008), three different stages of ICT infrastructure are distinguished in the learning organizations: an initial stage, an intermediate stage, and an advanced stage of ICT infrastructure. The matrix is designed with consideration to seven main factors that are assumed to determine the stage of the ICT infrastructure in a learning organization: location, network, support, Internet connection, software, equipment, and maintenance. The ICT infrastructure matrix is presented in Table 5.1 with relation to the different departments in the College of Basic Education in PAAET.

Table 5.1 shows that it is significant to distinguish between the Educational Technology department and the other departments in the College of Basic Education including the English Language department while describing the ICT infrastructure in this college. The reason for this differentiation is because the Educational Technology department focuses on technology as the subject matter, which accordingly improves the ICT infrastructure in this specific department. Whereas no computers for learners can be found in the other departments, the Educational Technology department has three computer laboratories with around fifteen computers in each laboratory. The computers in these laboratories are connected as a local network within the department, fully equipped with new hardware, up-to-date software on all computers, and connected to the Internet via an ADSL connection. Many types of ICT equipment are available in this department including digital cameras and projectors.

Regarding technical support and maintenance, PAAET has a computer department that is responsible for all issues related to the ICT infrastructure within the organization including the college of Basic Education. The number of technicians in the computer department with respect to the size of this organization is insufficient as only one person is responsible for each college or institute. However, the Educational Technology department has its own ICT technician who is responsible for the maintenance of the department's equipment as well as the technical support. 
Table 5.1 ICT infrastructure matrix (NCTE, 2008)

\begin{tabular}{|c|c|c|c|c|}
\hline 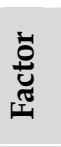 & Stage & Description & $\begin{array}{l}\text { Educational } \\
\text { Technology } \\
\text { department }\end{array}$ & $\begin{array}{c}\text { Other } \\
\text { departments }\end{array}$ \\
\hline \multirow{3}{*}{ 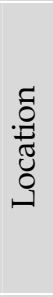 } & Initial & $\begin{array}{l}\text { Computers are confined to a computer } \\
\text { room }\end{array}$ & \multirow{3}{*}{$\begin{array}{c}3 \text { labs with } \\
\text { approximately } \\
45 \text { desktop } \\
\text { computers }\end{array}$} & \multirow{3}{*}{ None } \\
\hline & Intermediate & $\begin{array}{l}\text { Computers are located throughout the } \\
\text { school in classrooms }\end{array}$ & & \\
\hline & Advanced & $\begin{array}{l}\text { Network of computers distributed } \\
\text { throughout the school }\end{array}$ & & \\
\hline \multirow{3}{*}{ 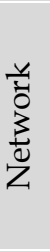 } & Initial & Computers are not networked & \multirow{3}{*}{$\begin{array}{c}\text { Local } \\
\text { network } \\
\text { within the } \\
\text { department }\end{array}$} & \multirow{3}{*}{ None } \\
\hline & Intermediate & $\begin{array}{l}\text { Peer network in place in the computer } \\
\text { room, but not throughout the school }\end{array}$ & & \\
\hline & Advanced & $\begin{array}{l}\text { All computers are networked; Internet } \\
\text { access is available throughout the school }\end{array}$ & & \\
\hline \multirow{3}{*}{$\begin{array}{l}\frac{1}{0} \\
0 \\
\text { مै } \\
\text { के }\end{array}$} & Initial & $\begin{array}{l}\text { There is no provision for technical } \\
\text { support }\end{array}$ & \multirow{3}{*}{$\begin{array}{c}\text { ICT } \\
\text { technician } \\
\text { Within the } \\
\text { department }\end{array}$} & \multirow{3}{*}{ None } \\
\hline & Intermediate & $\begin{array}{l}\text { Provision is made for the maintenance of } \\
\text { computers }\end{array}$ & & \\
\hline & Advanced & Technical support contract is in place & & \\
\hline \multirow{3}{*}{ 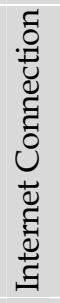 } & Initial & $\begin{array}{l}\text { Internet connection through one } \\
\text { telephone line to a computer }\end{array}$ & \multirow{3}{*}{$\begin{array}{l}\text { ADSL } \\
\text { connection }\end{array}$} & \multirow{3}{*}{ None } \\
\hline & Intermediate & $\begin{array}{l}\text { Internet connection via ISDN to most } \\
\text { computers }\end{array}$ & & \\
\hline & Advanced & $\begin{array}{l}\text { Internet connections to all computers via } \\
\text { multiple ISDN, ADSL or broadband }\end{array}$ & & \\
\hline \multirow{3}{*}{ 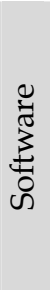 } & Initial & $\begin{array}{l}\text { Limited software is available, but not for } \\
\text { all classes and all subject areas }\end{array}$ & \multirow{3}{*}{$\begin{array}{l}\text { Up-to-date } \\
\text { software }\end{array}$} & \multirow{3}{*}{ None } \\
\hline & Intermediate & $\begin{array}{l}\text { Some software and Internet resources } \\
\text { are available }\end{array}$ & & \\
\hline & Advanced & $\begin{array}{l}\text { Appropriate software and Internet } \\
\text { resources are available }\end{array}$ & & \\
\hline \multirow{3}{*}{ 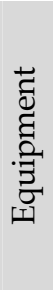 } & Initial & $\begin{array}{l}\text { Desktop computers and printers are the } \\
\text { only ICT equipment available }\end{array}$ & \multirow{3}{*}{$\begin{array}{l}\text { Advance ICT } \\
\text { equipment }\end{array}$} & \multirow{3}{*}{ None } \\
\hline & Intermediate & $\begin{array}{l}\text { Digital camera(s) and scanner(s) are } \\
\text { used for project and website work }\end{array}$ & & \\
\hline & Advanced & $\begin{array}{l}\text { Digital projector(s) and interactive } \\
\text { whiteboard(s) are in use in the school }\end{array}$ & & \\
\hline \multirow{3}{*}{ 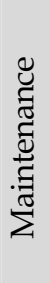 } & Initial & $\begin{array}{l}\text { Some computer equipment does not } \\
\text { work and has not been repaired }\end{array}$ & \multirow{3}{*}{$\begin{array}{l}\text { From the } \\
\text { computer } \\
\text { department } \\
\text { in PAAET if } \\
\text { needed }\end{array}$} & \multirow{3}{*}{$\begin{array}{c}\text { From the } \\
\text { computer } \\
\text { department } \\
\text { in PAAET if } \\
\text { needed }\end{array}$} \\
\hline & Intermediate & $\begin{array}{l}\text { Equipment is fixed or replaced only } \\
\text { when absolutely necessary }\end{array}$ & & \\
\hline & Advanced & $\begin{array}{l}\text { Provision is made for regular equipment } \\
\text { renewal }\end{array}$ & & \\
\hline
\end{tabular}


In all it can thus be concluded that the ICT infrastructure in the Educational Technology department is in a relatively advanced stage while the rest of the departments in the college are mostly in the initial stage. In the previous section it was already mentioned that this is one of the reasons for choosing the Educational Technology department as one of the departments for the field experiment.

Descriptions of the field training courses in this department as well as in the English Language department are presented in the next section.

\subsubsection{Field training in the College of Basic Education}

Because field training is considered an essential component in all of the specialties within the College of Basic Education an independent division under the direct supervision of the dean of the college is responsible for the management and the supervision of the practice of field training for all departments in the college. In the Field Training Manual (2007) the goals of the field training division are specified as follows:

- To prepare prospective teachers and trainers professionally for their future jobs,

- To provide opportunities for prospective teachers and trainers to practice what they learned in a real context,

- To develop the field training programs continually, and

- To support prospective teachers and trainers during their field training practice.

In order to accomplish the described goals, the field training division is involved in several tasks that aim to produce an effective field training practice. In addition to preparing and managing the financial and staff issues for the field training courses, the division plays the role of the coordinator between the college's departments and the workplaces such as schools, ministries, or private sectors. The field training division also supervises the process of the different field training courses, writing reports about the efficiency of these processes and studying and analyzing the results of these courses. Furthermore, the division is responsible for designing the evaluation procedure in cooperation with each department.

Based on the Field Training Manual (2007) two types of field training are distinguished in the College of Basic Education. The first type of field training is designed specifically for the departments of Information Science and Educational 
Technology. The second type of field training is designed for the other specialties in the college that are focused mainly on the practice of teaching and that include the other thirteen departments from the fifteen departments in the college as shown in Figure 5.1. This variation of the design of the field training is one of the reasons described in Section 5.1.1 for the choice of the English Language and the Educational Technology departments for the field experiment for this research. The second reason was the later roles of the graduates from these two departments in the work place. An elaboration on these two specialties clarifies these reasons further; therefore, Sections 5.1.3.1 and 5.1.3.2 provide more details about these two departments and the role of the field training in each of them.

\subsubsection{English Language department (prospective teachers)}

The English Language department is one of the thirteen departments in the College of Basic Education that aims to qualify teachers for the elementary schools in the governmental sector in Kuwait. The goal of the department is to prepare teachers that are able to teach effectively the English language as a second language. Nine objectives are specified by the department in order to reach this goal (College of Basic Education manual, 2004):

- To develop the learners academically, educationally, and psychologically to teach the English Language as a second language in the elementary schools in the governmental sector,

- To improve the different language skills of the learners including reading, writing, and conversation,

- To construct the scientific as well as the literate issues that are related to the English language of the learners,

- To provide the learners with the theoretical knowledge of the teaching methods for the languages,

- To develop learners ability to accommodate the scientific and the psychological characteristics of teachers,

- To train the learners to teach using modern techniques and skills,

- To introduce the English language culture and its relation to teaching the language,

- To introduce and to train the learners to use the technological aids in their teaching, and

- To train the learners to use the new information resources such as the Internet for self learning. 
In order to be qualified as English language teachers from this department, the students must pass the total of 130 credit points. These points are divided into three sectors in addition to a field training at the end of the program. First, students must collect 30 points for general knowledge that can be gained by passing 12 courses that are concerned with subjects related to religious and cultural issues. Second, students must collect 60 points for the specialty that can be gained by passing 20 courses, which concern four major topics-major language skills, linguistics, literature, and English as a second language. Third, students must collect 29 points for the professional development that can be gained by passing 15 courses concerned with instructional methods and psychology of teaching. Except for the field training course and the seminar sessions, the program follows the concurrent model of delivery; therefore, students collect the points from the three sectors at the same time during the first seven semesters of their program. After gaining most of the previous points, a minimum of 102 credit points including the four courses presented in Table 5.2, students are qualified to attend the field training for the last semester of the program. By passing the field training students will collect 9 points in addition to 2 points from the seminar sessions.

Table 5.2 Field training requirements for English language teachers (Field training manual, 2007)

\begin{tabular}{|lcll}
\hline Provider & Course code & Course name \\
\hline Educational Technology dept & 112 & Introduction of educational technology \\
\hline Curriculum dept & 325 & Teaching methods for English language \\
\hline Psychology dept & 414 & Psychology of learning \\
\hline English Language dept & 453 & Exams \\
\hline
\end{tabular}

The field training in this department aims to familiarize prospective English language teachers with school environments and give them the opportunity to implement what they learned during their study. The duration of field training is twelve weeks where prospective teachers spend five full days a week in a governmental school. These twelve weeks are divided into one week of observation followed by four weeks of training and guidance while the last seven weeks are used for evaluating the prospective teachers. In addition to the field training, prospective teachers are required to attend a two-hour seminar session each week for the twelve weeks. In the seminar, prospective teachers discuss with a supervisor from the department several topics concerning the practice of the field training including: 
- The importance, the goals, and the organization of the field training,

- The responsibilities of prospective teachers, supervisors, school administration, and the department in the field training, and

- The problems that face prospective teachers during the field training and how they can be solved.

The responsibility of evaluating prospective teachers during the field training is shared between the supervisor in the school (45 points), the supervisor from the department (45 points), and the school's administration (10 points). While the evaluation of the school's administration is focused mainly on organizational issues such as attendance and behavior, the evaluation of the supervisors from the department and in the school is focused on six major aspects (Field Training manual, 2007):

- The personal appearance and the attitude,

- The efficiency in planning the lessons,

- The efficiency in carrying out the lessons,

- The efficiency in controlling the classroom,

- The efficiency in the knowledge of the subject matter, and

- The efficiency in evaluating the learners.

Several factors are specified in the evaluation form for each of these six aspects. The evaluation form is prepared by the field training division in the college in cooperation with the department in order to cover both the general as well as the specialty aspects.

\subsubsection{Educational Technology department (prospective trainers)}

The departments of Educational Technology together with Information Science are the only two departments in the College of Basic Education that do not focus majorly on preparing teachers for the classroom. The goal of the Educational Technology department is to prepare educational technologists to work in the information centers in schools or in the other governmental sectors. The main objectives of the department based on this goal are specified as (College of Basic Education manual, 2004) followed:

- To provide the learners with the necessary knowledge about the importance of the educational technologies and the needed skills for applying these technologies in schools,

- To develop a positive attitude toward the importance of educational technologies for the learning process, 
- To provide the learners with theoretical and practical principles of the educational technologists' role in the learning process,

- To train the learners for designing, producing, and using a variety of educational technologists' aids in schools,

- To prepare specialists who are able to train teachers and learners for using a variety of educational technologies for supporting the learning process, and

- To prepare specialists who are able to design and organize information centers.

Even though the main goal of the department is to prepare educational technologists who are able to handle the different educational technologies in the schools, one of the major objectives of the department is to prepare specialists who are able to train teachers and learners for using these technologies. Similar to the requirements of the English Language department, students in the Educational Technology department are required to collect a total of 130 credit points in order to graduate. The points are also divided similarly to the English Language department with 30 points for general knowledge, 60 points for the specialty, and 29 points for the professional development. Also, similar to the English Language department, students must collect a minimum of 102 credit points including the nine courses presented in Table 5.3 as requirements for registering for the field training course and the seminar sessions. Students will collect 11 credit points by passing the field training (9 points) and the seminar sessions ( 2 points).

The goal of the field training in the Educational Technology department is to connect the academic knowledge of the learners with real workplace environments by involving them in practical training in different work environments. The duration of the field training is the whole semester and divided into two parts with four full days a week. The first part, the introductory part, which lasts for one week, is devoted to field visits to four different workplaces such as information centers and schools. The second part is the training part where prospective trainers work in three different work placesschools, ministries, and private organizations. The prospective trainers spend four weeks in each of these three work places. A two hours seminar session a week for the whole period of the field training is also required from the learners during this semester to discuss with a supervisor from the department their experiences from the field training. 
Table 5.3 Field training requirements for Educational technologists (Field training manual, 2007)

\begin{tabular}{|lcl|}
\hline Provider & Course code & Course name \\
\hline Educational Technology dept & 227 & Basics of educational computer \\
\hline Educational Technology dept & 235 & Design of educational programs \\
\hline Educational Technology dept & 247 & Sounds technology \\
\hline Educational Technology dept & 314 & Design and production of movies \\
\hline Educational Technology dept & 324 & Educational video \\
\hline Educational Technology dept & 334 & Design and production of models \\
\hline Educational Technology dept & 444 & Educational computer 2 \\
\hline Educational Technology dept & 458 & Managing information centers \\
\hline Educational Technology dept & 464 & Educational television 2 \\
\hline
\end{tabular}

The evaluation of the prospective trainers is divided between the internal supervisor from the department (60 points) and the external supervisor in the workplace (40 points). Prospective trainers are required to write and to discuss a report for each of the visits during the introductory part and that is the major evaluation instrument for this period in addition to other aspects such as the attendance and the behavior. The evaluation during the training part concerns different aspects such as the implementation of the production principles and the creativity in the work. The evaluation form for the prospective trainers is also prepared by the field training division in the college in cooperation with the Educational Technology department in order to cover both the general as well as the specialty aspects in the field training. A complete version of one of the evaluation forms that shows the list of required competences is presented in Appendix 2.

\subsubsection{Conclusion}

The main elements related to the context of our field experiment were discussed in this section. General information about the Public Authority for Applied Education and Training in Kuwait and the College of Basic Education in this authority was presented in Section 5.1.1 and the ICT infrastructure in this college was discussed in Section 5.1.2. Furthermore, the role of the field training in this college and specifically in the English Language and the Educational Technology departments as the selected departments for our field study was presented in Section 5.1.3. A discussion and elaboration of the findings of this section together with the findings in the next section will be presented in Section 5.2.5 to formulate an answer to RQ3. 


\subsection{PARTICIPANTS}

In this experiment, participants will use video applications in an interactive online learning environment to support the communication between them and to facilitate the activities of reflection during the field training. The number of participants of this experiment will be 16 prospective teachers and trainers from two different departments in the College of Basic Education in PAAET. The English Language and Educational Technology departments were chosen for this experiment based on several reasons that have been explained in the previous section. During the experiment, the participants will practice field training courses as a final requirement for graduating from the College of Basic Education. Considering the gender separation in this college where male and female studies are in different buildings, for practical reasons all of the 16 participants in our experiment will be from one gender (Female). The participants will be divided during the experiment into four groups: two English language groups (Groups 1 and 2) and two educational technology groups (Groups 3 and 4) and each group will consist of four participants.

Understanding participants' knowledge and skills concerning several subjects is a crucial factor for successful implementation of the reflective practice and the online environment. In order to investigate this factor, the Background Questionnaire described in Chapter 4 is used. On the one hand, the results of this questionnaire will be used to determine whether the participants have sufficient experience and skills that allow them to handle the different activities in the experiment. Considering that the participants are from two different specialties it is expected that there will be some variation in experience and skills between the participants. Therefore, the results of this questionnaire will be considered later in the design of the preparation stage of the field experiment in order to overcome this variation when it occurs. On the other hand, the results of the questionnaire will be used to discover the differences between the levels of competence of the different groups in the experiment. Therefore, the results were analyzed statistically, first to identify any significant differences regarding the specialty in the answers and second to find out the frequency of the answers in general. 
There were no missing data in the answers of the questionnaire as all the sixteen participants answered the twenty-five questions in the Background Questionnaire. The use of Fisher's exact test of independence is chosen here instead of chi-square test because of the small sample size in this experiment. With a large sample size, a chi-square test is the suitable test when the expected values in any of the cells of the statistic table is more than 5 while Fisher's exact test is exact and can therefore be used regardless of the sample characteristics. The result of fisher's exact test shows that only two questions showed significant difference between the observed and the expected frequency, which are question 13 in the section concerning the digital video cameras and question 21 in the section concerning the reflective practice approach. For the rest of the questionnaire, no significant differences are found between the observed and the expected frequency of prospective teachers and prospective trainers. Therefore, in the following sections, the participants from both departments will be treated as one group except for questions 13 and 21 as they will be discussed separately in each section. Section 5.2.1 presents participants' experience and skills regarding computers and the Internet while Section 5.2.2 presents their experience and skills regarding the use of the digital video cameras. The data regarding the channels of communication in the field training is presented in Section 5.2.3 and Section 5.2.4 presents the background data about the reflective practice approach. A discussion of the presented information in this section and in the previous section is given in Section 5.2.5 to answer RQ3.

\subsubsection{Computers and the Internet, experience, and skills}

This section describes the experience and skills of the participants regarding the use of computers and the Internet. Appling Fisher's exact test to the ten questions of this section showed no significant difference between the observed and the expected frequency of prospective teachers and prospective trainers. Therefore, analyzing the answers to this section will include all participants from both specialties. Table 5.4 shows the questions of the computer and the Internet experience and skills section. 
Table 5.4 Computers and Internet background's questions $(N=16)$

\begin{tabular}{|cl|}
\hline No. & Question \\
\hline 1 & Did you use a computer before? \\
\hline 2 & How often do you use a computer? \\
\hline 3 & Do you have regular access to a computer? \\
\hline 4 & Where do you have regular access to a computer? \\
\hline 5 & How often do you connect to the Internet? \\
\hline 6 & What type of Internet connection you use? \\
\hline 7 & How long have you been using the Internet? \\
\hline 8 & What do you use the Internet for? \\
\hline 9 & How would you rate your current computer skills? \\
\hline 10 & How would you rate your current Internet skills? \\
\hline
\end{tabular}

The answers to the questions that related to computer experience and skills show that all of the 16 participants have regular access to computers at home while only five of them have access to computers at both college and school. In addition, of the 16 participants, 13 of them use computers on a daily basis, two on a weekly basis, and one participant on a monthly basis. With respect to the computer skills, 10 of the 16 participants have very good computer skills while the remaining six participants have either good or fair computer skills. None of them have poor computer skills.

Regarding Internet experience and skills, almost all participants have used the Internet for more than two years except for one participant who has only had one year of Internet experience. Besides that, 13 of the participants connect to the Internet with high-speed connections on a daily basis. Finally, similar to their computer skills, 11 of the 16 participants have very good Internet skills while the other five participants have either good or fair Internet skills. Again, no participant has poor Internet skills. For detailed statistics on the answers to the questions of this section, see Appendix 3.

While the majority of the participants show a sufficient level of competences regarding the use of computers and the Internet, one of the participants will need some assistance regarding the use of the Internet in order to manage the tasks in the experiment. This participant will receive more attention in both the preparation stage and during the experiment stage in order to help her overcome this difficulty. In conclusion, it is, nevertheless, safe to assume that with the extra help for this particular participant all participants will have sufficient competences for using computers and the Internet in the experiment. 


\subsubsection{Digital video cameras, experience, and skills}

The focus of this section is on the experience and skills of the participants regarding the use of digital video cameras. To test the difference between the samples of frequency data, Fisher's exact test was used again here. The test shows a significant difference between the observed and the expected frequency of prospective teachers and prospective trainers of Question 13 only (See Table 5.5). There is a significant relationship between specialty and operating the camera for self-recording (Fisher exact $p=$.038). Prospective trainers are more likely to have difficulties setting-up a digital video camera for self-recording as $50 \%$ of them do not have the necessary skill while all prospective teachers have this required skill. This conclusion will be taken into consideration in the preparation stage of the experiment. Adjustments will be made to provide prospective trainers with extra attention on how to operate the self-recording functionality in a digital video camera during the workshop. For the rest of the questions in this section, there is no significant difference between the observed and the expected frequency of prospective teachers and prospective trainers. Therefore, analyzing the answers to the rest of the questions in this section will include all participants. Table 5.5 shows the questions of this section.

\section{Table 5.5 Digital video cameras background's questions $(N=16)$}

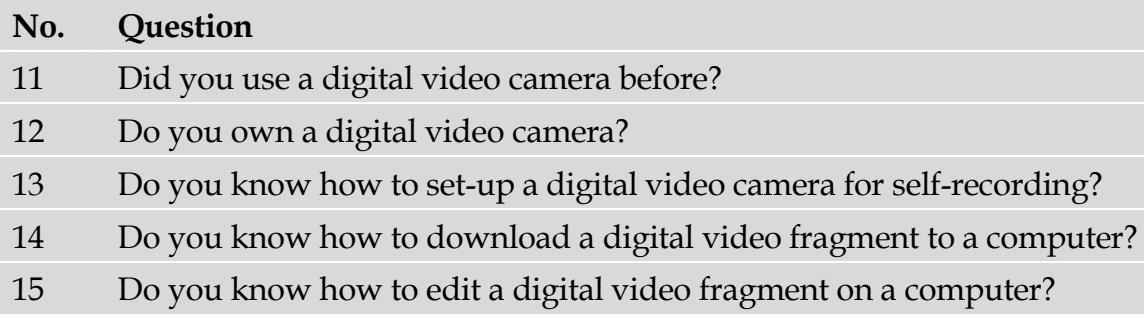

The answers to the rest of the questions of this section show that all 16 participants possess and use a digital video camera and 11 of them already know how to download a digital video fragment to a computer. Moreover, 10 of the 16 participants do know how to edit a video fragment on a computer. For detailed statistics on the answers to this section, see Appendix 3.

The results in this section show that even though more than $60 \%$ of the participants have the required competences some of them might face difficulties in using self-recording, downloading, and editing video fragments on a computer. In order to overcome these difficulties, extra support should be 
provided to the participants before and during the field experiment. More details about this support will be presented later in this chapter. Given this extra support for those who need it, it can be assumed that the competences of the participants regarding the use of digital video cameras will be sufficient for this experiment.

\subsubsection{Channels of communication, availability, and efficiency}

The focus of this section is on the availability and efficiency of the existing channels of communication in the field training. The results of the Fisher's exact test show no significant difference between the observed and the expected frequency of the data in this section. Therefore, analyzing the answers of this section will include all participants from both specialties. However, the last question in this section is an open-ended question, which will be treated separately. Table 5.6 shows the questions of this section.

Table 5.6 Availability and efficiency of the channels of communication's questions $(N=16)$
No. Question
16 How many times do you get to meet your fellow prospective teachers during your field training?
17 Do you think the number of meetings with your fellow prospective teachers, as you indicated in question 16, are sufficient for exchanging your experiences?
18 Where do you get to meet your fellow prospective teachers during your field training?
19 Do you think the place of meetings with your fellow prospective teachers, as you indicated in question 18 , is convenient for exchanging your experiences?
20 What do you suggest to do in order to improve the exchange of experiences between you and fellow prospective teachers during your field training?

The answers of this section show that the participants usually meet with their fellow students once a week in the college during a complementary course that is called "Seminar sessions". 10 of the 16 participants have answered Yes to Question 17, which indicates at first that they are satisfied with meeting once a week with their fellow students during the seminar session. However, since Question 17 asks the participants to explain their answers, most of these 10 participants relate the reason for this satisfaction to the fact that they do contact each other during their private times through the phone or by meeting unofficially. The other six participants explained their dissatisfaction with one meeting a week by the fact that the lecturer uses most of the seminar's time. Consequently, this causes lack of time for collaboration, exchanging experiences, and discussion among the students. 
Regarding the satisfaction with the college as the place of meeting, 14 of the 16 participants are satisfied as they consider that the environment and the facilities such as the library and the computer laboratories in the college encourage the process of learning. Both of the two participants who are not satisfied with the college as the place of meeting think that meeting in the workplace at schools will be more efficient. Finally, for the last question that asks for suggestions that may help the exchange of experiences among prospective teachers and trainers, several suggestions were made that can be interpreted as two major suggestions. The first suggestion is to exchange visits at the workplace among the learners to benefit from each other's experience while the second suggestion is to make use of advanced communication tools on the Internet such as e-mail. For detailed statistics on the answers of this section, see Appendix 3.

Even though it may appear at first that the participants are partly satisfied with the frequency of meeting (10 participants), the analysis of their elaborations on the answers leads to a different conclusion. The attitude of these participants to reach each other outside of the program time together with the responses of the six dissatisfied participants indicate strongly that the most of the participants think the frequency of meeting during the field training is not efficient for collaboration, discussion, and exchange of experiences among students. Furthermore, participants' suggestions for the last question show a desire for improvement in the communication in the field training, which confirm participants' dissatisfaction with the present situation.

\subsubsection{Reflective practice, knowledge, experience, and practice}

This section concerns the understanding of the reflective practice approach and the knowledge and experience among prospective teachers and trainers in practicing this method in field training. First, Fisher's exact test is applied to the questions of this section to determine the differences between the samples of frequency data among the specialties. The Fisher's exact test shows a significant difference between the observed and the expected frequency of prospective teachers and prospective trainers for Question 21 only. This reveals a significant relationship between specialty and knowledge about the reflective practice approach (Fisher exact $p=.038$ ). All eight prospective trainers responded that they knew what is meant by the reflective practice approach while half of the prospective teachers do not know this term. However, Question 21 asks the participants to explain their 
understanding of the reflective practice approach for those who answered 'Yes'. These written explanations from the participants together with our observation of the participants' understanding of the reflective practice approach show limited understanding of this term. All participants, in fact, from both specialties consider reflection another term for evaluation or assessment. Regarding the rest of the questions, there is no significant difference between the observed and the expected frequency of prospective teachers and prospective trainers. Therefore, analyzing the answers of the rest of the questions in this section will include all participants. Table 7.5 shows the questions of this section.

Table $5.7 \quad$ Knowledge and experiences of the reflective practice's questions $(N=16)$

No. Question
21 Do you know what is meant by the term reflective practice method?
22 Did you learn during the study program about the benefits of utilizing the reflection
activities?
$23 \quad$ Did you learn during the study program how to reflect on your own performance?
$24 \quad$ Did you learn during the study program how to reflect on your fellow students'
$25 \quad$ Derformance?

The results of Question 22 show that 10 of the 16 participants think that the curriculum does not include such competences and that they did not learn the benefits of utilizing reflection activities. Moreover, based on the results of Question 23, 12 participants think that they did not learn how to reflect on their own performance. Regarding Question 24, eight of the participants think that they did not learn how to reflect on their fellow students' performance. Most of the other eight participants who did think that they learned about these activities during their study, explained that it was in an indirect way and not systematically as a part of the study program. The last question concerns the participants' use of reflection in their life. 11 of the 16 participants answered that they did not use any kind of reflection in their daily life. For detailed statistics on the answers to this section, see Appendix 3.

The results of this section reveal some doubts about participants' understanding of the term reflection as well as the existence of the reflection activities in the curriculum of the study program. This supports our previous interpretation of participants' misunderstanding of the meaning of the term reflection and their confusion of this term with evaluation or assessment. Therefore, it should be 
assumed based on the results of this section that there is insufficient knowledge and experience with the reflective practice approach among the participants. Our personal observation and experience as an instructor in the College of Basic Education confirms this assumption to a degree.

Thus, in order to carry out the field experiment successfully and to ensure efficient engagement in the experiment's tasks by the participants, it is necessary to design the experiment under this assumption. Accordingly, there is a need to explicitly prepare the participants by clearly explaining in advance about the way of practicing and the goal and the meaning for each reflection activity that will be arranged during the experiment. Attention will be paid to this aspect during the design of the different stages in the field experiment in the next sections.

\subsubsection{Discussion}

The concern of this section is to investigate the opportunity of implementing the reflective practice approach through an online video-based learning environment in Kuwait, which assumes to provide an answer to RQ3. Several factors that influence the implementation of such intervention were discussed in Chapters 2 and 3. The educational program of the specific educational organization, the ICT infrastructure of this organization, and learners' previous knowledge and skills were highlighted as three major factors that are likely to determine the success of such an intervention. These factors were discussed separately in relation to the situation in Kuwait in Section 5.1 and to the knowledge and skills of the learners in Section 5.2. General discussion of those factors in light of RQ3 is presented here to formulate an answer to this question and to support the design of the field experiment and the reflective practice model in the coming sections in this chapter.

The results of the documents analysis of the educational program in the College of Basic Education and the existed ICT infrastructure in this college in Section 5.1 together with the results of the Background Questionnaire in this section show promising opportunities for practicing reflection in this college. Nevertheless, these results also reveal several important aspects to be considered in the design of the reflective practice model and the field experiment for this program. Studying the organization of the educational program and the ICT infrastructure in the College of Basic Education shows a sufficient degree of flexibility in this 
program for accommodating the reflective practice. The program is organized in a way that the last semester will be devoted only to field training, which gives the learners an opportunity to engage entirely in the different activities of reflection. Furthermore, even though the college in general has a relatively inadequate ICT infrastructure, the Educational Technology department in the college is distinguished as an exception with an advanced ICT infrastructure because of the department's nature.

The results of the questionnaire also indicate that most of the participants own the required equipment necessary for carrying out the different activities of the experiment. These results show that only one participant needs extra attention to handle some of the Internet's activities. Furthermore, even though the competences of the participants regarding the use of digital video cameras can be described generally as sufficient for the field experiment, more support may be needed to ensure smooth implementation. In addition, the results from the section concerning the availability and efficiency of the channels of communication in the field training show that there is a feeling of dissatisfaction among the participants about the present situation. The use of online communication tools and the exchange of visits to each other's workplace are suggested by the participants to improve the communication in the field training. Finally, there is reasonable doubt that the participants have sufficient information and clear understanding of the reflective practice approach. To sum up, the fact that most of the participants own the required equipment for carrying out the different activities of the experiment increase the opportunity of successful conduction of our experiment. Furthermore, these results indicate that almost all of the participants have adequate knowledge and skills, which is assumed to allow them to deal with the different ICT applications in the field experiment. Therefore, it can be said that the participants own promising competences for carrying out the activities of the field experiment except for some potential difficulties, which will be considered later during the design of the reflective practice model and the field experiment.

To reflect on RQ3 based on these results, it can be seen that these findings show promising opportunities for practicing reflection in the College of Basic Education and accordingly for conducting our field experiment. Furthermore, the described context of the experiment and the characteristics of the participants who function in this context, will determine the starting position of the 
experiment. Therefore, attention will be given in the next sections to the particular participant who needs help with the Internet's activities. Moreover, extra support will be provided to the participants to insure that all of them have the required skills for self-recording on a video camcorder and downloading and editing video fragments on a computer. In addition, the design of the field experiment and specifically the design of the reflective practice model will take into consideration the doubt about participants' background regarding their knowledge and skills for practicing reflection. All of these considerations are discussed in more detail in the next sections.

\subsection{MeTHOD AND PROCEDURE}

This field experiment will be conducted during ten weeks in the second semester of the year 2007/2008 from March 2 until May 8. The participants will be provided with several types of support during the experiment. An introduction session and a workshop will be given to the participants at the start of the experiment to explain the main issues about the experiment and to gain and practice the required skills for participation. The participants will also be provided with a manual that explains how to use the environment and how to work with digital video cameras. Another type of support that will be provided for the participants is weekly technical support in the computer labs. The participants also will have the opportunity to ask for help anytime via email or phone.

The experiment is divided into three main task-oriented stages. The first stage, the preparation stage, is an introductory stage that aims to provide the involved participants with the necessary knowledge and skills that will allow them to participate in this experiment. The aim of the second stage, the experimental stage, is to utilize the major activities of this experiment. The third stage, the data collection stage, aims to collect data regarding the activities, the performance, and the perspectives of the participants during the experiment. The major purpose of dividing the experiment into several stages is to organize the required activities in this experiment and to direct the focus toward specific goals at each stage. The next sections describe and explain further these three stages and the main activities in each of them. 


\subsubsection{Stage one: the preparation stage}

Sufficient skills of the participants in using computers and the Internet in addition to the use of digital video cameras are essential requirements for this experiment. Therefore, the Background Questionnaire that was presented in Section 5.1 was aimed to collect this information before the start of the experiment in order to understand participants' knowledge and background about these skills. This information will be used during this stage to ensure that all participants have the required knowledge and skills and to give more attention to the participants with insufficient skills during the activities of this stage. The duration of this stage will be two weeks and the researcher will perform most of the activities. The first week will be dedicated to introducing the experiment and to providing information about the reflective practice approach while the second week will be devoted to introducing and allowing the participants to practice the different activities that relate to the applications of video.

In the first week and for two hours, the researcher will organize a session in the computer lab that will consist of three parts. The session will start with an introduction and explanation to the goal of this field experiment. In addition, based on the results of the Background Questionnaire in Section 5.1, the participants will need more information regarding the theory beyond the concept of reflection. Therefore, theoretical background of the reflective practice approach and the major activities of this approach will also be introduced to the participants in this session. After a short break, the online course environment will be introduced in the second part of the session. The introduction to the course environment within the online video-based learning environment and the main sections and activities in this environment will be demonstrated during this part of the session. In the third part of the session, the researcher will distribute participants' access information to the environment and a manual for the use of the environment. The introduction session will end with participants' practice on how to access and to use the environment. Table 5.8 presents the main activities in the introduction session. 
Table 5.8 The main activities in the introduction session

\begin{tabular}{|c|c|c|}
\hline No. & Activities & Duration \\
\hline 1 & $\begin{array}{l}\text { 1. Introducing main issues related to the intended field experiment } \\
\text { 2. Introducing and explaining the theories that lead the practice of } \\
\text { reflection }\end{array}$ & 50 minutes \\
\hline \multicolumn{3}{|c|}{10 minutes break } \\
\hline 2 & $\begin{array}{l}\text { 1. Presenting the course environment within the online video-based } \\
\text { learning environment: Explaining the main sections in the } \\
\text { environment and how they will be used during the course }\end{array}$ & 30 minutes \\
\hline 3 & $\begin{array}{l}\text { 2. Distributing the V-class manual: a step by step procedure on how to } \\
\text { use the main functionalities in the environment } \\
\text { 3. Distributing participants' username and password: giving the } \\
\text { participants the opportunity to try to log in into the environment }\end{array}$ & 30 minutes \\
\hline
\end{tabular}

In the second week of this stage, the researcher will facilitate a two-hour workshop in the computer lab. This workshop is designed to overcome some of the difficulties that were diagnosed in Section 5.1 in relation to the applications of video. In the first part of the workshop, the researcher will demonstrate main functionalities of the digital video cameras. Major skills such as setting-up the camera, recording, and downloading the recorded material will be presented in this part. The participants will be given some time to practice these skills after the researcher's demonstration. After a ten minute break, the second part of the workshop will focus on presenting the software that is used to edit the recorded material on the computer. Furthermore, this part of the workshop will also demonstrate the procedure for uploading the edited material to the environment. Before the end of the workshop, the participants will be provided with a manual for the editing software and an opportunity to practice the demonstrated editing and uploading skills. Table 5.9 presents the main activities in this workshop.

To overcome the lack of knowledge and skills of the participants, the experiment will be organized in a way that there will be less required activities at the start of the experiment as opposed to later in the experiment. This arrangement will allow the researcher to control the process of the experiment and to overcome possible delays at the beginning of the experiment due to the newness of recently acquired skills of the participants. 
The participants will be asked in this stage to attend to both the introduction session and the workshop as well as to practice the use of the environment and the video recording and editing activities.

Table 5.9 The main activities in the workshop

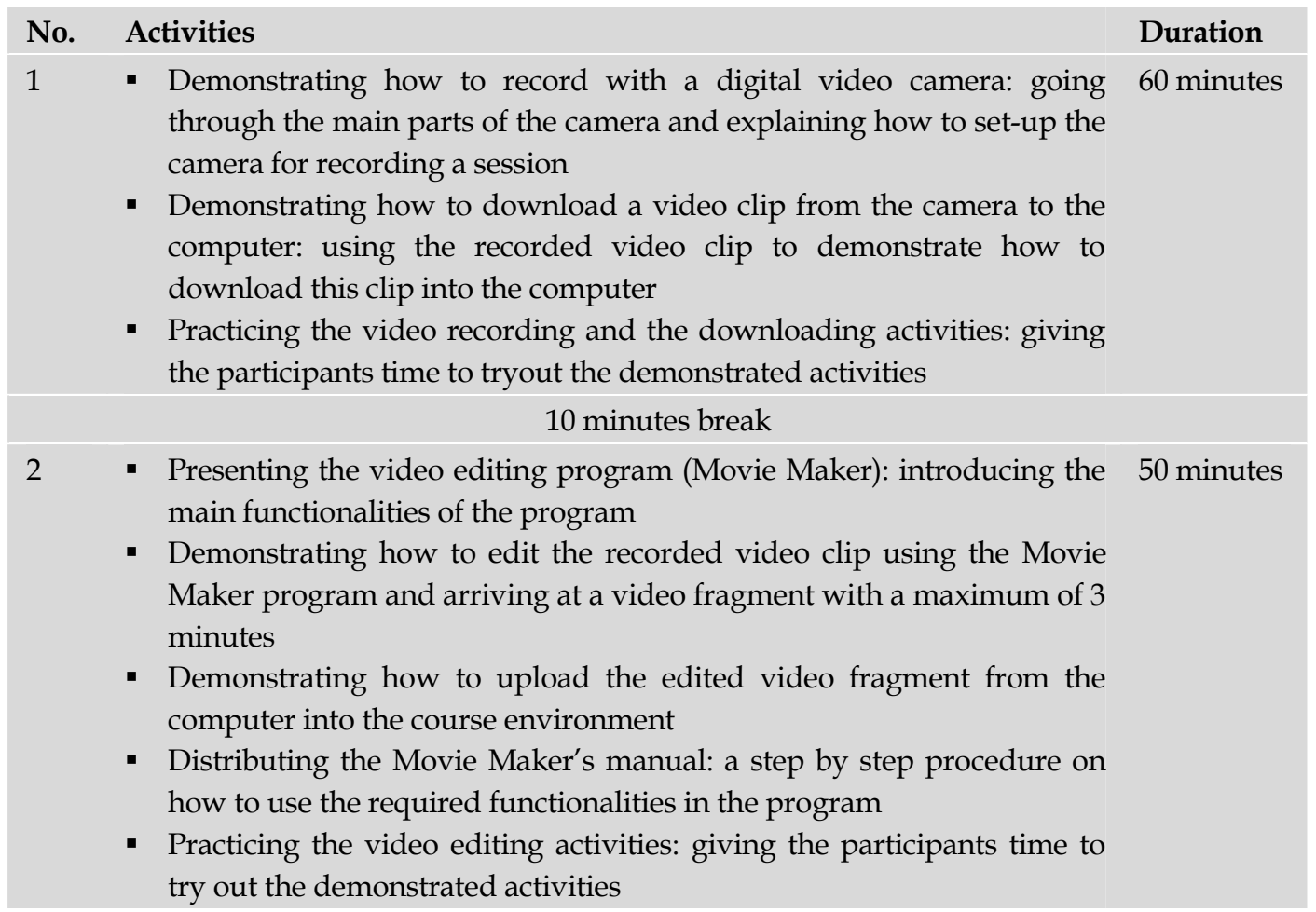

\subsubsection{Stage two: the experimental stage}

The major activities of our field experiment will take place at this stage, which will last for seven weeks (week three to week nine of the experiment). Six competences, three for each specialty, are selected for these activities, which are as follows:

- For the English language teachers (prospective teachers):

1. Maintaining discipline in classroom,

2. Effective use of white board, and

3. Appropriate use of audio and visual aids.

- For the educational technology trainers (prospective trainers):

1. Lesson presentation,

2. Effective mobility in class, and

3. Capability of attracting learner attention. 
The reason for selecting different competences for these two different specialties is that prospective teachers and prospective trainers are prepared to teach different types of learners. More discussion about the differences in the organization and the goals of these two specialties were discussed in Chapter 5. The difference of these two specialties is that while prospective teachers are prepared to teach at an elementary school level, prospective trainers are prepared to provide technical courses for mostly adult learners such as teachers or the administration staff in the school. Accordingly, the learners in these two specialties are required to obtain different types of competences, which can also be seen in the lists of competences for each specialty.

The chosen competences are selected from two different lists of competences that are provided by the field training supervisors in both specialties. The participants are required to master the competences in these lists during the field training course in order to pass this course. Two main reasons led to the selection of these specific six competences from the lists. The first reason is that these competences are assumed to be the most explicit and measurable. The second reason is that they are relatively similar in the practice. The supervisors who participated in the experiment are involved in the selection of these competences and confirmed our assumptions and selection of these competences.

The practice of the selected competences will be distributed over the first six weeks of this stage (week three to week eight of the experiment) while the last week of this stage (week nine of the experiment) will be devoted to a group reflection session. In order to give the participants an opportunity to become familiar with the experiment's procedure, the first competence will be practiced during the first three weeks of this stage (week three to week five of the experiment) while the second competence will be practiced during week four and five of this stage(week six and week seven of the experiment). Assuming that the participants get used to the procedure, the last competence will be practiced during week six of this stage only (week eight of the experiment). Table 5.10 presents the arrangement of these competences with respect to the timeline of this stage.

It can be seen in Table 5.10 that all four groups will be treated similarly in the first five weeks of this stage. However, only group 2 and 4 will be treated in week six. In this week (week six of this stage), group 1 and 3 will practice the traditional field training without using the online environment. The purpose of this 
arrangement is to produce data for comparing the practice of the field training with and without the online video-based learning environment. In this stage, the participants will perform most of the activities individually; however, the researcher will provide the required support for editing and uploading the materials and will facilitate the use of the environment.

Table 5.10 The arrangement of the competences within the experiment

\begin{tabular}{|l|l|c|}
\hline Weeks & Competences & Groups \\
\hline $1,2 \& 3$ & Maintaining discipline in the classroom & $1 \& 2$ \\
\cline { 2 - 3 } & Lesson presentation & $3 \& 4$ \\
\hline $4 \& 5$ & Effective use of white board & $1 \& 2$ \\
\cline { 2 - 3 } & Effective mobility in class & $3 \& 4$ \\
\hline 6 & Appropriate use of audio and visual aids & 2 \\
\hline & Capability of attracting learner attention & 4 \\
\hline
\end{tabular}

In order to fulfill the experiment's requirements, the participants will be asked to carry out the following activities for each competence:

1. Record the performance: the participants will be asked in this activity to record by themselves, on a digital video camera, their practice of teaching in the classroom (this activity will take place in the schools),

2. Review the recorded material: the participants will be asked in this activity to review the recorded material and to see how they performed during their teaching (this activity will be performed either at home or in the college's computer labs),

3. Choose the situation: the participants will be asked in this activity to choose a single situation from the recorded material that demonstrates the targeted competence (this activity will be performed either at home or in the college's computer labs),

4. Edit and upload the video clip: the participants will be asked in this activity to edit the recorded material and to make a single video clip (1 to 3 minutes) that shows the chosen competence. After, the participants will be asked to upload the edited video clip into the online environment (this activity will be performed either at home or in the college's computer labs), 
5. Self-reflection: the participants will then be asked to reflect on the video clip by describing the situation and their performance in this situation. They will be also asked here to explain their choice of this particular situation and their perspective towards their performance in this situation (this activity will be performed either at home or in the college's computer labs),

6. Ask for feedback: the participants will be asked in this activity to formulate a question for their colleagues asking for particular feedback regarding a specific point in the video clip (this activity will be performed either at home or in the college's computer labs),

7. Peer reflection: the participants will be asked in this activity to review the different video clips of the other members in their group and to reflect on these performances (this activity will be performed either at home or in the college's computer labs), and

8. Find alternatives: after receiving and reviewing the peer reflection, the participants will be asked in this activity to reassess their own performance and to develop alternative behaviors for the future (this activity will be performed either at home or in the college's computer labs).

In the last week of this stage (week nine of the experiment), the participants will be asked to attend a group's reflection session together with the supervisor and the researcher in order to reflect on their experiences and to evaluate the experiment. The length of this session will be two hours and it will consist of three parts. In the first part, the participants will be asked to nominate one video clip for each competence that shows the best practice of this competence. After, the participants will be involved in a discussion about the chosen clips in the second part of the session and the supervisor will later conclude the discussion by connecting the theories with the practiced competence. After a short break, the researcher will conclude this session with data collection activities using three different questionnaires for the participants that concern the difficulties of practicing reflection, the effectiveness of the online video-based learning environment, and the effect of this experiment on their learning achievement. The design and the goals of these questionnaires are discussed in Section 5.5. Table 5.11 presents the main activities in this session. 
Table 5.11 The main activities in the group's reflection session

No. Activities
$\begin{aligned} & \text { - Nominating the best performances: all participants in this session } \\ & \text { including the supervisor and the researcher will nominate one } \\ & \text { performance for each week that demonstrates the best performance for } \\ & \text { the targeted skill in that week }\end{aligned}$
$\begin{aligned} & \text { - } \\ & \text { - }\end{aligned}$
together on the nominated performances using their experiences in self
and peers reflection from the previous weeks
the supervisor will conclude the discussion by highlighting the
relationship between the performance and the theories

\subsubsection{Stage three: The data collection stage}

The aim of the data collection stage is to collect information for evaluating the use of the online video-based learning environment and the effect of the reflective practice on reducing the gap between theory and practice. In Chapter 4, different data collection instruments were discussed regarding the study in general and this experiment in particular and the design of these instruments is presented in Section 5.5 of this chapter. The interviews and the questionnaires are the major tools for collecting the needed information during this experiment. Even though the information will be collected during all stages of the experiment through observation, unstructured interviews, and the Background Questionnaire, the last week of the experiment (week ten) will be devoted entirely to collecting the data through structured interviews. All sixteen of the participants in this experiment and their four supervisors will be interviewed during this week. In general, there will be three different forms of interviews based on the role of the participants and each interview will last approximately 30 minutes. The design of these interviews is presented in Section 5.5 of this chapter.

\subsubsection{Schedule of the experiment}

It was explained in the beginning of this section that the duration of the experiment will be ten weeks: from March 2, 2008 until May 8, 2008, which is the 
second semester of the year 2007/2008 at the College of Basic Education in PAAET. Table 5.12 shows groups' treatment with respect to the experiment schedule.

Table 5.12 Groups' activities

\begin{tabular}{|c|c|c|c|c|c|c|c|c|c|c|}
\hline \multirow[b]{2}{*}{ Groups } & \multicolumn{10}{|c|}{ Weeks } \\
\hline & 1 & 2 & 3 & 4 & 5 & 6 & 7 & 8 & 9 & 10 \\
\hline Group 1 & $\begin{array}{c}\text { S3 } \\
+ \\
\text { S1 }\end{array}$ & S1 & S2 & S2 & S2 & S2 & S2 & - & $\begin{array}{c}\text { S2 } \\
+ \\
\text { S3 }\end{array}$ & S3 \\
\hline Group 2 & $\begin{array}{c}\text { S3 } \\
+ \\
\text { S1 }\end{array}$ & S1 & S2 & S2 & S2 & S2 & S2 & S2 & $\begin{array}{c}\text { S2 } \\
+ \\
\text { S3 }\end{array}$ & S3 \\
\hline Group 3 & $\begin{array}{c}\text { S3 } \\
+ \\
\text { S1 }\end{array}$ & S1 & S2 & $\mathrm{S} 2$ & S2 & S2 & S2 & - & $\begin{array}{c}\text { S2 } \\
+ \\
\text { S3 }\end{array}$ & S3 \\
\hline Group 4 & $\begin{array}{c}\text { S3 } \\
+ \\
\text { S1 }\end{array}$ & S1 & $\mathrm{S} 2$ & S2 & S2 & S2 & S2 & S2 & $\begin{array}{c}\text { S2 } \\
+ \\
\text { S3 }\end{array}$ & S3 \\
\hline
\end{tabular}

Note: S1 = Stage one; S2 = Stage two; S3 = Stage three.

As it can be seen in the table, although the experiment will be conducted during ten weeks, not all participants will be treated during the whole period. A slightly different treatment regarding the time will be given to group 1 and 3 particularly in the second stage of the experiment. While group 2 and 4 will be treated all through the second stage, group 1 and 3 will be given the sixth week of the second stage (week eight of the experiment) to practice the field training without the online video-based learning environment. Even though these groups will be treated differently regarding the time, all participants in the experiment will be asked to perform identical activities during each week. In the first and the third stage of the experiment, however, all groups will be treated similarly.

\subsection{MATERIALS}

In order to carry out this field experiment successfully, two major components are required to be carefully prepared. First is to design an explicit model for practicing reflection during the experiment that specifies the main activities in the process of reflection. Second is to select an online video-based learning 
environment to be used in this experiment and to make the necessary modifications to this environment in order to correspond to the design and the activities of our experiment. In Section 5.4.1, a generic model of reflection is presented and discussed based on the information from Chapter 2 and Chapter 3. However, it is important to differentiate here between our intended model of reflection and the reflection models that have been described in the Chapter 2. The models that have been described in Chapter 2 were mainly conceptual models while the intention of developing a model of reflection in this research is to be used as a procedural model that leads the participants through the different activities of the reflective approach. In Section 5.4.2 the online video-based learning environment that will be used by the participants in the field experiment is introduced.

\subsubsection{A generic model for practicing reflection}

The implementation of the reflective practice approach in an educational program is usually utilized through a model that illustrates the process and the main activities of this approach. Chapter 2 discussed different reflection models and highlighted major similarities and differences between these models. This discussion identified three components to be considered essential parts of most reflection models: the importance of participants' prior knowledge and background, the importance of conscious observation of the experience, and the emphasis on a cyclical and continuous process. These components actually correspond to the core of the reflection notion, which is the relationship between experience and understanding. The discussion in Chapter 2 also showed that the different reflection models can be identified by their level of generalization, which refers to the number of stages that construct a model. Another way of differentiating between the different reflection models is by looking into the accent on a specific aspect in a model, for example emphasizing the concrete experiences as with Kolb (1984) or underlining the emotions as with Boud et al. (1985). It can be seen from this interpretation that several factors related to the developer's specific learning environment have a great influence on the way the model is developed. The organization of a specific educational program and the knowledge and skills of the learners in this program are considered as two crucial factors that strongly influence the shape of the reflection model and activities. The results of the discussion in Chapter 2 led to the conclusion that in order to build a reflection model for our field experiment, the three previously 
described components of the reflection models as well as the two environmental related factors should be taken into account in the design of our model.

Therefore, Chapter 5 was devoted to presenting and discussing the results of investigating and analyzing the first environmental related factor, which is the organization of the educational program, in relation to the College of Basic Education in PAAET in Kuwait. Furthermore, the results of the Background Questionnaire in Section 5.1 present the required information regarding the second environmental factor, which is the knowledge and skills of the learners in this program. That was assumed to provide useful information to build our reflective practice model for this experiment. It was concluded that the program in the College of Basic Education has the required flexibility to accommodate the reflective practice approach, the time, and the ICT-infrastructure aspects. However, the educational content of this program as well as the knowledge and skills of the learners were seen as lacking the required theoretical foundation that allows effective practice of the reflection approach. It is significant, therefore, to take into account the program and participants' lack of information about the practice of reflection during the field experiment. To avoid this obstacle, several precautionary steps are included in the design of the experiment. First, it was explained previously in Section 5.3.1 that the participants will receive information about the theoretical and the philosophical notion behind the reflective practice approach in the preparation stage. Second, the schedule of the experiment was designed in Section 5.3.4 to give the participants opportunity to become involved gradually in the reflection activities as the experiment progressed by giving them more time at the beginning of the experiment.

In addition, the design of the reflective practice model here also accounts for this concern by trying to simplify the process of reflection in the model without losing the essence of the notion of reflection. In order to achieve this goal, the activities in our model are proposed in general terms to allow the participants to add their fingerprint to the different activities of reflection in the model through their own understanding for each of these activities. Given the participants' room to practice the different activities of reflection based on their understanding is assumed to increase the variation of this practice especially with the involvement of peer and group reflection. That might be a significant method to provide the participants with different ways for practicing each of the activities in the model and to broaden their horizons for possible alternatives. This simplification of the 
reflection model together with the design aspects in Sections 5.3.1 and 5.3.4 are assumed to overcome the lack of information about reflection.

These preparations are also assumed to cover the first common component to be included in most reflection models concerning the importance of participants' prior knowledge and background. The second component about the importance of conscious observation of the experience is naturally included in our model. The specifications of the different activities in the model and the required assignments to be completed by the participants insure the increase of participants' awareness of their experiences. Moreover, the third component of the reflection models is also considered here in the design of our reflection model. It is acknowledged that the process of reflection in the literature is mostly described as a cyclical process. It is proposed here in our reflection model, however, that the demonstration of reflection as a spiral process may provide a more accurate description especially in relation to classroom activities. Considering the activities in a classroom as unique every time they occur because of the variety of factors that are involved is a main reason for choosing the spiral as representative for the reflection process in our model. Based on this consideration, the odds of repeating an identical situation, therefore, seem fairly slim. Another reason for describing the reflection process as a spiral is to avoid the implication of the necessity of the evaluation activity at the end of the reflection cycle. Looking at the big picture beyond the notion of reflection reveals that the goal of reflection is to critically examine the performance and to explore the possible alternatives that may improve this performance. Utilizing the evaluation as the final activity of the reflection process may lead to a change in the concept of the reflection into a judgment about the success or failure of the performance. Other arguments about the possible negative impact of having the evaluation as an independent activity in the reflection is the possibility of creating participants' reservations towards their input and inaccurate evaluations (Richardson \& Maltby, 1995; Mackintosh, 1998). This understanding leads to the representation of the activities of finding alternatives as the last activity in the reflection cycle. Therefore, the reflective practice model that will be used in our field experiment consists of five stages. It starts with experience followed by description, self-reflection, and peer-reflection, and it ends with finding alternatives for the performance. Figure 5.2 shows a representation of the reflection process in this research. 


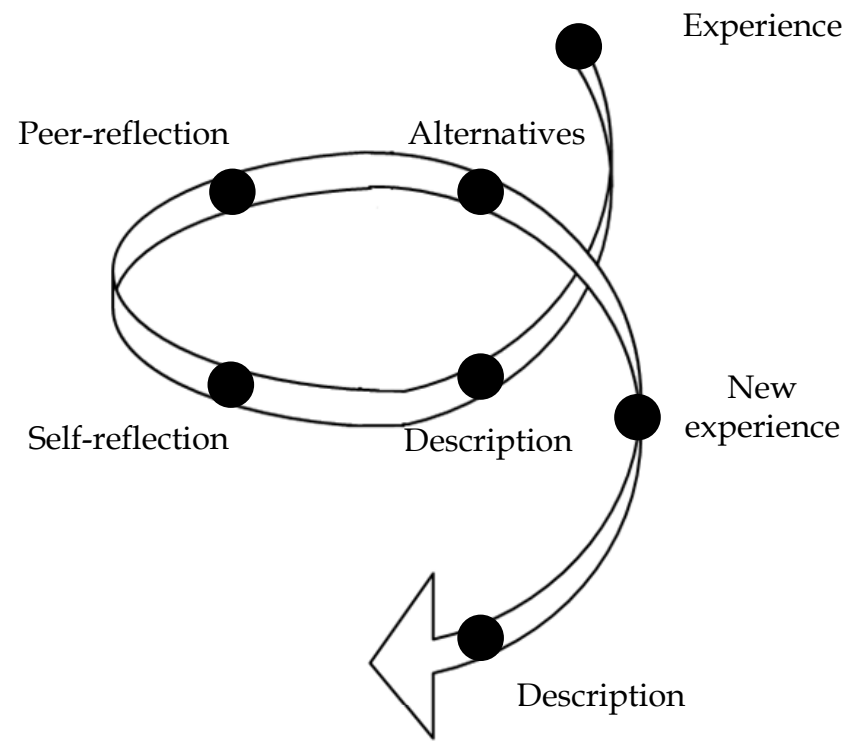

Figure 5.2 The reflective practice model

The emphasis in many of the reflection models is usually placed on the self as the source of reflection. For example, even though Boud et al. (1985) values the emotions and Kolb (1984) values the concrete experience, both of them place emphasis on the personal experience or the self-reflection as the source of knowledge. However, attention was paid to the importance of peer-reflection by other researchers such as Korthagen and Kessels (1999) and Leijen et al. (2008). In our model, an equal emphasis has been given to both the self and the peers as the source of knowledge and the materials that help lead to other alternatives. However, the activities in the first three stages in our reflection model, on the one hand, can be described as independent activities where each participant focuses on her own experience. On the other hand, the activities in the last two stages in the model are dependent activities where others' opinions and feedback are significant.

These activities of our field experiment were described previously in Section 5.3.2 and the following is an illustration of these activities as parts of the different stages in the reflection model:

1. Experience: the participants should practice their teaching competences during this stage with awareness of their behaviors and abilities. To satisfy the experiment requirements, each one of the participants should record her 
practice on a digital camera. By recording their practice, the participants will have the opportunity to review their performance and to focus on the specified competence,

2. Description: the participants should describe the different influential factors related to the situation during this stage such as the number of students, the content of the lesson, the cause of their specific behavior or reaction, and any other information that might help clarify the situation. This is assumed to provide a clear description of the experience for the participant herself, for her peers, and for her supervisor,

3. Self-reflection: using the recorded material and the description, each participant will have the opportunity to reflect on her own performance and the specified competence in each assignment. The participants should also analyze their performance in light of the theoretical knowledge that has been gained during the study program about the practiced competence,

4. Peer-reflection: after reflecting on the self, the participants should review the performance of their peers by watching their video and reading their description to the situation and their self-reflection. After, the participants will reflect on their peers' performance, and

5. Finding alternatives: using all the previously mentioned materials, the participants should be able to establish alternatives for their performance that are assumed to improve their practice of teaching. The participants should argue their alternatives based on their reflection, their peers' reflection, their supervisor's feedback, and the educational theories about the specific competence.

After specifying the different activities in our field experiment and the reflective practice model that will be used in this experiment, the next section discusses the online video-based learning environment that will be used during the experiment to facilitate the practice of reflection.

\subsubsection{The online video-based learning environment}

In order to conduct this experiment, an online video-based learning environment is needed to facilitate the communication and the practice of reflection. Chapter 3 discussed the use of the online video-based learning environments in education

and provided examples of such environments. The DiViDU video-based learning environment was discussed in Chapter 3 as a successful attempt to support the 
reflective practice in field training in the teacher education program. Although the DiViDU environment is a local Dutch system, they offer an international version that is called V-class. Except for the fact that DiViDU is a local system and V-class is an international system, DiViDU and V-class provide identical features and functionalities. Therefore, the V-class online video-based learning environment is used in this experiment as the technological tool for supporting video applications and communication in order to facilitate the reflective practice. The web address of the V-class environment is http://vclass.noterik.com. The first page of the environment is only in Dutch language, however, after login to the environment the users can change to an English version as explained later. Figure 5.3 shows the first page of the V-class online video-based learning environment.

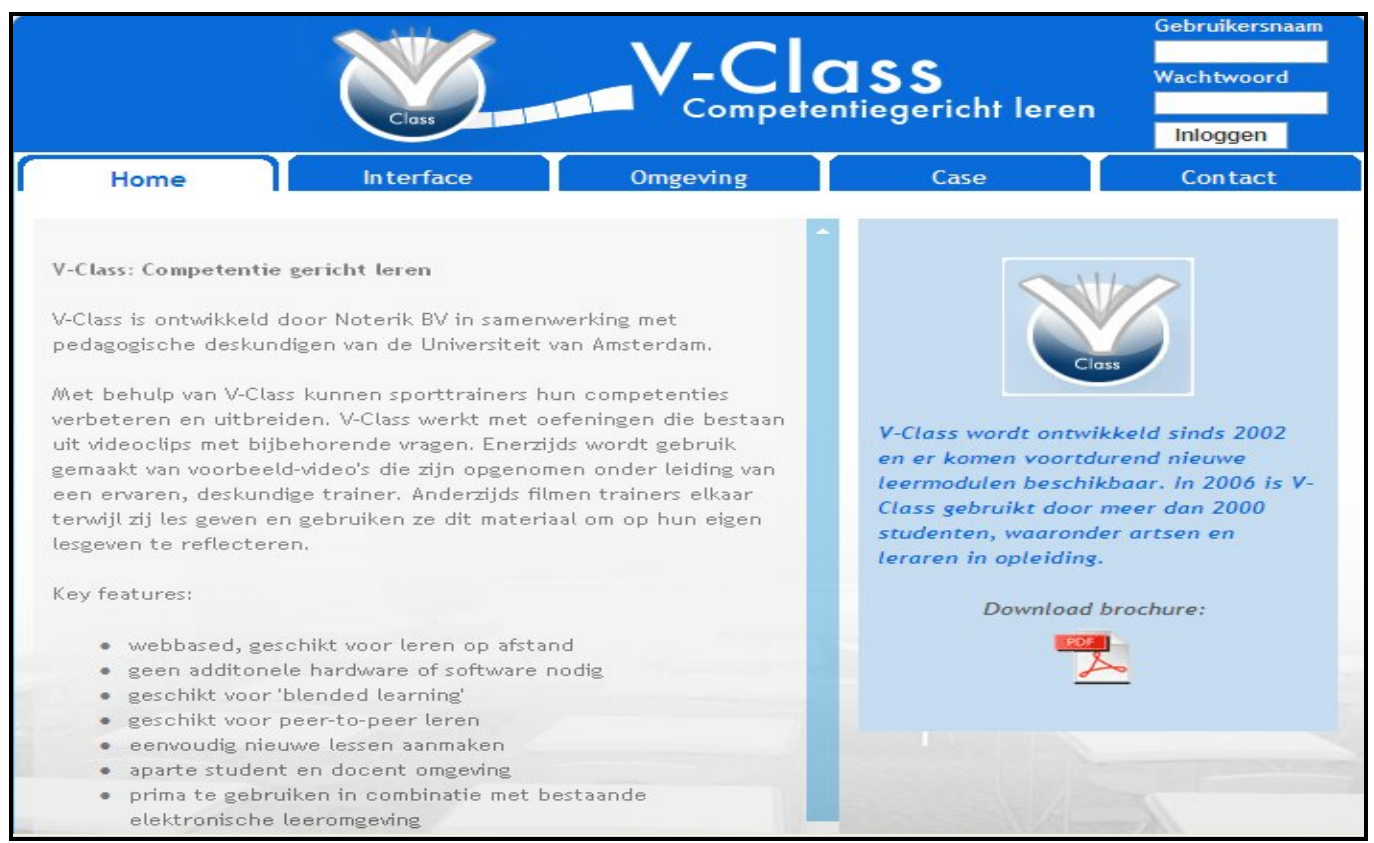

Figure 5.3 The V-class environment

The roles and the activities that will be required from the supervisors and the participants are different in this experiment. Accordingly, the functionalities that will be provided by the $\mathrm{V}$-class environment are also different for the supervisors and the participants. The general description of the main activities of the supervisors and the participants as well as the main functionalities in the environment for both of them is discussed here. 


\subsubsection{V-class for supervisors}

The major role of the supervisors in this experiment will be to create competencebased reflection modules that consist of several activities for their groups. Furthermore, the supervisors will have to supervise these modules and guide the participants through the module's activities. They will be required to manage these modules, to support the activities of their groups' members, and to guide them to draw an ideal conclusion for the practiced competence in each module. In order to fulfill these roles and requirements, the functionalities of the V-class environment will be made available to the supervisors. Tools such as module creation, catalogues, and reviewing students' work will be particularly important in this experiment. Figure 5.4 shows the structure of the V-class environment and the main functionalities that will be provided for the supervisors in this experiment.

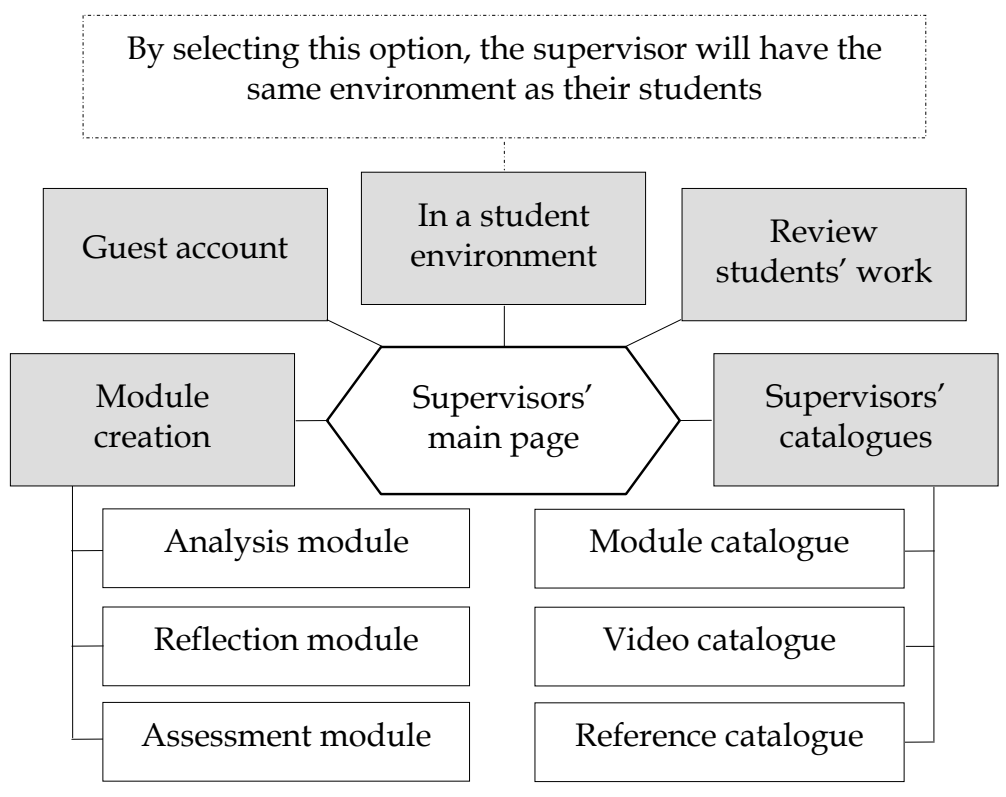

Figure 5.4 Flowchart of the structure of the supervisor's environment

In general, the V-class environment will provide the supervisors with five functionalities as it shows in Figure 5.4 that are assumed to facilitate the practice of analysis, reflection, and assessment. The following is a description of these functionalities:

1. Review students' work: In order to facilitate the evaluation and to compare students' work, this functionality will be provided to the supervisors. The aim of this functionality is to bring together the published assignments and the 
responses of all students in one place. This is assumed to facilitate the supervisors' tasks in reviewing and evaluating the work of their students. Furthermore, this functionality will allow the supervisors to reflect on the students' performances and to give them feedback. The supervisors will use this functionality as well to monitor the progress of their students,

2. Supervisors in a student environment: The environment will give the supervisors the ability to switch to a students' environment where they will use an identical environment with the same functionalities as their students. This environment will support the supervisors in several ways. By using students' environment, the supervisors will get an idea of how their students experience and use the module. Furthermore, this environment will allow the supervisors to play the role of another student,

3. Guest account: The V-class will also allow the supervisors to invite guests to the environment to participate in one or more of the supervisors' modules. To guarantee access, the supervisors will have to specify the name and the email address of the guest and the period of participation. The guest will immediately receive an email with a username and password; however, the guest will be guaranteed access for a limited period,

4. Module creation: This functionality is considered the heart of the V-class environment. Module creation will provide the supervisors with three deferent model's templates that organize the general components of the practice of analysis, reflection, and assessment.

1. The analysis module template: aims to facilitate the analysis activities by providing the learners with materials that help them observe, predict, and compare different professional performances. The idea behind this module is to extend students' own range of behavior through observation and modeling. The focus in this module is on professional behaviors of experienced teachers in practical situations. The main five learning tasks in this module are observation, prediction, comparison, making links to theory, and one's own actions in professional situations (Admiraal, Janssen \& Pijls, 2007),

2. The reflection module template: aims to facilitate learners' ability to reflect on their own performance, to request feedback from their peers and supervisors, and to find alternatives for their performance in order to form and to investigate different solutions. A more deeper discussion about the reflection notion was provided in Chapter 2, and 
3. The assessment module template: aims to create a portfolio for the learners. The focus here is on assessing the practiced competences such as the pedagogical competence, the didactical competence, and the reflective competence by the learners (Admiraal, Janssen \& Pijls, 2007).

5. Catalogues: The V-class environment consists mainly of three different materials: the modules, the video clips, and the references. Therefore, the catalogue functionality will provide the supervisors with separate repositories for each of these materials. There are three different catalogues and they will be used as a repository or library for the modules, the video clips, and the references in the environment. These catalogues are useful tools for organizing the materials in the environment and to facilitate the exchange of these materials among the users. These catalogues are also useful as an archive for the new users. The three catalogues share similar functionality and structure as they are divided into two main sections: a section that contains the materials that will be created or added by the user and another section that contains all materials related to the catalogue's category. The module catalogue includes all modules that will be created in the V-class environment. The 'my modules' section contains the modules that will be created by the individual user while the 'all modules' section contains all modules in the $\mathrm{V}$-class that the individual user will guarantee access to such as the modules that will be created by colleagues. Both the video catalogue and the reference catalogue will have a similar structure and functionality to the module catalogue.

The supervisors' main page and the functionalities in the V-class environment are demonstrated in Figure 5.5. It can be seen in the figure that several options in addition to the previously described functionalities will be offered for the users in the top part of the environment. This part will be always available from anywhere in the environment, which will allow the users to go back to the main page by using the home link or closing the site by using the log out link. Furthermore, the help link will provide an explanation to the different tools in the environment while the student link will change the environment into students' environment. Finally, the users will have the option to switch between the English and the Dutch languages by using the language link. 


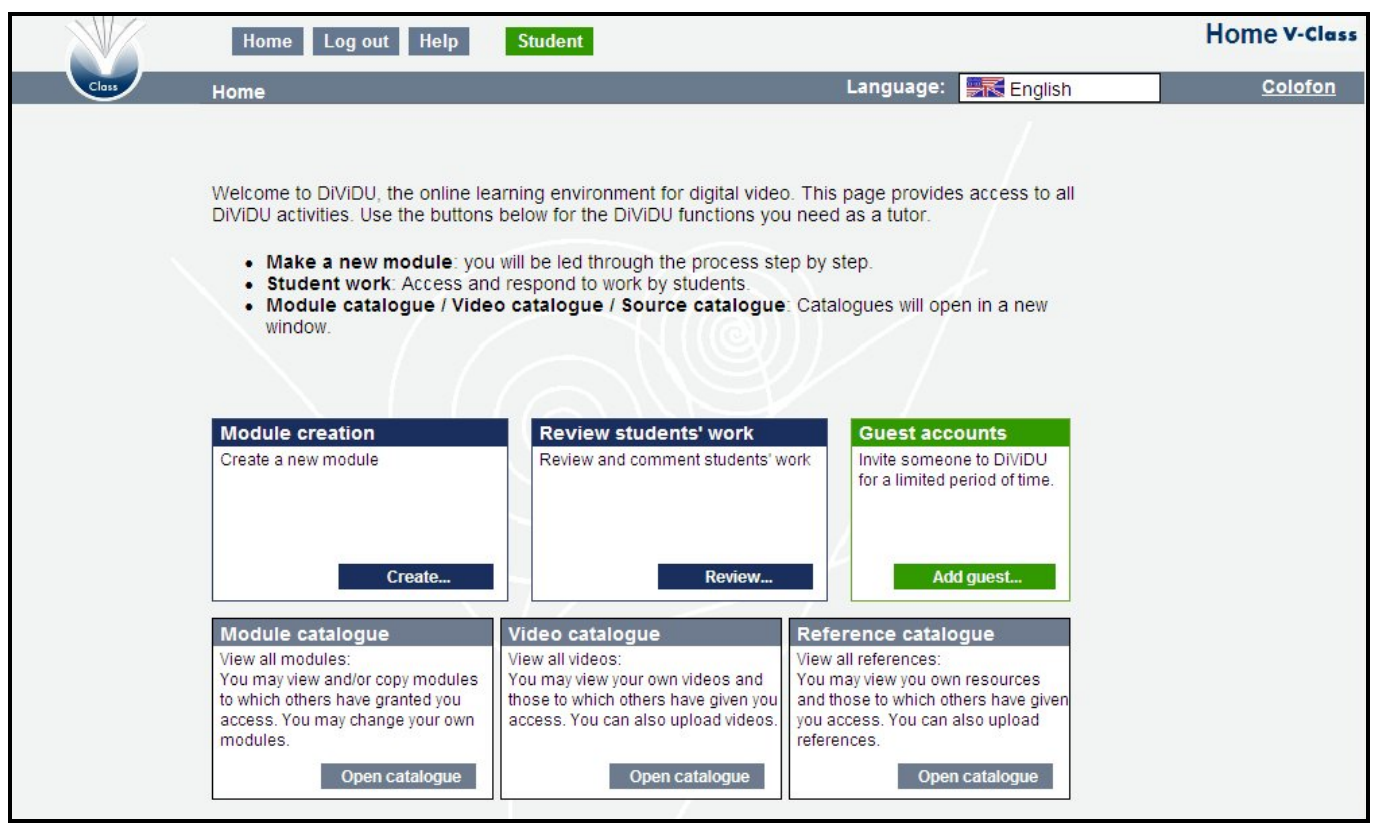

Figure 5.5 Supervisors' main page in the V-class environment

Generally, it can be said that these functionalities and options will provide the supervisors with powerful tools to practice the reflection approach in the field training. Appendix 4 provides more information about the functionalities of this environment for the supervisors.

\subsubsection{V-class for participants}

It was explained at the beginning of this section that the supervisors and the participants will be required in this experiment to carry out different roles and activities. The participants will have for that purpose their own environment's setting in the V-class. Considering the nature of the reflective practice approach, the participants will be required to carry out several activities. The major activities related to the V-class environment will be uploading the video fragments into the environment, reflecting on their own performance, asking for feedback, giving feedback, and finding alternatives to their own performance. The functionalities of the V-class environment, therefore, will be essential support for the participants to complete these activities. The structure and the main functionalities of the $\mathrm{V}$-class environment that will be provided for the participants in this experiment are shown in Figure 5.6. 


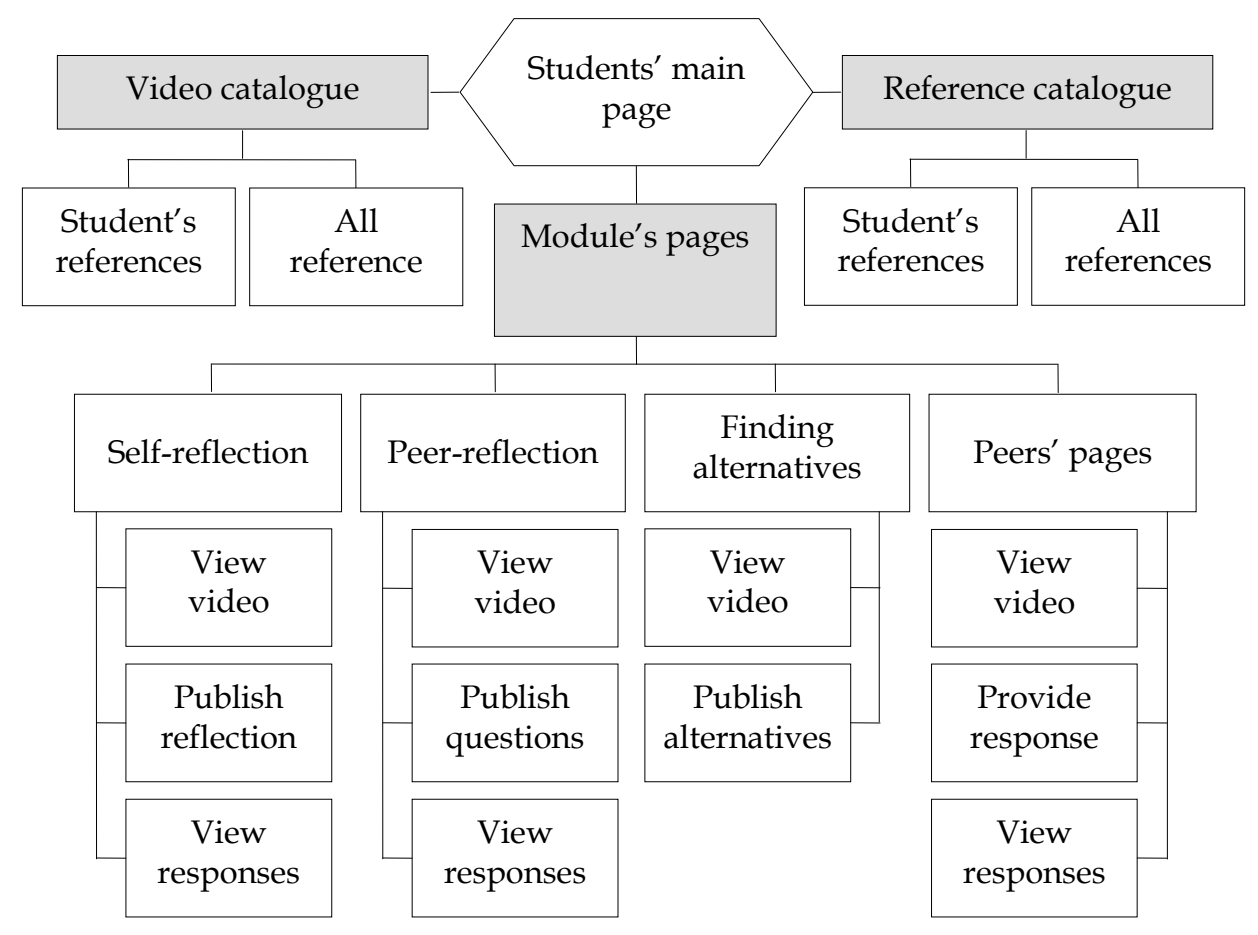

Figure 5.6 Flowchart of the structure of the participants' environment

As the figure shows the environment will provide three main tools to the participants: video catalogue, reference catalogue, and module's pages. The function of the two catalogues is similar to the previously described catalogues for the supervisors. The participants will have two sections in each catalogueone for their own materials and the other for the materials of the other users that are available in the environment. Furthermore, the module's page will consist of four pages in addition to the introduction section. This page aims to introduce the module, facilitate the self-reflection assignment, facilitate the peer-reflection assignment, facilitate the finding alternatives assignment, and provide access to the peers' pages. The different pages in the modules are described here as follows:

1. The introduction: an introduction to the module and links to the activities' pages will be provided to the participants. Via this page, the participants will have the opportunity to proceed to one of their assignments such as the selfreflection assignment or they can choose one of their peers' pages to reflect on their assignments,

2. The self-reflection assignment: this is the first assignment in the V-class environment. In order to complete this assignment, the participants will be 
required to display a video clip that shows their performance in a specific competence and reflect on this performance. To facilitate this activity, the Vclass environment will offer several functionalities to the participants in the self-reflection page. Via the environment, the participants can view their video clips, submit a description to the situation, reflect on their performance, and receive feedback from their peers and supervisors. The page will also provide guidance from the supervisors on how to deal with this assignment,

3. The peer-reflection assignment: This page will have almost identical sections and functionalities as those in the self-reflection page and the goal of the supervisors' guidance here is to advocate inquiry and encourage the participants to ask for feedback about their performance. Furthermore, the participants will have the opportunity to review their performance by using the video viewer option in order to submit a question for their peers and supervisors about a specific point in this performance on the peer-reflection page. When the peers and the supervisors submit an answer to the participant's question, the view-responses functionality in this page will allow the participants to see these answers,

4. The finding alternatives assignment: This page will organize the third assignment in the V-class environment. Similar to the self-reflection and peerreflection pages, this page will allow the participants to review their video clips and to submit their new conception regarding the practice of the discussed competence. The supervisors will also provide guidance for the participants to help them carry out this assignment. The first question in the supervisors' guidance should stimulate participants' ability to constitute and develop a new behavior and practice that should improve their performance regarding this competence. The second requirement in this guidance, however, should aim to trace participants' perspectives toward all performances in order to use these perspectives in the group reflection at the end of this experiment, and

5. The peers' pages: In the introduction page, the participants will be provided with two choices which are to select either getting into their own assignments or entering their peers' assignments. In order to reflect on their colleagues' performance, the participants will have to visit their peers' page. Clicking on one of the names in the list in the introduction page will open a new window that contains the published assignments of this specific participant. Even though this page is relatively similar to the assignments pages, different functionalities will be provided here. In the self-reflection assignment, the 
visitors will be able to view the video clips, the description, and the selfreflection of this participant. In addition, the visitors will be able to add their reflection of the performance of this participant. They will also be able to view the responses of their peers and supervisors about this performance. By switching into the peer-reflection assignment, the visitors can read the question that was formulated and submitted by the participant and give their answer and feedback. They can also see the answers of their peers and supervisors regarding this question.

The participants' main page in the V-class environment is presented in Figure 5.7 where it can be seen that the main page of the environment is divided into three parts.

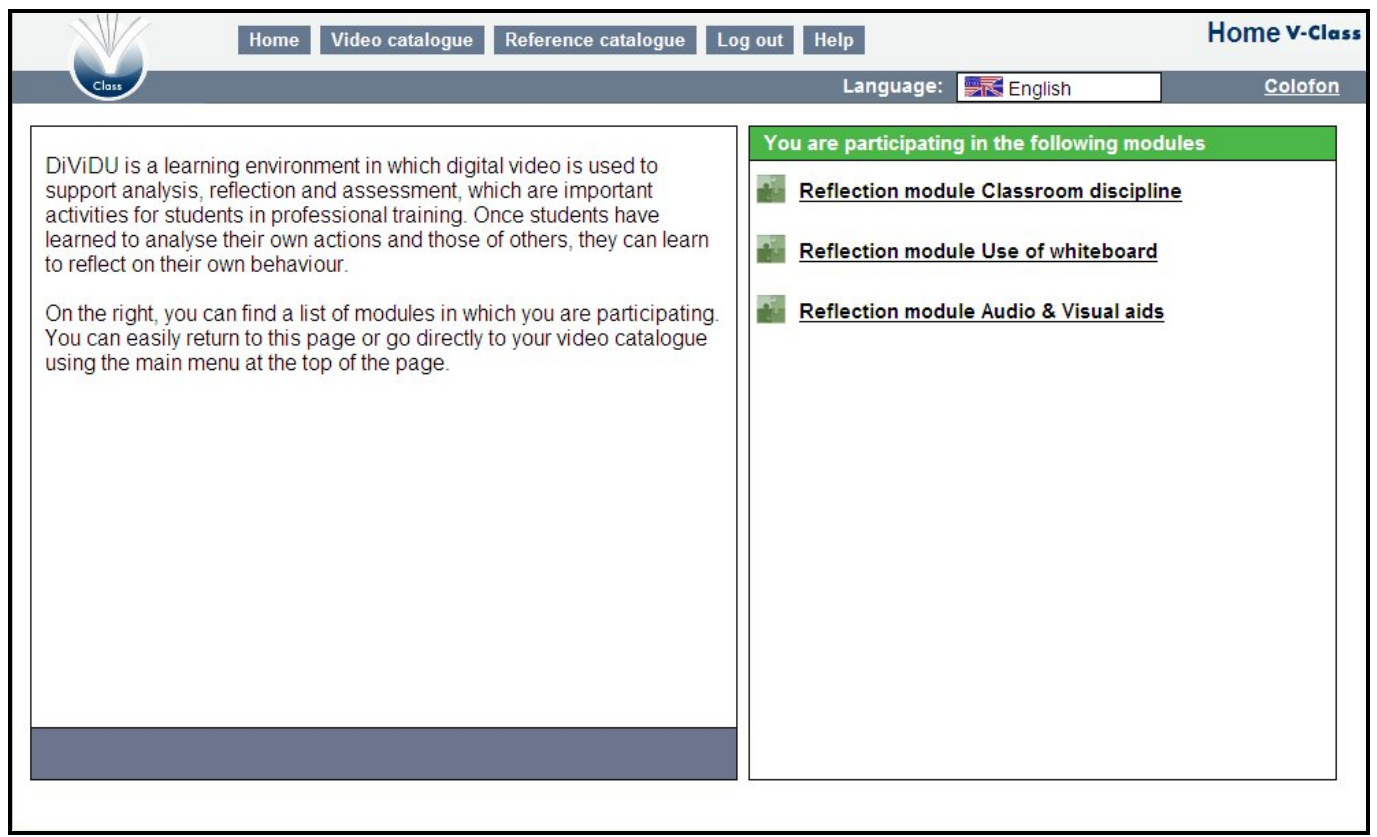

Figure 5.7 Participants' main page in the V-class environment

The top part of the page offers similar options to those described previously for the supervisors' page including home, log out, help, and language links. In addition, links to the video catalogue and the reference catalogue will be also offered in this section. These options will always be available for the participants from anywhere in the environment. The left side of the page will provide the participants with an introduction about the V-class environment and the usefulness of the environment for the participants. This part of the page is permanently fixed as part of the environment. On the right side of the page, 
however, the modules that the participants will be involved in are listed. By clicking on one of these modules, the participants will be linked to the introduction page of the module of their choice and will have access to the different pages that have been described above. The aim of the different functionalities and options that are provided for the participants through this environment is to facilitate their practice of reflection and to give them flexibility in time and place. See Appendix 5 for more information about this environment.

\subsection{DATA COLLECTION INSTRUMENTS FOR THE FIELD EXPERIMENT}

The goal of the field experiment is to understand the effects of using the reflective practice approach through an online video-based learning environment on the learning process and on the learners. Information regarding the difficulties in practicing reflection, the effectiveness of the online video-based learning environment, and the influence of this practice on learners' achievement are required to evaluate these effects. In Chapter 4 , an overview of the required information for answering the different questions in this research was presented in Section 4.4. Furthermore, the general design of the instruments that will be used to collect this information was discussed in Section 4.5 of the same chapter. Regarding the field experiment, specific types of data collection instrumentsquestionnaires and interviews-were proposed. The information that was collected by the preliminary investigation through the Background Questionnaire in Section 5.1 and the discussion and categorization of the difficulties in practicing reflection in Chapter 3 will be used here to support the development of several instruments for collecting the data during the field experiment. The development of the items in three different questionnaires - the Difficulties Questionnaire (Section 5.5.1), the Effectiveness Questionnaire (Section 5.5.2) and the Achievement Questionnaire (Section 5.5.3) - is discussed here. In addition to the questionnaires, Section 5.5.4 discusses the development of items for different types of interviews with the participants and with their supervisors.

\subsubsection{Difficulties Questionnaire}

The Difficulties Questionnaire aims to collect information about different types of difficulties that the participants may encounter when carrying out the reflection activities. The difficulties presented in this questionnaire reflect the difficulties 
that have been classified in Chapters 3. Participants have to respond to the first four statements in each part based on the provided scale where (1) is not applicable at all and (5) is applicable to a great extent in addition to a closedended question at the end of each part. Table 5.13 presents the different parts of this questionnaire.

The questionnaire consists of five parts, as can be seen in Table 5.13, where each part investigates one of the expected difficulties based on the difficulty's classification in Chapter 3:

- Part 1: Difficulties related to recording. The statements of this part illustrate difficulties that the participants may encounter in practicing the recording activities,

- Part 2: Difficulties related to description. The statements of this part illustrate difficulties that the participants may encounter in practicing the description activities,

- Part 3: Difficulties related to self-reflection. The statements of this part illustrate difficulties that the participants may encounter in practicing the selfreflection assignment,

- Part 4: Difficulties related to peer-reflection. The statements of this part illustrate difficulties that the participants may encounter in practicing the peerreflection assignment, and

- Part 5: Difficulties related to finding alternatives. The statements of this part illustrate difficulties that the participants may encounter in practicing the finding alternatives assignment.

The information that is collected from this questionnaire is presented, analyzed and discussed in Chapter 6 in order to answer the fourth question in this research. 
Table 5.13 The Difficulties Questionnaire

\begin{tabular}{|c|c|c|c|}
\hline \multirow[b]{2}{*}{ No } & \multirow[b]{2}{*}{ Question } & \multicolumn{2}{|c|}{ Responses } \\
\hline & & 12 & 345 \\
\hline \multicolumn{4}{|c|}{ Part 1: Difficulties related to recording } \\
\hline 1 & I find it difficult to record my performance by myself & & \\
\hline 2 & It is difficult for me to choose only one small part of my performance & & \\
\hline 3 & Dealing with the editing software is difficult for me & & \\
\hline 4 & $\begin{array}{l}\text { I feel I lack the proper skills to produce high-quality video clips of my } \\
\text { performance }\end{array}$ & & \\
\hline 5 & Did you encounter any other difficulties regarding the recording activities? & Yes & No \\
\hline \multicolumn{4}{|c|}{ Part 2: Difficulties related to description } \\
\hline 6 & I find it difficult to express myself in words & & \\
\hline 7 & In writing, I tend to write merely descriptions of events without an analysis & & \\
\hline 8 & $\begin{array}{l}\text { I tend to have an ideal image in my head about how I teach, which is different } \\
\text { from my actual teaching. }\end{array}$ & & \\
\hline 9 & $\begin{array}{l}\text { I feel I lack the proper skills to provide sufficient description about my } \\
\text { performance }\end{array}$ & & \\
\hline 10 & Did you encounter any other difficulties regarding the description activities? & Yes & No \\
\hline \multicolumn{4}{|c|}{ Part 3: Difficulties related to self-reflection } \\
\hline 11 & Reflecting on my professional identity as a teacher is difficult for me & & \\
\hline 12 & $\begin{array}{l}\text { I tend to wait for the teacher to provide me corrections instead of evaluating } \\
\text { my experience myself. }\end{array}$ & & \\
\hline 13 & While evaluating the experience, I tend to focus on aspects that I did wrong & & \\
\hline 14 & I feel I lack the proper skills to reflect on my own performance & & \\
\hline 15 & $\begin{array}{l}\text { Did you encounter any other difficulties regarding the self reflection } \\
\text { activities? }\end{array}$ & Yes & No \\
\hline \multicolumn{4}{|c|}{ Part 4: Difficulties related to peer-reflection } \\
\hline 16 & $\begin{array}{l}\text { Due to psychological reasons, I tend to avoid reflecting on others' } \\
\text { performance }\end{array}$ & & \\
\hline 17 & I tend to be ashamed of my own ideas and thoughts. & & \\
\hline 18 & $\begin{array}{l}\text { It is difficult for me to point out others' weaknesses while I am providing } \\
\text { feedback to them. }\end{array}$ & & \\
\hline 19 & I feel I lack the proper skills to reflect on my colleagues' performance & & \\
\hline 20 & $\begin{array}{l}\text { Did you encounter any other difficulties regarding the peer reflection } \\
\text { activities? }\end{array}$ & Yes & No \\
\hline \multicolumn{4}{|c|}{ Part 5: Difficulties related to finding alternatives } \\
\hline 21 & $\begin{array}{l}\text { Thinking of what I did in a session in relation to what I should have done is } \\
\text { difficult for me. }\end{array}$ & & \\
\hline 22 & $\begin{array}{l}\text { To question the corrections and comments given by my supervisor or my } \\
\text { colleagues is difficult for me }\end{array}$ & & \\
\hline 23 & $\begin{array}{l}\text { I tend to focus on teaching in one way, and I have difficulties with thinking } \\
\text { about alternatives }\end{array}$ & & \\
\hline 24 & I feel I lack the proper skills to assess my performance & & \\
\hline 25 & $\begin{array}{l}\text { Did you encounter any other difficulties regarding the finding alternatives } \\
\text { activities? }\end{array}$ & Yes & No \\
\hline
\end{tabular}

Note: 1 = Not applicable at all; 2 = Slightly applicable; 3 = Applicable to a some extent; 4 = Applicable; 5 = Applicable to a great extent. 


\subsubsection{Effectiveness Questionnaire}

The Effectiveness Questionnaire aims to collect information about participants' perspective toward the usability and the usefulness of the online environment for carrying out the reflection activities. This questionnaire consists of two parts where the first part concerns the usability and the second part concerns the usefulness of the environment. Table 5.14 presents the statements concerning the usability of the environment.

Table 5.14 The usability of the environment

\begin{tabular}{|c|c|c|}
\hline \multirow[b]{2}{*}{ No } & \multirow[b]{2}{*}{ Question } & Responses \\
\hline & & $\begin{array}{lllll}1 & 2 & 3 & 4 & 5\end{array}$ \\
\hline 1 & \multicolumn{2}{|l|}{ How would you rate the ease of use of the environment in general } \\
\hline 2 & \multicolumn{2}{|l|}{ How would you rate the ease of accessing the environment } \\
\hline 3 & \multicolumn{2}{|l|}{ How would you rate the ease of finding your way in the environment } \\
\hline 4 & \multicolumn{2}{|l|}{$\begin{array}{l}\text { How would you rate the ease of submitting a reflection to the } \\
\text { environment }\end{array}$} \\
\hline 5 & \multicolumn{2}{|l|}{$\begin{array}{l}\text { How would you rate the ease of submitting a feedback on the } \\
\text { environment }\end{array}$} \\
\hline 6 & \multicolumn{2}{|l|}{$\begin{array}{l}\text { How would you rate the ease of finding a submitted material in the } \\
\text { environment }\end{array}$} \\
\hline 7 & \multicolumn{2}{|l|}{$\begin{array}{l}\text { How would you rate the ease of uploading video clips to the } \\
\text { environment }\end{array}$} \\
\hline 8 & \multicolumn{2}{|l|}{ How would you rate the ease of viewing video clips on the environment } \\
\hline 9 & \multicolumn{2}{|l|}{$\begin{array}{l}\text { How would you rate the ease of communicating with your colleagues } \\
\text { through the environment }\end{array}$} \\
\hline 10 & \multicolumn{2}{|l|}{$\begin{array}{l}\text { How would you rate the ease of communicating with your supervisor } \\
\text { through the environment }\end{array}$} \\
\hline Note: & \multicolumn{2}{|c|}{$\begin{array}{l}1=\text { Not easy at all } ; 2=\text { Slightly easy; } 3=\text { Easy to a some extent; } 4=\text { Easy; } 5=\text { Easy to a great } \\
\text { extent. }\end{array}$} \\
\hline \multicolumn{3}{|c|}{ The statements of the first part of the questionnaire that are presented in Table } \\
\hline \multirow{6}{*}{\multicolumn{3}{|c|}{$\begin{array}{l}5.14 \text { aim to understand participants' satisfaction toward the ease of use of the } \\
\text { different functionalities in the V-class environment. This part consists of ten } \\
\text { statements and the participants have to respond based on the provided scale } \\
\text { where (1) is not easy at all and (5) is easy to a great extent. The statements of the } \\
\text { second part of this questionnaire concern participants' opinion toward the } \\
\text { usefulness of the environment. This part consists of five statements as presented }\end{array}$}} \\
\hline & & \\
\hline & & \\
\hline & & \\
\hline & & \\
\hline & & \\
\hline \multicolumn{3}{|c|}{$\begin{array}{l}\text { in Table } 5.15 \text {. The participants have to respond based on the provided scale } \\
\text { where (1) is not useful at all and (5) is useful to a great extent. }\end{array}$} \\
\hline
\end{tabular}


Table 5.15 The usefulness of the environment

\begin{tabular}{l|l} 
No & Question \\
\hline 11 & $\begin{array}{l}\text { How would you rate the usefulness of the online environment in } \\
\text { facilitating the reflective practice activities in general }\end{array}$ \\
12 & $\begin{array}{l}\text { How would you rate the usefulness of the online environment in } \\
\text { facilitating the description activities }\end{array}$ \\
13 & $\begin{array}{l}\text { How would you rate the usefulness of the online environment in } \\
\text { facilitating the self reflection activities }\end{array}$ \\
14 & $\begin{array}{l}\text { How would you rate the usefulness of the online environment in } \\
\text { facilitating the peer reflection activities }\end{array}$ \\
15 & $\begin{array}{l}\text { How would you rate the usefulness of the online environment in } \\
\text { facilitating the finding alternatives activities }\end{array}$ \\
Note: 1 = Not useful at all; 2 = Slightly useful; $3=$ Useful to a some extent; $4=$ Useful; $5=$ Useful \\
to a great extent.
\end{tabular}

The information that is collected from this questionnaire is presented, analyzed, and discussed in Chapter 7 in order to answer the fifth question in this research.

\subsubsection{Achievement Questionnaire}

The Achievement Questionnaire aims to collect information about the effect of practicing the reflection activities on the participants' learning achievement. This questionnaire consists of two parts and the participants have to respond based on the provided scale where (1) is not effective at all and (5) is effective to a great extent. The first part of the questionnaire investigates the effect of reflection in connecting theory to practice, in other words, the effect of reflection in understanding the relationship between the practiced competence and the related theories for this competence. The second part of the questionnaire focuses on the effect of reflection on the ability of participants in mastering the practiced competences. The questionnaire consists of ten statements as shown in Table 5.16.

The information that is collected from this questionnaire is presented, analyzed, and discussed in Chapter 8 in order to answer the sixth question in this research. 
Table 5.16 The Achievement Questionnaire

\begin{tabular}{|c|c|c|}
\hline \multirow[b]{2}{*}{ No } & \multirow[b]{2}{*}{ Question } & Responses \\
\hline & & $\begin{array}{lllll}1 & 2 & 3 & 4 & 5\end{array}$ \\
\hline \multicolumn{3}{|c|}{ Part 1: The effect of reflection in connecting theory to practice } \\
\hline 1 & $\begin{array}{l}\text { How would you rate the effectiveness of practicing the reflection, in } \\
\text { general } \text { on increasing your understanding to the theoretical concept }_{\text {behind the practiced competences? }}\end{array}$ & \\
\hline 2 & $\begin{array}{l}\text { How would you rate the effectiveness of describing your performance on } \\
\text { increasing your understanding to the theoretical concept behind the } \\
\text { practiced competences? }\end{array}$ & \\
\hline 3 & $\begin{array}{l}\text { How would you rate the effectiveness of reflecting on your own } \\
\text { performance on increasing your understanding to the theoretical concept } \\
\text { behind the practiced competences? }\end{array}$ & \\
\hline 4 & $\begin{array}{l}\text { How would you rate the effectiveness of reflecting on your peers' } \\
\text { performance on increasing your understanding to the theoretical concept } \\
\text { behind the practiced competences? }\end{array}$ & \\
\hline 5 & $\begin{array}{l}\text { How would you rate the effectiveness of reassessing your performance } \\
\text { after the self and peer reflection on increasing your understanding to the } \\
\text { theoretical concept behind the practiced competences? }\end{array}$ & \\
\hline \multicolumn{3}{|c|}{ Part 2: The effect of reflection in mastering the required competences } \\
\hline 6 & $\begin{array}{l}\text { How would you rate the effectiveness of practicing the reflection, in } \\
\text { general, on helping you in mastering the practiced competences? }\end{array}$ & \\
\hline 7 & $\begin{array}{l}\text { How would you rate the effectiveness of practicing the description } \\
\text { activities on helping you in mastering the practiced competences? }\end{array}$ & \\
\hline 8 & $\begin{array}{l}\text { How would you rate the effectiveness of practicing the self reflection } \\
\text { activities on helping you in mastering the practiced competences? }\end{array}$ & \\
\hline 9 & $\begin{array}{l}\text { How would you rate the effectiveness of practicing the peer reflection } \\
\text { activities on helping you in mastering the practiced competences? }\end{array}$ & \\
\hline 10 & $\begin{array}{l}\text { How would you rate the effectiveness of practicing the finding } \\
\text { alternatives activities on helping you in mastering the practiced } \\
\text { competences? }\end{array}$ & \\
\hline
\end{tabular}

Note: 1 = Not effective at all; 2 = Slightly effective; 3 = Effective to a some extent; 4 = Effective; 5 = Effective to a great extent. 


\subsubsection{Interviews}

In order to support the information that is gathered by the different questionnaires and to provide opportunity for the participants and their supervisors to explain in more detail their perspectives, three versions of interviews have been developed. The first version is designed to be conducted with the supervisors while the second and the third are designed for the participants. Considering the difference in the participants' treatment, which was explained in Section 5.3, the participants are interviewed based on their group where additional items are added to the interview of group 1 and 3 . The interviews with the participants and their supervisors will be conducted at the end of the field experiment.

\subsubsection{Supervisors interview}

The aim of the interview with the supervisors is to collect information regarding the influence of the reflective practice approach on the learning process and the learners' achievement. Moreover, the interview also aims to understand the supervisors' perspectives toward the influence of the reflective practice approach on the gap between theory and practice. The questions of the supervisors' interview are presented in table 5.17.

As it can be seen in Table 5.17 the interview is divided into three parts. In the first part, the questions generally aim to understand the supervisors' feelings towards this experiment. Furthermore, this part aims to see their opinion of the impact of the reflective practice on the process of learning and on learners' achievement. The second part focuses on comparing this field training with previous field training courses while the influence of the reflective practice on the gap between theory and practice is discussed in the third part of the interview. For the complete guidelines of the supervisor's interview, see Appendix 6. 
Table 5.17 Interview for the Supervisors

\section{General questions}

What is your general impression about this experiment?

In general, do you think the reflective practice method has an influence on the learning process?

In general, do you think the reflective practice method has an influence on students' achievement?

What do you think of the quality of the reflection students wrote?

Is the quality of reflection students wrote changed (increased / decreased) over time during the experiment?

\section{Questions related to the differences between this field training and previous courses in relation to the reflection activities}

In comparison with previous field training courses, which course is requiring more time and effort from the students?

In comparison with previous field training courses, which course is requiring more time and effort from the supervisor?

Do you think there is a difference in the performance of the students from this course in comparison with students from previous courses?

In comparison with previous field training courses, where do you find stronger presence of theory?

If asked to choose for your students between practicing field training with or without the reflective practice method, what would you choose?

\section{Questions related to the influence of practicing the reflection on the gap between theory and practice}

In general, do you think the reflective practice method has an influence on the gap between theory and practice?

Do you think the description activities during the experiment have an influence on connecting theory with practice?

Do you think the self-reflection activities during the experiment have an influence on connecting theory with practice?

Do you think the peer reflection activities during the experiment have an influence on connecting theory with practice?

Do you think the finding alternatives activities during the experiment have an influence on connecting theory with practice?

\subsubsection{Group 2 and 4 interview}

The aim of the interview with the participants from group 2 and 4 is to collect information that supports the responses that will be collected via the different questionnaires. The interview also aims to give the participants the opportunity to explain in more detail their experience with this experiment. 
The interview with group 2 and 4 is divided into four parts. General questions are asked at the beginning of the interview to give the participants opportunity to explain their impression about this experience and the influence of the experiment on them. The second part of the interview focuses on the difficulties of practicing the reflection to confirm the responses on the questions in the Difficulties Questionnaire while the third part is concerned with the effectiveness of the environment in order to confirm the responses of the questions in the Effectiveness Questionnaire. The last part of the interview focuses on the pedagogical influence of the reflective practice in order to confirm the responses on the questions in the Achievement Questionnaire. The questions of this interview are presented in Table 5.18 and the guidelines of this interview are presented in Appendix 7.

Table 5.18 Interview for the participants of group $2 \mathcal{E} 4$

General questions

What is your general impression about this experiment?

How would you describe your experience with the reflective practice method in this field training course?

At the end of the field training, do you feel that the reflection skills can help you later as a teacher?

Questions related to the pedagogical influence

of the reflective practice method on learners' achievement

What influence does the reflective practice have on your understanding of the imbedded theory behind the practiced skill?

What influence does the reflective practice have on your ability to master the practiced skill?

Questions related to the difficulties that may have been encountered with carting out the reflection activities

What were the difficulties that you may have encountered during the field training with relation to the reflection activities?

\section{Questions related to the effectiveness of the online environment in facilitating the reflection activities}

How would you evaluate the usability of the environment in general?

How would you evaluate the usefulness of the environment in facilitating the different reflection activities?

\subsubsection{Group 1 and 3 interview}

As it was explained in Section 5.3 group 1 and 3 will be treated similarly to group 2 and 4 regarding the first two competences. However, they will be practicing the third competence in the traditional way without the use of the reflective practice or the online environment. 
Therefore, the interview of the participants of group 1 and 3 partly aims to understand the same aspects that have been discussed regarding the interview of group 2 and 4 . In addition, the interview with group 1 and 3 aims as well to collect information related to the differences between practicing field training with and without the reflective practice approach and the online environment. In order to satisfy this goal, two general questions in the first part of the interview are added as well as a fifth section. The fifth section focused on comparing the practice of the field training with and without practicing reflection and the online environment to understand the participants' preferences between these two methods. Table 5.19 presents the questions of this interview while the complete guidelines are presented in Appendix 8.

Table 5.19 Interview for the participants of group $1 \mathcal{E} 3$

\section{General questions}

What is your general impression about this experiment?

How would you describe your experience with the reflective practice method in this field training course?

At the end of the field training, do you feel that the reflection skills can help you later as a teacher? How would you describe your experience without the reflective practice method at the second part of the field training course?

If you have been asked to choose between practicing field training with or without the reflective practice, what would you choose?

Questions related to the pedagogical influence of the reflective practice method on learners' achievement

What influence does the reflective practice have on your understanding of the imbedded theory behind the practiced skill?

What influence does the reflective practice have on your ability to master the practiced skill?

Questions related to the difficulties that may have been encountered with carting out the reflection activities

What were the difficulties that you may have encountered during the field training with relation to the reflection activities?

Questions related to the effectiveness of the online environment in facilitating the reflection activities

How would you evaluate the usability of the environment in general?

How would you evaluate the usefulness of the environment in facilitating the different reflection activities? 
Table 5.19 Interview for the participants of group $1 \mathcal{E} 3$ (Continued)

Questions related to the experience of practicing field training with and without the reflective practice method

By experiencing both the practice of field training with and without the reflection activities, which method provided you more experience?

By experiencing both the practice of field training with and without the reflection activities, which method required more time and effort from you?

In comparison between the period with the reflection (the first part of the semester) and the period without the reflection (the second part of the semester), where do you find stronger presence of theory?

During the practice of field training without the reflection at the second part of the semester, are there any reflection activities you continued to use?

At the second part of the semester when you were practicing field training without reflection, are there any reflection activities you wished to continue using?

\subsection{SUMMARY}

The data collection that relates to the three research questions that were mentioned in the beginning of this chapter as well as the subsequent data analysis is described in Chapters 6, 7, and 8, and each deals with one of these research questions. By way of summary, Table 5.20 presents the overall schedule of the experimental design which may be used for reference when reading the subsequent chapters.

Table 5.20 Summary of the main design and organization issues in the experiment

\section{Aspect Description}

What 1. Implementation of the reflective practice approach supported by an online videobased learning environment in field training in the teacher education program in Kuwait

Why 2. To determine the difficulties that prospective teachers and trainers in the field training may encounter by practicing reflection in an online video-based learning environment

3. To investigate the opportunities of an online video-based learning environment in facilitating reflection among those prospective teachers and trainers

4. To evaluate the effect of practicing reflection on the achievement of those prospective teachers and trainers, and

5. To evaluate whether the implementation of this intervention will help in reducing the gap between theory and practice in the teacher education program in Kuwait 
Table 5.20 Summary of the main design and organization issues in the experiment (Continued)

$\begin{array}{ll}\text { How } & \text { 6. } \\ \text { Where } & \begin{array}{l}\text { Three task-oriented stages: Preparation stage, experimental stage and data } \\ \text { collection stage }\end{array} \\ \text { Who } & \text { 7. Field training courses in the College of Basic Education in PAAET in Kuwait } \\ \text { When } & \text { 9. } \text { Ten weeks: from March 2, until May } 8,2008 \\ \text { Support } & \text { 10. Introduction session and workshop } \\ \text { 11. Technical support in the computer lab } \\ \text { 12. Manuals } \\ \text { 13. Personal support }\end{array}$




\section{CHAPTER 6 Difficulties in practicing reflection}

In order to implement the reflective practice approach in the field training, the participants have to carry out several types of activities. Chapter 2 discussed different types of difficulties that are associated with carrying out the different activities of reflection. Furthermore, difficulties related to the use of technology were discussed in Chapter 3. Based on the discussion of Chapters 2 and 3, a classification of five types of difficulties was developed in Section 3.4.2. This classification consists of the following categories:

- Difficulties related to recording

- Difficulties related to description

- Difficulties related to self-reflection

- Difficulties related to peer-reflection

- Difficulties related to finding alternatives

RQ4 was, therefore, formulated in order to investigate these difficulties in relation to the context of this research. This question was presented in Section 1.5 as follows:

RQ4: What are the difficulties that prospective teachers and trainers encounter by utilizing the reflective practice approach supported by the online videobased learning environment in field training in the teacher education program in Kuwait?

These difficulties are investigated in our experiment by two means. First, a questionnaire with twenty-five questions will be administered in the last week of the second stage of the experiment (the experimental stage). Second, these difficulties are investigated as well by five open-ended questions that have been asked during the participants' interview in the data collection stage of the experiment. More information about the Difficulties Questionnaire and the interview has been presented in Sections 5.5.1 and 5.5.4 in the previous chapter. 
In this chapter, Section 6.1 presents the results from the Difficulties Questionnaire while Section 6.2 presents the results from the participants' interview. In Section 6.3 these results are compared and discussed in order to answer RQ4.

\subsection{DIFFICULTIES QUESTIONNAIRE}

This questionnaire concerns the difficulties in practicing reflection and consists of twenty-five questions divided into five sections. The aim of this questionnaire is to collect information about the five types of difficulties that the participants might encounter by carrying out the different reflection activities. Each type of difficulty was presented in a separate section of the questionnaire that consisted of four Likert-scale questions in addition to one open-ended question. The participants had to score each of the four Likert-scale questions on a five-point scale with the following values:

- $1=$ Not applicable at all

- 2 = Slightly applicable

- 3 = Applicable to some extent

- 4 = Applicable

- 5 = Applicable to a great extent

Cronbach's alpha reliability test was applied to the twenty Likert-type items in this questionnaire, excluding the five open-ended questions. The Cronbach's alpha score of the twenty items was .80 , indicating that the scale had good reliability. The results for each type of difficulty are presented in the following sections.

\subsubsection{Difficulties related to the activities of recording}

Five questions that are related to some of the expected difficulties in carrying out recording activities in this experiment were formulated in the first section of this questionnaire. The first four questions ask about specific difficulties while the fifth question asks the participants to describe other difficulties that they might encounter during the experiment in relationship to the recording activities. Table 6.1 presents the questions of this section and the mean and the standard deviation scores for the first four questions. 
Table 6.1 Difficulties related to the activities of recording $(N=16)$

\begin{tabular}{|llcc|}
\hline No & Question & Mean & $\begin{array}{c}\text { Standard } \\
\text { deviation }\end{array}$ \\
\hline 1 & I find it difficult to record my performance by myself & 1.68 & 1.25 \\
\hline 2 & $\begin{array}{l}\text { It is difficult for me to choose only one small part of my } \\
\text { performance }\end{array}$ & 3.31 & 1.49 \\
\hline 3 & $\begin{array}{l}\text { Dealing with the editing software is difficult for me } \\
\text { I feel I lack the proper skills to produce high-quality video } \\
\text { clips of my performance }\end{array}$ & 2.18 & 1.10 \\
\hline 5 & $\begin{array}{l}\text { Did you encounter any other difficulties regarding the } \\
\text { recording activities? }\end{array}$ & Yes $=8$ & 1.03 \\
\hline
\end{tabular}

Based on the response to Question 1, it can be argued that the majority of the participants did not encounter difficulties with recording their performance. However, the answers to Question 2 show that a substantial number of them consider the selection of a small part of their performance was a bit hard as revealed by their answers to this question. Furthermore, even though the participants were during the preparation stage, attending a workshop in order to learn how to use the video editing software as well as receiving support during the experiment about this activity, their answers to Question 3 showed that some of the participants were still having some difficulties in using this software. Regarding the production of the high-quality video clip about their performance in Question 4, the answers showed that some of the participants believe that they lack these skills. It is important to mention here that the standard deviations of these four questions were between 1.03 and 1.49, which suggests a substantial spread among the answers to these questions.

Question 5 asked whether the participants did encounter any other difficulties regarding the recording activities. In response to this question, eight participants asserted that they did face different types of difficulties carrying out these activities other than those described in the other questions of this section. Most of those participants mentioned two similar difficulties that were related to the video cameras and the video editing software. Several participants complained that their personal cameras were not compatible with the computer and that caused them to borrow the cameras from the department. The difficulty was in arranging a schedule between the participants for using these cameras. In addition, the second complaint that was mentioned by several participants was that the video editing software was mostly slow and sometimes froze during the work. 


\subsubsection{Difficulties related to the activities of description}

The second section of the Difficulties Questionnaire concerned the difficulties related to the description activities. Similar to the first section, this section consisted of five questions that reflected different difficulties that might be encountered by carrying out the description activities. The five questions in this section are presented in Table 6.2 in addition to the mean and the standard deviation scores of the first four questions.

Table 6.2 Difficulties related to the activities of description $(N=16)$

\begin{tabular}{|c|c|c|c|}
\hline No & Question & Mean & $\begin{array}{l}\text { Standard } \\
\text { deviation }\end{array}$ \\
\hline 6 & I find it difficult to express myself in words & 3.12 & .95 \\
\hline 7 & $\begin{array}{l}\text { In writing, I tend to write merely descriptions of events } \\
\text { without an analysis }\end{array}$ & 2.62 & 1.02 \\
\hline 8 & $\begin{array}{l}\text { I tend to have an ideal image in my head about how I teach, } \\
\text { which is different from my actual teaching. }\end{array}$ & 3.12 & 1.14 \\
\hline 9 & $\begin{array}{l}\text { I feel I lack the proper skills to provide sufficient description } \\
\text { about my performance }\end{array}$ & 2.68 & 1.35 \\
\hline 10 & $\begin{array}{l}\text { Did you encounter any other difficulties regarding the } \\
\text { description activities? }\end{array}$ & Yes $=2$ & $\mathrm{No}=14$ \\
\hline
\end{tabular}

The mean scores for the first four questions in this second section show that the participants did encounter some difficulties in practicing the description activities. Expressing themselves verbally (Question 6) and accepting their actual performance (Question 8) were two difficulties that scored means of 3.12, which suggested that the participants did encounter these difficulties to some extent. Furthermore, encountering difficulty in analyzing the situation (Question 7) was described by the participants as a slightly applicable statement. Finally, the participants think that they may lack the right skills for providing sufficient description (Question 9) as they described this statement as slightly applicable. The standard deviations of these four questions were above one point except for Question 6 where it was 0.95 .

Only two participants mentioned additional difficulties regarding the description activities as an answer to the last question in this section (Question 10) and they both described similar difficulty. They explained that it was difficult for them to describe the whole situation briefly and that they always felt the need to further clarify their description in order to make it clear for the others. 


\subsubsection{Difficulties related to the activities of self-reflection}

The structure of the third section in the Difficulties Questionnaire was similar to the previous sections but the focus here was on the difficulties that might face the participants by carrying out the self-reflection activities. The questions that are presented in this section are shown in Table 6.3 including the mean and the standard deviation scores for the first four questions.

Table 6.3 Difficulties related to the activities of self-reflection $(N=16)$

\begin{tabular}{|llcc|}
\hline No & Question & Mean & $\begin{array}{c}\text { Standard } \\
\text { deviation }\end{array}$ \\
\hline 11 & $\begin{array}{l}\text { Reflecting on my professional identity as a teacher is difficult } \\
\text { for me }\end{array}$ & 3.00 & 1.31 \\
\hline 12 & $\begin{array}{l}\text { I tend to wait for the teacher to provide me corrections } \\
\text { instead of evaluating my experience myself. }\end{array}$ & 2.12 & 1.31 \\
\hline 13 & $\begin{array}{l}\text { While evaluating the experience, I tend to focus on aspects } \\
\text { that I did wrong }\end{array}$ & 3.31 & 1.19 \\
\hline 14 & $\begin{array}{l}\text { I feel I lack the proper skills to reflect on my own } \\
\text { performance }\end{array}$ & 2.68 & .87 \\
\hline 15 & $\begin{array}{l}\text { Did you encounter any other difficulties regarding the self- } \\
\text { reflection activities? }\end{array}$ & Yes $=0$ & No $=16$ \\
\hline
\end{tabular}

The answers to Question 11 showed that the participants found it difficult to some extent to reflect on their teaching performance. Furthermore, they agreed to some extent in Question 13 that they usually focus on the mistakes of their performance in the self-reflection. Regarding the statements of Questions 12 and 14, the participants think that these statements are slightly applicable for them. Except for Question 14 where the standard deviation was 0.87, which shows consistency of the answers, the standard deviations of the rest of the questions in this section were above one point and ranged between 1.19 and 1.31. This implies that there was a substantial spread in the answers to these questions. The participants in the last question in this section (Question 15) reported no more difficulties regarding the activities of self-reflection.

\subsubsection{Difficulties related to the activities of peer-reflection}

The questions that concerned the difficulties that are associated with practicing the peer-reflection activities were presented to the participants in the fourth section of this questionnaire. This section consisted of five questions that are presented in Table 6.4 with the mean and standard deviation scores of the first four questions. 
From Table 6.4 it can be seen that the mean scores of the answers to the first four questions in this section ranged between 2.00 and 2.43. The participants think that these four statements were slightly applicable to their practice. However, a spread of the answers can be distinguished here based on the standard deviations of these answers, which ranged between 1.21 and 1.54. Nevertheless, reflecting on others' performances (Question 16) and pointing out their mistakes (Question 18) were the more recognizable difficulties by the participants in practicing the activities of peer-reflection. The participants considered the statements of Questions 17 and 19 slightly applicable to them. Furthermore, the participants in the last question of this section (Question 20) reported no further difficulties related to the activities of peer-reflection.

Table 6.4 Difficulties related to the activities of peer-reflection $(N=16)$

\begin{tabular}{|c|c|c|c|}
\hline No & Question & Mean & $\begin{array}{l}\text { Standard } \\
\text { deviation }\end{array}$ \\
\hline 16 & $\begin{array}{l}\text { Due to psychological reasons, I tend to avoid reflecting on } \\
\text { others' performance }\end{array}$ & 2.43 & 1.54 \\
\hline 17 & I tend to be ashamed of my own ideas and thoughts. & 2.00 & 1.21 \\
\hline 18 & $\begin{array}{l}\text { It is difficult for me to point out others' weaknesses while I } \\
\text { am providing feedback to them. }\end{array}$ & 2.18 & 1.37 \\
\hline 19 & $\begin{array}{l}\text { I feel I lack the proper skills to reflect on my colleagues' } \\
\text { performance }\end{array}$ & 2.00 & 1.21 \\
\hline 20 & $\begin{array}{l}\text { Did you encounter any other difficulties regarding the peer } \\
\text { reflection activities? }\end{array}$ & Yes $=0$ & $\mathrm{No}=16$ \\
\hline
\end{tabular}

\subsubsection{Difficulties related to the activities of finding alternatives}

The last section of this questionnaire also consisted of five questions and concerned the difficulties that might face the participants from carrying out the activities of finding alternatives. Table 6.5 presents the questions of this section and the mean and the standard deviation scores for the first four questions. 
Table 6.5 Difficulties related to the activities of finding alternatives $(N=16)$

\begin{tabular}{|llcc} 
No & Question & Mean & $\begin{array}{l}\text { Standard } \\
\text { deviation }\end{array}$ \\
\hline 21 & $\begin{array}{l}\text { Thinking of what I did in a session in relation to what I } \\
\text { should have done is difficult for me. }\end{array}$ & 2.06 & .92 \\
\hline 22 & $\begin{array}{l}\text { To question the corrections and comments given by my } \\
\text { supervisor or my colleagues is difficult for me }\end{array}$ & 2.12 & 1.25 \\
\hline 23 & $\begin{array}{l}\text { I tend to focus on teaching in one way, and I have difficulties } \\
\text { with thinking about alternatives }\end{array}$ & 1.81 & .83 \\
\hline 24 & $\begin{array}{l}\text { I feel I lack the proper skills to assess my performance } \\
\text { Did you encounter any other difficulties regarding the } \\
\text { finding alternatives activities? }\end{array}$ & 1.68 & Yes $=0$ \\
\hline
\end{tabular}

Based on the mean scores, the statements of Questions 21 and 22 are considered slightly applicable by the participants. However, the participants expressed almost no difficulties in finding alternatives for their way of teaching (Question 23). Furthermore, the participants showed some confidence in evaluating their own performance (Question 24). With the exception of Question 22 where the standard deviation score was 1.25, the standard deviations of the rest of the questions were less than one point and ranged between 0.79 and 0.92, which suggests consistency in the answers to these questions. No more difficulties were reported by the participants in relation to practicing the activities of finding alternatives when they responded to the last question in this section.

\subsubsection{Summary of the results of the Difficulties Questionnaire}

The previous sections presented the data that have been collected via the Difficulties Questionnaire concerning the five types of difficulties that are associated with the different activities of reflection. The responses of the participants in this questionnaire revealed several kinds of difficulties.

The responses to the questions in section one of this questionnaire concerning the recording difficulties (Section 6.1.1) highlighted three different kinds of difficulties that have been experienced by the participants: (a) the participants found it difficult to select a small part of their performance, (b) they found it slightly difficult to deal with the video editing software mainly because of some software functionality problems, and (c) participants described the incompatibility of their personal cameras with the computer as another difficulty that occurred during the practice of the activities of reflection. However, doubts about possessing the right skills for carrying out the activities of recording were expressed by some participants. 
The results of section two of the questionnaire in relationship to the difficulties associated with the description activities (Section 6.1.2) also underlined three different kinds of difficulties that have been experienced by the participants: (a) using written text to express their thoughts and behaviors was described by the participants as a difficult task to some extent, (b) difficulty acknowledging the differences between the ideal image that they have about their teaching skills and their actual performance that has been recorded, and (c) being unable to provide a clear description of the situation that reflects their insights. Once again some of the participants expressed doubts regarding their skills for carrying out the activities of description.

Another two difficulties in relationship with the activities of self-reflection were pointed out by the participants in section three of the questionnaire (Section 6.1.3). The participants found it difficult to (a) reflect on their own performance and particularly to (b) point out the good side of their performance as they tend to focus mainly on what they did wrong. Similar to the previous sections, some doubts about having the right skills for practicing the activities of self-reflection were presented by the participants.

Based on the results of section four of the questionnaire concerning the peerreflection difficulties (Section 6.1.4), it is safe to assume here that the participants in general faced few difficulties during their practice of the activities of peerreflection. Similar to section four, the responses to the questions in section five of the questionnaire concerning the difficulties associated with the activities of finding alternatives (Section 6.1.5) showed that the participants encountered no real difficulties practicing the activities of finding alternatives. For detailed statistics on the answers to this questionnaire, see Appendix 9.

It can be concluded here based on the results of the five sections in the Difficulties Questionnaire that the participants did indeed experience some difficulties by carrying out the activities of reflection in the field experiment. Yet, none of these difficulties were presented as a major obstacle that may prevent the participants from carrying out the different tasks in practicing reflection. Elaborative discussion of these difficulties in light of the results of the participants' interview and the difficulties that have been described in the literature in Chapter 2 will be presented later in Section 6.3. 


\subsection{PARTICIPANTS' INTERVIEW}

The last week of the experiment was devoted to interviewing the participants and their supervisors. All interviews were recorded on tapes and fully transcribed. The procedure for cross-case analysis suggested by Miles and Huberman (1994) was used to order and analyze the data. The information from each participant was entered in several matrices that are categorized by the interview's parts. Using these matrices, a meta-matrix for each part including all the participants was created. After, the information that has been collected from the participants in these meta-matrices were refined, summarized, and reduced through partitioning and clustering. The matrices entries, therefore, were a combination of short blocks of text, quotes, and phrases. This procedure produced six partially ordered data displays for the whole data of the interview. The data that concern the reflection difficulties, therefore, were contained in one matrix in order to be presented and explained here.

The aim of the interview is to collect information that supports and confirms the information that has been collected in the different questionnaires. It was assumed that by providing the participants with the opportunity to elaborate on their perspectives in the interviews, more thoughtful information would be collected. Five questions (similar to those from the Difficulties Questionnaire) about possible difficulties encountered during field training with relation to the reflection activities were asked:

- What were the difficulties that you may have encountered during the field training with relation to the reflection activities?

- Difficulties related to the recording activities

- Difficulties related to the description activities

- Difficulties related to the self reflection activities

- Difficulties related to the peer reflection activities

- Difficulties related to the finding alternatives activities

The responses to these questions are presented in Table 6.6. The entries in this table were filled in based on the similarity of the mentioned responses following the principle of the modal problem type. Miles and Huberman described the modal problem type as "the one mentioned by most informants when there were more than one" (1994, p.181). 
In response to the first question concerning the difficulties that are associated with the activities of recording, the participants described five different difficulties. The most described difficulty in this regard was related to (a) the use of the digital video cameras. The participants explained that the incompatibility of their personal video cameras with the computer caused them to look for other cameras and to record their performance several times. Another difficulty that was mentioned by several participants was about (b) uploading their video clips into the V-class environment. The participants explained that uploading the video clips was a bit of a complicated procedure for them. In addition, they also described technical problems that repeatedly occurred in the environment during the uploading activities. Furthermore, the participants complained about (c) the inefficiency of the video editing software. They also pointed out that (d) both their and their students' awareness of the camera in the classroom caused some difficulties. Finally, some participants talked about the difficulty of (e) selecting the situation that presents their own performance for others. The results here show that except for their awareness of the camera and selecting the situation, which were the least mentioned difficulties, the major difficulties in the recording activities were related to organizational and technical factors. 
Table 6.6 Participants' responses on the difficulties questions of the interview $(N=16)$

\begin{tabular}{|c|c|c|c|c|c|c|c|c|c|c|c|c|c|c|c|}
\hline \multirow[b]{3}{*}{ 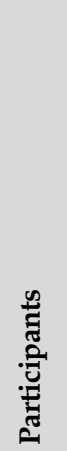 } & \multicolumn{14}{|c|}{ Individually reported difficulties during the reflection activities } & \\
\hline & \multicolumn{5}{|c|}{ Recording } & \multicolumn{2}{|c|}{ Description } & \multicolumn{3}{|c|}{ Self-reflection } & \multicolumn{2}{|c|}{$\begin{array}{l}\text { Peer- } \\
\text { reflection }\end{array}$} & \multicolumn{2}{|c|}{ Finding alternatives } & 离 \\
\hline & 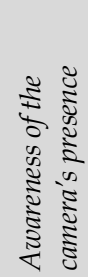 & 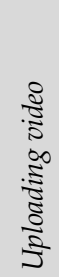 & 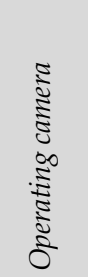 & 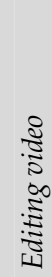 & 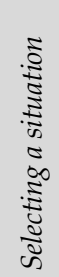 & 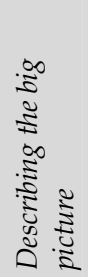 & $\begin{array}{c}0 \\
0 \\
0 \\
0 \\
0 \\
0 \\
0 \\
5 \\
0 \\
0 \\
0 \\
0 \\
0 \\
0\end{array}$ & 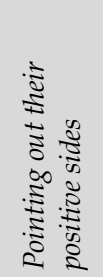 & 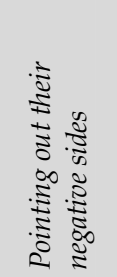 & 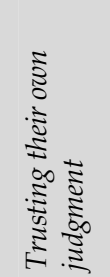 & 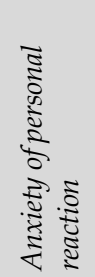 & 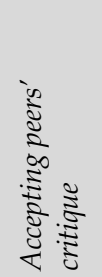 & 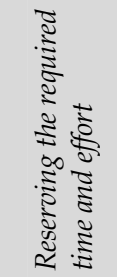 & 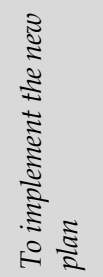 & 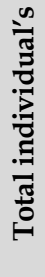 \\
\hline 1 & $\mathrm{x}$ & & & & & & & $\mathrm{x}$ & & & & & $\mathrm{x}$ & & 3 \\
\hline 2 & $\mathrm{x}$ & & & & & & & & $\mathrm{x}$ & & $\mathrm{X}$ & & & & 3 \\
\hline 3 & & $\mathrm{x}$ & & & & & & & & & & & & & 1 \\
\hline 4 & & $\mathrm{x}$ & & & & & $\mathrm{x}$ & & $\mathrm{X}$ & & $\mathrm{X}$ & & & & 4 \\
\hline 5 & & & $\mathrm{x}$ & & & & & $\mathrm{x}$ & & & $\mathrm{X}$ & & & & 3 \\
\hline 6 & & $\mathrm{x}$ & $\mathrm{x}$ & $\mathrm{x}$ & & & & & & & & $\mathrm{X}$ & & & 4 \\
\hline 7 & & & & & & & & & & & & & & & 0 \\
\hline 8 & & & & & & & & & & & $\mathrm{x}$ & & & & 1 \\
\hline 9 & & & & & & & & & & $\mathrm{x}$ & & & & $\mathrm{x}$ & 2 \\
\hline 10 & & & & & & & & & & $\mathrm{x}$ & & $\mathrm{X}$ & & $\mathrm{x}$ & 3 \\
\hline 11 & & & $\mathrm{x}$ & & & & & & $\mathrm{x}$ & & & & & $\mathrm{x}$ & 3 \\
\hline 12 & & & $\mathrm{x}$ & $\mathrm{x}$ & & & & & & $\mathrm{x}$ & & & & & 3 \\
\hline 13 & & & & $x$ & $x$ & $X$ & & & $x$ & & & & & & 4 \\
\hline 14 & & & & & $x$ & & & & $x$ & & & & & & 2 \\
\hline 15 & & $x$ & & & & & & & & & & & $x$ & & 2 \\
\hline 16 & & & $x$ & & & & & & & & $X$ & & & & 2 \\
\hline Total & 2 & 4 & 5 & 3 & 2 & 1 & 1 & 2 & 5 & 3 & 5 & 2 & 2 & 3 & \\
\hline
\end{tabular}


The second question of this part of the interview concerns the difficulties that are related to the activities of description. Only two participants pointed out difficulties in practicing the description activities related to (a) describing the whole situation and (b) describing this situation in written text. However, no more difficulties were mentioned in relationship to the activities of description.

The difficulties in practicing the activities of self-reflection were discussed in the third question of this part. Two difficulties described by seven participants were concerned with finding what the (a) positive or (b) negative remarks in their performance were. While five of those participants found it difficult to point out their negative performance, two of them, contrarily, found it difficult to point out their positive performance. In addition, the participants encountered another difficulty in the activities of self-reflection related to (c) their self-confidence in their judgment. Some of the participants were questioning their ability to evaluate their own performance. The response to this question shows that the three mentioned difficulties are actually connected to each other and all of them relate to personal factors.

The fourth question of this part discussed the difficulties that related to the activities of peer-reflection. A common difficulty described by several participants is (a) the concern about their peers' reaction to their comments. They explained that it was very difficult to try to provide negative comments to their peers without feeling worried that they will be upset or offended to some extent. Furthermore, (b) accepting the feedback, especially from their peers, was difficult for some of the participants because they do not trust their peers' judgment. It can be seen from these results here that both difficulties are related to personal factors and cultural aspects

The last difficulties investigated in this part were related to the activities of finding alternatives. The difficulties that were described by the participants in relation to finding alternatives were mainly concerned with (a) the implementation of the new behavior and (b) the amount of time and effort that it required. They argued that coming up with a new plan is different from implementing this plan in a real situation. They also pointed out that the activities of finding alternatives require them to look back into all the materials and that was consuming a large amount of their time and effort. Therefore, the results here show that in addition to the complexity of implementing a new behavior, the required time and effort is considered an issue by the participants. To sum up, participants' complaints regarding the difficulties associated with the different activities of reflection show that each activity comes with different and 
unique challenges for the participants. Nevertheless, from the results of this part of the interview it can be assumed that practicing the activities of recording are considered by the participants to be the most complicated tasks. This can be related strongly to the fact that those complaints were mainly concerning the equipment and technical factors. On the other hand, based on the small number of complaints, the activities of description can be viewed as the easiest tasks among other activities of reflection. It was also noticeable from the response to the third and fourth questions that personal factors were affecting the activities of self-reflection and peer-reflection while for the activities of finding alternatives time and effort were the critical issues in these activities.

\subsection{DiscUSSION}

By practicing the reflective practice approach, several difficulties that practitioners might encounter were recognized in the literature in Chapter 2. Furthermore, more difficulties were highlighted in Chapter 3 as a result of using ICT applications to support the practice of reflection. The fourth question in this research, therefore, focused on investigating these difficulties in relation to the field training in Kuwait. Information concerning the difficulties that have been reported by the participants was collected via the Difficulties Questionnaire and the participants' interview in this experiment.

To answer RQ4, comparison of the results from the questionnaire and the interview will be presented in 6.3.1 in order to confirm these responses while 6.3.2 will discuss these findings with respect to RQ4.

\subsubsection{Results comparison}

To collect more reliable data regarding the difficulties in practicing the reflective practice approach, similar questions to those that have been asked in the Difficulties Questionnaire were asked again during the participants' interview. The answers to these questions from both the questionnaire and the interview were presented and explained previously in Sections 6.1 and 6.2. It is assumed that comparing and discussing the results of these similar questions here will confirm the responses and provide sufficient information to discuss RQ4.

The first type of difficulty investigated is related to the activities of recording where the participants did describe several kinds of difficulties in both the 
questionnaire and the interview. All the difficulties described in the questionnaire concerning (a) the use of the digital camera, (b) the selection of part of the performance, and (c) the operation of the video editing software were confirmed and elaborated on in the interview. Furthermore, the results of the interview revealed two additional difficulties concerning (d) the activity of uploading the video clips into the online environment and (e) the awareness of the camera in the classroom.

The questionnaire results regarding the difficulties from practicing the activities of description highlighted three difficulties related to participants' ability: (a) providing clear description of the situation, (b) providing this description in a written form, and (c) acknowledging the differences between the ideal and the actual performance. The interview results confirmed only the first two difficulties while none of the participants mentioned the third difficulty in the interview.

The results from investigating the difficulties from practicing the activities of selfreflection in the questionnaire revealed two types of difficulties: (a) reflecting on their own performance and (b) pointing out the good side of this performance. The interview results did confirm both of these difficulties. However, in contrast with the second difficulty that is presented in the questionnaire, the majority of the participants explained in the interview that (c) they found it more difficult to point out the negative side of their performance instead of the positive side. In addition, in line with participants' doubts about the adequacy of their skills to practice this activity that was expressed in the questionnaire, some of the participants expressed in the interview their (d) lack of confidence in their own judgment.

While the participants described few difficulties regarding the peer-reflection activities in the questionnaire, a substantial number of them expressed real concern toward providing or accepting feedback during the interview. They explained that (a) it was difficult for them to provide honest feedback to their peers without worrying about offending them. Furthermore, they explained that (b) it was difficult for some of them to accept the negative feedback from their peers.

The last type of difficulty investigated was related to the activities of finding alternatives where no real difficulties were presented from the questionnaire. The interview results, however, showed that the participants were concerned with (a) the implementation of a new behavior and (b) the amount of time and effort that is required for practicing these activities. The participants differentiated between creating a new behavior and the implementation of this behavior in a real situation. The participants were also concerned that the activities of finding 
alternatives require them to look back into all the materials as this was timeconsuming and took effort.

To summarize the different difficulties that have been described previously in this section and throughout this chapter, Table 6.7 presents these difficulties based on our difficulties' classification that is presented in Section 3.4.2.

Table 6.7 Summary of the difficulties from practicing reflection in the field training in Kuwait

\begin{tabular}{|c|c|}
\hline Categories & Difficulties \\
\hline Recording & $\begin{array}{l}\text { - Using the digital camera } \\
\text { - Ignoring the presence of the camera in the classroom } \\
\text { - Operating the video editing software } \\
\text { - Uploading the video clips into the online environment } \\
\text { - Selecting part of the performance }\end{array}$ \\
\hline Description & $\begin{array}{l}\text { - Providing clear description to the situation } \\
\text { - Providing the description in a written form } \\
\text { - Acknowledging the differences between the ideal and the actual } \\
\text { performance }\end{array}$ \\
\hline Self reflection & $\begin{array}{l}\text { - Reflecting on their own performance } \\
\text { - Pointing out the negative side of their performance } \\
\text { - Trusting their own judgment } \\
\text { - Pointing out the positive side of their performance }\end{array}$ \\
\hline Peer reflection & $\begin{array}{l}\text { - Overcoming their anxiety toward offending their peers by their feedback } \\
\text { - Accepting the negative feedback from their peers }\end{array}$ \\
\hline $\begin{array}{l}\text { Finding } \\
\text { alternatives }\end{array}$ & $\begin{array}{l}\text { - Implementing the alternative behavior } \\
\text { - Reserving the required time and effort for the activities of finding } \\
\text { alternatives }\end{array}$ \\
\hline
\end{tabular}

After comparing the results from the Difficulties Questionnaire with the results from the participants' interview and highlighting the difficulties that have been encountered by the participants, the next section will discuss these findings with respect to RQ4.

\subsubsection{Difficulties in practicing the activities of reflection}

To discuss the difficulties that occurred during our experiment and to connect them to other difficulties that have been described in the literature, a new classification consisting of three categories has been developed here. The aim of this classification is to take a step beyond these difficulties into the source or the cause of these difficulties. This is also assumed to provide more customized classification to the difficulties in our study and to simplify the process of sorting out these difficulties. Nevertheless, an overlap may be seen between these three 
categories considering the strong relationship between the different difficulties in this study. A discussion of the encountered difficulties in our field experiment is presented in the following sections based on these three categories.

\subsubsection{Personal E social barriers}

The personal barrier here refers to the manners, attitudes, and behaviors of the participants while the social barrier concerns the influence of the Kuwaiti culture and traditions on the participants. Six of the difficulties that have been encountered by the participants are classified here under the personal and social barriers. The following order of these difficulties is organized based on the presence and the influence of each of these difficulties on the practice of reflection as reported by the participants in the interview (see Table 6.6):

1. Pointing out the negative side of their performance

2. Overcoming their anxiety toward offending their peers by their feedback

3. Trusting their own judgment

4. Pointing out the positive side of their performance

5. Ignoring the presence of the camera in the classroom

6. Accepting the negative feedback from their peers

The influence from participants' personality and emotions on their practice of reflection was pointed out in several studies. For example, emotions such as feeling vulnerable, exposed, ashamed, lacking the necessary knowledge, and fearing criticism and judgment have all been described by many researchers as major barriers affecting the practice of reflection (Wade, 1994; Platzer et al., 2000; Leijen, 2008). The six difficulties that are presented in this section can be strongly associated with the personality barrier.

Similar to difficulty number 4, Leijen (2008) asserted that "students mainly focused on aspects which they did wrong and ignored positive aspects" (2008, p.98). This difficulty was sorted out in Leijen's (2008) classification under difficulties in evaluating an experience. In contrast to this finding, difficulty number 1 here shows that some participants did also face difficulty in finding negative aspects in their performance. In fact, difficulty 1 was mentioned by five of the participants while only two pointed out difficulty 4 . In addition, a connection can be made between these two difficulties ( $1 \& 4)$ together with difficulty number 3 . One may argue that by possessing confidence in their ability to judge their own performance, the participants are likely to be able to point out both the negative and the positive sides of their performance. Therefore, both difficulties 1 and 4 
might be seen as the result of difficulty number 3, which is related directly to participants' self-confidence and consequently to their personality. That explains our reason to sort out difficulties 1 and 4 under the personal barrier. Similar findings in relation to participants' devaluating their own knowledge are also found in Wade (1994), Mountford and Rogers (1996), and Leijen (2008).

Difficulties number 2 and 6 concern the activities of providing and receiving feedback, which could be related to the specific cultural influence in this context. Therefore, an explanation of the effect of society on the personal factor in relation to the Kuwaiti context may help in the understanding of the cause of these difficulties. The Arabic and Islamic cultures play major roles in defining the personality of the Kuwaiti citizen in general where moral aspects such as respecting others and showing consideration to their feelings are extremely valued. Considering that females were the only gender in our experiment, it is relevant here to point out that these moral aspects are usually demonstrated more explicitly in females than in males in this society. That may explain participants' anxiety toward offending their peers and in return that may also explain their reservations in accepting their peers' feedback, especially the negative remarks. Another moral aspect that had an influence on the practice of reflection in our experiment is the shyness that Kuwaiti females usually express, which could explain difficulty number 5. While participants' awareness of the camera in the classroom may be explained as the result of their shyness, students in the classroom were also curious about the presence of the camera as it was described by the participants, which led to considering this a difficulty in practicing the activities of reflection.

On the one hand, difficulties that correspond to some of the difficulties presented here $(1,3 \& 4)$ can be found in other studies about reflection (Wade, 1994; Mountford \& Rogers, 1996; Platzer et al., 2000; Leijen, 2008). Reporting similar difficulties in other researches shows that those difficulties are associated strongly with the practice of reflection. The cause of the other difficulties that are presented in this section $(2,5$, and 6$)$, on the other hand, can be related mainly to cultural and traditional aspects in Kuwaiti society.

\subsubsection{Knowledge $\mathcal{E}$ skills barriers}

Considering that the knowledge and skills of a person is in fact a part of his or her personality, an overlap might be seen here with the previous category. However, even with acknowledging the presence of the personality barrier in the difficulties of this section, the dominant barrier here concerns participants' 
knowledge and skills in general and in relationship to the reflective practice approach in particular. Another six of those difficulties that have been encountered by the participants are classified here under the knowledge and skills barriers and ordered based on the presence and the influence of these difficulties as described by the participants in the interview (see Table 6.6) except for Difficulties 5 and 6, which were described only in the questionnaire:

1. Implementing the alternative behavior

2. Selecting a part of the performance

3. Providing clear description of the situation

4. Providing the description in written form

5. Reflecting on their own performance

6. Acknowledging the differences between the ideal and the actual performance

Knowing beforehand from the preliminary investigation that our participants are lacking the necessary knowledge and skills about the reflective practice approach, this issue was taken into account during the design of the field experiment and the reflective practice model in Chapter 5. Nevertheless, it is not surprising here that some of the difficulties in this regard were encountered by the participants considering the brief information that they received during the preparation stage of the experiment. Difficulties 1, 5, and 6 demonstrate explicitly this lack of knowledge about reflection. The participants found it difficult to recognize and to connect the differences between the image in their mind about their teaching practice and the recorded performance of their actual teaching (Difficulty 6). Furthermore, the participants found it difficult to replace their old practice with the developed alternatives (Difficulty 1) even though they did not face a problem with developing these alternatives based on their own reflection and the different feedbacks they received from their peers and supervisor. Assumingly, difficulty number 6 can be presented here as the cause of difficulty 1 where by being not able to identify and connect these differences makes the implementation of a new alternative challenging. Difficulty number 6 might also be partly seen as causing difficulty in selecting a part of the performance (Difficulty 2). Furthermore, being provided with no precise instructions on how to reflect, the participants were not sure about their practice of this activity (Difficulty 5), yet they did complete this activity based on their own understanding. As it was explained in Chapter 5, not providing precise instructions was purposely planned in order to provide the participants with room to add their personal touch to this activity. 
The participants reported two other difficulties (3 and 4) that concern the activities of description. To cover all aspects that surround the situation and particularly in written form in order to make it understandable for others was described as a difficult task by the participants. This finding is consistent with other findings in several studies. The cause of this difficulty is associated by Eraut (2000) with participants' unawareness of their actions; however, the use of video application in our experiment should have an influence on this cause. Another explanation that may better suit the context of our experiment is presented by Chung, Mak and Paul (1995) as they refer to participants' lack of vocabulary as the cause of this difficulty. Leijen (2008) presented a similar finding where she described it as difficulty in verbalizing ideas.

Some of the difficulties that are presented in this section ( 3 and 4) were also found in other studies while the rest of these difficulties $(1,2,5$, and 6) seem exclusive to our study. The reason for this might be related to the type of knowledge and skills that are required from the participants for these difficulties. The difficulties that corresponded to other findings ( 3 and 4 ), on the one hand, mainly require general knowledge and skills from the participants in relation to richness in the language. The exclusivity of the other difficulties $(1,2,5$, and 6$)$ to our experiment, on the other hand, can be strongly associated with the fact that our participants did not have prior knowledge or experience regarding the practice of reflection.

\subsubsection{Technical E organizational barriers}

This category concerns the difficulties that are caused by technical barriers, which are related to the use of the different technologies during the experiment. Technical barriers here refer to the inefficiency of the technologies involved in facilitating the activities of reflection. This category also concerns the difficulties that are caused by the way the field training in our experiment was organized. Four difficulties that have been reported by the participants are classified here under the technical and organizational barriers, which are also ordered based on the presence and the influence of these difficulties as described by the participants in the interview (see Table 6.6):

1. Using the digital camera

2. Uploading the video clips into the online environment

3. Operating the video editing software

4. Reserving the required time and effort for the activities of finding alternatives 
In relation to the technical barrier, the use of the digital camera is described by some participants as a difficult task (Difficulty 1). Operating the camera, in fact, did not cause this difficulty; it was rather the incompatibility between the participants' personal cameras and the operating system of their computers which caused this problem. They had to make a schedule to borrow the only two available cameras in the Educational Technology department and to record again their first session. Actually, a more precise description of this difficulty would be 'inconvenience' rather than 'difficulty'. Nevertheless, this difficulty disappeared after the practice of the first competence in the experiment. Another temporary difficulty that faced the participants in the beginning of the experiment was uploading the video to the online environment (Difficulty 2). This problem was also solved during the practice of the first competence by the environment's technical support staff. Moreover, some of the participants described operating the video editing software as a difficult task (Difficulty 3). The participants were trained during the preparation stage of the experiment to work with Windows Movie Maker software. The participants complained that this software was mostly slow and sometimes froze during the work, which cost them to lose some of their work. In order to overcome this difficulty, the participants were given the freedom to select any other video editing software that is compatible with the online environment. The last difficulty that has been described by the participants concerns the required time and effort to complete the activities of finding alternatives (Difficulty 4). Even though the semester was devoted mainly to the field training and the seminar sessions, some of the participants did have to attend one or two other courses. It was difficult for those participants to spare enough time and effort to go thoroughly though their reflection, their peers' reflection, and their supervisors' feedback in order to develop a new alternative for their behavior. The four difficulties that were presented in this section are thus connected specifically to the context of our experiment.

To sum up, it can be concluded based on the information presented in this chapter as an answer to RQ4 that the participants indeed encountered several difficulties and faced different barriers by practicing reflection, though these difficulties and barriers did not prevent the utilization of this learning approach. However, in order to allow the reflective practice approach to make a real difference and to improve the field training, those difficulties and barriers must be eliminated or at least reduced. Elaboration on this discussion together with suggestions and recommendations concerning the elimination of these difficulties will be presented in Chapter 9 . 


\section{CHAPTER 7}

\section{Facilitating reflection: Effectiveness of the V-class environment}

The use of an online video-based learning environment as an ICT tool to support and to facilitate the utilization of the reflective practice approach in the field training in Kuwait is a central part of our research. The viability for using such online environments in teacher education and the opportunities of these environments for the field training were investigated and discussed in Chapter 3. Furthermore, the V-class online video-based learning environment was selected and modified for our experiment as described in Chapter 5. To understand participants' perspectives toward the effectiveness of the $\mathrm{V}$-class environment in supporting and facilitating the different activities of reflection during the experiment, RQ5 was formulated in Section 1.5 to question the usability and the usefulness of such online environments for the field training in Kuwait:

RQ5: Will the use of the online video-based learning environment provide adequate support to facilitate the practice of reflection among prospective teachers in field training in the teacher education program in Kuwait?

Information concerning the usability and the usefulness of the V-class environment were collected through a questionnaire (Effectiveness Questionnaire) and an interview. Seventeen questions that concern the usability and the usefulness of the environment were asked of the participants. Fifteen questions were presented in Likert-scale form in the questionnaire in addition to two open-ended questions that were asked during the participants' interview. In this chapter, Section 7.1 presents the results from the Effectiveness Questionnaire and Section 7.2 presents the results from the participants' interview. Comparison and discussion of these results is then presented in Section 7.3 in order to formulate an answer to RQ5. 


\subsection{EFFECTIVENESS QUESTIONNAIRE}

The fifteen questions in this questionnaire are divided into two sections. The first section concerns the usability of the environment for carrying out the reflection activities while the second section concerns the usefulness of the environment for carrying out the different activities of reflection. The Cronbach's alpha reliability of the fifteen-item scale in this questionnaire was .86, indicating that the scale had good reliability. The data regarding the usability (Section 7.1.1) and the usefulness (Section 7.1.2) of the V-class environment are discussed in the following sections.

\subsubsection{The usability of the V-class environment}

The usability section of this questionnaire consists of ten Likert-scale questions and aims to understand participants' satisfaction toward the ease of use of the Vclass environment. The participants had to score each of these ten questions on a five-point scale with the following values:

- $1=$ Not easy at all

- 2 = Slightly easy

- 3 = Easy to a some extent

- 4 = Easy

- 5 = Easy to a great extent

The questions of this section are presented in Table 7.1 together with the mean and the standard deviation scores of their answers. 
Table 7.1 The usability of the $V$-class environment $(N=16)$

\begin{tabular}{|c|c|c|c|}
\hline No & Question & Mean & $\begin{array}{l}\text { Standard } \\
\text { deviation }\end{array}$ \\
\hline 1 & $\begin{array}{l}\text { How would you rate the ease of use of the environment in } \\
\text { general }\end{array}$ & 4.31 & .87 \\
\hline 2 & How would you rate the ease of accessing the environment & 4.43 & .89 \\
\hline 3 & $\begin{array}{l}\text { How would you rate the ease of finding your way in the } \\
\text { environment }\end{array}$ & 4.68 & .47 \\
\hline 4 & $\begin{array}{l}\text { How would you rate the ease of submitting a reflection to the } \\
\text { environment }\end{array}$ & 4.62 & .88 \\
\hline 5 & $\begin{array}{l}\text { How would you rate the ease of submitting a feedback on } \\
\text { the environment }\end{array}$ & 4.62 & .88 \\
\hline 6 & $\begin{array}{l}\text { How would you rate the ease of finding a submitted material } \\
\text { in the environment }\end{array}$ & 4.62 & .50 \\
\hline 7 & $\begin{array}{l}\text { How would you rate the ease of uploading video clips to the } \\
\text { environment }\end{array}$ & 3.50 & 1.41 \\
\hline 8 & $\begin{array}{l}\text { How would you rate the ease of viewing video clips in the } \\
\text { environment }\end{array}$ & 4.37 & 1.08 \\
\hline 9 & $\begin{array}{l}\text { How would you rate the ease of communicating with your } \\
\text { colleagues through the environment }\end{array}$ & 4.81 & .40 \\
\hline 10 & $\begin{array}{l}\text { How would you rate the ease of communicating with your } \\
\text { supervisor through the environment }\end{array}$ & 4.87 & .34 \\
\hline
\end{tabular}

Based on the mean and standard deviation scores of the answers in this section, it can be interpreted that the majority of the participants consider the V-class an easy or even a very easy environment. Except for the answer to Question 7, the mean scores of the answers in this section were above four points and ranged between 4.31 and 4.87. The standard deviations also showed consistence regarding these answers with less than one point, and ranging between 0.34 and 0.89 for most answers except to Questions 7 and 8. Concerning question 7 where the mean score was 3.50, which still suggests that uploading the video clips to the environment was easy to some extent, the standard deviation score was 1.41 and that means a substantial spread in the answers. The answer to Question 8 showed a standard deviation score of 1.08. However, with a high score of the mean (4.37) answer to this question, it is still safe to assume that the majority of the participants consider viewing the video clips in the environment as easy to a certain level. It can be concluded in spite of the mean scores of Questions 7 and 8 that the responses to the questions of this section show a high level of satisfaction among the participants toward the usability of the V-class environment. 


\subsubsection{The usefulness of the V-class environment}

The second section of this questionnaire consists of five Likert-scale questions for expressing the participants' appreciation of the usefulness of the V-class environment in facilitating and supporting the different activities of reflection. The participants had to score each of these five questions on a five-point scale with the following values:

- $1=$ Not useful at all

- 2 = Slightly useful

- 3 = Useful to a some extent

- 4 = Useful

- 5 = Useful to a great extent

The questions, the mean, and the standard deviation scores of the answers in this section are presented in Table 7.2.

Table 7.2 The usefulness of the $V$-class environment $(N=16)$

\begin{tabular}{|llcc} 
No & $\begin{array}{l}\text { Question } \\
11\end{array}$ & $\begin{array}{l}\text { Mean } \\
\text { environment in facilitating the reflective practice activities in } \\
\text { general }\end{array}$ & $\begin{array}{c}\text { Standard } \\
\text { deviation }\end{array}$ \\
\hline 12 & $\begin{array}{l}\text { How would you rate the usefulness of the online } \\
\text { environment in facilitating the description activities }\end{array}$ & .61 \\
\hline 13 & $\begin{array}{l}\text { How would you rate the usefulness of the online } \\
\text { environment in facilitating the self reflection activities }\end{array}$ & 4.50 & .73 \\
\hline 14 & $\begin{array}{l}\text { How would you rate the usefulness of the online } \\
\text { environment in facilitating the peer reflection activities }\end{array}$ & 4.62 & .60 \\
\hline 15 & $\begin{array}{l}\text { How would you rate the usefulness of the online } \\
\text { environment in facilitating the finding alternatives activities }\end{array}$ & 4.56 & .62 \\
\hline
\end{tabular}

The mean scores of the answers that are presented in Table 7.2 were all above four points and ranged between 4.50 and 4.68. These scores suggest that the participants appreciate to a great extent the usefulness of the V-class environment in supporting and facilitating the different activities of reflection. This suggestion is supported by the scores of the standard deviation, which ranged between 0.60 and 0.73 , which shows strong consistence in the answers. 


\subsubsection{Summary of the results of the Effectiveness Questionnaire}

The result of the usability section in the Effectiveness Questionnaire supports the conclusion that the V-class environment was ease to use for carrying out the different activities of reflection. Even though the functionalities of uploading and viewing the video clips in the environment may not be as easy as the rest of the functionalities, they can be safely considered easy to use based on these results. Furthermore, the results of the second section showed extreme appreciation by the participants for the usefulness of the V-class environments regarding the facilitation and the support for the activities of reflection. For detailed statistics on the answers to this questionnaire, see Appendix 10.

To sum up, the results from both sections in this questionnaire suggest strongly that the participants consider the V-class environment as easy to use and at the same time very useful in supporting and facilitating the different activities of the reflective practice approach.

\subsection{PARTICIPANTS' INTERVIEW}

One of the major aims of the interview with the participants, as it was explained before in Chapter 5, is to collect information that supports and confirms the information that has been collected through the different questionnaires. This interview consists of either four or five parts dependent on the participants' group as it was described in Section 5.5.4. The fourth part of the two different interviews aims to collect information concerning the effectiveness of the V-class environment in supporting and facilitating the activities of reflection. This is assumed to provide the participants with an opportunity to elaborate on their responses to similar questions in the Effectiveness Questionnaire. This part of the interview consists of the following two major questions and their sub-questions:

- How would you evaluate the usability of the environment in general?

- In accessing the environment

- In finding your way

- In submitting material

- In finding material

- In uploading and viewing video

- In communicating with the others 
- How would you evaluate the usefulness of the environment in facilitating the activities of reflection?

- The activities of description

- The activities of self-reflection

- The activities of peer-reflection

- The activities of finding alternatives

The sub-questions were given to help the participants elaborate on their answers and cover all aspects of the experiment. The procedure for cross-case analysis that has been suggested by Miles and Huberman (1994) is used with the answers to these questions to order and to analyze these results. After, these results were contained in one matrix that is presented in Table 7.3. Based on the similarity of responses, several categories were created using quotes that were mentioned by most participants to fill in the entries in this table.

The results of the first question and the follow up questions show a general agreement among the participants on the ease of use of the V-class environment. Yet, some complaints were mentioned by the participants concerning some of the environment's functionalities. A serious complaint that was stated by more than half of the participants concerned the activities of uploading their video clips into the environment. Those participants argued that the procedure to upload the video clips into the environment was a bit complicated along with other limitations and requirements in this activity such as the size and the length of the clip. Another complaint from some participants concerned the navigation within the environment where it was difficult for them to find their way at the beginning. However, most of them explained that this problem gradually faded during the experiment as they grew familiar with this new environment. Some participants also complained that they lost their comments repeatedly during the publishing activities. This problem, in fact, occurred only during the first competency in the experiment and was avoided later by removing the punctuation marks from the text as advised by the environment's technical support staff. Three of the participants did criticize that the first page and some of the help information in the V-class environment was only in the Dutch language and they were not able to read this information. 
Table 7.3 Participants' responses to the questions of the fourth part of the interview $(N=16)$

\begin{tabular}{|c|c|c|}
\hline 䒕 & The effectiveness of the online environment in facilitating the refl & ction activities \\
\hline 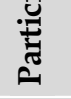 & The usability of the environment & $\begin{array}{l}\text { The usefulness of the } \\
\text { environment }\end{array}$ \\
\hline 1 & - Very easy except for when I lost what I wrote & - Very useful \\
\hline 2 & - Very easy except for when I lost what I wrote & - Very useful \\
\hline 3 & - Very easy except for uploading the video clips & - Very useful \\
\hline 4 & $\begin{array}{l}\text { - Easy except for the Dutch language and uploading the video } \\
\text { clips }\end{array}$ & - Useful \\
\hline 5 & $\begin{array}{l}\text { Easy except for when I lost what I wrote and uploading the } \\
\text { video clips }\end{array}$ & - Very useful \\
\hline 6 & - Very easy except for uploading the video clips & - Useful \\
\hline 7 & $\begin{array}{l}\text { - Easy except for the Dutch language, finding my way in the } \\
\text { system at the beginning and uploading the video clips }\end{array}$ & - Very useful \\
\hline 8 & $\begin{array}{l}\text { - Very easy except for the Dutch language, finding my way in the } \\
\text { system at the beginning }\end{array}$ & - Very useful \\
\hline 9 & - Easy except for when I lost what I wrote & - Very useful \\
\hline 10 & - Very easy & - Very useful \\
\hline 11 & - Easy except for uploading the video clips & - Useful \\
\hline 12 & $\begin{array}{l}\text { - Easy except for finding my way in the system at the beginning, } \\
\text { uploading the video clips and when I lose what I wrote }\end{array}$ & - Useful \\
\hline 13 & $\begin{array}{l}\text { Easy except for finding my way in the system at the beginning } \\
\text { and uploading the video clips }\end{array}$ & - Very useful \\
\hline 14 & - Very easy except for uploading the video clips & - Very useful \\
\hline 15 & - Not easy at the beginning but with practice it is easy now & - Very useful \\
\hline 16 & $\begin{array}{l}\text { - Very easy except for finding my way in the system at the } \\
\text { beginning }\end{array}$ & - Very useful \\
\hline
\end{tabular}

In their responses to the second question and the follow up questions regarding the usefulness of the $\mathrm{V}$-class environment in facilitating reflection, all participants without exception agreed that the environment was useful for supporting and facilitating the different activities of reflection.

It can be seen based on the results of this part of the interview that the participants consider the V-class environment usable as tool for supporting and facilitating reflection although some difficulties were stated. Yet, even with the complaints described regarding the ease of use of the environment, all participants agreed that this environment is a very useful tool for their practice. Therefore, regarding the effectiveness of the V-class environment in general, it can be safely assumed that this environment is both usable and useful for practicing the activities of reflection. 


\subsection{DISCUSSION}

This chapter serves the purpose of finding an answer to RQ5 by presenting, comparing, and discussing the information collected during the field experiment regarding the effectiveness of the $\mathrm{V}$-class environment. The results from the Effectiveness Questionnaire (Section 7.1) and the results from the participants' interview (Section 7.2) are compared here in Section 7.3.1 to confirm these results. Section 7.3.2 then discusses these results in relationship to RQ5 in order to formulate an answer to this question.

\subsubsection{Results comparison}

To confirm the results from the Effectiveness Questionnaire regarding the usability and the usefulness of the V-class environment in facilitating the reflective practice approach, similar questions were asked as a part of the participants' interview.

The results from the questionnaire regarding the usability of the environment showed that the V-class is considered a useable environment in general. However, the response to Question 7 concerning the activities of uploading the video clips in the environment suggested that this functionality was more difficult than the other functionalities; yet, it was still considered by the participants as easy to use. In the interview, the participants described in more detail their perspective toward the usability of the V-class environments and stated three other complaints in addition to the complaint about the difficulty of uploading and viewing the video clips in the environment. First, it was difficult for some of them at the beginning to find their way in the environment. Second, it was frustrating for them to lose repeatedly their comments during the publishing activity. Finally, the first page of the V-class environment was in the Dutch language only and that caused some difficulties for the participants. Nevertheless, the participants asserted that these difficulties were mostly encountered only at the beginning of the experiment.

The results from the questionnaire regarding the usefulness of the V-class environment in facilitating the reflection activities were highly positive and these results were supported strongly by the results from the interview as it was described by the participants. 


\subsubsection{Effectiveness of the V-class environment}

Studying the opportunities of ICT and specifically the online video-based learning environments in Chapter 3 showed many advantages that these environments could provide for the practice of reflection. In order to evaluate such intervention, two major factors that are expected to determine the effectiveness of the online video-based learning environment for our research were investigated during the field experiment. The usability of an ICT application is considered an essential requirement for successful utilization of this application. Understanding participants' appreciation of the ease of use of the V-class environment, therefore, is assumed to provide a strong indicator of the effectiveness of this environment. Furthermore, the degree of support the Vclass environment provided to the participants during their reflection practice and the usefulness of this support is also considered another strong indicator of the effectiveness of the online environment.

There were no reservations among the participants toward the usefulness of the V-class environment as all of them showed high appreciation of the support that this environment provided for practicing their reflection activities. On the other hand, four complaints were expressed by the participants regarding the usability of the V-class environment. Actually, these four difficulties are related to using new, yet unfamiliar, equipment and applications and they gradually faded as the experiment unfolded. Furthermore, even with the presence of these difficulties, the participants asserted that it was still easy to operate the V-class environment. Therefore, it is safe to assume that any of the presented difficulties can possibly be avoided through several alternatives or solutions. Modifying the V-class environment, providing the users with additional explanations and practices regarding the use of this environment, or even developing another new environment are all examples of actions that can be taken to avoid any difficulties in the future concerning the usability. The significant fact here is that the environment showed promising roles in supporting the practice of reflection. It is important to point out here that even though some of the participants had some reservations and complaints toward the usability of the V-class environment, a general agreement among all participants without exception was shown toward the usefulness of this environment for supporting the practice of reflection.

To take this discussion beyond the boundary of our experiment, the difference between the usability and the usefulness factors must be identified here. While the results from investigating the usability of an environment are indeed valuable indicators in evaluating this environment, the results from investigating the 
usefulness, in fact, go beyond evaluating this specific environment. These results are indicators to evaluate the usefulness of the online video-based learning environments in general for supporting the reflective practice approach. In other words and in relationship to our experiment, the results of the usability investigation are, in fact, exclusive to the use of the V-class environment while the results of the usefulness investigation concern the use of the online video-based learning environments to support the reflective practice approach, in general. To conclude, assembling the findings from the usability and the usefulness investigations in our experiment shows promising effects from the V-class environment on carrying out the activities of reflection. These results correspond and confirm the findings in other studies that were discussed in Chapter 3 regarding the added value from using video and the Internet to support learning and particularly to support the reflective reflection approach (Cannings \& Talley, 2002; Schrader et al., 2003; Kulk et al., 2005; Eilam \& Poyas, 2006; Admiraal et al., 2008; Leijen, Lam, Wildschut, Simons \& Admiraal, 2009).

Thus, based on the information that has been presented in this chapter, it can be confidently stated here as an answer to RQ5 that the use of the online videobased learning environment indeed provides valuable support for the participants in our experiment to carry out the different activities of reflection. Yet, the discussion that is presented in this chapter and particularly the discussion of the alternatives that may improve the usability of the V-class environment must be explained further. Therefore, a further elaboration on the information that is presented in this chapter together with the other findings in this research will be presented in Chapter 9. 


\section{CHAPTER 8 Reflection and learning achievement}

The ultimate goal of this study is to improve the practice of field training in the teacher education programs in Kuwait in order to reduce the gap between theory and practice. To evaluate the success in accomplishing this goal, users' satisfaction with the process of learning and the achievements made during the implementation of such intervention are considered two strong indications for this evaluation. RQ6 in this study, therefore, was formulated in Section 1.5 as follows:

RQ6: Will the use of reflection supported by the online video-based learning environment in field training facilitate the learning process and improve learners' achievement in the teacher education programs in Kuwait?

This chapter will present, compare, and discuss the data that have been collected during the experiment in relationship to the process of learning and learners' achievement. Section 8.1 presents the data that have been collected from the Achievement Questionnaire. Furthermore, the data that have been collected from the interviews with the participants (Section 8.2) and the data that have been collected from the interviews with the supervisors (Section 8.3) will be presented in this chapter. Comparison and discussion of the different results will be made in Section 8.4.

\subsection{ACHIEVEMENT QUESTIONNAIRE}

The Achievement Questionnaire consists of ten questions that are divided into two sections. The aim of this questionnaire is to understand the effect of practicing the reflection activities on participants' learning achievement. Particularly, this questionnaire focused on two main aspects: (a) the effect of reflection on the

relationship between theory and practice and (b) the effect of reflection on the ability of the participants to master the practiced competences. Four activities of 
reflection were targeted in this section: the activities of description, self-reflection, peer-reflection, and finding alternatives. The Cronbach's alpha reliability of the ten Likert-type items in this questionnaire was .80, indicating that the scale had good reliability. The participants had to score each of these ten questions on a fivepoint scale with the following values:

- $1=$ Not effective at all

- 2 = Slightly effective

- 3 = Effective to a some extent

- 4 = Effective

- 5 = Effective to a great extent

\subsubsection{Effect on connecting theory and practice}

The first section of this questionnaire consists of five questions and aims to understand the effect of the reflective practice on the relationship between theory and practice. The questions of this section and the mean and standard deviation scores of the answers are presented in Table 8.1.

Table 8.1 The effect of the reflection in connecting theory to practice $(N=16)$

\begin{tabular}{|c|c|c|c|}
\hline No & Question & Mean & $\begin{array}{l}\text { Standard } \\
\text { deviation }\end{array}$ \\
\hline 1 & $\begin{array}{l}\text { How would you rate the effectiveness of practicing the reflection, } \\
\text { in general, on increasing your understanding of the theoretical } \\
\text { concept behind the practiced competences? }\end{array}$ & 4.37 & .61 \\
\hline 2 & $\begin{array}{l}\text { How would you rate the effectiveness of describing your } \\
\text { performance on increasing your understanding of the theoretical } \\
\text { concept behind the practiced competences? }\end{array}$ & 4.18 & .75 \\
\hline 3 & $\begin{array}{l}\text { How would you rate the effectiveness of reflecting on your own } \\
\text { performance on increasing your understanding of the theoretical } \\
\text { concept behind the practiced competences? }\end{array}$ & 4.12 & .80 \\
\hline 4 & $\begin{array}{l}\text { How would you rate the effectiveness of reflecting on your peers' } \\
\text { performance on increasing your understanding of the theoretical } \\
\text { concept behind the practiced competences? }\end{array}$ & 4.56 & .62 \\
\hline 5 & $\begin{array}{l}\text { How would you rate the effectiveness of reassessing your perfor- } \\
\text { mance after the self and peer reflection on increasing your under- } \\
\text { standing of the theoretical concept behind the practiced competences? }\end{array}$ & 4.62 & .61 \\
\hline
\end{tabular}

The data in Table 8.1 demonstrate a substantially positive perspective from the participants toward the effect of the different activities of reflection on connecting the practiced competences with their theoretical concepts. The mean scores of all answers in this section were higher than four points and ranged between 4.12 and 4.62 , which suggest that the participants consider reflection as effective to a 
great extent. Furthermore, the standard deviations of these answers ranged from between 0.61 and 0.80 and that shows consistence in these answers and support our previous assumption.

\subsubsection{Effect on mastering the practiced competences}

The second section of this questionnaire also consists of five questions and concerns the effect of the activities of reflection on the ability of the participants in mastering the practiced competences. Table 8.2 presents the questions of this section and the mean and standard deviation scores to the answers.

With a mean score of 4.31 and standard deviation of 0.60 in Question 6, it can be interpreted that the participants showed very positive attitude toward the effect of reflection on the practiced competences. This interpretation can be also true regarding the activities of description, self-reflection, and peer-reflection where the mean scores of Questions 7, 8, and 9 were above four points. However, while the standard deviations of Questions 7 and 9 were 0.83 , the standard deviation of Question 8 was 1.18, which suggests a bigger spread in the answers of this question than those of Questions 7 and 9. Moreover, the response to Question 10 showed a lower mean score compared with other questions with 3.87 and 1.20 for the standard deviation. Even with this score, the response to this question still shows positive attitude toward the effect of reflection.

Table 8.2 The effect of the reflection in mastering the required competences $(N=16)$

\begin{tabular}{|llcc}
\hline No & Question & Mean & $\begin{array}{l}\text { Standard } \\
\text { deviation }\end{array}$ \\
\hline 6 & $\begin{array}{l}\text { How would you rate the effectiveness of practicing the } \\
\text { reflection, in general, on helping you in mastering the practiced } \\
\text { competences? }\end{array}$ & 4.31 & .60 \\
\hline 7 & $\begin{array}{l}\text { How would you rate the effectiveness of practicing the } \\
\text { description activities on helping you in mastering the practiced } \\
\text { competences? }\end{array}$ & 4.18 & .83 \\
\hline 8 & $\begin{array}{l}\text { How would you rate the effectiveness of practicing the self- } \\
\text { reflection activities on helping you in mastering the practiced } \\
\text { competences? }\end{array}$ & 4.06 & 1.18 \\
\hline 9 & $\begin{array}{l}\text { How would you rate the effectiveness of practicing the peer- } \\
\text { reflection activities on helping you in mastering the practiced } \\
\text { competences? }\end{array}$ & 4.18 & .83 \\
\hline 10 & $\begin{array}{l}\text { How would you rate the effectiveness of practicing the finding } \\
\text { alternatives activities on helping you in mastering the practiced } \\
\text { competences? }\end{array}$ & 3.87 & 1.20 \\
\hline
\end{tabular}




\subsubsection{Summary of the results of the Achievement Questionnaire}

The results of the first section of the Achievement Questionnaire asserted without a doubt that the participants consider the use of the reflective practice approach supported by the online environment to increase their understanding of the theoretical concepts behind the practiced competences as an effective approach to a great extent. The same conclusion can also be drawn in relationship to the second section of this questionnaire where the results showed that the participants consider the influence of this intervention on mastering the practiced competences as also effective to a great extent.

Considering that the questions of the two sections were formulated similarly (e.g. $1=6,2=7$ ) to understand the effect of the different activities of reflection on theory and on practice, a comparison between the responses to each activity of these two sections is applicable here. Based on this comparison, it can be stated that the response to the first four questions in each section were greatly similar. However, a small but maybe significant difference can be found between the response to Question 5 with a mean score of 4.62 and the response to Question 10 with a mean score of 3.87. Both Questions 5 and 10 concern the effect of the activities for finding alternatives. The results of these two questions show that even though the participants consider finding alternatives an effective activity for improving their practice of the competency (Question 10), higher appreciation was given by the participants to the effect from the activity of finding alternatives on increasing their understanding of the theoretical concepts behind the practiced competences. For detailed statistics on the answers to this questionnaire, see Appendix 11.

A general conclusion that can be drawn from the results of the Achievement Questionnaire is that the effect of the activities of reflection on both the relationship with theory and with the practice of the competences was highly appreciated by the participants.

\subsection{PARTICIPANTS' INTERVIEW}

As it has been presented in Section 5.5.4, the aim of the interview is to collect information that supports and confirms the information that has been collected in the different questionnaires. It is assumed that by providing the participants with 
opportunity to elaborate on their perspectives in the interviews, information that is more thoughtful would be collected. Furthermore, the interview with the participants from groups 1 and 3 here aims also to collect information related to the differences between practicing the field training with and without the reflection supported by the $\mathrm{V}$-class environment. The interview, therefore, was divided into four sections for all participants in order to reflect the different questionnaires. Moreover, two additional questions in the general section and a fifth section were only added to the interview with the participants from groups 1 and 3. In Chapters 6 and 7, the sections concerning the difficulties in the reflection and the effectiveness of the $\mathrm{V}$-class environment were presented and discussed. The rest of the interview is presented in this section including the sections that discuss the general impression about the experiment, the pedagogical influence of reflection, and the additional questions to groups 1 and 3.

The procedure for cross-case analysis suggested by Miles and Huberman (1994), which has been explained in Chapter 6, was used with the questions of these sections as well to order and to analyze the data. Four partially ordered data displays produced by this procedure will be used in this section to present the participants' responses. The information that was collected in the general section is presented in Section 8.2.1 and the information concerning the pedagogical influence of the reflection is presented in Section 8.2.2. Section 8.2.3 presents the information that is related to the additional questions for groups 1 and 3 . These results are then summarized in Section 8.2.4.

\subsubsection{General questions}

In this section of the interview with the participants, three general questions concerning participants' experiences and the influence of this field experiment on their professional development were asked.

- What is your general impression about this experiment?

- How would you describe your experience with the reflective practice approach in this field-training course?

- At the end of the field training, do you feel that the reflection skills can help you later as a teacher? If so, how? Please give an example

These were general questions and a variety of answers was expected. Therefore, the use of direct quotes or a summary of participant's answers is considered the most appropriate approach for displaying the data here. 
Table 8.3 presents participants' responses to the first question in this section. It can be seen from the response that the experiment left a positive impression on those participants. They used several expressions such as unique, fun, exciting, organized, new, and enjoyable to describe their impressions about this experience. In addition, some comments such as "I wished if it was longer", "The use of technology increased the excitement", and "It broke the traditional course routine", all show great appreciation for this experience. Nevertheless, the participants also expressed some concerns. The difficulties in practicing the recording activities indeed left negative impressions on one of the participants while another participant was worried at the beginning about the use of the different applications of new technology.

Table 8.3 Participants' response to the first question of this section $(N=16)$

\begin{tabular}{|c|c|}
\hline $\begin{array}{l}\text { Е } \\
\text { ٌ }\end{array}$ & The general section \\
\hline تָ & What is your general impression about this experiment? \\
\hline 1 & - Useful experience and I learned a lot by participating \\
\hline 2 & - Unique and useful experience and I wished it was longer \\
\hline 3 & - Useful experience to watch myself and it helped me improve my performance \\
\hline 4 & - It was a nice experience, useful but also fun. \\
\hline 5 & - Exciting experience and I learned many new things \\
\hline 6 & - Useful experience and many things to learn \\
\hline 7 & - It was organized and the use of technology increased the excitement \\
\hline 8 & - Nice experience but the recording was difficult \\
\hline 9 & - I didn't like watching myself on video \\
\hline 10 & $\begin{array}{l}\text { - I was worried at the beginning about all these technologies but it is fun, I am happy I } \\
\text { joined }\end{array}$ \\
\hline 11 & - New and useful experience \\
\hline 12 & - Useful and enjoyable experience \\
\hline 13 & - The intensive use of technology made me feel that I am really at the university level \\
\hline 14 & - New, useful, and fun experience that made me learn many things about myself \\
\hline 15 & - It was a useful experience \\
\hline 16 & - It was an enjoyable and organized experience and it broke the routine of this course \\
\hline
\end{tabular}

The general impression about the experiment, as the response shows, can be described as positive as the participants consider it a useful and meaningful experience. Furthermore, based on some of the repeatedly used expressions by the participants such as fun, enjoyable, and exciting, an unexpected effect from using technology applications to support reflection in our experiment can be seen as combining learning with joy. The involvement of several new activities in relation 
to the use of technology had an influence on the way in which the field training is normally carried out. As a result, the participants enjoyed breaking the routine of this course and felt excited carrying out these new activities. Highlighting the enjoyment as an important factor here raises the possibility of the novelty effect. This possible effect will be discussed in Chapter 9 in relation to other findings.

The participants were asked in the second question to describe their experience with practicing reflection and the response to this question is presented in Table 8.4. The results show another positive response from the participants regarding the experience with the reflective practice approach. In general, all participants appreciated this experience. However, when they were asked about each activity separately, their answers were varied in respect to the activities that they seem to consider the most influential. As a completely new experience, self-reflection was the most appreciated activity by the participants.

Table 8.4 Participants' response to the second question of this section $(N=16)$

\begin{tabular}{|c|c|}
\hline $\begin{array}{l}\ddot{\Xi} \\
\text { こ }\end{array}$ & The general section \\
\hline صُ & $\begin{array}{c}\text { How would you describe your experience with the reflective practice approach } \\
\text { in this field-training course? }\end{array}$ \\
\hline 1 & - Helped me improve my performance and prepared me to be a good teacher \\
\hline 2 & - Difficult to reflect on myself because of the required skills for such activity \\
\hline 3 & - I learned that the most important evaluation is the evaluation of a person for himself \\
\hline 4 & - Not easy to practice the reflection, it needs high skill level \\
\hline 5 & $\begin{array}{l}\text { - Supervisor's reflection improved my performance and self-reflection is now part of } \\
\text { me }\end{array}$ \\
\hline 6 & - Self reflection was new for me, it was very useful \\
\hline 7 & - Helped me improve my performance strongly \\
\hline 8 & - Looking to my peers' experiences was beneficial \\
\hline 9 & - It was a new useful method \\
\hline 10 & - I didn't think I was able to evaluate my peers but now I have the confidence to do it \\
\hline 11 & - I learned how to evaluate and criticize myself and others \\
\hline 12 & - The reflection provided us with remarks and useful information, not only grades \\
\hline 13 & - Provided me the chance to evaluate myself and helped me avoid face to face critiques \\
\hline 14 & - Reflecting on myself and my peers were difficult, but I enjoyed receiving feedback \\
\hline 15 & - I learned a lot from watching myself and reflecting on my video \\
\hline 16 & - Learned how to see both my and my peers' weaknesses and strengths \\
\hline
\end{tabular}

In addition, the participants also valued several other reflection activities such as receiving remarks and comments as opposed to only grades, avoiding face-to- 
face critiques, learning how to evaluate, and acquiring confidence in evaluating themselves and others. Nevertheless, two participants consider reflection a difficult approach that requires high-level skills.

The participants were also asked in this section about the expected influence from acquiring the different activities of reflection on their identity as teachers in the future. Table 8.5 presents participants' response to this question.

Table 8.5 Participants' response to the third question of this section $(N=16)$

\begin{tabular}{|c|c|}
\hline$\vec{\Xi}$ & The general section \\
\hline בै & At the end of the field training, do you feel that the reflection skills can help you later as a teacher? \\
\hline 1 & - Yes, will help improving my performance in several areas \\
\hline 2 & - Yes, almost all skills we learned will be useful for the future \\
\hline 3 & - Yes, especially the self and peer reflection but less frequently than now \\
\hline 4 & - Difficult to record but reflection can be done by visiting each others' classes \\
\hline 5 & $\begin{array}{l}\text { - Record and self reflect from time to time but difficult to practice peer reflection at } \\
\text { work }\end{array}$ \\
\hline 6 & - Yes, planning to continue practicing these activities \\
\hline 7 & - Yes, the recording and self reflection \\
\hline 8 & - Yes, especially the self reflection \\
\hline 9 & - Not sure how it will affect me in the future \\
\hline 10 & $\begin{array}{l}\text { - Yes, I have the confidence in myself now and I feel I can evaluates myself and my } \\
\text { peers }\end{array}$ \\
\hline 11 & $\begin{array}{l}\text { - Yes, to improve my performance frequently and I am now more open for accepting } \\
\text { criticism }\end{array}$ \\
\hline 12 & - Yes, I have the confidence now to evaluate myself and my peers \\
\hline 13 & $\begin{array}{l}\text { - Yes, my self reflection now is more efficient and I feel confidence to ask others for } \\
\text { feedback }\end{array}$ \\
\hline 14 & - Yes, I am able to see now the weaknesses in the performance not only the strengths \\
\hline 15 & - I will criticize my peers in the workplace later without feeling guilty \\
\hline 16 & - I will criticize myself in the future but not give feedback to others \\
\hline
\end{tabular}

After evaluating reflection as an effective approach to improve the performance in the workplace by the participants, it seems that most of them were planning to use this approach later when they start working as teachers. Different perspectives were presented by the participants toward the use of reflection as teachers. Some of them were planning to use only a single type of reflection such as self-reflection or peer-reflection while others were planning to use a combination of different reflection activities. Furthermore, one of the participants 
indicated that the recording might cause a problem with the school administration and another participant was not sure about the way that the reflection could be carried out in the workplace. Based on their examples the rest of the participants seem to have a plan to use the reflective practice activities in a specific way.

To sum up, the results of the general section in the interview show that the impression of this experiment on almost all participants was positive and they appreciated greatly this experience with the reflective practice approach. Most of the participants, therefore, are planning to use some kind of reflection activities in their future workplace in order to improve their performance.

\subsubsection{The pedagogical influence of the reflection activities}

The second section of the participants' interview concerns the pedagogical influence of the reflective practice approach on the learning achievements of the participants. The questions of this section are asked here to provide the participants an opportunity to elaborate on their response in relation to similar questions that have been asked in the Achievement Questionnaire. Two questions are asked here regarding the influence of practicing reflection on their understanding of the theories behind the practiced competencies and on their ability to perform this competency:

- What influence does the reflective practice have on your understanding of the imbedded theory behind the practiced skill?

- What influence does the reflective practice have on your ability to master the practiced skill?

Participants' responses to the questions in this section are presented in Table 8.6, using both phrases and quotes from the participants to fill in the entries in this table in a readable manner.

The response to the first question shows a positive perspective from the participants toward the influence of the different activities of reflection on their understanding of the theories that relate to their practice. Almost half of the participants connected this positive influence to the practice of reflection in

general while others specified certain activities or factors that stimulated the relationship between theory and practice. 
Table 8.6 Participants' response to the questions of this section $(N=16)$

\begin{tabular}{|c|c|c|}
\hline \multirow{2}{*}{ 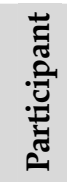 } & \multicolumn{2}{|c|}{ The pedagogical influence of the reflective practice method on learners' achievement } \\
\hline & $\begin{array}{l}\text { The influence on understanding } \\
\text { the theory behind the practiced skill }\end{array}$ & The influence on mastering the practiced skill \\
\hline 1 & $\begin{array}{l}\text { When several opinions come together, } \\
\text { theory will be connected to practice more } \\
\text { strongly }\end{array}$ & $\begin{array}{l}\text { Especially when I watch and reflect on my } \\
\text { self }\end{array}$ \\
\hline 2 & $\begin{array}{l}\text { The supervisor usually explains our } \\
\text { strengths and weaknesses based on the } \\
\text { theories }\end{array}$ & $\begin{array}{l}\text { The practice of a skill was improved by } \\
\text { understanding views and practices of others }\end{array}$ \\
\hline 3 & $\begin{array}{l}\text { The reflection reminded us of forgotten } \\
\text { theories in addition to introducing new } \\
\text { theories }\end{array}$ & $\begin{array}{l}\text { Others' feedback helped me avoid my } \\
\text { mistakes and watching others' performance } \\
\text { gave me new ideas }\end{array}$ \\
\hline 4 & $\begin{array}{l}\text { The group reflection was an effective } \\
\text { method in connecting theory to the } \\
\text { practiced skill }\end{array}$ & $\begin{array}{l}\text { During my teaching now, I am always } \\
\text { aware of the feedback that I received about } \\
\text { the practiced skill }\end{array}$ \\
\hline 5 & $\begin{array}{l}\text { I connect theories to my practice based on } \\
\text { supervisor's explanations about the strengths } \\
\text { and weaknesses of my performance }\end{array}$ & $\begin{array}{l}\text { The good feedback I received maintains and } \\
\text { stabilizes my performance }\end{array}$ \\
\hline 6 & Positive & $\begin{array}{l}\text { Now I am always recalling the feedback } \\
\text { about my practice during my teaching }\end{array}$ \\
\hline 7 & $\begin{array}{l}\text { I understood now clearly some of the } \\
\text { theories that I had learned before only after } \\
\text { connecting it with my practice }\end{array}$ & $\begin{array}{l}\text { Now I know my strengths and weaknesses } \\
\text { which makes me focus on what I am good at }\end{array}$ \\
\hline 8 & Positive & $\begin{array}{l}\text { When I watch myself I see things that I } \\
\text { wasn't aware of at the class }\end{array}$ \\
\hline 9 & $\begin{array}{l}\text { The supervisor feedback provides rich } \\
\text { theoretical explanation that helps } \\
\text { connecting theory to practice }\end{array}$ & $\begin{array}{l}\text { I think it has positive influence but since I } \\
\text { didn't try yet to re-perform the same } \\
\text { activities I can't be sure }\end{array}$ \\
\hline 10 & $\begin{array}{l}\text { Brings together several understandings to } \\
\text { same theory and applied it to the practiced } \\
\text { skill }\end{array}$ & $\begin{array}{l}\text { Understanding the theory correctly helped } \\
\text { me master the skill }\end{array}$ \\
\hline 11 & Positive & Positive \\
\hline 12 & Positive & $\begin{array}{l}\text { The experience of watching my } \\
\text { performance was very useful }\end{array}$ \\
\hline 13 & $\begin{array}{l}\text { Mostly the feedback from the supervisor } \\
\text { that connects theory to the practiced skill }\end{array}$ & $\begin{array}{l}\text { Being aware of the feedback of my } \\
\text { performance helps me avoid the same } \\
\text { mistakes }\end{array}$ \\
\hline 14 & Positive & $\begin{array}{l}\text { I will avoid the mistakes that I made and } \\
\text { those I saw my peers do }\end{array}$ \\
\hline 15 & $\begin{array}{l}\text { Most of the feedback plays the role of } \\
\text { connecting theory to the practiced skills }\end{array}$ & $\begin{array}{l}\text { Planning again how to practice the skill after } \\
\text { watching myself and the feedback is an } \\
\text { improvement in and of itself }\end{array}$ \\
\hline 16 & $\begin{array}{l}\text { I used to practice without awareness of any } \\
\text { theory, but the feedback made me connect } \\
\text { my performance with the discussed theory }\end{array}$ & $\begin{array}{l}\text { By watching my performance, I noticed } \\
\text { things that I have to avoid. The feedback } \\
\text { highlighted other things that have to be } \\
\text { changed }\end{array}$ \\
\hline
\end{tabular}


A major factor in the reflection approach that connects theory to practice as described by several participants is the feedback in general and supervisors' feedback in particular. Furthermore, some of the participants also described the exchange of perspectives among the participants regarding specific situations and the group reflection session conducted at the end of the experiment as other activities that played an important role in connecting theory to practice.

Similar to the first question, participants' responses to the second question in this section were also positive. However, the participants were more precise here compared with their response to the first question about the activities that supported them in mastering the practiced competences. The participants consider the activities of reflecting on their own performance and the feedback that they received from their peers and supervisors as the major factors that helped them improve their performance. In addition, reflecting on their peers' performances is also described by some participants as an activity that helped them see the strengths and the weaknesses of those performances.

To conclude, it can be stated here that the participants consider reflection as an influential approach for both connecting theories and practice as well as for mastering the practiced competences. The feedback, however, was described as the most influential factor in both inquiries. Furthermore, the activities of selfreflection were also described as an important factor that influences participants' ability to master the practiced competence.

\subsubsection{Additional questions (Groups 1 and 3)}

It was explained in Chapter 5 that the participants of Groups 1 and 3 were treated similarly to the participants of Groups 2 and 4 regarding the first two competences; however, Groups 1 and 3 were asked to practice the third competence in the traditional way without the use of the reflective practice or the online environment. The response to the additional questions in this section of the interview that were asked of the participants of Groups 1 and 3 will be presented here. The aim of these questions is to collect information related to the differences between practicing field training with and without the reflective practice and the V-class environment. Two general questions were added to the first section of the interview and a fifth section was also added at the end of the interview. The two questions that were asked in the general section were as follows: 
- How would you describe your experience without the reflective practice approach at the second part of the field training course?

- If you have been asked to choose between practicing field training with or without reflection, what would you choose?

Participants' response to these two questions is presented in Table 8.7 and the entries of this table were formulated based on the most mentioned phrases by those participants.

Table 8.7 Participants' responses on the additional questions of the first section of the interview $(N=8)$

\begin{tabular}{|lll|}
\hline \multicolumn{2}{|c|}{ General questions Groups $\mathbf{1}$ and 3} \\
\hline 1 & I wished to continue with the reflection activities & $\begin{array}{l}\text { The choice between practicing field } \\
\text { training with and without reflection }\end{array}$ \\
\hline 2 & I learned more with reflection & With reflection \\
\hline 3 & Almost the same & With reflection \\
\hline 4 & I wished to continue with the reflection activities & With reflection \\
\hline 9 & I wished to continue with the reflection activities & With reflection \\
\hline 10 & $\begin{array}{l}\text { The reflection was more effective comparing with } \\
\text { the traditional training }\end{array}$ & With reflection \\
\hline 11 & Almost the same & With reflection \\
\hline 12 & I learned more with reflection & With reflection \\
\hline
\end{tabular}

Describing their experiences in the field training course without the activities of reflection, the majority of the participants favored working with reflection. They argued that learning through reflection was more beneficial regarding their learning achievement. Nevertheless, some of the participants asserted that practicing without reflection in the second part of the semester was almost similar to their practice with reflection in the first part. The reason for this similarity as described by some of these participants is that the major knowledge and skills of reflection are already possessed by the participants, which were gained during the first part of the semester. Therefore, the essence of reflection was also applied in the second part of the semester by some of those participants.

There was no hesitation among the participants about the choice of practicing the field training course with or without the reflection activities. All of the participants without exception selected to practice the field training with 
reflection. They emphasized that even though it may require more time and effort the benefits from this practice will certainly be worth it.

A fifth section consists of five questions that were added to the interview with the participants from Groups 1 and 3 as has been explained before. The focus of this section is on comparing the practice of the field training with and without the activities of reflection to understand participants' preferences between these two approaches. The questions that were asked in this section were as follows:

- By experiencing both the practice of field training with and without the reflection activities, which method provided you with more experience?

- By experiencing both the practice of field training with and without the reflection activities, which method required more time and effort from you?

- In comparison between the period with reflection activities (the first part of the semester) and the period without reflection activities (the second part of the semester), where do you find a stronger presence of theory?

- During the practice of field training without reflection at the second part of the semester, were there any reflection activities you continued to use?

- At the second part of the semester when you were practicing field training without reflection, were there any reflection activities you wished to continue using?

The first three questions in this section aim to compare the practice of field training with and without reflection in relation to time, effort, and presence of theory. Participants' response to these three questions is presented in Table 8.8. As it shows in this table, all participants agreed that practicing field training with the activities of reflection provided them with more teaching and training experiences than without the activities of reflection. Furthermore, the majority of the participants asserted that practicing field training with reflection required more time and effort from them especially at the beginning. However, two of these participants disagreed with this opinion and felt that the practice of field training without the activities of reflection required rather more time and effort. They explained that the flexibility provided by practicing field training with reflection saved some of their time and effort. With respect to the presence of theories, five of the eight participants think that the activities of reflection stimulate more attention to theories while the other three participants believed that theories were present with and without reflection. However, not one of the participants thinks that the presence of theories was higher when practicing field training without the activities of reflection. 
Table 8.8 Participants' response to the first three questions in the additional section of the interview for Groups 1 and $3(N=8)$

\begin{tabular}{|c|c|c|c|c|c|c|c|c|c|}
\hline \multirow[b]{3}{*}{ 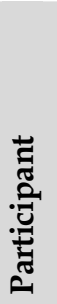 } & \multicolumn{9}{|c|}{$\begin{array}{l}\text { Practicing field training with and without the reflective practice approach } \\
\text { Groups } 1 \text { and } 3\end{array}$} \\
\hline & \multicolumn{3}{|c|}{ Provides more experience } & \multicolumn{3}{|c|}{ Requires more time and effort } & \multicolumn{3}{|c|}{ Stronger presence of theory } \\
\hline & 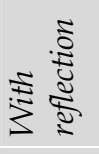 & 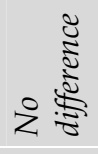 & 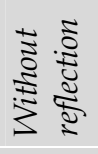 & 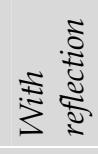 & 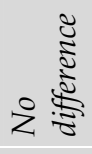 & 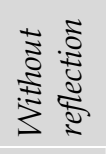 & 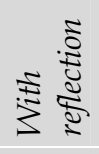 & 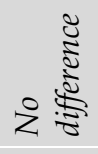 & 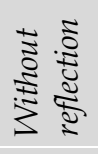 \\
\hline 1 & $x$ & & & $X$ & & & $x$ & & \\
\hline 2 & $x$ & & & $x$ & & & $x$ & & \\
\hline 3 & $x$ & & & $x$ & & & & $X$ & \\
\hline 4 & $x$ & & & $x$ & & & $x$ & & \\
\hline 9 & $x$ & & & $x$ & & & $x$ & & \\
\hline 10 & $x$ & & & $x$ & & & & $x$ & \\
\hline 11 & $x$ & & & & & $x$ & & $x$ & \\
\hline 12 & $x$ & & & & & $x$ & $x$ & & \\
\hline
\end{tabular}

Participants' response to the last two questions in this section is presented in Table 8.9 and the entries of this table were formulated based on the main activities of reflection.

Table 8.9 Participants' response to questions four and five in the additional section of the interview for Groups 1 and $3(N=8)$

\begin{tabular}{|c|c|c|c|c|c|c|c|c|c|c|}
\hline \multirow[b]{3}{*}{ 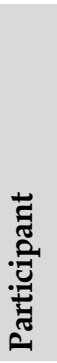 } & \multicolumn{10}{|c|}{$\begin{array}{l}\text { Practicing field training with and without the reflective practice approach } \\
\text { Groups } 1 \text { and } 3\end{array}$} \\
\hline & \multicolumn{5}{|c|}{ Activities continued to use } & \multicolumn{5}{|c|}{ Activities wished to continue use } \\
\hline & 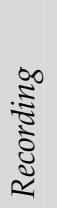 & 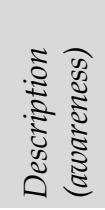 & 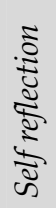 & 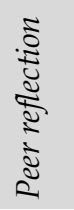 & 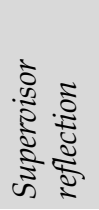 & 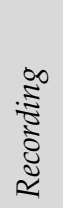 & 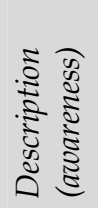 & 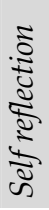 & 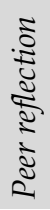 & 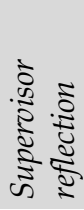 \\
\hline 1 & & $x$ & $x$ & & & & & & $x$ & $x$ \\
\hline 2 & & $x$ & $x$ & & & $x$ & $\mathrm{x}$ & $x$ & $x$ & $x$ \\
\hline 3 & & $x$ & $x$ & & & $x$ & & & $x$ & \\
\hline 4 & & $x$ & $x$ & & & $x$ & & & $x$ & \\
\hline 9 & & $x$ & $x$ & & & & & & $x$ & \\
\hline 10 & & $x$ & $x$ & & & $x$ & & & $x$ & \\
\hline 11 & & $x$ & $x$ & & & $x$ & $x$ & $X$ & $x$ & $x$ \\
\hline 12 & & & & & & & & & $x$ & \\
\hline
\end{tabular}


It can be seen from the response in Table 8.9 that almost all participants continued using two specific activities in the second part of the semester: self-reflection and description. The description here refers to their awareness of their performance or as it may be called self-description and not the activities of describing their performance for others. The participants asserted that during this part of the semester they were aware of their performance and they continued evaluating and observing themselves as they taught even though they did not record their performances. Regarding the reflection activities they wished to continue using, on the other hand, the activities of recording, peer-reflection, and supervisor feedback, were mentioned by several participants. Recognizably, all participants wished to practice the activities of peer-reflection during this part of the semester, which shows high appreciation for this specific activity by all participants. Recording their performance was another activity that five of the eight participants wished to continue using.

Generally, a positive perspective is shown from the results of the first three questions in this section as the participants appreciate the experience with reflection and the influence of this approach in increasing the presence of theories. Nevertheless, most of the participants were concerned with the time and effort that this approach consumes. The results of the last two questions in this section show an influence from practicing the activities of reflection during the first part of the semester on participants' performance during the second part of the semester. Although the participants were asked directly to practice traditional field training in the second part without using any of the reflection activities, all of them except one did apply some kind of reflection during their training. Yet, all of the participants expressed that they wished to use one or more of the reflection activities.

\subsubsection{Summary}

Several aims were behind the different sections of participants' interview that were presented here. The aim of the interview in Section 8.2.1 was to understand the general impression that the experiment left behind on the participants. The results of this section show that the majority of the participants were pleased and satisfied with this experiment. The aim of the part of the interview that was presented in Section 8.2.2 was to support the results from the achievement questionnaire and the results show that the participants appreciated the influence of the reflection 
activities on both connecting the theories to the practiced competences and on mastering these competences. Understanding the perspectives of the participants from Groups 1 and 3 toward the differences between practicing field training with and without reflection was the aim of the last part of the interview, which was presented in Section 8.2.3. The results of this section show that the participants appreciated more the practice of the field training with the activities of reflection in comparison with field training without this approach.

Briefly, based on the results from these different sections of the interview it can be seen that (a) the experiment had a positive impression on the participants, (b) according to the participants the reflective practice approach has an influence on both theory and practice, and (c) practicing field training with this approach was appreciated more than the traditional field training practice.

\subsection{SUPERVISORS' INTERVIEW}

Together with the participants' interviews in the last week of the experiment, the four supervisors who participated in this experiment were also interviewed. The first aim of this interview is to understand supervisors' perspectives toward the influence of the reflective practice approach on the learning process and on learners' achievement. Furthermore, another aim of this interview is to understand their perspectives toward the influence of the reflective practice approach on the gap between theory and practice. To cover these two aims, the interview is divided into three sections. Each interview took approximately 30 minutes and all interviews were recorded on tapes and fully transcribed. The same procedure that has been used with the participants' interviews is followed here to analyze this data. This procedure produced three partially ordered data displays that will be presented in the following sections.

Section 8.3.1 presents the information that is collected from the general section of this interview and Section 8.3.2 presents the collected information about the influence of the reflection on the field training whereas the information that is collected regarding the influence of the reflection on the gap between theory and practice is presented in Section 8.3.3. A summary of the results from the interviews will then be presented in Section 8.3.4. 


\subsubsection{General questions}

The first section of the supervisors' interview concern supervisors' general reactions toward this experiment and their opinions about the impact of the reflective practice approach on the process of learning and on learners' achievement. This section consists of five questions:

- What is your general impression about this experiment?

- In general, do you think the reflective practice approach has an influence on the learning process?

- In general, do you think the reflective practice approach has an influence on the students' achievement?

- What do you think of the quality of the reflections students wrote?

- Has the quality of reflection students wrote changed (increased/decreased) over time during the experiment?

The response to these questions is presented in Table 8.10 where the entries of this table are filled in by short blocks of text that summarize the responses.

The supervisors described their impression of this experiment with several terms such as new, beneficial, interesting, and enjoyable. They valued the online feedback and the opportunity to give precise feedback. All supervisors agreed on the positive influence of this experience on the learning process by facilitating the communication and collaboration, and by providing flexibility in the time and place. In addition, the supervisors asserted that the availability of the video clips helped them provide precise feedback. They also agreed on the positive influence of this experience on learners' achievement. The supervisors mentioned several advantages in this regard. The focus on a competence at the time was a very effective way to make students master this competence. The exchange of experiences among the participants and the explicit demonstration of the strengths and weaknesses in the performances were other factors that influenced positively learners' achievement. The quality of students' reflections was considered inefficient by almost all supervisors arguing that the reflections did not go beyond a description of the situation or an encouragement to their peers. The lack of experience, social restraints, and difficulties in expressing themselves were the main reasons behind this poor quality based on supervisors' perspectives. However, they all agreed that the quality increased during the experiment mainly because of the feedback the participants received. 
Table 8.10 Supervisors' response to the questions of the first section of the interview $(N=4)$

\begin{tabular}{|c|c|c|c|c|c|}
\hline \multirow{2}{*}{ 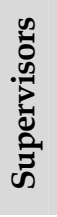 } & \multicolumn{5}{|c|}{ General questions } \\
\hline & $\begin{array}{l}\text { General } \\
\text { impression }\end{array}$ & $\begin{array}{l}\text { Influence on the } \\
\text { learning process }\end{array}$ & $\begin{array}{l}\text { Influence on the } \\
\text { learners' } \\
\text { achievement }\end{array}$ & $\begin{array}{l}\text { Quality of } \\
\text { reflection }\end{array}$ & $\begin{array}{l}\text { Changes in the } \\
\text { quality }\end{array}$ \\
\hline 1 & $\begin{array}{l}\text { It was a new } \\
\text { and good expe- } \\
\text { rience for both } \\
\text { students and } \\
\text { supervisors. } \\
\text { Enjoyed giving } \\
\text { feedback online }\end{array}$ & $\begin{array}{l}\text { Yes, especially } \\
\text { the } \\
\text { collaboration } \\
\text { and facilitating } \\
\text { deep analysis } \\
\text { for the } \\
\text { situations }\end{array}$ & $\begin{array}{l}\text { Strong } \\
\text { influence by } \\
\text { exchanging the } \\
\text { experiences } \\
\text { among group } \\
\text { members }\end{array}$ & $\begin{array}{l}\text { They have } \\
\text { some problems } \\
\text { in expressing } \\
\text { themselves }\end{array}$ & $\begin{array}{l}\text { I saw some } \\
\text { improvement } \\
\text { in their } \\
\text { reflection with } \\
\text { time }\end{array}$ \\
\hline 2 & $\begin{array}{l}\text { It was beneficial } \\
\text { for all of us. The } \\
\text { performance } \\
\text { improved a lot } \\
\text { through the } \\
\text { precise } \\
\text { feedback }\end{array}$ & $\begin{array}{l}\text { It was a useful } \\
\text { tool to give } \\
\text { more precise } \\
\text { feedback using } \\
\text { the clips. } \\
\text { "Seeing is } \\
\text { believing" }\end{array}$ & $\begin{array}{l}\text { Yes, the } \\
\text { reflection } \\
\text { improved their } \\
\text { understanding } \\
\text { of the practiced } \\
\text { skill }\end{array}$ & $\begin{array}{l}\text { Not efficient, } \\
\text { because of } \\
\text { social barriers } \\
\text { and lack of } \\
\text { experience }\end{array}$ & $\begin{array}{l}\text { To some extent } \\
\text { by reading the } \\
\text { supervisor and } \\
\text { their peers' } \\
\text { reflections }\end{array}$ \\
\hline 3 & $\begin{array}{l}\text { I think it is a } \\
\text { very interesting } \\
\text { and useful } \\
\text { method for } \\
\text { field training }\end{array}$ & $\begin{array}{l}\text { Helps explain } \\
\text { the feedback } \\
\text { and brought } \\
\text { several } \\
\text { experiences } \\
\text { together }\end{array}$ & $\begin{array}{l}\text { Focusing on a } \\
\text { specific skill at } \\
\text { the time helps } \\
\text { mastering it. }\end{array}$ & $\begin{array}{l}\text { It was mostly } \\
\text { description or } \\
\text { encouragement } \\
\text { instead of } \\
\text { criticism }\end{array}$ & $\begin{array}{l}\text { In the group } \\
\text { reflection they } \\
\text { used theories to } \\
\text { support their } \\
\text { arguments }\end{array}$ \\
\hline 4 & $\begin{array}{l}\text { It was an } \\
\text { enjoyable } \\
\text { experience for } \\
\text { me and } \\
\text { students } \\
\text { enjoyed it also }\end{array}$ & $\begin{array}{l}\text { Yes, by making } \\
\text { time and place } \\
\text { flexible and } \\
\text { facilitating the } \\
\text { communication }\end{array}$ & $\begin{array}{l}\text { Yes, by } \\
\text { showing them } \\
\text { their strengths } \\
\text { and weaknesses } \\
\text { in a real } \\
\text { situation }\end{array}$ & $\begin{array}{l}\text { Most of them } \\
\text { were able to } \\
\text { reflect to some } \\
\text { extent }\end{array}$ & $\begin{array}{l}\text { The quality } \\
\text { increased } \\
\text { because of the } \\
\text { exchange of } \\
\text { reflections }\end{array}$ \\
\hline
\end{tabular}

The results in this section show a positive impression of the experiment from the supervisors. In addition, they valued the influence of the reflection activities on both the learning process and on learners' achievement. Furthermore, even though the supervisors were not convinced of the quality of participants' reflection, they believed that their ability to provide reflection was gradually increasing.

\subsubsection{The influence of reflection on the field training}

This section of the supervisors' interview focuses on comparing the practice of field training with reflection in our experiment to previous field training courses that have been guided by the same supervisors via the following questions: 
- In comparison with previous field training courses, which course requires more time and effort from the students?

- In comparison with previous field training courses, which course requires more time and effort from the supervisor?

- Do you think there is a difference in the performance of the students from this course in comparison with students from previous courses?

- In comparison with previous field training courses, where do you find a stronger presence of theory?

- If you were asked to choose between practicing field training with or without the reflective practice method for your students, what would you choose?

Supervisors' response to the questions of this section is presented in Table 8.11 and the entries of the table are formulated based on the most mentioned phrases by the supervisors.

Table 8.11 Supervisors' response to the questions of the second section of the interview $(N=4)$

\begin{tabular}{|c|c|c|c|c|c|}
\hline \multirow{2}{*}{ 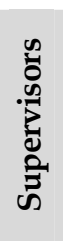 } & \multicolumn{5}{|c|}{$\begin{array}{c}\text { The differences between this field training and previous courses } \\
\text { in relation to the reflection activities }\end{array}$} \\
\hline & $\begin{array}{l}\text { Regarding } \\
\text { students' time } \\
\text { and effort }\end{array}$ & $\begin{array}{l}\text { Regarding } \\
\text { supervisors' time } \\
\text { and effort }\end{array}$ & $\begin{array}{l}\text { Regarding the } \\
\text { performance } \\
\text { differences }\end{array}$ & $\begin{array}{l}\text { Regarding the } \\
\text { presence of } \\
\text { theory }\end{array}$ & $\begin{array}{l}\text { Regarding the } \\
\text { choice of practice }\end{array}$ \\
\hline 1 & $\begin{array}{l}\text { In this course, } \\
\text { at the begin- } \\
\text { ning only } \\
\text { because it is a } \\
\text { new method }\end{array}$ & No difference & $\begin{array}{l}\text { The performan- } \\
\text { ce improved } \\
\text { faster in this } \\
\text { course }\end{array}$ & $\begin{array}{l}\text { In this course, } \\
\text { connecting the } \\
\text { theories into } \\
\text { their practices }\end{array}$ & $\begin{array}{l}\text { This method, it } \\
\text { is more } \\
\text { convenient for } \\
\text { me }\end{array}$ \\
\hline 2 & $\begin{array}{l}\text { In this course, } \\
\text { because of the } \\
\text { recording and } \\
\text { uploading }\end{array}$ & No difference & $\begin{array}{l}\text { The performan- } \\
\text { ce improved } \\
\text { faster in this } \\
\text { course }\end{array}$ & $\begin{array}{l}\text { In this course, } \\
\text { having together } \\
\text { the feedback } \\
\text { and the } \\
\text { performance }\end{array}$ & $\begin{array}{l}\text { This method, it } \\
\text { will make the } \\
\text { supervision } \\
\text { easier for me }\end{array}$ \\
\hline 3 & $\begin{array}{l}\text { In this course, } \\
\text { at the begin- } \\
\text { ning only } \\
\text { because it is } \\
\text { new method }\end{array}$ & $\begin{array}{l}\text { In this course, } \\
\text { at the begin- } \\
\text { ning only } \\
\text { because it is a } \\
\text { new method }\end{array}$ & $\begin{array}{l}\text { The performan- } \\
\text { ce improved } \\
\text { faster in this } \\
\text { course }\end{array}$ & $\begin{array}{l}\text { In this course, } \\
\text { because of the } \\
\text { intensive } \\
\text { feedback }\end{array}$ & This method \\
\hline 4 & $\begin{array}{l}\text { In this course, } \\
\text { at the begin- } \\
\text { ning only } \\
\text { because it is a } \\
\text { new method }\end{array}$ & $\begin{array}{l}\text { In this course, } \\
\text { at the begin- } \\
\text { ning only } \\
\text { because it is a } \\
\text { new method }\end{array}$ & $\begin{array}{l}\text { The performan- } \\
\text { ce improved } \\
\text { faster in this } \\
\text { course }\end{array}$ & $\begin{array}{l}\text { In this course, } \\
\text { because of the } \\
\text { feedback and } \\
\text { the discussion }\end{array}$ & $\begin{array}{l}\text { This method, it } \\
\text { helps me in the } \\
\text { evaluation }\end{array}$ \\
\hline
\end{tabular}


The four supervisors agreed that practicing the field training with the reflection activities required more time and effort from the students. They explained that, being a new experience to the students, it was expected to consume more time and effort at the beginning but would be reduced with practice. However, one of the supervisors, based on students' complaints, referred to the recording and the uploading of the video clips to the environment as a reason for consuming more time and effort. Regarding the time and the effort of the supervisors themselves, two of them considered the field training with the reflection to require more time and effort from them but only at the beginning. The other two supervisors experienced no difference. They all agreed that the performance of the students who used the activities of reflection improved more rapidly compared with those who practiced the traditional field training from the previous semesters. They also agreed that the presence of theory was stronger in this course. The intensive and precise feedback and the discussions presented by the supervisors were mentioned as the main reasons for connecting the theory to practice. Finally, several reasons were presented by the supervisors for choosing to apply this experience in the field training such as it is more convenient, easier, and facilitates the evaluation.

In short, the response of the supervisors in this section of the interview showed that they consider the practice of the field training with the activities of reflection to consume more time and effort from them and their students only at the beginning. Yet, the result showed that they still value the practice of the field training with reflection and prefer to practice it instead of the traditional field training.

\subsubsection{The influence of reflection on the gap between theory and practice}

The last section of the supervisors' interview concerns the influence of the reflective practice on the gap between theory and practice and consists of the following questions:

- In general, do you think that the reflective practice approach has an influence on reducing the gap between theory and practice?

- Do you think that the description activities during the experiment have an influence on connecting theory to practice?

- Do you think that the self-reflection activities during the experiment have an influence on connecting theory to practice? 
- Do you think that the peer reflection activities during the experiment have an influence on connecting theory to practice?

- Do you think that the finding alternatives activities during the experiment have an influence on connecting theory to practice?

Supervisors' responses to the questions of this section are presented in Table 8.12. Values of Yes and No in addition to short blocks of text that summarize supervisors' response were used here to fill in the entries of this table.

Table 8.12 Supervisors' response on the questions of the third section of the interview $(N=4)$

\begin{tabular}{|c|c|c|c|c|c|}
\hline \multirow{2}{*}{ 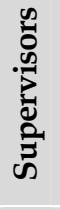 } & \multicolumn{5}{|c|}{ The influence of practicing the reflection on the gap between theory and practice } \\
\hline & $\begin{array}{l}\text { Influence from } \\
\text { the reflection }\end{array}$ & $\begin{array}{l}\text { Influence from } \\
\text { description }\end{array}$ & $\begin{array}{l}\text { Influence from } \\
\text { self reflection }\end{array}$ & $\begin{array}{l}\text { Influence from } \\
\text { peer reflection }\end{array}$ & $\begin{array}{l}\text { Influence from } \\
\text { finding } \\
\text { alternatives }\end{array}$ \\
\hline 1 & $\begin{array}{l}\text { Yes, most of the } \\
\text { activities, but it } \\
\text { is important } \\
\text { that they } \\
\text { learned the } \\
\text { theory before }\end{array}$ & $\begin{array}{l}\text { No, they only } \\
\text { describe what } \\
\text { they did }\end{array}$ & $\begin{array}{l}\text { Yes, they had to } \\
\text { use theories to } \\
\text { defend their } \\
\text { performance }\end{array}$ & $\begin{array}{l}\text { Yes, they had to } \\
\text { find the right } \\
\text { theory that } \\
\text { supports their } \\
\text { argument }\end{array}$ & $\begin{array}{l}\text { Yes, the new } \\
\text { plan on how to } \\
\text { perform in the } \\
\text { future should } \\
\text { be theory based }\end{array}$ \\
\hline 2 & $\begin{array}{l}\text { Yes, It has } \\
\text { strong } \\
\text { influence on } \\
\text { this gap }\end{array}$ & $\begin{array}{l}\text { No, at least } \\
\text { there is no } \\
\text { direct influence }\end{array}$ & $\begin{array}{l}\text { Yes, they had to } \\
\text { recall their } \\
\text { prior know- } \\
\text { ledge and con- } \\
\text { nect it with } \\
\text { their perfor- } \\
\text { mance }\end{array}$ & $\begin{array}{l}\text { Yes, they had to } \\
\text { find the right } \\
\text { theory that } \\
\text { supports their } \\
\text { argument }\end{array}$ & $\begin{array}{l}\text { Yes, they have } \\
\text { to rely on } \\
\text { theories to } \\
\text { build their new } \\
\text { plan }\end{array}$ \\
\hline 3 & $\begin{array}{l}\text { Yes, I think all } \\
\text { of the reflection } \\
\text { activities have } \\
\text { an influence in } \\
\text { general }\end{array}$ & $\begin{array}{l}\text { No, only if they } \\
\text { used the } \\
\text { theories to } \\
\text { clarify their } \\
\text { description }\end{array}$ & $\begin{array}{l}\text { Yes, they were } \\
\text { forced to think } \\
\text { deeper about } \\
\text { their perfor- } \\
\text { mance }\end{array}$ & $\begin{array}{l}\text { Yes, the same } \\
\text { as the self } \\
\text { reflection }\end{array}$ & $\begin{array}{l}\text { Yes, they used } \\
\text { the feedback } \\
\text { they got to } \\
\text { build a new } \\
\text { plan }\end{array}$ \\
\hline 4 & $\begin{array}{l}\text { Yes, comparing } \\
\text { with traditional } \\
\text { courses, it is a } \\
\text { step forward } \\
\text { into reducing } \\
\text { this gap }\end{array}$ & I don't think so & $\begin{array}{l}\text { Yes, they had to } \\
\text { use theory to } \\
\text { argue their } \\
\text { cases }\end{array}$ & $\begin{array}{l}\text { Yes, they had to } \\
\text { rely on some } \\
\text { theories to } \\
\text { evaluate their } \\
\text { peers }\end{array}$ & $\begin{array}{l}\text { Yes, they used } \\
\text { the feedback } \\
\text { they got to } \\
\text { build a new } \\
\text { plan }\end{array}$ \\
\hline
\end{tabular}

As a response to the first question, all supervisors confirmed that reflection in general as an educational approach has positive influence on reducing the gap between theory and practice. The description activity in particular was 
considered by all supervisors to have no influence on the gap between theory and practice. The rest of the activities, on the other hand, were appreciated by all supervisors for having different effects on this gap. In the self-reflection, the students will recall different theories from their prior courses in order to justify their performance. Furthermore, the students in the peer-reflection will need the theories to support their argument. Finally, the idea of planning and finding alternatives for the performance will rely on different theories that were provided as a feedback or in the discussion.

In general, it can be seen here based on the result of this section that all activities of the reflective practice approach (except for the description activity) were highly appreciated by the supervisors regarding the effect on the gap between theory and practice.

\subsubsection{Summary}

The interview with the supervisors is conducted in order to find out their perspectives toward the influence of the reflective practice approach on the learning process, learners' achievement, and the gap between theory and practice. A positive impression was shown from the supervisors toward this experiment and they appreciated the effect of the reflection activities on both the learning process and learners' achievement. Furthermore, the supervisors preferred the practice of field training with the reflection activities over the traditional field training courses. With respect to the gap between theory and practice, all of the activities of reflection except for the description were considered effective activities.

\subsection{DisCUSSION}

Several types of data were presented in the previous sections. First, data related to the effect of the reflection activities on two major elements in the process of learning were investigated. Information regarding the effect of reflection on the relationship between theories and the practiced competences as well as the effect of reflection on participants' ability to master the practiced competences was collected. These two factors were investigated in both the Achievement 
Questionnaire and the interview with the participants. Section 8.4.1, therefore, will compare the results from the questionnaire and the interview with relation to the effect of reflection. Second, information concerning participants and supervisors' impression of this experiment and the influence of the reflection on the gap between theory and practice was also presented in this chapter. Finally, information regarding the differences between the field training course with and without the activities of reflection was presented. These different types of information will be used to discuss RQ6 in this study in Section 8.4.2.

\subsubsection{Results comparison}

Comparing the results of the questionnaire and the interview regarding the effect of the reflective practice approach on the learning achievement is assumed to confirm these results and to support the effort for finding an answer to RQ6. This comparison of the results shows similarity in the response regarding the effect of reflection on the relationship between the theories and the practiced competences. In the questionnaire, the participants valued strongly the effect of reflection, in general, in helping to increase their understanding of the theoretical concept behind the practiced competences. The participants confirmed this appreciation of reflection in the interview as the reflection was considered influential in both inquiries. Furthermore, the participants in the interview added that the feedback, which is mostly practiced during the peer-reflection and the finding alternatives activities, was the most influential factor that stimulated this relationship. In addition, the participants asserted that the exchange of perspectives among them regarding a specific situation and the group reflection that was conducted at the end of the experiment also helped in connecting theory to practice. The effect of reflection on participants' ability to master the practiced competences was also highly appreciated by the participants themselves in the questionnaire. However, even though the effect of the activities of finding alternatives on their ability to master the competences were considered positive by the participants in the questionnaire, less appreciation was given to these activities in comparison with other activities. This result was also confirmed during the interview. In addition, the participants specified in the interview that the reflection on themselves, the feedback from their peers and supervisors, as well as the reflection on their peers' performances were the most influential activities that helped them improve their performance. 


\subsubsection{Reflection and learning}

RQ6 questions whether the use of reflection supported by the online video-based learning environment in this experiment facilitated the learning process and improved learners' achievement. Before formulating an answer to this question, it is important to make clear here that using the reflection to evaluate or assess student performance during our experiment has been avoided. The reasons for this were presented and discussed during the design of the reflective practice model for our experiment in Section 5.4.1. Consequently, answering this research question will rely mainly on the perspectives of the participants and their supervisors. The use of participants' self reporting as indicator for real progress may be considered a limitation in this study which will be discussed in more detail in the next chapter. To avoid this limitation, all four of our supervisors in this experiment were chosen based on their long time experience in supervising the practice of field training. They all have respectable experience regarding the learning process and learners' achievement in the field training. Thus, supervisors' perspectives are used here as experts' evaluation to evaluate the progress and to confirm participants' reports. Furthermore, considering that both the participants and their supervisors were involved greatly in the process of this experiment rather than just observing this process, it is expected that they will formulate a concrete and reliable perspective from this experience. Understanding these perspectives, therefore, is assumed to provide a reliable indication of the effect of reflection on the practice of the field training and accordingly the effect of reflection on the relationship between theory and practice in this course.

Previously in this chapter different kinds of information were presented in order to understand the different perspectives of the participants and their supervisors. The impression that the experiment left on the participants and their supervisors, their preference toward the practice of field training with or without reflection, and their perspectives toward the role of reflection on strengthening the presence of theory during the field training are all considered as useful indicators that can help in understanding the effect of reflection on the practice of the field training. This information was presented, analyzed, and discussed previously in separate sections while this section aims to bring together this information in order to extend the discussion of the effect of reflection and to formulate an answer to RQ6.

Looking into the different data that were presented in this chapter, a consistency can be found between the response of the participants and the response of the 
supervisors in relation to their impressions toward this experience (Sections 8.2.1, 8.2.3 \& 8.3.1). The participants stated that they enjoyed this experience very much and most of them asserted as well that they would use some kind of reflection activities in their future workplace. The supervisors showed a similar perspective toward this experience and they believed that practicing reflection had a positive influence on the learning process and on learners' achievement. This result shows an acceptance from both the participants and their supervisors of the importance and effective role of the reflective practice in the field training. Considering that the acceptance of any new intervention is a critical factor for successful implementation and accordingly for making a difference in the situation, the responses regarding the acceptance showed a positive view toward our intervention. Another consistency that can be found between the response of the participants and the response of the supervisors concerns the importance and the requirement of the reflection approach. Having the choice between practicing field training with or without reflection, the participants and their supervisors all chose to practice the field training with reflection even though the majority thought that it will require more time and effort from them at the beginning in comparison to the traditional practice of field training. In the view of the majority of the participants and all of their supervisors, the reflection activities stimulate explicit presence of theory in the field training and this view could explain their choice to practice the field training with reflection.

Several questions were asked of both the participants and the supervisors concerning the presence of theory and the role of the reflection approach in strengthening this presence. Participants' perspectives toward the effect of the different activities of reflection on (a) understanding the theoretical concept behind the practiced competences and on (b) helping them master the practiced competences were investigated via the Achievement Questionnaire (Section 8.1) and confirmed during the participants' interview (Section 8.2.2). Comparing the results from these two instruments in Section 8.4.1 demonstrates explicitly a strong appreciation by the participants for the role of all activities of reflection in strengthening the presence of theory in the field training. More specific, the participants highlighted the feedback in particular to be the most influential factor that helped them understand the theoretical concept behind the practiced competences. They specified their own reflection on their performance as well as their reflection on their peers' performance as the most influential factors that helped them master the practiced competences. 
The supervisors were also asked about the effect of reflection on the gap between theory and practice but in rather a direct approach. They were asked if each of the different activities involved in the practice of reflection had an influence on connecting theory and practice (Section 8.3.3). By distinguishing in the questions between the four major activities of the reflection process-description, selfreflection, peer-reflection, and finding alternatives - the supervisors asserted that except for the description activity all other activities did have a positive influence on the relationship between theory and practice.

It can be recognized in the responses of the participants and the supervisors that while the participants consider all activities of reflection to be valuable activities for connecting theory and practice, the supervisors dismissed any influence from the description activity in the relationship between theory and practice. This difference in perspectives toward the description activity can be related to the different roles of the participants and the supervisors in the field training. An explanation is that while the participants view the description activity through learners' eyes, the supervisors view this activity through evaluators' eyes. In other words, the appreciation of the description activity by the participants comes from the opportunity that this activity provided for them to learn from their own performance and to explain themselves to other participants. On the other hand, the supervisors' view that the activity of description has no impact on the relationship between theory and practice is justified by their argument that there was no theory involved in participants' description.

The supervisors' point of view is indeed accurate that the involvement of theory is absent during the description activity which is, in fact, in line with the nature of this activity as a presentation activity. However, that does not mean that the description activity has no indirect impact on the theory-practice relationship. The discussion in Section 2.4 may be presented here as a valid explanation of the importance of the indirect impact of the description activity on the practice of reflection. This discussion concerns the importance of the description activity for other activities of reflection. The precise description, supported by real demonstration of the situation through the recorded video clips, is an effective facilitator for other activities of reflection and accordingly strengthens the process of reflection. Participants' response to the additional question concerning the activities that they continued to use in the second part of the semester (Section 8.2.3), shows that the participants will continue to use only two of the four 
activities and one of them is the description activity. That shows the importance of this activity for the participants. Furthermore, supervisors stated that the quality of reflection was poor at the beginning and it was closer to description rather than reflection. They also asserted that the quality of reflection increased as the experiment unfolded and that may be seen as another indicator of the important role of the description activity in improving participants' reflection.

Given all this, was the use of reflection supported by the online video-based learning environment in this experiment facilitating the learning process during the field training and did it improve learners' achievement? According to the presented information, the implementation of this intervention showed promising changes in the field training. The positive attitude and the acceptance from the participants and their supervisors toward the practice of the reflective approach and the online environment present encouraging indications regarding the effect of reflection. Moreover, their common agreement that this intervention was effective in facilitating the relationship between theory and practice is another strong indicator of the positive influence of reflection.

To sum up based on the information that has been presented in this chapter, it can be concluded as an answer to RQ6 that the utilization of the reflective practice approach supported by the online video-based learning environment showed promising results in facilitating the learning process and in improving learners' achievement in the field training course. An elaboration of the discussion in this chapter will be presented in the next chapter together with the discussion from the previous chapters in this dissertation in order to formulate an answer to the main question of this research. 


\section{CHAPTER 9 \\ General discussion}

This final chapter aims to provide a reflective overview and a discussion of the main findings of this research. Bringing together and discussing these findings will allow drawing an answer to the main question in this research:

Does the use of the reflective practice approach supported by an online videobased learning environment in field training in teacher education programs have pedagogical advantages in reducing the gap between theory and practice?

A journey through several topics was taken throughout this project to provide an answer to this question that accounts for different related aspects. As a start, an investigation was conducted into the two main elements in our intervention where the notion behind the reflective practice approach was discussed in Chapter 2 (RQ1) and the role of ICT in supporting the reflection approach was discussed in Chapter 3 (RQ2).

The investigation in Chapter 2 concerning the reflective practice approach led to the conclusion that reflection in simplest terms is a process where the practitioners look back consciously on their experience, think about and question it in light of their prior knowledge, and then judge their actions in this experience in order to develop an alternative knowledge and action. The core of reflection based on this understanding is to build a bridge between practitioners' knowledge and their experience or, in other words, to build a bridge between theory and practice. The role of reflection in learning, therefore, is to continually connect practitioners' understanding to their experiences and to connect their experiences back to their prior knowledge in order to facilitate learning. Furthermore, the models that describe the approach for practicing reflection in the literature show a variety of approaches although they share a similar view toward the ultimate goal of this practice. Some influential factors in the educational program such as the social influence of the society, the level of 
learners' awareness, and the type of delivery in this specific program played the role of altering these strategies and models in terms of number of stages or the major focus. Nevertheless, it was found that three components are commonly present in the majority of these models: the importance of practitioner's prior knowledge and background, the importance of conscious observation of the experience, and the emphasis on a cyclical and continuous process. Finally, reviewing the literature on the reflection topic brought into focus different types of difficulties that are expected to come along with practicing reflection. The difficulties that are associated with the description activity were found to be a critical barrier that prevents effective reflection. ICT showed promising tools and applications that may be presented as facilitators for the reflective practice, which was the focus of Chapter 3.

The role of ICT in supporting reflection was investigated and discussed in Chapter 3 and the conclusion that was drawn from this discussion is that ICT indeed provides a variety of possibilities for supporting the practice of the reflective approach. The literature showed that ICT advantages are expected to go beyond solving some existing problems, bringing the effectiveness of learning to a new level. Video applications were presented as an effective tool for supporting the practice of reflection. The history of video in education shows that since the early attempts to use video applications in education in the 1960s, this tool shows promising results. However, many factors such as the expense and the accessibility were huge obstacles at that time and prevented the effective use of video in education. Today, video is a convenient option among an array of ICT applications. In recent years, a new trend of ICT implementation is emerging that encourages the use of a combination of several ICT applications in one system or as a package instead of using each individual application separately. The advancement of the Internet provides a rich ground for such integration and accordingly several kinds of online environments that aim to deliver and facilitate the use of ICT applications have been developed in many educational institutes. One of these environments is focusing on facilitating the integration of video applications together with other ICT applications such as the communication or material exchange tools on the net. This online video-based learning environment is considered suitable technology to overcome some of the obstacles that faced the use of video in education in the past; therefore, these environments are increasingly utilized in education. The advantages of such environments are expected to free some of the restrictions that are associated 
with practicing reflection and accordingly to extend the effectiveness of this approach. Hence, facilitating the reflective practice approach through an online video-based learning environment is assumed to positively influence the relationship between theory and practice in the field training.

Building a conceptual framework of context-related knowledge based on the findings from investigating the reflective practice approach and ICT supports led to the selection of Action Research as the suitable research methodology in Chapter 4 and the design of the experimental field study in this project in Chapter 5. An investigation of the context of this study is presented in Chapter 5 which reflects the query of RQ3. The findings from this investigation show promising opportunities for practicing reflection in the College of Basic Education in Kuwait and accordingly for conducting our field experiment. These findings were also taken into consideration during the design of the field experiment. The aim of the field experiment was to collect information that has the capability to provide answers to RQ4, RQ5, and RQ6. The findings from the field experiment are presented in the next section.

\subsection{REVISITING THE EXPERIMENT'S FINDINGS}

The implementation of the reflective practice approach supported by an online video-based learning environment in the field experiment of this research is assumed to bridge the gap between the different theories that have been taught during the study program and the practice of teaching in the field training. In order to assess the influence of this intervention on the field training, the investigation was conducted from three different angles. The first angle concerns the difficulties that are expected to come along from implementing this intervention and the effect of these difficulties on the implementation of this intervention. The second angle concerns the effectiveness of the used environment including the usability and the usefulness of this environment as two critical factors influencing the utilization of this intervention. The focus of these two angles is on factors that are related to the implementation and the acceptance of our intervention. The third angle concerns the impact of this intervention on the learning process of the field training and focuses on learners' achievement in this course. The findings from these three investigations are discussed in the following sections. 


\subsubsection{Discussion related to the difficulties (RQ4)}

The implementation or the integration of a new intervention is expected to bring with it some obstacles and difficulties. The number of these difficulties and their influence on participants' practice and acceptance are important indicators of the success of the utilization of the intervention. Therefore, the findings that are related to the difficulties in practicing reflection is discussed in Chapter 6 and several conclusions are drawn based on that discussion with respect to the reported difficulties by the participants. As a general conclusion, there were indeed several difficulties that have been reported by the participants in relation to their practice of reflection, yet none of these difficulties were considered to be a major obstacle that could prevent the practice of this approach. The described difficulties in our investigation were classified into three new categories as an attempt to sort out these difficulties to determine the likely causes and sources of these difficulties.

Under the category of personal and social barriers, it was found that (a) the attitudes or the behaviors of the participants and (b) the culture and traditions of the society appear to be major sources of some of the main reported difficulties. The second category is the knowledge and skills barrier and the difficulties that were sorted under this category are those which were caused by participants' lack of knowledge and skills in relation to the reflective practice approach in particular and to their knowledge and skills background in general. The technical and organizational barriers are presented as the third category and the focus of this category is on the difficulties that have been caused by (a) technical problems such as the inefficiency of the involved technologies in facilitating the activities of reflection or by (b) the way the field training in our experiment was organized.

Among the reported difficulties, it was found that some of these difficulties reflect similar difficulties that are reported in other studies on the implementation of the reflective practice approach while the rest of the difficulties are found to be exclusive to our experiment. It is relevant here to clarify that the reviewed research in our study regarding the implementation of reflection are all conducted either in one of the European countries or in the USA while no similar studies are found in environments similar to that in Kuwait with respect to factors such as the culture, learning characteristics, and educational structure. This may provide an explanation for the absence of similarity in some of the reported difficulties. Understanding the strong influence of such factors on 
causing these difficulties, similar difficulties may be found when an experiment is conducted in countries or regions with similar characteristics to the State of Kuwait. Thus, the reported difficulties can be divided into two types. The first type is the difficulties that are caused by the complexity of the reflective practice approach while the second type is the difficulties that are caused by environmental factors.

In a Kuwaiti context, several measures are suggested to be considered in order to overcome or at least to reduce the influence of these two types of difficulties on the practice of reflection in the field training. First and in relation to the difficulties that are caused by the complexity of the reflective practice approach, introducing reflection as a pedagogical approach prior to the practice of field training is highly recommended. Students could, for instance, learn about this approach as a part of the study program in the teaching methods course. Furthermore, a preparation period prior to the field training where students can receive proper knowledge, practice, and demonstration of the pedagogy and the technology involved in the field training may also be seen as another measure for reducing the influence from this type of difficulty. Second, a suggestion that may provide a solution to some of the difficulties that are caused by environmental factors is the modification of the structure of the study program. Practicing field training as a part in the whole study program instead of only in the last semester is assumed to have several positive possibilities. Among these possibilities, implementing field training from the beginning of the program is assumed to increase gradually students' familiarity with the pedagogy and the technology of the field training. It is also assumed to provide students with the opportunity to turn just-learned theories into real practice. In all, action must be taken to overcome these difficulties in order to optimize the effects from practicing reflection in field training.

\subsubsection{Discussion related to the effectiveness (RQ5)}

The perspective of the users toward the effectiveness of the online environment that they used to facilitate their practice is another important indicator of the success of utilizing our intervention. The findings regarding the effectiveness of the $\mathrm{V}$-class online video-based learning environment in supporting the practice of reflection are discussed in Chapter 7 and it was concluded that the $\mathrm{V}$-class environment showed promising effects on carrying out the activities of reflection. This conclusion corresponds and confirms the findings in other 
studies that were discussed in Chapter 3 regarding the added value from using video and the Internet to support learning and particularly to support the reflective reflection approach.

In order to reach this conclusion, two major factors were investigated: the usability and the usefulness of this environment. The participants asserted that the environment was both usable and useful although they expressed some concerns regarding the usability. The participants described some problems related to the usability which are mostly caused by the use of new and unfamiliar equipment and applications. They also explained that these problems gradually faded as the experiment unfolded. The usefulness of the Vclass environment, on the other hand, was highly appreciated by the participants and no complaints were expressed as all participants valued the support that the environment provided for the practice of reflection. The difference between the findings about the usability and the findings about the usefulness is that while the usability findings reflect the use of the V-class environment specifically, the usefulness findings can be generalized to reflect the use of any online video-based environment that aims to support the practice of the reflection activities.

Therefore, and based on the findings of this study, it can be asserted that the use of the online video-based learning environments proves to provide valuable support for practicing reflection in the field training. Yet the findings also bring attention to the importance of the usability factor and the expected difficulties that may be caused by the complexity of the environment. As it was explained in Section 9.1.1, the inefficiency or the complexity of the involved technologies in facilitating the activities of reflection is a major barrier toward effective use of reflection in the field training. Thus, a serious consideration must be given to the process of selecting and implementing the most suitable environment for the specific educational organization. Some of the recommendations that may be considered in the selection and implementation process are as follows:

- To investigate the capability of the ICT infrastructure in the organization

- To investigate whether the organization already has an online environment that might be able to accommodate the required applications without the need to introduce a new environment

- To provide introductory sessions to explain the main functionalities of the environment and to provide handouts, tutorials, and practical sessions, and

- To provide technical supports for the users 
To conclude, the findings of this study regarding the usability and the usefulness did confirm the effectiveness of the online video-based learning environment in supporting the practice of reflection in the field training. Nevertheless, the attention should always be paid to the difficulties that may come along from the environments' usability and measures must be taken to avoid such difficulties.

\subsubsection{Discussion related to the achievement (RQ6)}

The effect of our intervention on the learning process and on learners' achievement during the field training was investigated and the findings are presented and discussed in Chapter 8. As a conclusion, it was found that the implementation of the reflective practice supported by the online environment showed promising changes in the field training. This can be interpreted based on the presented and discussed findings in Chapter 8 regarding participants' and supervisors' perspectives toward the influence of our intervention on learning and on the achievement. This conclusion was reached by combining the findings from three different inquiries that concern participants' and supervisors' (a) impressions, (b) preferences, and (c) perspectives.

The findings showed a consistency in the responses of the participants and their supervisors toward the impression that the experiment left on them as they both asserted that they benefited and enjoyed this experience. Furthermore, all participants as well as supervisors show agreement in that in comparison with the traditional practice of the field training they all prefer to practice the field training using the reflective practice approach supported by the online environment. Preferring the practice of field training with our intervention, even though it will require more time and greater effort from them as they stated, shows that they appreciate greatly the positive influence of our intervention. Moreover, understanding the perspectives of the participants and their supervisors toward the role of the activities of reflection in bridging the gap between theory and practice reveals high appreciation of the different activities in this approach. Nevertheless, the supervisors considered the description activity as an insignificant activity for this particular role. Looking through supervisors' eyes to the natural role of the description as a presentation activity, this perspective may be understandable. 
It can be concluded based on the findings from this section that the use of our intervention influenced positively both the process of learning and learners' achievement in the field training. The aim of the field experiment is to investigate the impact of our intervention on the practice of the field training from three different angles presented through RQ4, RQ5, and RQ6. Accordingly, this investigation is assumed to provide data that can help in answering the main question of this study. Therefore, the next section will discuss the main research question in light of these data together with the data from the conceptual questions (RQ1, RQ2).

\subsection{REFLECTION AND THE GAP BETWEEN THEORY AND PRACTICE}

So, does the use of the reflective practice approach supported by the online video-based learning environment in field training in teacher education programs have pedagogical advantages in reducing the gap between theory and practice? The findings from the conceptual questions (RQ1, RQ2) that are discussed in the introduction of this chapter promise an effective intervention that is able to provide pedagogical advantages for the practice of the field training. After the implementation of this intervention, a positive impact on the gap between theory and practice is recognized in most of the findings from the empirical questions (RQ4, RQ5, and RQ6) that are discussed in Section 9.1.

Reviewing the literature on the topic of the reflective practice demonstrated a common contentment among researchers and educators in looking at this approach as a very promising method able to improve the process of learning and learners' achievement (Chapter 2). Furthermore, the use of video applications, particularly within an online environment, is presented as an effective tool that can support learning and specifically the implementation of the reflective practice approach (Chapter 3 ). Integrating the promising pedagogy and this technology, therefore, is assumed to empower the practice of field training and to create a bridge that can connect theory to practice in this course.

Evaluating the integration of these two components in a real context by means of an intervention in the field training in teacher education in Kuwait showed positive impact. Expectedly, there were some difficulties but none of them were 
seen as obstacles that may prevent the utilization of such intervention. On the other hand, both components in our intervention were highly appreciated by the participants and their supervisors. The effectiveness of the technological component in our intervention, which is presented through the V-class online video-based learning environment, was strongly valued by the users in terms of usability and usefulness. They asserted that the V-class environment is easy to use and no real problems were reported by the users. The role of this environment in facilitating the activities of reflection, however, is considered by the users as useful to a great extent. The advantages of the pedagogical component in our intervention, which is presented through the reflective practice approach, were also highly appreciated by the users in relation to both connecting theory and practice and mastering the practiced competences. In general, all activities of reflection were appreciated by the users in relation to strengthening the presence of theory in the field training. However, the participants specified that the reflections they received from their peers and supervisors were the most significant factor in relation to connecting theory to practice while their own reflections on their performance and on their peers performance was the most significant factor in relation to mastering the practiced competences.

Combining the different findings in this study, it can be stated with confidence as an answer to the main research question in this study that our intervention indeed shows pedagogical advantages in reducing the gap between theory and practice in the field training. However, confirming the advantage of our intervention introduces the question of how this intervention can be realized in the real practice of field training in teacher education in Kuwait?

The realization of such an intervention will require an intensive collaboration between several actors in the educational organization. As it was discussed in Sections 9.1.1 and 9.1.2, several actions need to be taken in order to utilize effectively this intervention including needs and capability assessment and changes in the program structure and content. Therefore, the realization of this intervention should start first with a decision from the administration level. That will ensure the collaboration of several departments in relation to changing the content, modifying the program structure, and facilitating the needs of ICT applications and support. It is also important to find supervisors who are willing and also have the required knowledge and skills to manage both the pedagogical 
and the technological components of this intervention. Above all, ensuring enough time for the implementation process and giving room for becoming familiar with this intervention in the field training needs to take place.

\subsection{CONCEPTUAL AND PRACTICAL CONTRIBUTIONS OF THE STUDY}

Reflection and the reflective practice approach is a learning strategy that has been around for a long time and it has been used in education in diverse forms. The assumption of this study, which was supported by some practical examples in Chapter 3, was that when ICT supports the practice of reflection it will increase the potential of this approach for the field training. This assumption was confirmed through the findings of the presented study as it was found that supporting the reflective approach by ICT applications and specifically by the online video-based learning environment creates a suitable method for bridging the gap between theory and practice in the field training.

As a contribution to the literature concerning the reflective practice approach, this study proposed a new conceptual perspective toward the notion and the process of this approach. An attempt was made to find the core of the reflection notion which led to the development of a general description of the process of this approach. The aim of the proposed description is to accommodate the major differences in the reflection's theories and accordingly to incorporate the similarities in these theories, which resulted in the development of the reflective practice model. Another contribution to the literature in this study relates to the models or strategies for practicing reflection. The practical translation of the philosophy behind the reflection notion through the proposed description made it possible to design an innovative and workable model for practicing reflection. The result, therefore, was the development of a new generic model for practicing reflection that was described in Section 5.4.1 which accounts for a combination of reflection activities. Furthermore, a philosophical argument against the strong emphasis in other reflection models on the evaluation activities within the reflection processes was introduced in this study. It was argued that the emphasis on the evaluation activities or the end product of the reflection process will lead to several constraints that hold back the participants from practicing the activities of reflection freely (See Section 5.4.1 for more details concerning this argument). Therefore, the developed model is designed to shift the emphasis from the end product of the reflection activities to the process of these activities. 
Regarding the practical contributions, the ultimate goal of this study was to improve the practice of the field training in teacher education programs through connecting the theories that have been studied during the program to the real practice of teaching in the classroom. The main practical contribution in this study, thus, is the development and application of a new learning strategy and structure for the practice of the field training course. The developed reflective practice model functions as a systematic framework of an innovative approach for practicing field training that rely on ICT applications to facilitate this practice. Therefore, this study also contributes to research concerning the pedagogy-technology integration. Although the study was conducted in a specific teacher education institute-the College of Basic Education in PAAET in Kuwait-some of the findings could be useful as well for other educational institutes, particularly for those with similar educational and cultural characteristics as in the State of Kuwait.

To sum up, it can be concluded here that the utilization of the reflective practice approach supported by the online environment showed pedagogical advantages and introduced new contributions to the practice of field training in teacher education. Nevertheless, several limitations were also encountered in this study which will be discussed in the next section.

\subsection{LIMITATIONS OF THE STUDY}

The present study has certain limitations that need to be taken into account when considering the implications and the contributions of this study. Furthermore, some of these limitations can be seen as fruitful avenues for future research under the same theme. Three major limitations that were encountered in this study are discussed in the following sections.

\subsubsection{Possible novelty effect}

The novelty effect theory suggests that sometimes the improvement in learning or achievement that occurs when new technology is introduced is, in fact, not an actual improvement but rather a response to increased interest in this new medium. Therefore, it is assumed that if the achievement's gain is due to a novelty effect, this gain tends to diminish as learners become more familiar with the new medium (Clark \& Sugrue, 1988). 
The heavy emphasis in participants' responses presented in Section 8.2.1 on the enjoyment factor that comes with the use of the new intervention in the experiment points to the possible novelty effect. Nevertheless, admitting that the novelty effect may indeed have contributed to the increase of participants' attention in this experiment does not necessarily dismiss the possibility of permanent effects of this intervention. Based on our findings, the responses from the participants as well the supervisors should be interpreted beyond just appreciating the new method as attractive for its novelty. In addition to the effect of the novelty, the utilization of this intervention brought to the field training at least two major pedagogically beneficial innovations in comparison with the traditional practice of field training. The findings show that the utilization of the reflective practice approach stimulated stronger presence of theory and accordingly created explicit connection between theory and practice in the field training. Furthermore, there was a positive influence from this experiment on the quality of feedback in the field training. It is therefore expected that even though participants' level of interest may indeed decrease after the initial novelty effect wears off, which is understandable based on the novelty-effect theory, participants' level of interest based on our previous argument will probably remain at least greater than in the traditional courses (Pisapia, 2009). However, attention should always be paid in future researches under this theme to the possibility of the novelty that may be attached to the implementation of a new intervention.

\subsubsection{The trustworthiness of the self reporting findings}

Based on a design objective that was discussed previously in this dissertation, the use of any type of evaluation or assessment was avoided during the field experiment (see Section 5.4.1 for a detailed argument for this design objective). Understanding the real progress was accordingly taken from participants' own perspectives and judgments. Therefore, the reliance on self reporting as the main

representative of progress in this study can be seen here as one of the limitations that should be considered. An effort was made in the design of the data collection instruments in this study to overcome this limitation by the use of supervisors' perspectives and observations. Using data that are collected from the supervisors as experts of the progress of the field training is assumed to support the participants' data and to confirm participants' arguments and judgments about the real progress and the achievement in this experiment. 


\subsubsection{Sample's constraints}

Two limitations can be found in relation to the sample of this study. The first limitation concerns the size of the sample (16 participants) while the second limitation relates to gender representation (only female). The limited number of participants and the selection of only one gender in the field experiment were the consequence of some design factors of the field experiment as well as logistic factors related to the organization of the educational program in the College of Basic Education. Accordingly, as the statistical tests normally require a larger sample size in order to justify that the effect did not just happen by chance alone, it was hard to find a statistically significant relationship in this data. Furthermore, the absence of the male gender representation may also have an effect on the finding of this study especially because gender characteristics were used to justify some of the findings of this study (see Section 6.3.2.1).

Taking onto consideration the contributions of this study that were discussed in Section 9.3 as well as the presented limitations in this section, the next section will provide some suggestions for further research under the same theme.

\subsection{RECOMMENDATIONS FOR FURTHER RESEARCHES}

The findings from the presented study indicate that the implementation of the reflective practice approach supported by the online video-based learning environment in the field training in Kuwait showed positive effects on the gap between theory and practice. Yet more research on the same theme is needed in two different avenues in order to (a) further validate the findings from the presented study and (b) to increase the effectiveness of the practice of such intervention.

In relation to the first research avenue, more studies are needed to further evaluate the proposed model of reflection. Although the findings of this study showed a positive impact, questions concerning the generalization, the novelty effect, and the uncertainty of self reporting are still valid for more investigations. Further studies with broader samples and context in term of participants' number, variation in the gender, and the place of experimenting may be seen as the most demanding research avenues in relation to this study. The findings of such studies when conducted are expected to overcome the limitations of the presented study and accordingly to further validate the presented findings. 
A step forward toward increasing the effectiveness of this intervention as the second research avenue may take the direction of research studies concerning the effects from users' preparation or technology improvement. First, it was recognized during the presented study that users' prior knowledge in relation to the reflection theory as a pedagogical approach and the concept behind this theory plays a critical role in the implementation of our intervention. Along this line, the implementation of reflection as a part of the field training will accordingly require an early introduction to reflection theory during the educational program. Therefore, a study concerning the integration of the pedagogical concept of the reflective practice approach in the educational program may be a significant addition to the implementation of this intervention. Second, the rapid development of ICT applications may be an interesting research avenue that is assumed to provide solutions to the difficulties that have been encountered by the users of online video-based learning environments in this study. As it was suggested in Section 7.3.2 these difficulties can be avoided in different ways such as modifying the used environment, preparing courses for the users, or developing a new environment. Any of these three suggestions can be seen as an avenue for future research aiming to increase the effectiveness of our intervention.

\subsection{CONCLUDING REMARKS}

In all, it can be confidently stated here that the findings of this study provided positive contributions to both the body of knowledge as well as the practice of the field training. The philosophy behind the reflection notion was translated into a new conceptual perspective. Based on this perspective, a new learning strategy for the practice of field training was developed. This strategy aimed to introduce reflective practice as a pedagogical approach for field training that relies on advanced ICT applications to facilitate its activities. Two major pedagogical innovations were introduced by utilizing this strategy in the field training: strengthening the relationship between theory and practice and enhancing the quality of feedback. These two innovations are not the end, however. Much work lies ahead and research is recommended to further validate the presented findings and to enhance the impacts of this intervention on the field training. The fact that this study has demonstrated that the two innovations have pedagogical advantages in reducing the gap between theory and practice, provides a strong argument to pursue this work further. 


\section{REFERENCES}

AbuZaina, F., Hassan, A., \& AlJazzar, A. (1990). Development of teaching processes and methods and educational technology in teacher training and preparation. Risalat ULKhaleej AL-Arabi, 35, 137-165.

Acheson, K. A., \& Zigler, C. J. (1971). A comparison of two teacher training programs in higher cognitive questioning. San Francisco: Far West Laboratory for Educational Research and Development.

Admiraal, W., Janssen, J., \& Pijls, M. (2007). Design study of digital video portfolio in University education. Paper presented at the ECER 2007, Friday 21 September 2007, Ghent, Belgium. Network 16 ICT and Education. Retrieved August 15, 2008 from http://info.dividu.nl/docs/Paper_ECE_19_sept_2007.pdf

Admiraal, W., Janssen, J., Pijls, M., \& Gielis, A. M. (2008). Transfer between learning and practice: Digital video portfolio as a means to support the reciprocal relation between learning and work. Paper presentation at the Ninth International Conference on Human Resource Development Research and Practice across Europe, Lille, France. Retrieved December 10, 2008 from http://info.dividu.nl/docs/paper_HRDI.pdf

AlDeeb, F. (1997). Preparing teachers in the educational colleges. The Educational Journal, 22, 90-102.

AlHamad, R., Behbahani, B., \& AlShargawi, A. (1995). The academic preparation in the College of Basic Education and the teachers' needs in elementary level: First episode. The Educational Journal, 15, 24-35.

Allen, A. (2007). A critical reflection on the methodology of teaching law to non-law students. Web journal of current legal issues, 4. Retrieved August 15, 2008 from http://webjcli.ncl.ac.uk/2007/issue4/allen4.html

Allen, D. W. (1966). A new design for teacher education: The teacher intern program at Stanford University. The Journal of Teacher Education, 17(3), 296-300.

Allen, D. W., \& Ryan, K. (1969). Microteaching. Reading, Mass: Addison-Wesley.

AlThuwaini, S. (2003). Visualizing abstract scientific concepts by virtual reality. Studies on using virtual reality techniques in Kuwait education. Unpublished doctoral dissertation. Enschede: University of Twente.

Argyris, C., \& Schön, D. (1974). Theory in practice: Increasing professional effectiveness. San Francisco: Jossey-Bass 
Barron, L. C., \& Goldman, E. S. (1994). Integrating technology with teacher preparation. In B. Means (Ed.), Technology and education reform: The reality behind the promise (pp. 81-110). Jossey-Bass: San Francisco.

Becta. (2004). What the research says about virtual learning environments in teaching and learning. Second Edition revised and updated. Retrieved August 15, 2008 from http:// partners.becta.org.uk/upload-dir/downloads/ page_documents/research/wtrs_vles.pdf

Benbasat, I. G., Goldstein, D. K., \& Mead, M. (1987). The case research strategy in studies of information systems. Management Information Systems Quarterly, 11(3), 369-386.

Bengtsson, J. (1995). What Is Reflection? On Reflection in the Teaching Profession and Teacher Education. Teachers and Teaching: Theory and Practice, 1(1), 23 -32

Bengtsson, J. (2003). Possibilities and limits of self-reflection in the teaching profession. Studies in Philosophy and Education, 22(3) - 4, 295-316.

Biggs, J. (1999). Teaching for quality learning at university. Buckingham: Open University Press.

Bimmel, P., \& Janssen, J. V. (2004). Experimenten met DiViDU: verslag van zes pilots uitgevoerd in de Realisatiefase (voorjaar 2004). Rapportage RF DiViDU, WP1, 2, 6, 7 en 8. Projectgroep DiViDU, Utrecht, DU. Retrieved August 15, 2008 from http://info.dividu.nl/docs/Expserie1.pdf

Blijleven, P. (2005). Multimedia-cases: Naar een brug tussen theorie en praktijk. Unpublished doctoral dissertation. Enschede: University of Twente.

Blurton, C. (1999). New directions in education. In M. Tawfik (Ed.), UNESCO's World Communication and Information Report 1999-2000. Paris: UNESCO.

Boud, D., \& Walker, D. (1998). Promoting reflection in professional courses: The challenge of context. Studies in Higher Education, 23(2), 192.

Boud, D., Keogh, R., \& Walker, D. (1985). Reflection: Turning experience into learning. London: Kogan Page.

Boyd, E., \& Fales, A. (1983). Reflective learning: Key to learning from experience. Journal of Humanistic Psychology, 23(2), 99 - 117.

Buckingham, J. (2005), Good teachers where they are needed. Issue Analysis, No. 64, October, Centre for Independent Studies.

Calderhead, J. (1989). Reflective teaching and teacher education. Teaching and Teacher Education, 5, 43-51.

Cannings, T. R., \& Talley, S. (2002). Multimedia and online video case studies for preservice teacher preparation. Education and Information Technologies, 7(4), 359 - 367.

Carter, K. (1990). Teachers' knowledge and learning to teach. In W. R. Houston (Ed.), Handbook of research on teacher education (pp. 291-310). New York: MacMillan.

Christie, M., Rowe, P., Perry, C., \& Chamard, J. (2000). Implementation of realism in case study research methodology. International Council for Small Business, Brisbane. Retrieved November 25, 2007 from

http://ecsocman.edu.ru/images/pubs/2002/12/24/0000031912/case_st.pdf 
Chung, C. M., Mak, S. Y., \& Paul, S. (1995). Reflective lesson planning in refresher training programs for experienced physics teachers. Journal of Science Education and Technology $4(2), 151-161$.

Clark, C. M., \& Yinger, R. J. (1979). Teachers' thinking. In P. L. Peterson, \& H. J. Walberg (Eds.), Research on teaching: Concepts, findings, and implications (pp. 231-263). Berkeley, CA: McCutchan.

Clark, R. E., \& Sugrue, B. M. (1988). Research on instructional media, 1978-1988. In D. Ely (Ed.), Educational media and technology yearbook, Vol. 14, pp. 19-36. Colorado: Libraries Unlimited, Inc.

College of Basic Education Manual. (2004). The college of basic education and training. Published by the Public Authority for Applied Education and Training, Kuwait.

Cuban, L. (1986). Teachers and machines: The classroom use of technology since 1920. New York: Teachers College Press.

Currier, S., Brown, S., \& Ekmekioglu, C. (2001). INSPIRAL: Investigating Portals for Information Resources and Learning. Final report. Glasgow: University of Strathclyde, Centre for Digital Library Research and the Centre for Educational Systems. Retrieved August 15, 2008, from http://inspiral.cdlr.strath.ac.uk/documents/INSPfinrep.pdf

Davison, R. M. (1998). An action research perspective of group support systems: How to improve meetings in Hong Kong. Unpublished doctoral dissertation. Hong Kong: City University of Hong Kong.

De Korte, D. A. (1967). Television in education and training (English Edition). Eindhoven, The Netherlands: N.V. Philips' Gloeilampenfabrieken.

Dewey, J. (1910). How we think. Boston, DC: Heath and Co.

Dewey, J. (1933). How we think, a restatement of the relation of reflective thinking to the educative process. Boston, DC: Heath and Co.

Doerr, H. M., Bowers, J. S., Masingila, J. O., \& McClain, K. (2000). Facilitator's guide: Making weighty decisions, a case study. NSF Grant \#REPP 9725512. Retrieved August 15, 2008 from http://www-rohan.sdsu.edu/faculty/jbowers/Facilitator_Guide_weighty.pdf

Drake, P., \& Dart, L. (1995). Intellectual challenges for partnership. In V. Griffiths, \& P. Owen (Eds.), Schools in partnership: Current initiatives in school-based teacher education. London: Paul Chapman.

Eilam, B., \& Poyas, Y. (2006). Promoting awareness of the characteristics of classrooms' complexity: A course curriculum in teacher education. Teaching and Teacher Education, 22, 337-351.

Eraut, M. (2000). Non-formal learning and tacit knowledge in professional work. British Journal of Educational Psychology, 70(1), 113-136.

European Commission. (2002). The teaching profession in Europe: Profile, trends and concerns. Report 1: Initial training and transition to working life - General lower secondary education. Brussels: Eurydice European Unit. 
European Commission. (2005). Key data on education in Europe 2005. Eds. Jan Figel., Joaquin Almunia. Eurydice, Eurostat, Luxembourg. Retrieved November 1, 2007 from http://www.okm.gov.hu/doc/upload/200601/key_data_2005.pdf

Farrell, T. (1995a). Reflective teaching. Principles and practice. Forum (36)4. Retrieved November 6, 2007, from http://exchanges.state.gov/forum/vols/vol36/no4/p10.htm

Farrell, T. (1995b). Second language teaching: Where are we and where are we going? An interview with Jack Richards. Language Teaching: The Korea TESOL Journal, (3)3, 94-95.

Fendler, L. (2003). Teacher reflection in a hall of mirrors: Historical influences and political reverberations. Educational Researcher, 32(3), 16-25.

Ferl (2006). VLEs and MLEs. Why have a VLE? Further Education Resources for Learning. Becta ICT advice. Retrieved August 15, 2008 from

http:/ / ferl.becta.org.uk/ display.cfm?page $=247$

Field Training Manual. (2007). The college of basic education and training. Published by the Public Authority for Applied Education and Training, Kuwait.

Fisser, P. (2001). Using information and communication technology: A process of change in higher education. Enschede: University of Twente.

Galliers, R. D. (1991) Choosing information systems research approaches. In R. D. Galliers (Ed.), (1992) Information systems research: Issues, methods and practical guidelines (pp. 144162). Alfred Waller: Henley-on-Thames.

Griffiths, V. (2000). The reflective dimension in teacher education'. International Journal of Educational Research, 33(5), 539-55.

Grinnell, R. M., \& Williams, M. (1990). Research in social work: A primer. Itasca, IL: F. E. Peacock.

Grundy, S., \& Kemmis, S. (1981). Educational action research in Australia: The state of the art. Paper presented at the annual meeting of the Australian association for research in education, Adelaide.

Grundy, S., \& Kemmis, S. (1982). Educational action research in Australia: The state of the art (an overview). In S. Kemmis, et al. (Eds.), The action research reader. Waurn Ponds, Victoria: Deakin University.

Hasan, E. (2001). Instructional design and media selection. A study on the use of instructional-design theories and models in a college for teacher education. Unpublished doctoral dissertation. Enschede: University of Twente.

Hiebert, J., Gallimore, R., Garnier, H., Bogard Giwin, K., Hollingsworth, H., \& Jacobs, J. et al., (2003). Teaching mathematics in seven countries: Results from the TIMSS 1999 video study. (NCES 2003-013). Washington, DC: United States Department of Education, National Center for Education Statistics.

Hinett, K. (2002). Improving learning through reflection: part one. York: Higher Education Academy.

Hirschheim, R. A. (1985). Information systems epistemology: A historical perspective. In R. D. Galliers (Ed.), (1992) Information systems research: Issues, methods and practical guidelines (pp. 28-60). Alfred Waller: Henley-on-Thames. 
Holodick, N. A., Scappaticci, F. T., \& Drazdowski, T. (1999). Developing reflective practices of preservice teachers through a video assessment program. Proceedings of the Society for Information Technology in Teacher Education, San Antonio, Texas.

Holter, I. M., \& Schwartz-Barcott, D. (1993). Action research: What is it? How has it been used and how can it be used in nursing? Journal of Advanced Nursing, 128, 298-304.

Idalovichi, I. (2003). Grounds and perspectives of critical reflection. An educational and philosophical inquiry, essays in education 6.

Kelly, G. A. (1955). The psychology of personal constructs, Vols. 1 \& 2. New York: Norton.

Kemmis, S., \& McTaggert, R. (1988). The action research planner geelong. Deakin: University Press.

Kinsella, E. A. (2003). Toward understanding: Critiques of reflective practice and possibilities for dialogue. In P. Cranton (Ed.), Canadian Association for the Study of Adult Education. Halifax NS.

Kolb, D. A. \& Fry, R. (1975). Towards an applied theory of experiential learning In C. L. Cooper (Ed.), Theories of group processes (pp. 33 - 58). New York: Wiley.

Kolb, D. A. (1984). The process of experiential learning. Englewood Cliffs, NJ: Prentice Hall.

Kolodner, J. L. (2006). Case-based reasoning. In R. K. Sawyer (Eds.), The Cambridge handbook of the learning sciences. Cambridge: Cambridge University Press

Korthagen, F. (1993). Two modes of reflection. Teaching and Teacher Education, 9(3), 317-326.

Korthagen, F., \& Kessels, J. (1999). Linking theory and practice: Changing the pedagogy of teacher education. Educational Researcher, 28(4), 4-17.

Korthagen, F., \& Vasalos, A. (2005). Levels in reflection: Core reflection as a means to enhance professional growth. Teachers and teaching, 11(1), $47-71$.

Korthagen, F., Kessels, J., Koster, B., Lagerwerf, B., \& Wubbels, T. (2001). Linking practice and theory: The pedagogy of realistic teacher education. Mahwah: NJ, Lawrence Erlbaum Associates.

Korthagen, F. A. J. (1985). Reflective teaching and preservice teacher education in the Netherlands. Journal of Teacher Education, 36(5), 11-15.

Korthagen, F. A. J. (1992). Techniques for stimulating reflection in teacher education seminars. Teaching and Teacher Education 8(3), 265-274.

Kovalchick, A. M., Hrabe, E., Julian, M. F., \& Kinzie, M. B. (1999). ID case studies via the World Wide Web. In P. A. Ertmer \& J. Quinn (Eds), The ID casebook: Case studies in instructional design (pp. 141-148). Prentice-Hall, Merrill: NJ.

Kulk, R., Janssen, J., Gielis, A., \& Scheringa, E. (2005). DiViDU - Learning from professional practice through online video. Proceedings from the World Conference on Educational Multimedia, Hypermedia and Telecommunications 2005: Chesapeake, VA: AACE. 3199-3204.

Kuwait University. (2007). The website of College of Education in Kuwait University. Center goals. Retrieved November 1, 2007 from http:/ / coe.kuniv.edu.kw/page_sublink.php?subid=46\&id=45\&pid=3

Lakoff, G., \& Johnson, M. (1980). Metaphors we live by. Chicago: University of Chicago Press. 
Lamberson, M., \& Lamb, B. (2003). Course management systems: Trapped content silos or sharing platforms? The Ohio State University. Retrieved August 15, 2008 from http://telrresearch.osu.edu/learning_objects/documents/TELR-LO7screen.pdf

Lather, P. (1986). Research as Praxis. Harvard educational review, 56(3), 257-77.

Leijen, A. (2008). The reflective dancer: ICT support for practical training. Unpublished doctoral dissertation. Utrecht: Utrecht University.

Leijen, A., Lam, I., Simons, P., \& Wildschut, L. \& (2008). Pedagogical practices of reflection in tertiary dance education. European Physical Education Review, 14(2), 223-241

Leijen, A., Lam, I., Wildschut, L., Simons, P. R., \& Admiraal, W. (2009). Streaming video to enhance students' reflection in dance education. Computers \& Education, 52, 169-176

Levin, W. C. (1988). Sociological ideas: Concepts and applications. California: Wadsworth.

Lewin, K. (1946). Action research and minority problems. Journal of social issues, 2, 34 - 46.

Lewin, K. (1948). Resolving social conflict. New York: Harper Bros.

Limbacher, P. C. (1971). A study of the effects of microteaching experiences upon the classroom behavior of social studies student teachers. Paper presented at the American Education Research Association, New York, February.

Loughran, J. (2002). Effective reflective practice: In search of meaning in learning about teaching. Journal of Teacher Education, 51(1), 33 - 43.

Mackintosh, C. (1998). Reflection: A flawed strategy for the nursing profession. Nurse Education Today, 18(7), 553-557.

Masters, J. (1995). The history of action research. in I. Hughes (Ed.), Action research electronic reader. The University of Sydney. Retrieved November 25, 2007 from http://www.behs.cchs.usyd.edu.au/arow/Reader/rmasters.htm

McCurry, D. S. (2000). Technology for critical pedagogy: Beyond self-reflection with video. Society for Information Technology \& Teacher Education International Conference: Proceedings of SITE 2000, San Diego, CA, 1(3), 6-11.

Merseth, K. (1994). Cases, case methods, and the professional development of educators. (Digest ED401272). ERIC Digest Number, 95-5.

Mezirow J. (1981). A critical theory of adult learning and education. Adult education: Learning styles and facilitating reflection. London: English National Board of Nursing, Midwifery and Health Visiting.

Miles, M. B., \& Huberman, A. M. (1994). Qualitative data analysis. London: Sage Publications.

Miller C., Tomlinson, A., \& Jones, M. (1994). Researching professional education: Learning styles and facilitating reflection. London: English National Board for Nurses, Midwives and Health Visitors.

Moreno, R., \& Valdez, A. (2007). Immediate and delayed effects of using a classroom case exemplar in teacher education: The role of presentation format. Journal of Educational Psychology, 99(1), 194 - 206.

Morgan, G. (2003). Faculty use of course management systems. Research study from the EDUCAUSE Center for applied research. Boulder, CO: EDUCAUSE Center for Applied Research. 
Morley, D. (1991). Resource analysis as action research. In Wilkinson, P., \& William C. (Eds.), Resource analysis research in developing countries (pp. 1 - 16). Toronto: York University.

Mountford, B., \& Rogers, L. (1996). Using individual and group reflection in and on assessment as a tool for effective learning. Journal of Advanced Nursing, 24, 1127-1134.

Murphy, J. (2003). Teaching practice conversations. Plans, action and performance. Singapore: Pearson.

NCTE. (2008). ICT planning matrix, ICT resources and infrastructure. The National Center for Technology in Education. Retrieved August 15, 2008 from http:/ / www.ncte.ie/ICTPlanning/ICTPlanningMatrix/ICTResourcesandinfrastructure

Nemirovsky, R., \& Galvis, A. (2004). Facilitating grounded online interactions in video-casebased teacher professional development. Journal of Science Education and Technology, 13(1), $67-79$.

Newell, R. (1992). Anxiety, accuracy and reflection: The limits of professional development. Journal of Advanced Nursing, 17, 1326-1333.

Newhouse, P., Lane, J., \& Brown, C. (2007). Reflecting on teaching practices using digital video representation in teacher education. Australian Journal of Teacher Education. August, 2007. Retrieved November 1, 2007 from http:/ / ajte.education.ecu.edu.au/issues/PDF/323/Newhouse.pdf

Newman, S. J. (1996). Reflection and teacher education. Journal of education for teaching, 22( 3), $297-310$.

O'Brien, R. (2001). An overview of the methodological approach of action research. In Roberto Richardson (Ed.), Theory and practice of action research. João Pessoa, Brazil: Universidade Federal da Paraíba. (English version). Retrieved November 25, 2007 from http://www.web.net/ robrien/papers/arfinal.html

PAAET. (2004). The college of basic education and training. Published by the Public Authority for Applied Education and Training, Kuwait.

Pisapia, J. (2009). Learning technologies and student performance. The Metropolitan Education and Research Consortium (MERC). Virginia Commonwealth University. Retrieved August 15, 2008 from http://www.soe.vcu.edu/merc/briefs/brief4.htm

Platzer, H., Blake, D., \& Ashford, D. (2000). Barriers to learning from reflection: A study of the use of groupwork with post-registration nurses. Journal of Advanced Nursing, 31(5), 1001-1008.

Potashnik, M., \& Capper, J. (1998). Distance education: Growth and diversity. Finance and development. Retrieved August 15, 2008 from

http://www.worldbank.org/fandd/english/pdfs/0398/0110398.pdf

Procee, H. (2006). Reflection in education: A Kantian epistemology. Educational Theory, 56(3), 237-362.

Quintana, C., Shin, N., Norris, C., \& Soloway, E. (2006). Learner-centered design. In R. K. Sawyer (Eds.), The Cambridge handbook of the learning sciences. Cambridge: Cambridge University Press 
Race, P. (2002). Evidencing reflection: Putting the ' $w$ ' into reflection. The higher education academy, ESCALATE Learning Exchange. Retrieved August 15, 2008 from http://escalate.ac.uk/resources/reflection/index.html

Rainer, T. (1980). The new diary. London: Angus and Robertson.

Rapoport, R. N. (1970). Three dilemmas in action research. Human relations: Studies towards the integration of the social sciences, 23(6), 499.

Ravitch, D. (2002). A brief history of teacher professionalism. Proceedings from the White House Conference on Preparing Tomorrow's Teacher. Washington, D.C. Retrieved November 1, 2007 from http://www.ed.gov/admins/tchrqual/learn/preparingteachersconference/ravitch.html

Reece Jones, P. (1995). Hindsight bias in reflective practice: An empirical investigation. Journal of Advanced Nursing, 21, 783-788.

Richardson, G., \& Maltby, H. (1995). Reflection on practice: Enhancing student learning. Journal of Advanced Nursing, 22, 235-242.

Richert, A. E. (2005). Inquiring about practice: Using web-based materials to develop teacher inquiry. Teaching Education, 16(4), 297-310.

Santagata, R., Zannoni, C., \& Stigler, J. (2007). The role of lesson analysis in pre-service teacher education: An empirical investigation of teacher learning from a virtual videobased field experience. Journal of Mathematics Teacher Education, 10(2) 123-140.

Sarac-Suzer, H. (2007). Action research. Turkey: Hacettepe University. Retrieved November 25, 2007 from http://www3.telus.net/linguisticsissues/actionresearch

Schön, D. (1983). The reflective practitioner: How professionals think in action. New York, NY: Basic Books, Inc.

Schön, D. (1987). Educating the reflective practitioner: Toward a new design for teaching and learning in the professions. San Francisco, CA: Jossey-Bass.

Schrader, P. G., Leu, D. J., Kinzer, C. K., Ataya, R., Teale, W. H., Labbo, L. D. et al. (2003). Using Internet delivered video cases, to support pre-service teachers' understanding of effective early literacy instruction: An exploratory study. Instructional Science, 31, 317 340.

Schrag, P. G., \& Meltsner, M. (1998). Reflections on clinical legal education. Boston: Northeastern University Press.

Seago, N. (2004). Using video as an object of inquiry for mathematics teaching and learning. In J. Brophy (Ed.), Using video in teacher education (pp. 259-286). Oxford, UK: Elsevier.

Sherin, M. G. (2004). New perspectives on the role of video in teacher education. In J. Brophy (Ed.), Using video in teacher education (pp. 1 - 27). Oxford, UK: Elsevier.

Sherin, M. G., \& Van Es, E. A. (2005). Using video to support teachers' ability to notice classroom interactions. Journal of Technology and Teacher Education, 13(3), 475-491

Shulman, L. (1992). Toward a pedagogy of cases. In J. H. Shulman (Ed.), Case methods in teacher education (pp. 1-30). Teachers College Press: New York. 
Smith, M. K. (2001). Donald Schön: Learning, reflection and change. The encyclopedia of informal education. Retrieved August 15, 2008 from

www.infed.org/thinkers/et-schon.htm

Smith, R. (2000). The future of teacher education: Principles and prospects. Asia Pacific Journal of Teacher Education, 28(1), 7-28.

Stake, R. E. (1995). The art of case study research. Thousand Oaks, CA: Sage Publications

Stein, D. (2000). Teaching critical reflection: Myths and realities. ERIC Clearinghouse on Adult, Career and Vocational Education.

Stigler, J. W., \& Hiebert, J. (1999). The teaching gap: Best ideas from the world's teachers for improving education in the classroom. New York: The Free Press.

Stockero, S. L. (2008). Using a video-based curriculum to develop a reflective stance in prospective mathematics teachers. Journal of Mathematics Teacher Education, 11, 373 - 394.

Strijker, A. (2004). Reuse of learning objects in context: Human and technical aspects. Unpublished doctoral dissertation. Enschede: University of Twente.

Susman G. I., \& Evered, R. D. (1978). An assessment of the scientific merits of action research. Administrative Science Quarterly, 23, 582-603.

Taba, H., \& Noel, E. (1957). Steps in the action research process. Action research: A case study. Washington, DC: Association for Supervision and Curriculum Development.

Taghioff, D. (2001). Seeds of consensus. The potential role for information and communication technologies in development: Empowerment, appropriateness and measuring as if needs really get met. Doctoral dissertation. London: University of London.

Teacher Education Material website. (1995). Bibliographic data. Retrieved August 15, 2008 from http:/ / www.te-mat.org/Reviews/ViewProduct.aspx?ProductID=17432

The New-York Times. (1890, August 4). The first normal school: Early efforts to secure training for teachers. Webster and the Hanover convention - work of Horace Mann - Normal schools of the world. New York Times. P. 8. Retrieved November 1, 2007 from http:/ query.nytimes.com/gst/abstract.html?res=9E07EEDA133BE533A25757C0A96E9 C94619ED7CF

Tinio, L. V. (2003). ICT in education. UNDP Asia-Pacific Development Information Programme. UNDP-APDIP. Retrieved August 15, 2008 from http://www.apdip.net/publications/iespprimers/eprimer-edu.pdf

Ullman, C., \& Rabinowitz, M. (2004). Course management systems and the reinvention of instruction. T.H.E. Journal. Retrieved August 15, 2008 from http://thejournal.com/magazine/vault/A5070.cfm

Usher, R., Bryant, I., \& Johnston, R. (1997). Adult education and the postmodern challenge. London: Routledge.

Vallance, M. (2006). The Impact of synchronous inter-networked teacher training in ICT integration. ProQuest: Ann Arbor.

Vallance, M. (2008). Using a database application to support reflective practice. TechTrends, $52(6), 69-74$. 
Van den Berg, E. (2001). An exploration of the use of multimedia cases as reflective tool in teacher education. Research in Science Education, 31(2), 245-265.

Vreede, G. J. (1995). Facilitating organisational change: The participative application of dynamic modelling. Unpublished doctoral dissertation. Delft University of Technology.

Vygotsky, L. S. (1978). Mind and society: The development of higher mental processes. Cambridge, MA: Harvard University Press.

Wade R. C. (1994). Teacher education students' views on class discussion: Implications for fostering critical reflection. Teaching and Teacher Education, 10, 231-243.

Wang, J., \& Hartley, K. (2003). Video technology as a support for teacher education reform. Journal of Technology and Teacher Education, 11(1), 105-138.

Warburton, E. C. (2004). Knowing what it takes: The effect of perceived learner advantages on dance teachers' use of critical-thinking activities. Research in Dance Education, 5(1), $69-82$.

Ward, B. E. (1970). A survey of microteaching in NCATE-accredited secondary education programs. Research and Development Memorandum, Stanford Center for Research and Development in Teaching, Stanford University

Warrick, W. R. (2001). Constructivism: Pre-historical to post-modern. Ways of Knowing. Final Paper. Retrieved November 1, 2007 from http://mason.gmu.edu/ wwarrick/Portfolio/Products/PDF/constructivism.pdf

Winter, G. (2000). A comparative discussion of the notion of 'validity' in qualitative and quantitative research. The qualitative report, 4 (3/4). Retrieved 25 November, 2007 from http://www.nova.edu/ssss/QR/QR4-3/winter.html.

Winter, R. (1989) Learning from experience. Principles and practice in action research. Lewes, UK: Falmer Press.

Yin, R. K. (1994). Case study research, design and methods, $2^{\text {nd }}$ ed. Newbury Park, NJ: Sage Publications.

Zeichner, K. (1982). Reflective teaching and field-based experience in teacher education Interchange, 12(4), 1-22.

Zeichner, K., \& Liston, D. (1996). Reflective teaching: An introduction. Reflective teaching and the social conditions of schooling, A series for prospective and practicing teachers. Mahwah, NJ: Lawrence Erlbaum Associates, Publishers.

Zuber-Skerritt, O. (1992). Professional development in Higher Education: A theoretical framework for action research. London: Kogan Page. 


\section{SUMMARY}

The ability to convert theoretical knowledge into practical behavior is a common obstacle facing newly graduated employees in most professions. To overcome this obstacle, educational institutes are offering some kind of field training courses that allow their students to practice and gain experience in a real professional situation. In some professional training institutes, such as teacher education and nursing institutes, these courses are usually mandatory requirements for completing the program. The goal of the field training is to give the students the opportunity to apply their theoretical knowledge, under experienced supervision, in a real professional context. In other words, field training supports the period of transition between the initial training of prospective teachers and their entry into professional life as fully qualified teachers (European Commission, 2002). In teacher education, many educators, for instance Buckingham (2005), Smith (2000), Stigler and Hiebert (1999) and Schön (1987) warn about a gap between the theoretical knowledge that is acquired from the educational program and the practical skills that are required at the schools in this transition period. This gap is also found in the teacher education programs in Kuwait (Al Deeb, 1997). The poor performance of the field training in developing prospective teachers' competences is presented as an important factor that is causing this gap in teacher education in Kuwait (Hasan, 2001). Improving the performance of the field training in these programs could lead to reducing the gap between theory and practice. This study attempts to improve the field training in the teacher education programs in Kuwait through the facilitation of the reflective practice approach among prospective teachers in these programs.

A general definition for the reflective practice approach is described by Leijen, Lam, Simons and Wildschut (2008) as "a cognitive process carried out in order to learn from experiences through individual inquiry and collaboration with others" (p.224). Biggs (1999) describes the activities of reflection by comparing the professional practice of reflection with a mirror's reflection: the mirror reflects an 
exact replica of the object in front of it while the reflection in professional practice offers what might be an improvement of the original. The competence behind the concept of reflective practice or reflective teaching has been considered an important competence among educators and researchers in the field of teacher education since the beginning of the 1980s (Korthagen, 1993). Stein (2000) describes the process of reflection as blending experience with theoretical and technical learning in order to create alternatives in the knowledge, the behavior, or the insight of the practitioner. Educators such as Schön (1987) and Calderhead (1989) state that the competence of reflection is essential for teachers to learn from their experience. Furthermore, Procee (2006) rates reflective practice as one of the most promising innovations in education. Today, reflection is indeed one of the essential goals in many teacher education programs (Newman, 1996; Korthagen \& Vasalos, 2005). Yet, several barriers are likely to interfere with the utilization of the reflective practice approach in teacher education programs in Kuwait. A major barrier relates to the complexity of recalling the different details in an experience in order to describe and analyze this experience. This barrier has been highlighted in several research studies as a major obstacle in realizing the potential of the reflection approach and is also described sometimes as a major weakness in this approach (Boud, Keogh \& Walker, 1985; Mackintosh, 1998). A second barrier is related to the arrangement of the field training in the teacher education programs in Kuwait specifically where each prospective teacher performs his or her task alone in a different school. This arrangement is isolating these trainees from each other with almost no channel of communication. It is considered another major obstacle in using peer-reflection activities in the field training. Thirdly, introducing a completely new pedagogical approach is expected to bring along with it some complexities. Therefore, in order for prospective teachers to reflect on their own experiences effectively, they need first to be able to clearly recall these experiences. Furthermore, for prospective teachers to practice the peer-reflection activities they also need to have access to their peers' experiences and be able to observe their peers' behaviors in similar situations. The practice of a new approach also requires some kind of support and guidance. Thus, this research attempts to find a solution to these barriers in practicing the reflective approach to reduce the gap between theory and practice in the teacher education in Kuwait.

Providing prospective teachers with tools that facilitate the recall of experienced activities and strengthen the channels of communication among prospective 
teachers is assumed to support the implementation of the reflective practice approach. Several attempts have already been made in the last decade to use technology for improving the performance of field training (Kulk et al., 2005; Newhouse et al., 2007). Particularly, the use of video applications in an online learning environment in teacher education programs was tested on several occasions and showed promise and potential for the field training (Kulk et al., 2005; Newhouse et al., 2007). The use of video in an online learning environment in some of the previous researches showed significant opportunities in the context of our research. For instance, recording the performance on video will allow prospective teachers to watch their performance, which will facilitate the self-reflection activities. Furthermore, through the recorded video prospective teachers will be able to demonstrate objectively their performance to their peers, facilitating peer reflection. Moreover, with respect to the separation of the prospective teachers during the field training, the use of the online learning environment will provide them with communication channels that support the exchange of experiences and the reflection activities. Based on those expected opportunities from the online video-based learning environments for our research, the aim of this research is formulated as follows:

To reduce the gap between theory and practice in the teacher education programs in Kuwait by the utilization of the reflective practice approach in the field training supported by an online video-based learning environment.

Based upon this aim of the research, a general question has been developed that serves as the overall question for this research:

Does the use of the reflective practice approach supported by an online videobased learning environment in field training in teacher education programs have pedagogical advantages in reducing the gap between theory and practice?

This overall research question is studied in the context of the Kuwait teacher education programs by six more focused questions that are formulated to cover all aspects of this question and answered throughout this dissertation.

It was found with respect to the meaning behind the reflective practice approach that most of the existing notions of reflection can be seen as a development of Dewey's relationship between perception and experience which is in and of itself an elaboration of Kant's relationship between understanding and experience as 
an iterative process of determinative and reflective judgment. Reflection based on this interpretation plays the role of continually connecting practitioners' understanding with their experiences and connecting their experiences back to their prior knowledge in order to facilitate learning. Looking into the reflective practice from this perspective reveals the core of the reflection notion as building a bridge between practitioners' knowledge and their experiences, therefore, connecting theory to practice. To better understand reflection, a broad description of reflection activities taking the different notions of reflection into consideration could be useful here. The reflection activities in most of these notions can be generically described as a process whereby the practitioners look back into their experience, think about and question this experience in light of their prior knowledge, and judge their action in this experience in order to develop an alternative knowledge and action. In education, reflection is increasingly implemented in teacher education programs and is considered important by many educators and researchers in the field of teacher education for the acquisition of teachers' reflective competence (Dewey, 1933; Kolb, 1984; Boud et al., 1985; Schön, 1987; Calderhead, 1989; Zeichner \& Liston, 1996; Korthagen \& Vasalos, 2005).

It was also found that although the common understanding of reflection among educators has resulted in formulating similar goals, different strategies and models for practicing reflective activities can be found in the field of education. The differentiation among these strategies and models could be presented by the level of generalization or elaboration in the model or by the emphasis on specific aspects in practicing reflection. The reason for this variation is that the development of these different reflection models is mostly influenced by different environmental factors that shaped the focus of the implementation and the stages of the models. Some of the important factors that may determine the design and implementation of reflection activities are the level of learners' awareness, the social influence of society, or the type of program delivery in the specific education program. However, there are three common components in the majority of these models: the importance of practitioner's prior knowledge and background, the importance of conscious observation of the experience and the emphasis on a cyclical and continuous process. These components do, in fact, agree with the core of the notion of reflection, which focuses on the relationship between the experience and the understanding. Using these three components to develop a generic model of reflection that takes into account practitioners' 
characteristics and the social and organizational aspects in a specific educational program will presumably increase the opportunity of successful implementation of reflective practice. Therefore, these three components were used in the design stage of this research to develop a generic model of reflection that may best suit the situation in Kuwait considering the characteristics of Kuwait's teacher education programs and the level of awareness about reflective practice among learners in Kuwait.

Our understanding of the notion of reflection led us to conclude that in order to build a reflection model for our field experiment, the three common components of the reflection models as well as the two environmental factors should be taken into account. Regarding the environmental factors, it was found that the program in the College of Basic Education has the required flexibility to accommodate the reflective practice approach, the time, and the ICT-infrastructure aspects. However, the educational content of this program as well as the knowledge and skills of the learners were seen as lacking the required theoretical foundation to effectively practice the reflection approach. Therefore, in addition to considering these findings in the design of the experiment, the design of the reflective practice model here also accounts for this concern by trying to simplify the process of reflection in the model without losing the essence of the notion of reflection. In order to achieve this goal, the activities in our model are proposed in general terms to allow the participants to add their fingerprints to the different reflection activities in the model through their own understanding of these activities. The participants' freedom to practice the different reflection activities based on their understanding is assumed to increase the variation of this practice especially with the involvement of peer and group reflection. That might be a significant method to provide the participants with different ways to practice each of the activities in the model and to broaden their horizons for possible alternatives. The combined simplification of the reflection model and the consideration given in the design of the experiment are assumed to overcome the lack of information about reflection.

These preparations are also assumed to cover the first common component included in most reflection models concerning the importance of participants' prior knowledge and background. The second component about the importance of conscious observation of the experience is naturally included in our model. The specifications of the different activities in the model and the necessary 
assignments to be completed by the participants insure an increase in participants' awareness of their experiences. Moreover, the third component of the reflection models is also considered here in the design of our reflection model. It is acknowledged that the process of reflection in the literature is mostly described as a cyclical process. It is proposed here in our reflection model, however, that the demonstration of reflection as a spiral process may provide a more accurate description especially in relation to classroom activities. Considering the activities in a classroom as unique every time they occur is a main reason for choosing the spiral as representative for the reflection process in our model. Based on this, the odds of repeating an identical situation seem fairly slim. Another reason for describing the reflection process as a spiral is to avoid the implication of the necessity of the evaluation activity at the end of the reflection cycle. Looking at the big picture beyond the notion of reflection reveals that the goal of reflection is to critically examine the performance and to explore the possible alternatives that may improve this performance. Utilizing the evaluation as the final activity of the reflection process may lead to a change in the concept of the reflection into a judgment about the success or failure of the performance. Another argument about the possible negative impact of having the evaluation as an independent reflection activity is the possibility of creating participants' reservations towards their input and inaccurate evaluations (Richardson \& Maltby, 1995; Mackintosh, 1998). This understanding leads to the finding of alternative activities as the last activity in the reflection cycle. Therefore, the reflective practice model that was used in our field experiment consists of five stages. It starts with experience followed by description, selfreflection, and peer-reflection, and it ends with finding alternatives for the performance that can be the starting point for new rounds of experience and reflection. The emphasis in many of the reflection models is usually placed on the self as the source of reflection. In our model, an equal emphasis has been given to both the self and peers as the source of knowledge and the materials that help lead to other alternatives. However, the activities in the first three stages in our reflection model can, on the one hand, be described as independent activities where each participant focuses on her own experience. On the other hand, the activities in the last two stages in the model are dependent activities where others' opinions and feedback are significant. The following is an illustration of the activities as parts of the different stages in our reflection model: 
1. Experience: the participants should practice their teaching competences during this stage with awareness of their behaviors and abilities. To satisfy the experiment requirements, each participant should record her practice on a digital camera. By recording their practice, the participants will have the opportunity to review their performance and to focus on the specified competence;

2. Description: the participants should describe the different influential factors related to the situation during this stage such as the number of students, the content of the lesson, the cause of their specific behavior or reaction, and any other information that might help clarify the situation. This is assumed to provide a clear description of the experience for the participant herself, for her peers, and for her supervisor;

3. Self-reflection: using the recorded material and the description, each participant will have the opportunity to reflect on her own performance and the specified competence in each assignment. The participants should also analyze their performance in light of the theoretical knowledge that has been gained during the study program about the practiced competence;

4. Peer-reflection: after reflecting on the self, the participants should review the performance of their peers by watching their video and reading their description to the situation and their self-reflection. Afterwards, the participants will reflect on their peers' performance; and

5. Finding alternatives: using all the previously mentioned materials, the participants should be able to establish alternatives for their performance that are assumed to improve their practice of teaching. The participants should argue their alternatives based on their reflection, their peers' reflection, their supervisor's feedback, and the educational theories about the specific competence.

This model was implemented in an experimental field study in a teacher education program in Kuwait to evaluate the feasibility of such approach. The following table summarizes the main design and organization issues in this experiment. 


\begin{tabular}{|c|c|}
\hline Aspect & Description \\
\hline What & $\begin{array}{l}\text { 1. Implementation of the reflective practice approach supported by an online } \\
\text { video-based learning environment in field training in the teacher education } \\
\text { program in Kuwait; }\end{array}$ \\
\hline Why & $\begin{array}{l}\text { 2. To determine the difficulties that prospective teachers and trainers in field } \\
\text { training may encounter by practicing reflection in an online video-based } \\
\text { learning environment ; } \\
\text { 3. To investigate the opportunities of an online video-based learning } \\
\text { environment in facilitating reflection among those prospective teachers and } \\
\text { trainers; } \\
\text { 4. To evaluate the effect of practicing reflection on the achievement of those } \\
\text { prospective teachers and trainers; and } \\
\text { 5. To evaluate whether the implementation of this intervention will help in } \\
\text { reducing the gap between theory and practice in the teacher education } \\
\text { program in Kuwait. }\end{array}$ \\
\hline How & $\begin{array}{l}\text { 6. Three task-oriented stages: Preparation stage, experimental stage and data } \\
\text { collection stage }\end{array}$ \\
\hline Where & 7. Field training courses in the College of Basic Education in PAAET in Kuwait \\
\hline Who & $\begin{array}{l}\text { 8. Sixteen prospective teachers and trainers from PAAET divided into four } \\
\text { groups }\end{array}$ \\
\hline When & 9. Ten weeks: from March 2, until May 8, 2008 \\
\hline Support & $\begin{array}{l}\text { 10. Introduction session and workshop } \\
\text { 11. Technical support in the computer lab } \\
\text { 12. Manuals } \\
\text { 13. Personal support }\end{array}$ \\
\hline
\end{tabular}

In order to facilitate the implementation of our reflection model and to provide solutions to the commonly encountered difficulties in practicing reflection, the use of Information and Communication Technology (ICT) was seen as the most effective approach. ICT offers many types of equipment and applications that support the education process. The practice of reflection could also make use of some of the technological aids to overcome the difficulties in practicing the description activities. ICT, in fact, may offer tools that go beyond solving a specific problem in practicing reflection into providing applications that improve the outcomes from practicing reflection in general.

The history of ICT shows a considerable variety of tools that have been used in education, and a great deal of examination concerning the usefulness of ICT tools such as telephone, radio, video, film, and television in education can be found in the literature (De Korte, 1967; Cuban, 1986; Blurton, 1999). Despite this long tradition, Tinio (2003) argues that enthusiasm among educators towards many of these tools such as video and television has faded over time because of the 
accessibility and the expense of these tools in comparison with print materials. In relation to the use of video in education, Santagata, Zannoni and Stigler (2007) assert that educators recently have shown new interest in the use of video for teacher education. This interest can be associated with the development of digital forms of media that provide promising interventions and great advantages for using video in education (Blurton, 1999). Digital recording techniques are useful for capturing the complexity of the classroom and they also allow random access to this material (Schrader et al., 2003). This interest is also related to online applications provided through the Internet. Online environments offer several tools that facilitate video delivery and exchange, providing valuable means of communication and accessibility for prospective teachers and their supervisors. The advantages of these new technologies has, in fact, revived the enthusiasm among educators towards the implementation of video in education and has expanded the usefulness of video specifically in teacher education.

The development of the role of video in recent years shows strong potential for a new use of video in teacher education that can effectively support the practice of reflection. Video can now be used during reflection as a tool for practitioners to capture the complexity of the classroom during their own teaching in order to reflect on the self and on other practitioners. It is assumed that this new use of video will overcome some of the major difficulties in practicing reflection that relate to the description activities. As a consequence, the use of video to facilitate the description activities is assumed to influence and to improve the major activities of reflection such as self-reflection, peer-reflection, and finding alternatives. The potential of this new video usage has become attainable by the fact that the advancement of technologies such as computers, the Internet, and the new digital and streaming video formats has provided promising solutions for the obstacles that faced video use in the past. Furthermore, the current trend of grouping several ICT applications in one learning environment instead of using each of these applications separately shows an increase in the effectiveness of these environments. These developments in the last few years have led to several attempts to examine the use of video as part of learning environments that are accessible through the use of computers and the Internet (Cannings \& Talley, 2002; Schrader et al., 2003; Kulk et al., 2005; Eilam \& Poyas, 2006; Admiraal et al., 2008; Leijen, Lam, Wildschut, Simons \& Admiraal, 2009). Some of these attempts illustrate promising opportunities for online video-based learning environments for the support of the reflective practice in particular and for 
teacher education in general. In order to support the practice of reflection effectively via online video-based learning environments, consideration should be given to essential applications to be included in these environments. Generally, the number of applications in an environment differs from one environment to another based on their purpose. Nevertheless, computers and video and Internet applications are considered the essential components that are always integrated into the main parts of any online video-based learning environment. Other applications that may contribute to the functionality of these environments vary from applications for communication such as a chat room or a discussion forum, applications for exchanging materials, or software applications for playing and manipulating the recorded materials. Therefore, and based on the promising support that is expected for facilitating the practice of reflection in the field training, an online video-based learning environment was selected for our experiment. The chosen environment is called the $\mathrm{V}$-class environment that is part of the so-called DiViDU system (Kulk et al., 2005).

The goal of our field experiment was to investigate the difficulties of practicing reflection, the effectiveness of the online environment in supporting the activities of reflection, and the influence of reflection on the learning process and learners' achievement.

The first aspect that we investigated in our field experiment was the difficulties of practicing reflection supported by the online environment. By recognizing that practicing reflection is a challenging activity for practitioners, different types of difficulties have been reported by several researchers regarding the practice of reflection (Mackintosh, 1998; Platzer, Blake \& Ashford, 2000; Leijen, 2008). By comparing and clustering these difficulties, a new classification was added to the main categories of expected difficulties from practicing reflection with consideration of the expected difficulties from using the online environment. Accordingly, this classification was used in our experiment to collect the data concerning the difficulties in practicing reflection in Kuwait. Therefore, a classification that consists of five types of categories was used in this research: difficulties related to recording, description, self-reflection, peer-reflection, and finding alternatives. The results of the experiment led to the development of a new classification consisting of three categories of difficulties that go a step beyond these difficulties into the source or the cause of them. Furthermore, this is also assumed to provide more customized classification to the difficulties in our 
study and to simplify the process of sorting out these difficulties. The first category is defined as personal and social barrier. The personal barrier here refers to the manners, attitudes, and behaviors of the participants while the social barrier concerns the influence of the Kuwaiti culture and traditions on the participants. Six of the sixteen difficulties encountered by the participants are classified here under the personal and social barriers. It was concluded that three of the difficulties in this category corresponded to some of the difficulties that were found in other studies about reflection which shows that those difficulties are associated strongly with the practice of reflection. The other three difficulties in this category can, therefore, be related mainly to cultural and traditional aspects in Kuwaiti society. The second category is defined as knowledge and skills barrier. Considering that the knowledge and skills of a person is in fact a part of his or her personality, an overlap might be seen here with the previous category. However, even acknowledging the presence of the personality barrier in the difficulties of this section, the dominant barrier here concerns participants' knowledge and skills in general and in relationship to the reflective practice approach in particular. Another six of the sixteen difficulties that have been encountered by the participants are classified here under the knowledge and skills barriers. Two of the difficulties in this category were also found in other studies while four seem exclusive to our study. The reason for this might be related to the type of knowledge and skills that are required from the participants for these difficulties. The two difficulties that corresponded to other findings, on the one hand, mainly require general knowledge and skills from the participants in relation to richness in the language. The exclusivity of the other four difficulties to our experiment, on the other hand, can be strongly associated with the fact that our participants did not have prior knowledge or experience regarding the practice of reflection. The third category is defined as technical and organizational barrier. This category concerns the difficulties that are caused by technical barriers, which are related to the use of the different technologies during the experiment. Technical barriers here refer to the inefficiency of the technologies involved in facilitating the activities of reflection. This category also concerns the difficulties that are caused by the way the field training in our experiment was organized. Four of the sixteen difficulties that have been reported by the participants are classified here under the technical and organizational barriers. The four difficulties that were presented in this section are connected specifically to the context of our experiment. It was concluded based on the difficulties results that the participants indeed encountered several 
difficulties and faced different barriers by practicing reflection, though these difficulties and barriers did not prevent the utilization of this learning approach. However, in order to allow the reflective practice approach to make a real difference and to improve the field training, those difficulties and barriers must be eliminated or at least reduced.

The second aspect that was investigated in our field experiment was the effectiveness of the online environment in supporting the activities of reflection. Studying the opportunities of ICT and specifically the online video-based learning environments showed many advantages that these environments could provide for the practice of reflection. In order to evaluate such intervention, two major factors that are expected to determine the effectiveness of the online videobased learning environment for our research were investigated during the field experiment. The usability of an ICT application is considered essential for successful utilization of this application. Understanding participants' appreciation of the ease of use of the V-class environment, therefore, is assumed to provide a strong indicator of the effectiveness of this environment. Furthermore, the degree of support the V-class environment provided to the participants during their reflection practice and the usefulness of this support is also considered another strong indicator of the effectiveness of the online environment. There were no reservations among the participants toward the usefulness of the V-class environment as all of them showed high appreciation of the support that this environment provided for practicing their reflection activities. On the other hand, four complaints were expressed by the participants regarding the usability of the V-class environment. Actually, these four difficulties are related to using new, yet unfamiliar, equipment and applications and they gradually faded as the experiment unfolded. Furthermore, even with these difficulties, the participants asserted that it was still easy to operate the Vclass environment. Therefore, it is safe to assume that any of the presented difficulties can be avoided through several alternatives or solutions. Modifying the V-class environment, providing the users with additional explanations and practices regarding the use of this environment, or even developing another new environment are all examples of actions that can be taken to avoid any difficulties in the future concerning the usability. The significant fact here is that the environment showed promising roles in supporting the practice of reflection. It is important to point out that even though some of the participants had some reservations about the usability of the $\mathrm{V}$-class environment, they generally agreed 
without exception about the usefulness of this environment for supporting the practice of reflection. To take this discussion beyond the boundary of our experiment, the difference between the usability and the usefulness factors must be identified here. While the results from investigating the usability of an environment are indeed valuable indicators in evaluating this environment, the results from investigating the usefulness, in fact, go beyond evaluating this specific environment. These results are indicators to evaluate the usefulness of the online video-based learning environments in general for supporting the reflective practice approach. In other words and in relationship to our experiment, the results of the usability investigation are exclusive to the use of the $\mathrm{V}$-class environment while the results of the usefulness investigation concern the use of the online video-based learning environments to support the reflective practice approach, in general. Assembling the findings from the usability and the usefulness investigations in our experiment shows promising effects from the Vclass environment on carrying out the activities of reflection. These results correspond and confirm the findings in other studies discussed in this dissertation regarding the added value of using video and the Internet to support learning and particularly to support the reflective reflection approach (Cannings \& Talley, 2002; Schrader et al., 2003; Kulk et al., 2005; Eilam \& Poyas, 2006; Admiraal et al., 2008; Leijen, Lam, Wildschut, Simons \& Admiraal, 2009). It was concluded based on these results that the use of the online video-based learning environment indeed provides valuable support for the participants in our experiment to carry out the different activities of reflection. However, the alternatives that may improve the usability of the $\mathrm{V}$-class environment must be researched further.

The third aspect investigated in our field experiment was the influence of reflection on the learning process and learner achievement. Considering that the ultimate goal of this study is to improve the practice of field training, user satisfaction with the process of learning and their achievements during the implementation of such intervention are considered two strong indications for evaluating this intervention. Three aspects considered useful in helping understand the effect of reflection on the practice of the field training were the impression that the experiment left on the participants and their supervisors, their preference toward the practice of field training with or without reflection, and their perspectives on the role of reflection in strengthening the presence of theory during the field training. The results show a consistency between the 
response of the participants and the response of the supervisors in relation to their impressions toward this experience. Another consistency between the response of the participants and the response of the supervisors concerns the importance and the requirement of the reflection approach. The results also demonstrated explicitly a strong appreciation by the participants for the role of all activities of reflection in strengthening the presence of theory in the field training. More specifically, the participants highlighted the feedback in particular to be the most influential factor in helping them understand the theoretical concept behind the practiced competences. They specified their own reflection on their performance as well as their reflection on their peers' performance as the most influential factors that helped them master the practiced competences. It can be recognized in the responses of the participants and the supervisors that while the participants consider all activities of reflection to be valuable activities for connecting theory and practice, the supervisors dismissed any influence from the description activity in the relationship between theory and practice. This difference in perspectives toward the description activity can be related to the different roles of the participants and the supervisors in the field training. One explanation is that while the participants view the description activity through learners' eyes, the supervisors view this activity through evaluators' eyes. In other words, the appreciation of the description activity by the participants comes from the opportunity that this activity provided for them to learn from their own performance and to explain themselves to other participants. On the other hand, the supervisors' view that the activity of description has no impact on the relationship between theory and practice is justified by their argument that there was no theory involved in participants' description. According to the positive results from these three aspects, the implementation of this intervention showed promising changes in the field training. The positive attitude and the acceptance of the participants and their supervisors toward the practice of the reflective approach and the online environment present encouraging indications regarding the effect of reflection. Moreover, their common agreement that this intervention was effective in facilitating the relationship between theory and practice is another strong indicator of the positive influence of reflection. It was concluded therefore that the utilization of the reflective practice approach supported by the online video-based learning environment showed promising results in facilitating the learning process and in improving learners' achievement in the field training course. 
Combining the different findings in this study, it can be stated with confidence that our intervention indeed shows pedagogical advantages in reducing the gap between theory and practice in the field training. However, confirming the advantage of our intervention introduces the question of how this intervention can be realized in the real practice of field training in teacher education in Kuwait.

The realization of such an intervention will require an intensive collaboration between several actors in the educational organization. Several actions need to be taken in order to utilize effectively this intervention including needs and capability assessment and changes in the program structure and content. Therefore, the realization of this intervention should start with a decision from the administration level. That will ensure the collaboration of several departments in relation to changing the content, modifying the program structure, and facilitating the needs of ICT applications and support. It is also important to find supervisors who are willing and also have the required knowledge and skills to manage both the pedagogical and the technological components of this intervention. Above all, it is necessary to ensure enough time for the implementation process and give room for becoming familiar with this intervention in the field training.

In all, it can be confidently stated here that the findings of this study provided positive contributions to both the body of knowledge as well as the practice of the field training. The philosophy behind the reflection notion was translated into a new conceptual perspective. Based on this perspective, a new learning strategy for the practice of field training was developed. This strategy aimed at introducing reflective practice as a pedagogical approach for field training that relies on advanced ICT applications to facilitate its activities. Two major pedagogical innovations were introduced by utilizing this strategy in the field training: strengthening the relationship between theory and practice and enhancing the quality of feedback. These two innovations are not the end, however. Much work lies ahead and research is recommended to further validate the presented findings and to enhance the impacts of this intervention on the field training. The fact that this study has demonstrated that the two innovations have pedagogical advantages in reducing the gap between theory and practice, provides a strong argument to pursue this work further. 


\title{
APPENDIX 1 \\ The background questionnaire
}

Group No.:

Participant ID:
Questionnaire version (A)

\author{
Questionnaire measuring \\ Participants' knowledge and background toward the use of computers, the Internet, digital video \\ cameras, and the reflective practice
}

Dear participant,

This questionnaire is a preliminary data collection instrument that aims to understand the background of the Kuwaiti prospective teachers who will be involved in an experiment in the second semester of the year 2007 / 2008. This experiment is part of a research that aims to evaluate the use of an online video- based learning environment in facilitating the communication and the reflective activities among prospective teachers in the field training. In order to understand participants' background in several areas, this questionnaire is divided into the following sections:

- Section A: consists of ten questions that focus on participants' experience and skills regarding the use of computers and the Internet

- Section B: consists of five questions that focus on participants' experience and skills regarding the use of digital video cameras and the familiarity with this kind of equipment

- Section C: consists of five questions that focus on the availability and efficiency of the existed channels of communication among prospective teachers during the field training

- Section D: consists of five questions that focus on participants' background regarding the reflective practice method

All the responses will be treated confidentially. Before starting, please be sure that you wrote your group and ID numbers on the top of this page.

Thank you for your time and effort, 
Section A: Computers and the Internet, experience and skills

1. Did you use a computer before?

$\square$ Yes

$\square$ No If no, please skip the remainder of this section

2. How often do you use a computer?

$\square$ Once or more a month

$\square$ Once or more a week

$\square$ Once or more a day

3. Do you have regular access to a computer?

$\square$ Yes

$\square$ No $\quad$ If no, please skip question 4

4. Where do you have regular access to a computer? (please check all that apply)

$\square$ Home

$\square$ College

$\square$ Work

If other, please specify:....

5. How often do you connect to the Internet?

$\square$ Once or more a month

$\square$ Once or more a week

$\square$ Once or more a day

6. What type of Internet connection do you use?

$\square$ Modem

$\square$ Cable

$\square$ Wireless

$\square$ No idea 
7. How long have you been using the Internet?

$\square 1$ - 6 months

$\square 7$ - 12 months

$\square 1$ - 2 years

$\square 2$ years or more

8. What do you use the Internet for? (please check all that apply)

$\square$ search for information

$\square$ Education

$\square$ Communication

$\square$ Shopping

$\square$ Entertainment

If other, please specify:

9. How would you rate your current computer skills

$\square$ Very poor

$\square$ Poor

$\square$ Fair

$\square$ Good

$\square$ Very good

10. How would you rate your current Internet skills?

$\square$ Very poor

$\square$ Poor

$\square$ Fair

$\square$ Good

$\square$ Very good 
Section B: Digital video cameras, experience and skills

11. Have you used a digital video camera before?

$\square$ Yes

$\square$ No If no, please skip the remainder of this section

12. Do you own a digital video camera?

$\square$ Yes

$\square$ No

13. Do you know how to set up a digital video camera for self-recording?

$\square$ Yes

$\square$ No

14. Do you know how to download a digital video fragment to a computer?

$\square$ Yes

$\square$ No

15. Do you know how to edit a digital video fragment on a computer?

$\square$ Yes

$\square$ No 
Section C: Channels of communication among prospective teachers in the field training, availability, and efficiency

16. How many times did you get to meet your fellow prospective teachers during your field training?

$\square$ Never (If 'Never', please answer only question 20 in this section)

$\square$ Monthly

$\square$ Weekly

$\square$ Daily

If other, please specify:

17. Do you think the number of meetings with your fellow prospective teachers, as you indicated in question 16, are sufficient for exchanging your experiences?

$\square$ Yes $\quad$ Please explain your answer:.

$\square$ No Please explain your answer:

18. Where do you get to meet your fellow prospective teachers during your field training?

$\square$ School

$\square$ College

If other, please specify:

19. Do you think the place of meetings with your fellow prospective teachers, as you indicated in question 18 , is convenient for exchanging your experiences?

$\square$ Yes $\quad$ Please explain your answer:.

No $\quad$ Please explain your answer:

20. What do you suggest to do in order to improve the exchange of experiences between you and fellow prospective teachers during your field training? 
Section D: Reflective practice, Knowledge, experience, and practice

21. Do you know what is meant by the term reflective practice method?

$\square$ Yes

$\square$ No

If yes, please describe reflective practice in your own words:

22. Did you learn during the study program about the benefits of utilizing the reflection activities?

$\square$ Yes

$\square$ No

If yes, please describe some of these benefits:

23. Did you learn during the study program how to reflect on your own performance?

$\square$ Yes

$\square$ No

If yes, please explain how you can do that:

24. Did you learn during the study program how to reflect on your fellow students performance?

$\square$ Yes

$\square$ No

If yes, please explain how you can do that:

25. Do you use any kind of reflection activities in your daily life?

$\square$ Yes

$\square$ No

If yes, please describe one or two examples:. 
If you would like to add comments regarding any of the previous sections, please use this space here

Thank you for your time and effort, 


\section{APPENDIX 2 \\ Field training evaluation form}

List of competences

بطاقة تقويم الطالب المطلم

في تخصص اللغة الإنجليزية

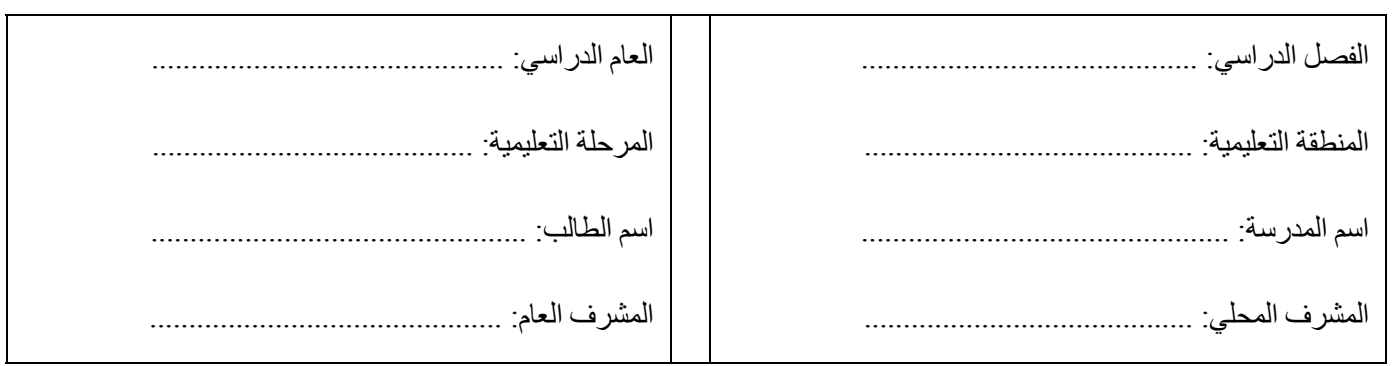

درجة المشرف من (45 درجة):

الدرجة بالأرقام: - -

الدرجة بالحروف:

توقيع المشرف:

الثاريخ والختم: 
بطاقة تقويم الطالب المعلم في تخصص اللغة الإنجليزية

\begin{tabular}{|c|c|c|c|c|c|c|}
\hline \multicolumn{5}{|c|}{ التقدير } & \multirow{3}{*}{ الكفاية } & \multirow{3}{*}{ م } \\
\hline ضعيف & مقبول & جيد & جيد جدا & ممتاز & & \\
\hline 1 & 2 & 3 & 4 & 5 & & \\
\hline
\end{tabular}

أو لا: الكفاية الشخصية

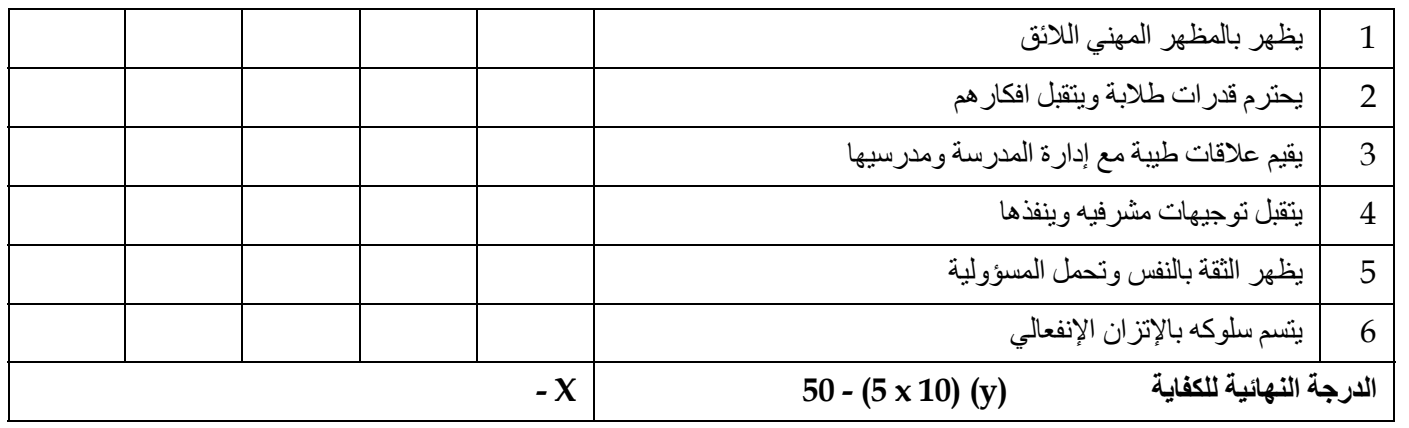

ثانيا: كفاية تخطيط الدرس

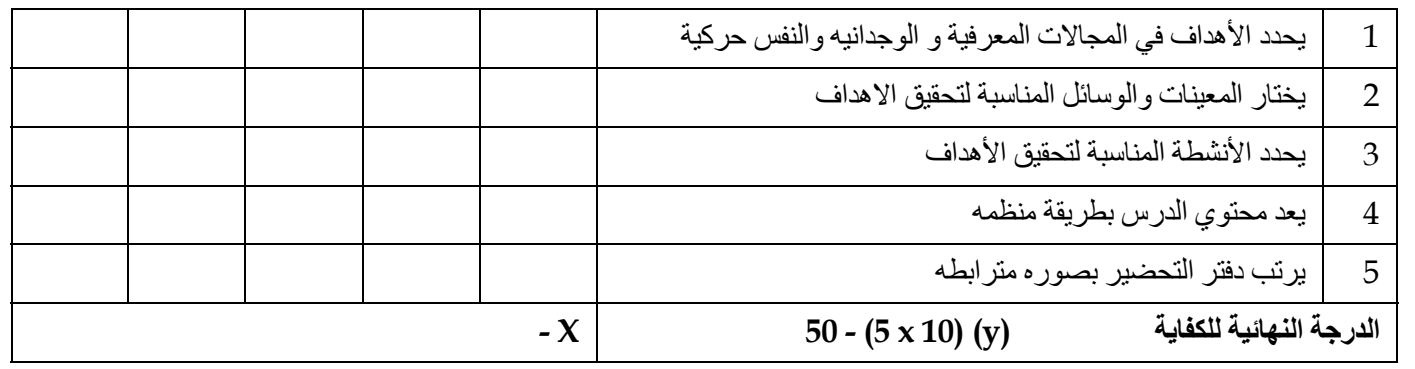

ثالثا: كفاية تتفيذ الدرس

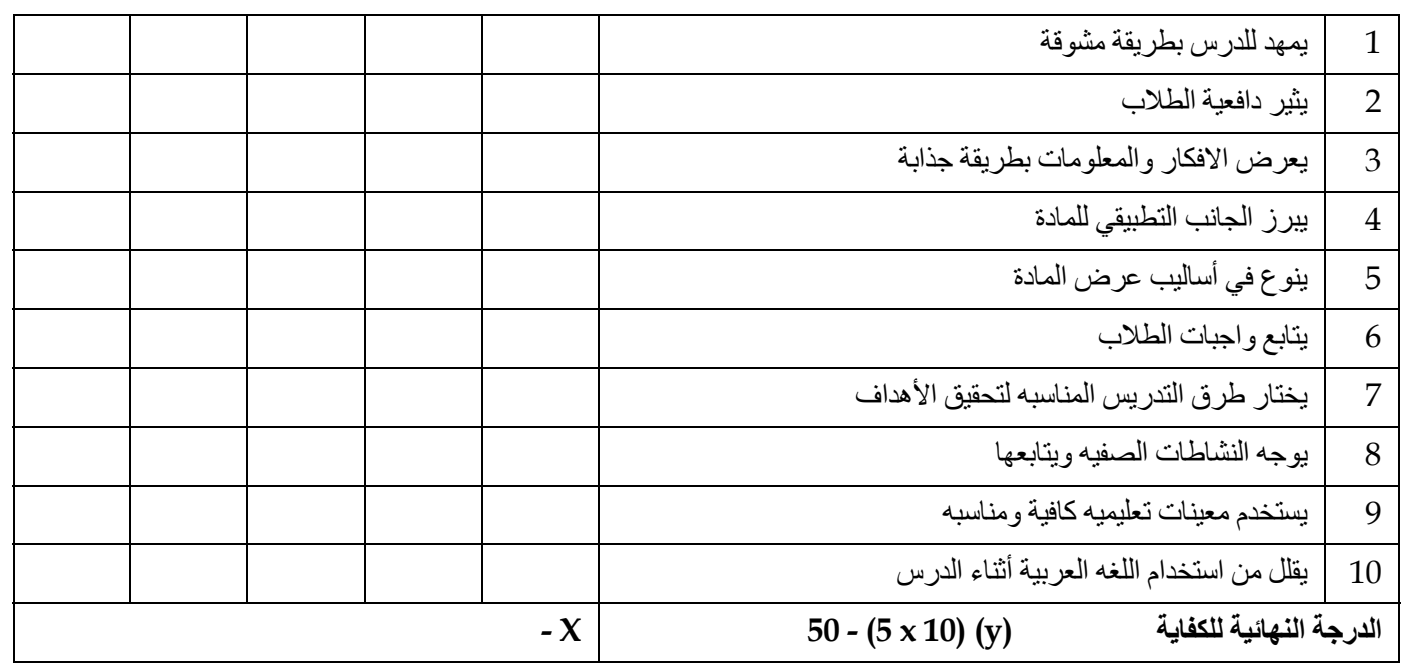




\begin{tabular}{|c|c|c|c|c|c|c|}
\hline \multicolumn{5}{|c|}{ التقاير } & \multirow{3}{*}{ الكفاية } & \multirow{3}{*}{ م } \\
\hline ضعيف & مقبول & جيد & جيد جذا & ممتاز & & \\
\hline 1 & 2 & 3 & 4 & 5 & & \\
\hline
\end{tabular}

رابعا: كفاية إدارة الفصل

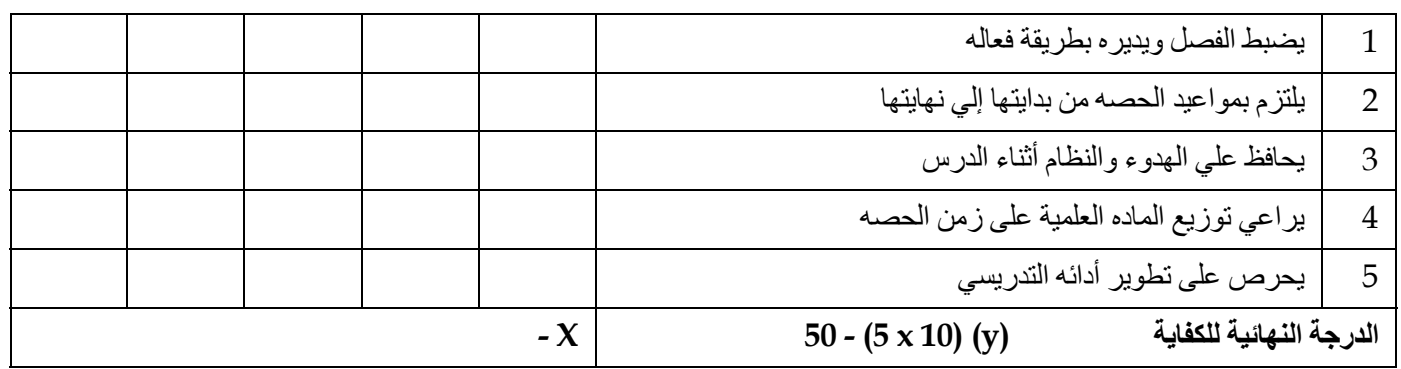

خامسا: الكفاية العلمية

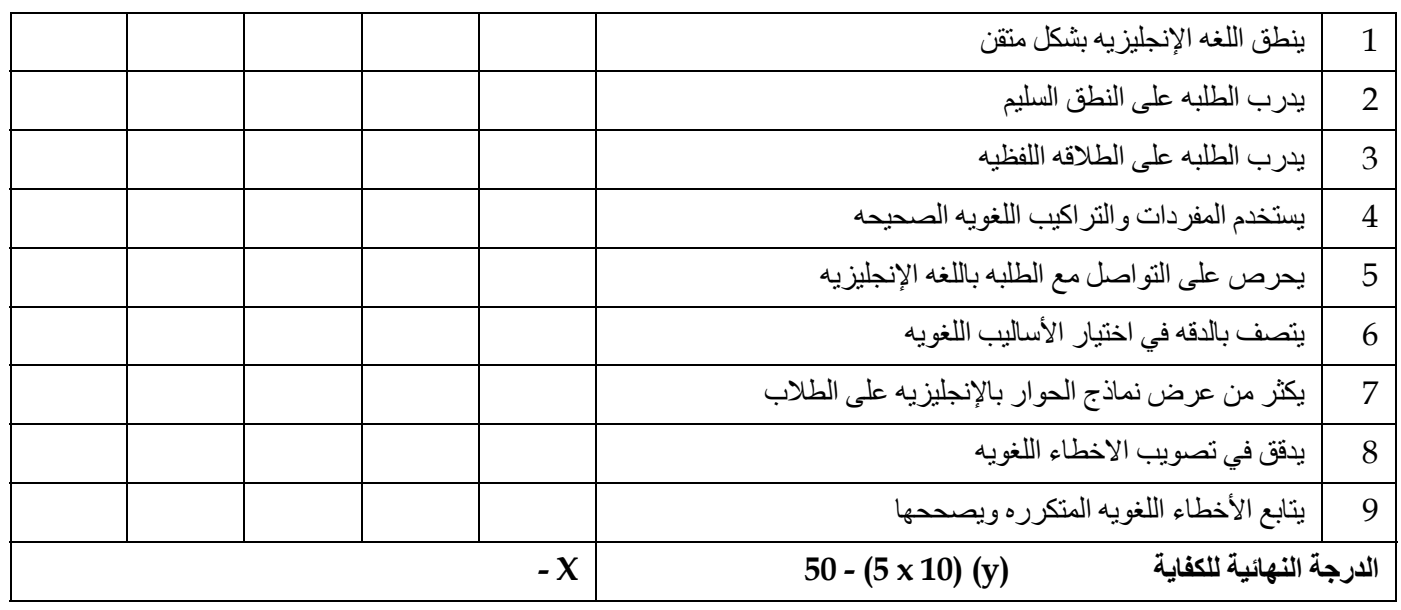

ثالثا: كفاية التقويم

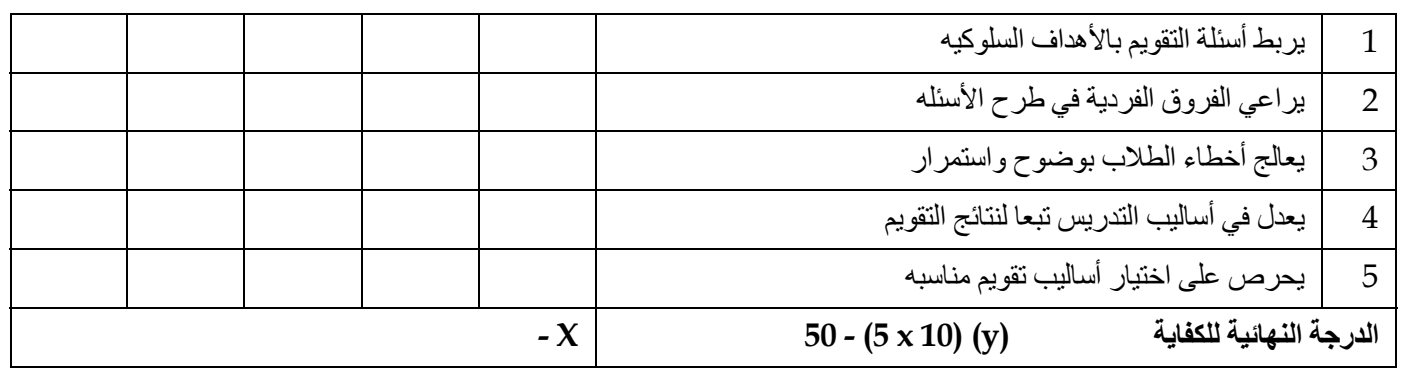

الدرجة النهائية للطالب المعلم

توقيع المشرف 


\title{
APPENDIX 3 \\ Results of the background questionnaire
}

\author{
Section A: Computers and the Internet, experience and skills
}

Q1: Did you use a computer before?

\begin{tabular}{|c|c|c|c|c|}
\hline & Frequency & Percent & $\begin{array}{c}\text { Valid } \\
\text { Percent }\end{array}$ & $\begin{array}{c}\text { Cumulative } \\
\text { Percent }\end{array}$ \\
\hline Valid & 16 & 100.0 & 100.0 & 100.0 \\
\hline
\end{tabular}

Q2: How often do you use a computer?

\begin{tabular}{|c|c|c|c|c|c|}
\hline & & Frequency & Percent & $\begin{array}{l}\text { Valid } \\
\text { Percent }\end{array}$ & $\begin{array}{c}\text { Cumulative } \\
\text { Percent }\end{array}$ \\
\hline \multirow[t]{4}{*}{ Valid } & $\begin{array}{l}\text { Once or more a } \\
\text { month }\end{array}$ & 1 & 6.3 & 6.3 & 6.3 \\
\hline & Once or more a week & 2 & 12.5 & 12.5 & 18.8 \\
\hline & Once or more a day & 13 & 81.3 & 81.3 & 100.0 \\
\hline & Total & 16 & 100.0 & 100.0 & \\
\hline
\end{tabular}

Q3: Do you have regular access to a computer?

\begin{tabular}{|c|c|c|c|c|}
\hline & Frequency & Percent & $\begin{array}{c}\text { Valid } \\
\text { Percent }\end{array}$ & $\begin{array}{c}\text { Cumulative } \\
\text { Percent }\end{array}$ \\
\hline Valid & 16 & 100.0 & 100.0 & 100.0 \\
\hline
\end{tabular}

Q4: Where do you have regular access to a computer?

\begin{tabular}{|c|c|c|c|c|c|}
\hline & & Frequency & Percent & $\begin{array}{l}\text { Valid } \\
\text { Percent }\end{array}$ & $\begin{array}{l}\text { Cumulative } \\
\text { Percent }\end{array}$ \\
\hline \multirow[t]{4}{*}{ Valid } & Home & 11 & 68.8 & 68.8 & 68.8 \\
\hline & Home and college & 1 & 6.3 & 6.3 & 75.0 \\
\hline & $\begin{array}{c}\text { Home, college, and } \\
\text { work }\end{array}$ & 4 & 25.0 & 25.0 & 100.0 \\
\hline & Total & 16 & 100.0 & 100.0 & \\
\hline
\end{tabular}


Q5: How often do you connect to the Internet?

\begin{tabular}{|c|c|c|c|c|c|}
\hline & & Frequency & Percent & $\begin{array}{c}\text { Valid } \\
\text { Percent }\end{array}$ & $\begin{array}{c}\text { Cumulative } \\
\text { Percent }\end{array}$ \\
\hline Valid & $\begin{array}{c}\text { Once or more a } \\
\text { month }\end{array}$ & 2 & 12.5 & 12.5 & 12.5 \\
\hline & Once or more a week & 1 & 6.3 & 6.3 & 18.8 \\
\hline & Once or more a day & 13 & 81.3 & 81.3 & 100.0 \\
\hline & Total & 16 & 100.0 & 100.0 & \\
\hline
\end{tabular}

Q6: What type of Internet connection do you use?

\begin{tabular}{|c|c|c|c|c|c|}
\hline & & Frequency & Percent & $\begin{array}{c}\text { Valid } \\
\text { Percent }\end{array}$ & $\begin{array}{c}\text { Cumulative } \\
\text { Percent }\end{array}$ \\
\hline \multirow[t]{4}{*}{ Valid } & Cable & 3 & 18.8 & 18.8 & 18.8 \\
\hline & Wireless & 12 & 75.0 & 75.0 & 93.8 \\
\hline & $\begin{array}{l}\text { Don't } \\
\text { know }\end{array}$ & 1 & 6.3 & 6.3 & 100.0 \\
\hline & Total & 16 & 100.0 & 100.0 & \\
\hline
\end{tabular}

Q7: How long have you been using the Internet?

\begin{tabular}{|c|c|c|c|c|c|}
\hline & & Frequency & Percent & $\begin{array}{c}\text { Valid } \\
\text { Percent }\end{array}$ & $\begin{array}{c}\text { Cumulative } \\
\text { Percent }\end{array}$ \\
\hline \multirow[t]{3}{*}{ Valid } & 1 - 2 years & 1 & 6.3 & 6.3 & 6.3 \\
\hline & 2 or more years & 15 & 93.8 & 93.8 & 100.0 \\
\hline & Total & 16 & 100.0 & 100.0 & \\
\hline
\end{tabular}

Q8: What do you use the Internet for?

\begin{tabular}{|c|c|c|c|c|c|}
\hline & & Frequency & Percent & $\begin{array}{c}\text { Valid } \\
\text { Percent }\end{array}$ & $\begin{array}{c}\text { Cumulative } \\
\text { Percent }\end{array}$ \\
\hline Valid & $\begin{array}{c}\text { More than one } \\
\text { purpose }\end{array}$ & 10 & 62.5 & 62.5 & 62.5 \\
\hline & All & 6 & 37.5 & 37.5 & 100.0 \\
\hline & Total & 16 & 100.0 & 100.0 & \\
\hline
\end{tabular}


Q9: How would you rate your current computer skills?

\begin{tabular}{|c|c|c|c|c|c|}
\hline & & Frequency & Percent & $\begin{array}{c}\text { Valid } \\
\text { Percent }\end{array}$ & $\begin{array}{c}\text { Cumulative } \\
\text { Percent }\end{array}$ \\
\hline \multirow[t]{4}{*}{ Valid } & Fair & 4 & 25.0 & 25.0 & 25.0 \\
\hline & Good & 2 & 12.5 & 12.5 & 37.5 \\
\hline & $\begin{array}{l}\text { Very } \\
\text { good }\end{array}$ & 10 & 62.5 & 62.5 & 100.0 \\
\hline & Total & 16 & 100.0 & 100.0 & \\
\hline
\end{tabular}

Q10: How would you rate your current Internet skills?

\begin{tabular}{|c|c|c|c|c|c|}
\hline & & Frequency & Percent & $\begin{array}{c}\text { Valid } \\
\text { Percent }\end{array}$ & $\begin{array}{c}\text { Cumulative } \\
\text { Percent }\end{array}$ \\
\hline \multirow[t]{4}{*}{ Valid } & Fair & 4 & 25.0 & 25.0 & 25.0 \\
\hline & Good & 1 & 6.3 & 6.3 & 31.3 \\
\hline & $\begin{array}{l}\text { Very } \\
\text { good }\end{array}$ & 11 & 68.8 & 68.8 & 100.0 \\
\hline & Total & 16 & 100.0 & 100.0 & \\
\hline
\end{tabular}

Section B: Digital video cameras, experience, and skills

Q11: Have you used a digital video camera before?

\begin{tabular}{|rr|r|r|r|c|}
\hline & Frequency & Percent & \multicolumn{1}{c|}{$\begin{array}{c}\text { Valid } \\
\text { Percent }\end{array}$} & $\begin{array}{c}\text { Cumulative } \\
\text { Percent }\end{array}$ \\
\hline Valid & Yes & 16 & 100.0 & 100.0 & 100.0 \\
\hline
\end{tabular}

Q12: Do you own a digital video camera?

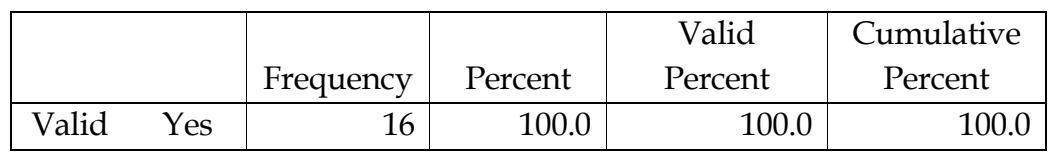

Q13: Do you know how to set up a digital video camera for self-recording?

\begin{tabular}{|rr|r|r|r|r|}
\hline & & & \multicolumn{1}{|c|}{ Valid } \\
Percent & $\begin{array}{c}\text { Cumulative } \\
\text { Percent }\end{array}$ \\
\hline Valid & Yes & 12 & 75.0 & 75.0 & 75.0 \\
& No & 4 & 25.0 & 25.0 & 100.0 \\
& Total & 16 & 100.0 & 100.0 & \\
\hline
\end{tabular}


Q14: Do you know how to download a digital video fragment to a computer?

\begin{tabular}{|rr|r|r|r|r|}
\hline & & & \multicolumn{1}{|c|}{ Valid } \\
Percent & $\begin{array}{c}\text { Cumulative } \\
\text { Percent }\end{array}$ \\
\hline Valid & Yes & 11 & 68.8 & 68.8 & 68.8 \\
& No & 5 & 31.3 & 31.3 & 100.0 \\
& Total & 16 & 100.0 & 100.0 & \\
\hline
\end{tabular}

Q15: Do you know how to edit a digital video fragment on a computer?

\begin{tabular}{|rr|r|r|r|r|}
\hline & & & \multicolumn{1}{|c|}{ Valid } \\
Percent & $\begin{array}{c}\text { Cumulative } \\
\text { Percent }\end{array}$ \\
\hline Valid & Yes & 10 & 62.5 & 62.5 & 62.5 \\
& No & 6 & 37.5 & 37.5 & 100.0 \\
& Total & 16 & 100.0 & 100.0 & \\
\hline
\end{tabular}

Section C: Channels of communication among prospective teachers in the field training, availability, and efficiency

Q16: How many times did you get to meet your fellow prospective teachers during your field training?

\begin{tabular}{|c|c|c|c|c|c|}
\hline & & Frequency & Percent & $\begin{array}{c}\text { Valid } \\
\text { Percent }\end{array}$ & $\begin{array}{c}\text { Cumulative } \\
\text { Percent }\end{array}$ \\
\hline \multirow[t]{3}{*}{ Valid } & Never & 10 & 62.5 & 62.5 & \multirow{3}{*}{100.0} \\
\hline & $\begin{array}{c}\text { Monthl } \\
\mathrm{y}\end{array}$ & 6 & 37.5 & 37.5 & \\
\hline & Total & 16 & 100.0 & 100.0 & \\
\hline
\end{tabular}

Q17: Do you think the number of meetings with your fellow prospective teachers, as you indicated in question 16, are sufficient for exchanging your experiences?

\begin{tabular}{|c|c|c|c|c|c|}
\hline & & Frequency & Percent & $\begin{array}{c}\text { Valid } \\
\text { Percent }\end{array}$ & $\begin{array}{c}\text { Cumulative } \\
\text { Percent }\end{array}$ \\
\hline \multirow[t]{3}{*}{ Valid } & Yes & 10 & 62.5 & 62.5 & 62.5 \\
\hline & No & 6 & 37.5 & 37.5 & 100.0 \\
\hline & Total & 16 & 100.0 & 100.0 & \\
\hline
\end{tabular}


Q18: Where did you get to meet your fellow prospective teachers during your field training?

\begin{tabular}{|c|c|c|c|c|c|}
\hline & & Frequency & Percent & $\begin{array}{c}\text { Valid } \\
\text { Percent }\end{array}$ & $\begin{array}{c}\text { Cumulative } \\
\text { Percent }\end{array}$ \\
\hline \multirow[t]{4}{*}{ Valid } & School & 3 & 18.8 & 18.8 & 18.8 \\
\hline & College & 4 & 25.0 & 25.0 & 43.8 \\
\hline & $\begin{array}{c}\text { School and } \\
\text { college }\end{array}$ & 9 & 56.3 & 56.3 & 100.0 \\
\hline & Total & 16 & 100.0 & 100.0 & \\
\hline
\end{tabular}

Q19: Do you think the place of meetings with your fellow prospective teachers, as you indicated in question 18 , is convenient for exchanging your experiences?

\begin{tabular}{|ll|r|r|r|r|}
\hline & & & Valid & Cumulative \\
& & Frequency & Percent & Percent & Percent \\
\hline Valid & Yes & 14 & 87.5 & 87.5 & 87.5 \\
& No & 2 & 12.5 & 12.5 & 100.0 \\
& Total & 16 & 100.0 & 100.0 & \\
\hline
\end{tabular}

Q20: What do you suggest to do in order to improve the exchange of experiences between you and fellow prospective teachers during your field training?

\begin{tabular}{|ll|r|r|}
\hline & & Frequency & Percent \\
\hline Missing & System & 16 & 100.0 \\
\hline
\end{tabular}

Section D: Reflective practice, knowledge, experience, and practice

Q21: Do you know what is meant by the term reflective practice method?

\begin{tabular}{|lc|r|r|r|r|}
\hline & & & Valid & Cumulative \\
& & Frequency & Percent & Percent & Percent \\
\hline Valid & Yes & 12 & 75.0 & 75.0 & 75.0 \\
& No & 4 & 25.0 & 25.0 & 100.0 \\
& Total & 16 & 100.0 & 100.0 & \\
\hline
\end{tabular}

Q22: Did you learn during the study program about the benefits of utilizing the reflection activities?

\begin{tabular}{|rc|r|r|r|r|}
\hline & & & Valid & Cumulative \\
& & Frequency & Percent & Percent & Percent \\
\hline Valid & Yes & 6 & 37.5 & 37.5 & 37.5 \\
& No & 10 & 62.5 & 62.5 & 100.0 \\
& Total & 16 & 100.0 & 100.0 & \\
\hline
\end{tabular}


Q23: Did you learn during the study program how to reflect on your own performance?

\begin{tabular}{|rr|r|r|r|r|}
\hline & & & \multicolumn{1}{|c|}{ Valid } \\
Percent & $\begin{array}{c}\text { Cumulative } \\
\text { Percent }\end{array}$ \\
\hline Valid & Yes & 4 & 25.0 & 25.0 & 25.0 \\
& No & 12 & 75.0 & 75.0 & 100.0 \\
& Total & 16 & 100.0 & 100.0 & \\
\hline
\end{tabular}

Q24: Did you learn during the study program how to reflect on your fellow students' performance?

\begin{tabular}{|rr|r|r|r|r|}
\hline & & & \multicolumn{1}{|c|}{ Valid } \\
Percent & $\begin{array}{c}\text { Cumulative } \\
\text { Percent }\end{array}$ \\
\hline Valid & Yes & 8 & 50.0 & 50.0 & 50.0 \\
& No & 8 & 50.0 & 50.0 & 100.0 \\
& Total & 16 & 100.0 & 100.0 & \\
\hline
\end{tabular}

Q25: Do you use any kind of reflection activities in your daily life?

\begin{tabular}{|rr|r|r|r|r|}
\hline & & Frequency & Percent & \multicolumn{1}{c|}{$\begin{array}{c}\text { Valid } \\
\text { Percent }\end{array}$} & $\begin{array}{c}\text { Cumulative } \\
\text { Percent }\end{array}$ \\
\hline Valid & Yes & 5 & 31.3 & 31.3 & 31.3 \\
& No & 11 & 68.8 & 68.8 & 100.0 \\
& Total & 16 & 100.0 & 100.0 & \\
\hline
\end{tabular}




\section{APPENDIX 4 \\ Main functionalities in the supervisors' V-class environment}

\section{- Module creation}

This functionality was described in Chapter 5 as the heart of the V-class environment because of the important role of the modules in the practice of this experiment. Module creation provides the supervisors with three different deferent templates that organize the general components of the practice of analysis, reflection, and assessment. The module creation page is showed in Figure 1 in this appendix. Brief description for each of these modules is presented here as follows:

1. The analysis module: The aim of this module is to facilitate the analysis activities by providing the learners with materials that help them observe, predict, and compare different professional performances. The idea behind this module is to extend students' own range of behavior through observation and modeling. The focus in this module is on professional behaviors of experienced teachers in practical situations. The main five learning tasks in this module are observation, prediction, comparison, making links to theory, and one's own actions in professional situations (Admiraal, Janssen \& Pijls, 2007)

2. The reflection module: The aim of this module is to facilitate learners' ability to reflect on their own performance, to request feedback from their peers and supervisors, and to reassess their performance in order to form and to investigation different solutions. Deeper discussion about reflection was provided in Chapter 2

3. The assessment module: The aim of this module is to create a portfolio for the learners. The focus here is on assessing the practiced competences such as the pedagogical competence, the didactical competence, and the reflective competence by the learners (Admiraal, Janssen \& Pijls, 2007). 


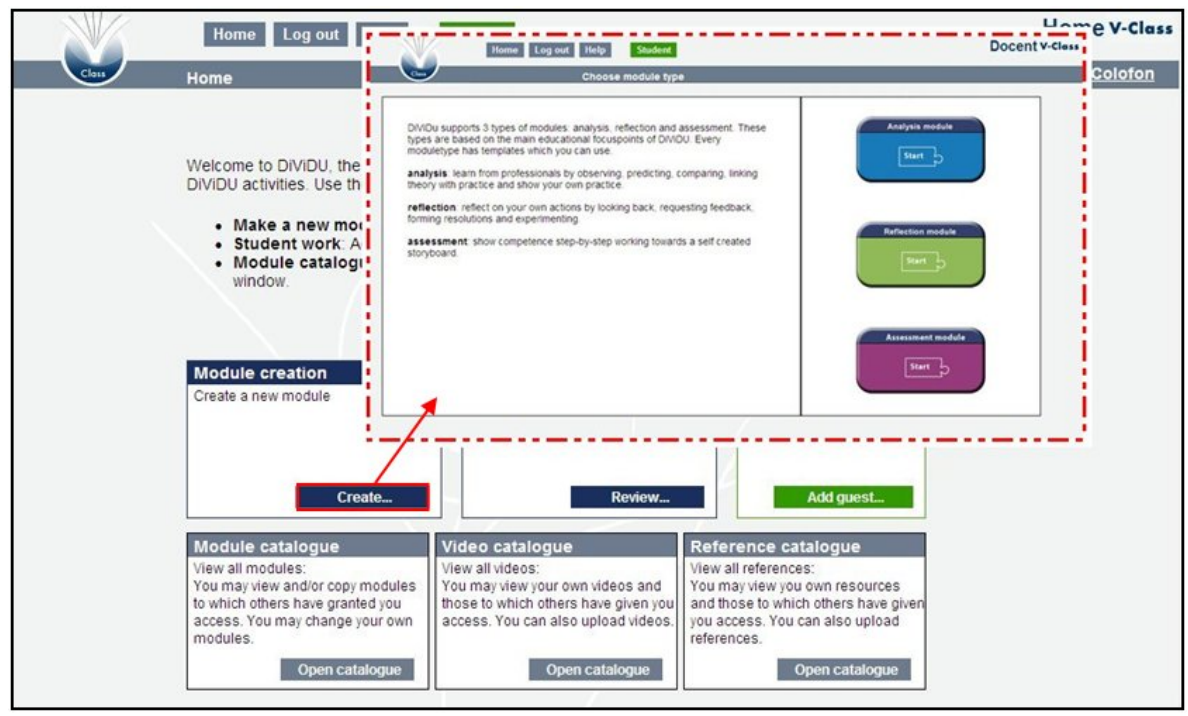

Figure 1 Module creation page

Since the supervisors in this investigation practiced only the reflection module, more details about the process of creating a reflection module is provided here. The reflection template consists of six main steps that lead eventually to creating a reflection module. Figure 2 shows the main steps in creating a reflection module.

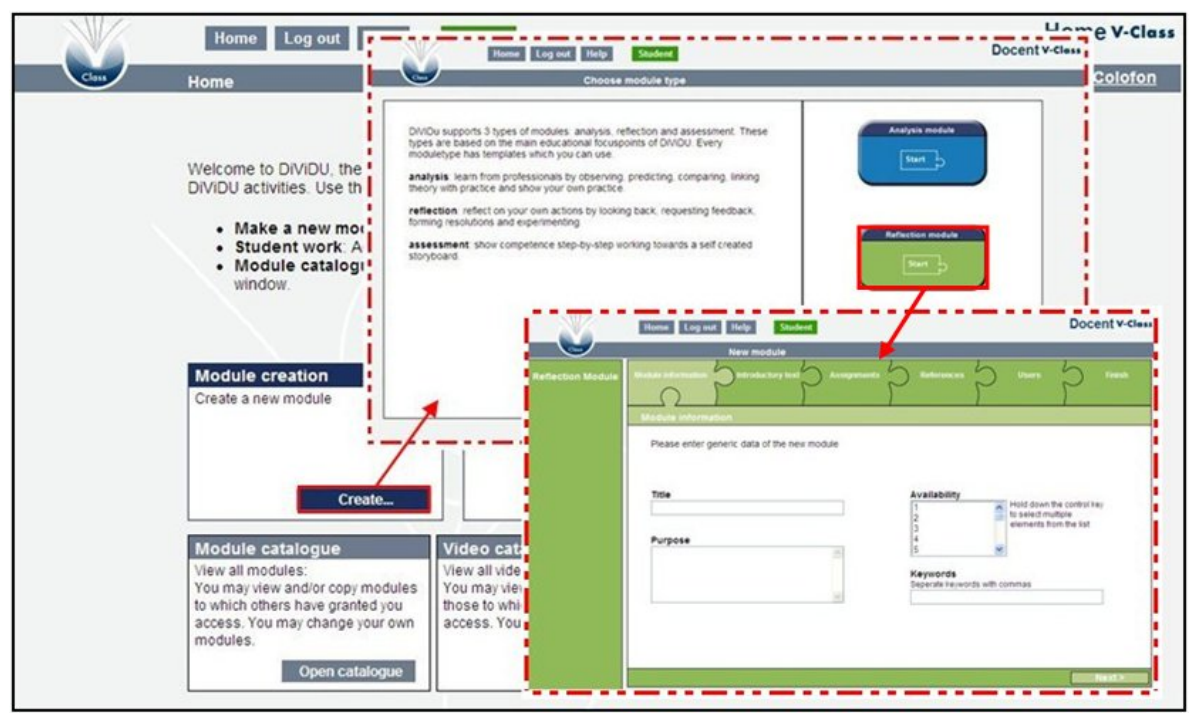

Figure 2 Steps for creating reflection module

1. Module information: In this step, the supervisors have to fill in the title, the purpose, the availability and the keywords for the module. Only by filling in all the requested information, can they proceed to the next step

2. Introductory text: the introductory text is the information that the learners see when they first login to the module. In the introductory text, the supervisors can describe the goal, the requirements, and the strategy of their module 
3. Assignments: The assignments are the activities that the learners have to perform in this module. The supervisors have the option either to create a new assignment or to adopt an already created assignment by another user in the environment. In the case of adopting an assignment, the supervisors have the ability to copy and to revise the assignment in order to fit their goals and objectives. To create a new assignment, the supervisors have to provide description for the assignment including the title, the name of the tab, and the targeted users. Furthermore, they have to introduce the assignment and to formulate the questions. Finally, the supervisors have the option to add references and resources to this specific assignment. Up to four assignments can be added in each module

4. References: In order to add references to the module, the supervisors can either upload new references or select from the available references in the references catalogue

5. Users: In this step, the supervisors have to select their users for the module from a provided list. The module cannot be published without at least one user assigned. They can add any registered user in the environment from both students and supervisors. However, it is always possible to add new users to the module at a later stage

6. Finish: The final step in creating a module is to select between either saving or publishing the module. On the one hand, saving the assignment gives the supervisors the opportunity to revise any part of the module. Publishing the assignment, on the other hand, limits the changes that they can make to only three elements, which are changing the name of the module, adding new users, and adding new references.

It is also possible to adopt an already existing module that has been created by another user in the environment. The supervisors can find in the module catalogue different kinds of modules for analysis, reflection, and assessment. Similar to the adoption of the assignments, they have the ability to copy and to revise the module to fit their goals and objectives.

\section{- Review students' work}

The aim of this functionality is to bring together the published assignments and the responses of all students in one place. This is assumed to facilitate the supervisors' task in reviewing and evaluating the work of their students. Furthermore, this functionality allows the supervisors to reflect on the students' performances and to give them feedback. The supervisors can use this functionality as well to monitor the progress of their students. Figure 3 shows the main steps in reviewing and evaluating students' work. 


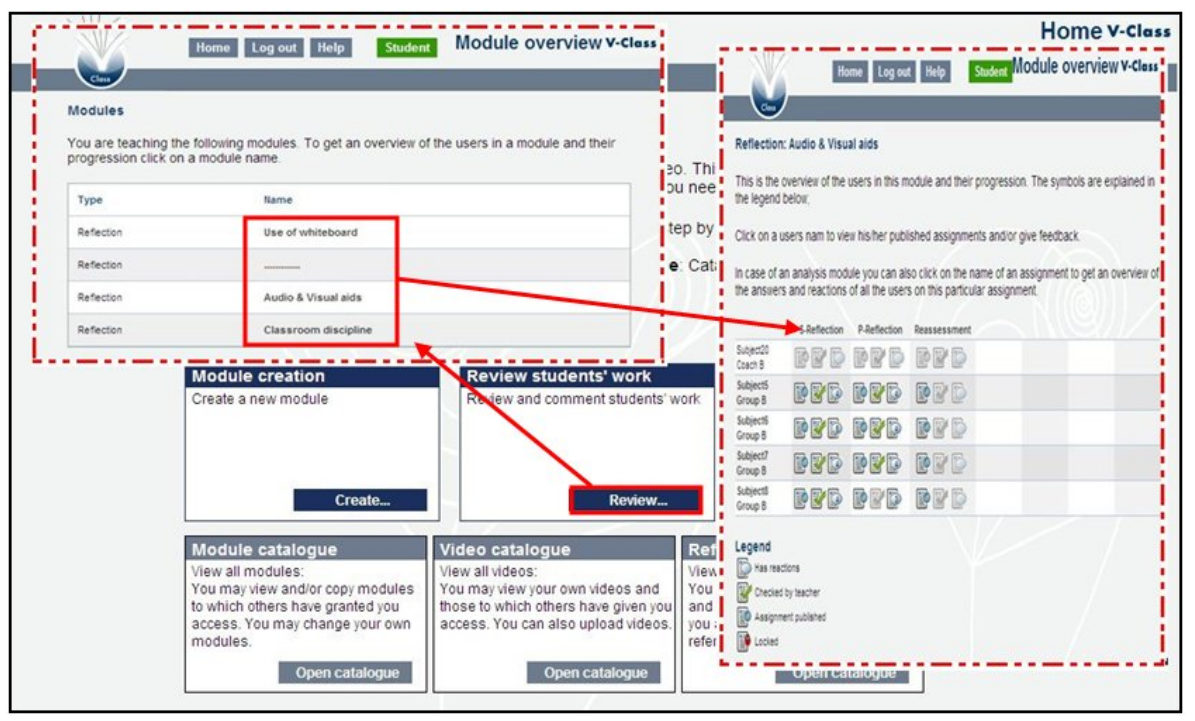

Figure 3 Review students' work windows

In the first step, all modules that the supervisors are involved in will be listed and they have to select the module that they want to review. In the model page the second step, an overview about the completed assignments, the number of responses, and the status of the assignment are stated based on the activities and the users. The supervisors will be given the choice between reviewing students' work by the activity or by the user. On the one hand, reviewing by the activities will give the supervisors only a general overview about the answers and the responses of the whole group. On the other hand, reviewing by the user will allow the supervisors to evaluate the performance and give feedback for each user. Figure 4 shows both the review by the activity and the review by the user.

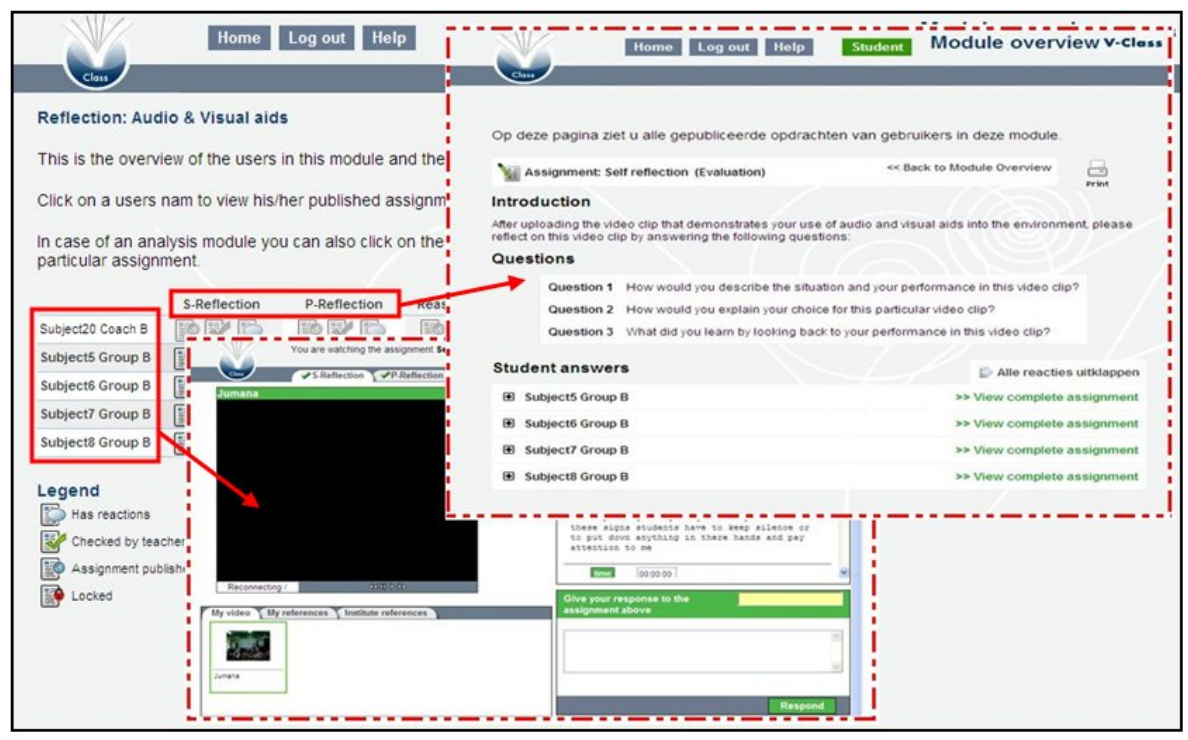

Figure 4 Review students' work by the activity or by the user 


\section{- Catalogues}

In the V-class environment, there are three different catalogues used as a repository or library for the modules, the video clips, and the references in the environment. These catalogues are useful tools for organizing the materials in the environment and for facilitating the exchange of these materials among the users. These catalogues are also useful as an archive for the new users. Figure 5 shows the three different catalogues in the V-class environment.

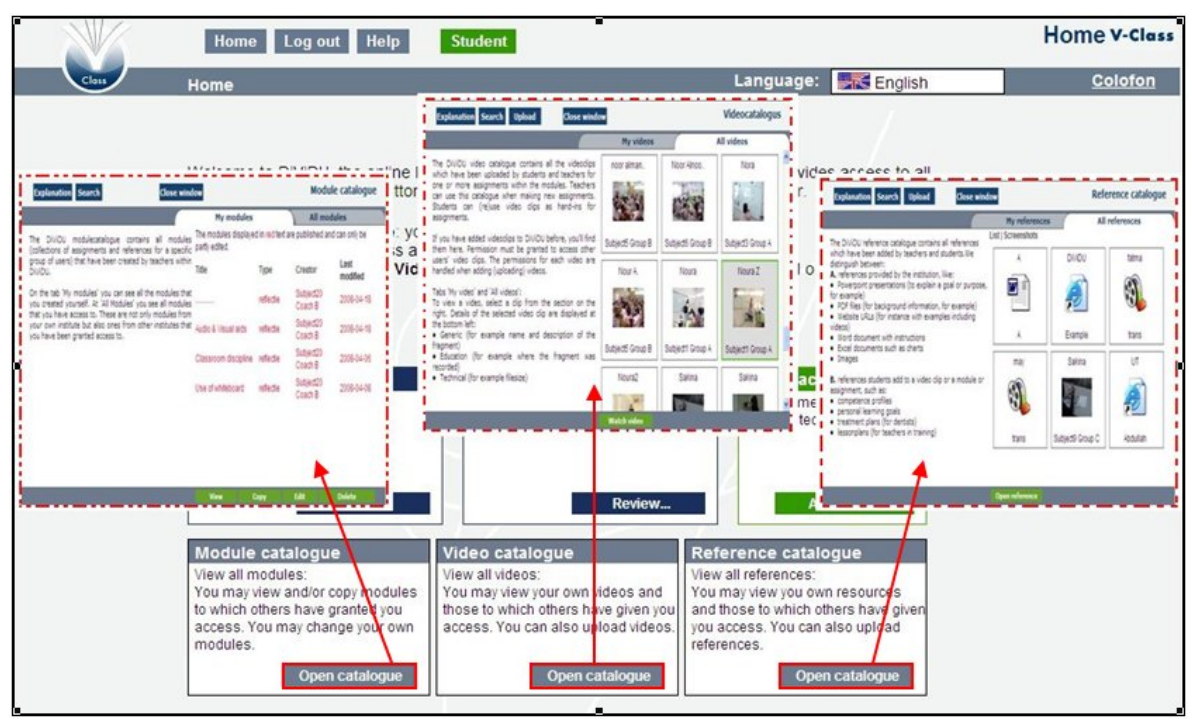

Figure 5 The catalogues in the V-class environment

The three catalogues share similar functionality and structure as they are divided into two main sections: a section that contains the materials that was created or added by the user and another section that contains all materials related to the catalogue's category. The module catalogue includes all modules that have been created in the V-class environment. The my modules section contains the modules that have been created by the individual user while the all modules section contains all modules in the V-class that the individual user was guaranteed access to such as the modules that have been created by colleagues. Similar to the module's catalogue, the video catalogue includes all video fragments that have been created in the V-class environment. The catalogue is also divided into a 'my video' section and 'all video' section. Finally, the reference catalogue has the same functionality as the catalogues for modules and for video clips with two sections, one for the user's references and another for all the references in the environment. The references here could be a document like a Word or PowerPoint file, a PDF file, a website address, a video fragment, or many other types of references. 


\section{APPENDIX 5}

\section{Main components of the participants' module page in the V-class environment}

The module's page in the participants' environment consists of four pages aiming to introduce the module, facilitate the self-reflection activities, facilitate the peer-reflection activities and facilitate the finding alternatives activities. The module's pages and the main tools and functionalities that have been used by the participants in these modules to facilitate the reflection activities will be described and discussed here.

\section{- Introduction page}

In this page, an introduction to the module and links to the activities' pages are provided to the participants. Via this page, the participants can proceed to one of their assignments such as the self-reflection assignment or they can choose to go into one of their peers' pages to reflect on their assignments. For explanation purposes, one of the modules that have been exercised in our experiment will used as an example in order to demonstrate the module's structure and activities. The introduction page of the module (classroom discipline) is shown in Figure 1.

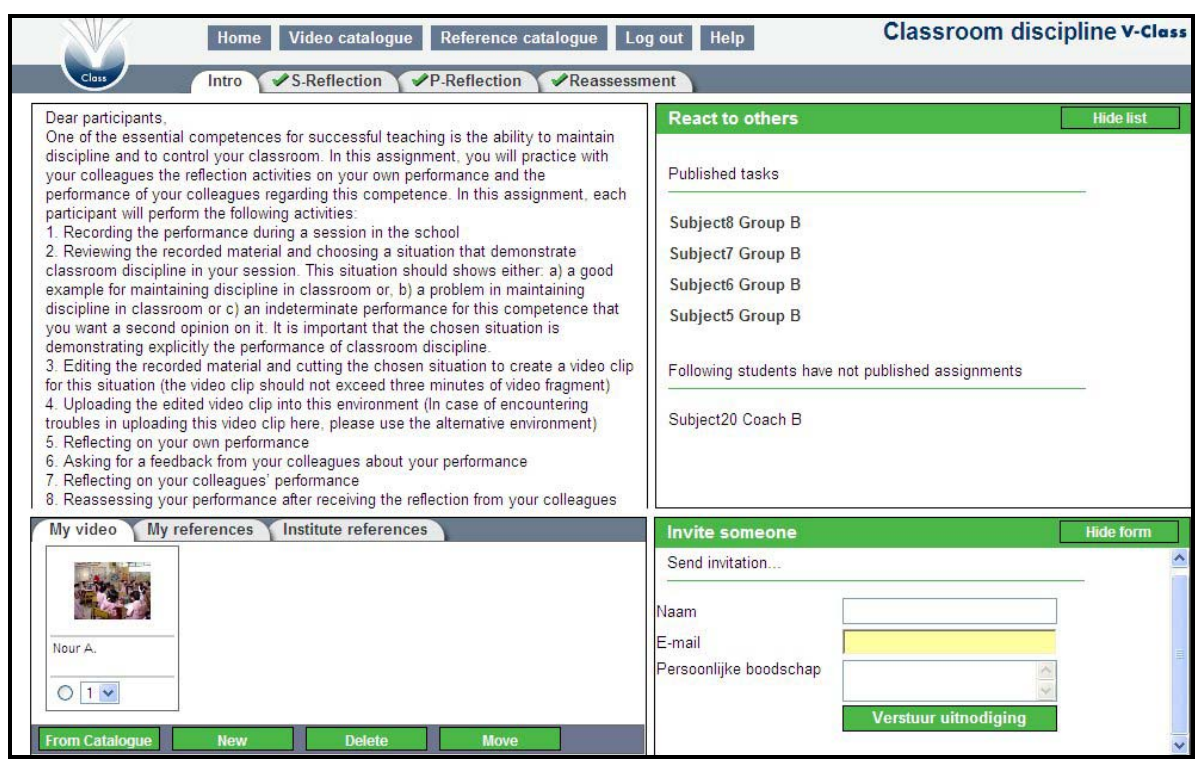

Figure 1 The introduction page in the modules 
Four sections can be distinguished in the introduction page in addition to the already described permanent options at the top of the page. The first section is the introductory text in the upper left side of the page. In this section, the supervisors provide a description of the goal and the requirements of the module. The introductory text that has been given to the participants in the classroom discipline module is presented in Figure 2.

Dear participants,

One of the essential competences for successful teaching is the ability to maintain discipline and to control your classroom. In this assignment, you will practice with your colleagues the reflection activities on your own performance and the performance of your colleagues regarding this competence. In this assignment, each participant will perform the following activities:

1. Recording the performance during a session in the school

2. Reviewing the recorded material and choosing a situation that demonstrates classroom discipline in your session. This situation should show either: a) a good example for maintaining discipline in classroom or, b) a problem in maintaining discipline in classroom, or c) an indeterminate performance for this competence that you want a second opinion on it. It is important that the chosen situation is demonstrating explicitly the performance of classroom discipline.

3. Editing the recorded material and cutting the chosen situation to create a video clip for this situation (the video clip should not exceed three minutes of video fragment)

4. Uploading the edited video clip into this environment (In case of encountering troubles in uploading this video clip here, please use the alternative environment)

5. Reflecting on your own performance

6. Asking for feedback from your colleagues about your performance

7. Reflecting on your colleagues' performance

8. Finding alternatives for your performance after receiving the reflection from your colleagues

Figure 2 The introductory text in the classroom discipline module

The second section in the left side of the page beneath the introductory text consists of three parts that categorize participants' video clips, participants' references, and the references that have been added by the supervisors in relation to this module. The participants can use any of these materials to support their assignments and they will have the ability to add, move, or delete any of these materials. The third section provides a list of names for all participants in this module and is located in the upper right side of the page. The participants who have already published any of their assignments will appear in the top of this section. By clicking on the name of the participant, a new window will appear presenting the assignments of the chosen participant. The invitation section that is located under the participants' name is the fourth section in the introduction page. This section allows the participants to invite a guest to participate in this module. Finally, there are four tabs in the top of the page that allow the participants to switch between the introduction, the self reflection, the peer-reflection, and the finding alternatives pages in this module.

In the introductory text of the classroom discipline module, the supervisors asked the participants to carry out eight different activities as can be seen in Figure 2. To complete the first three activities, the participants used a digital video camera, media player software, and video editing software. However, the participants used the functionalities of the V-class environment to carry out the last five activities. In order to upload the edited video clip into the environment, the fourth 
activity, the participants used the video catalogue in the environment described previously in this chapter. In the following sections, the functionalities of the V-class environment offered to the participants to facilitate the last four activities will be discussed.

\section{- The self-reflection assignment}

The fifth activity that was stated in the introductory text of the classroom discipline module was the self-reflection, which is the first assignment in the V-class environment. In order to complete this assignment, the participants are required to display a video clip that shows their performance in controlling the classroom and reflect on this performance. To facilitate this activity, the V-class environment offered several functionalities to the participants in the self-reflection page. The page can be reached by using the s-reflection tab on the top of the module page. Via the environment, the participants can view their video clips, submit a description to the situation, reflect on their performance, and receive feedback from their peers and supervisors. Figure 3 shows the selfreflection page in the V-class environment and its functionalities.

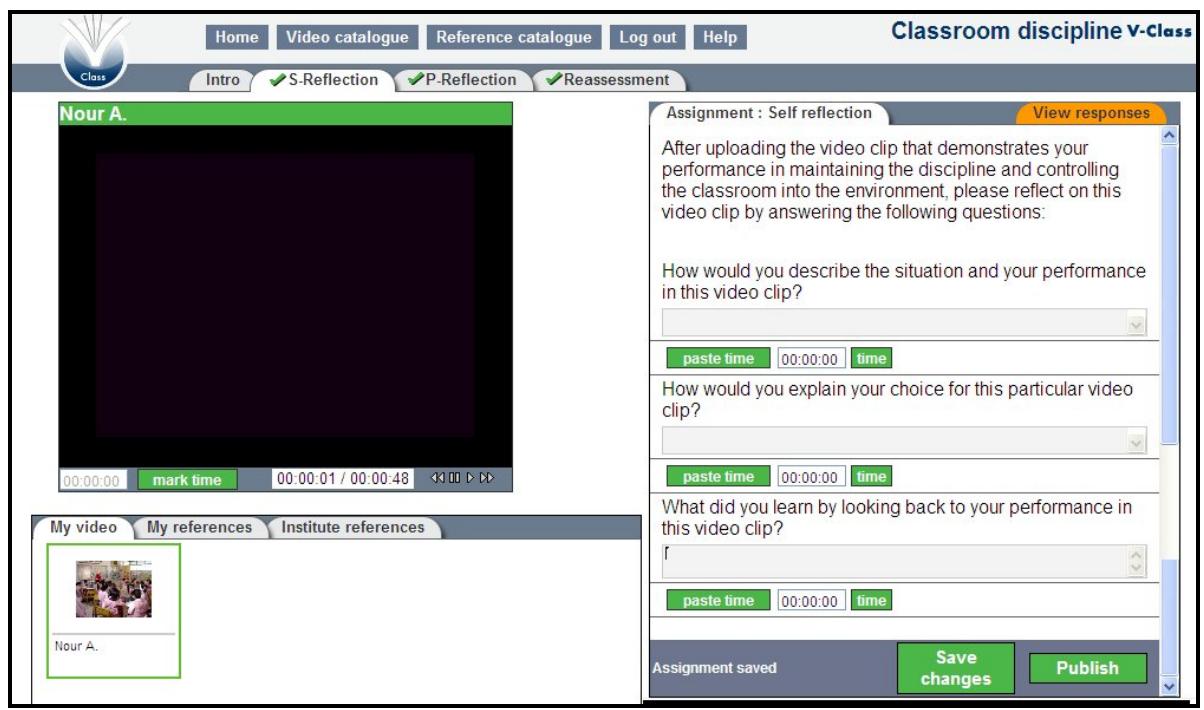

Figure 3 The self-reflection page in the V-class environment

To describe the self-reflection page, three new functionalities are added here in addition to the options on the top of the page, the link tabs, and materials' catalogues that were described previously in the introduction page. In the upper left side of the page, the environment provides a window that allows the participants, as well as their peers and supervisors, to watch their video clips. In the right side of the page, the supervisors provide the participants with description and guided questions aiming to lead the participants to describing the situation and reflect on their performance effectively. Furthermore, the environment gives the participants the option of saving or publishing the assignment. The saving option should be used when the participants are still working on their answers while the publishing option should be used when they want to allow their peers and supervisors to see their description and reflection. The guidance by the supervisors for the self-reflection assignment is shown in Figure 4. 
After uploading the video clip that demonstrates your performance in maintaining the discipline and controlling the classroom in the environment, please reflect on this video clip by answering the following questions:

- How would you describe the situation and your performance in this video clip?

- How would you explain your choice for this particular video clip?

- What did you learn by looking back on your performance in this video clip?

Figure 4 Guided questions for the self-reflection activity

The third functionality offered for the participants in the self-reflection page is viewing the responses from their peers and supervisors. The supervisors and the other members of the group were asked to provide feedback to the participant regarding the performance after watching the video clip and reading the self-reflection of the participant. The participants can access and view these responses by clicking the orange tab in the upper right side of the page as shown in Figure 5.

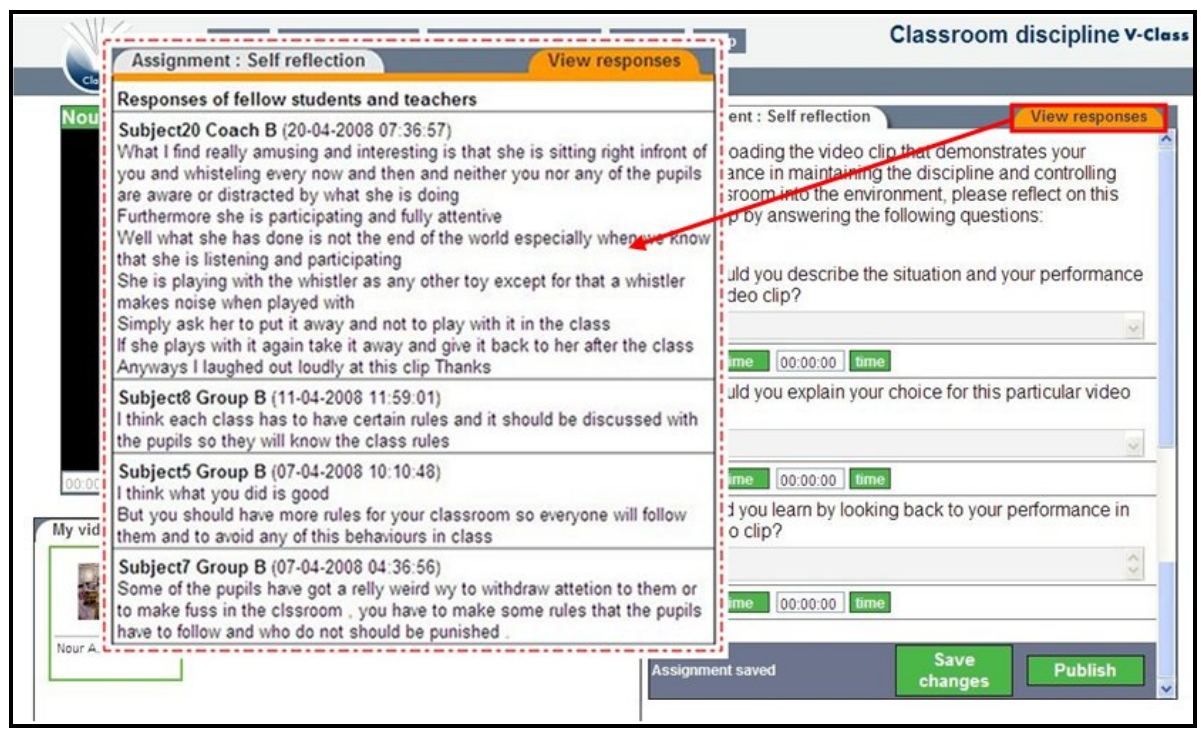

Figure 5 The responses viewer window

\section{- The peer-reflection assignment}

The second assignment in the V-class environment is given in the peer-reflection page. This assignment is the sixth activity presented in the introductory text of the classroom discipline module in Figure 2. The participants can get to the peer-reflection page by clicking the preflection tab on the top of the module page. The page has almost identical sections and functionalities as those described in the self-reflection page. However, the guidance provided by the supervisors to help the participants carry out this assignment differ from those in the self-reflection assignment. The goal of the guidance in the peer-reflection assignment is to advocate inquiry and to encourage the participants to ask for feedback about their performance. This guidance is presented in Figure 6. 
Receiving fresh opinions from your colleagues can help you improve your own performance. In this section, you will ask your colleagues to reflect on your performance in maintaining the discipline and controlling the classroom in order to understand how others assess your performance:

- Ask your colleagues to reflect on a specific point in this video clip concerning your performance that you would like to get a second opinion on

Figure 6 Directions for the peer-reflection activity

Furthermore, the participants can review their performance by using the video viewer option in order to submit a question for their peers and supervisors about a specific point in this performance in the peer-reflection page. When the peers and the supervisors submit an answer to the participant's question, the view responses functionality in this page allows the participants to see these answers.

\section{- The peers' pages}

It was explained in the introduction page section that the participants have two choices in the introduction page. They can select either to get into their own assignments by using the tabs in the top of the page or to enter their peers' assignments by using the names' list in the right side of the page. In order to carry out the seventh activity in the introductory text, which is to reflect on their colleagues' performance (Figure 2), the participants have to visit their peers' page. Clicking on one of the names in the list will open a new window that contains the published assignments of this specific participant as it can be seen in Figure 7.

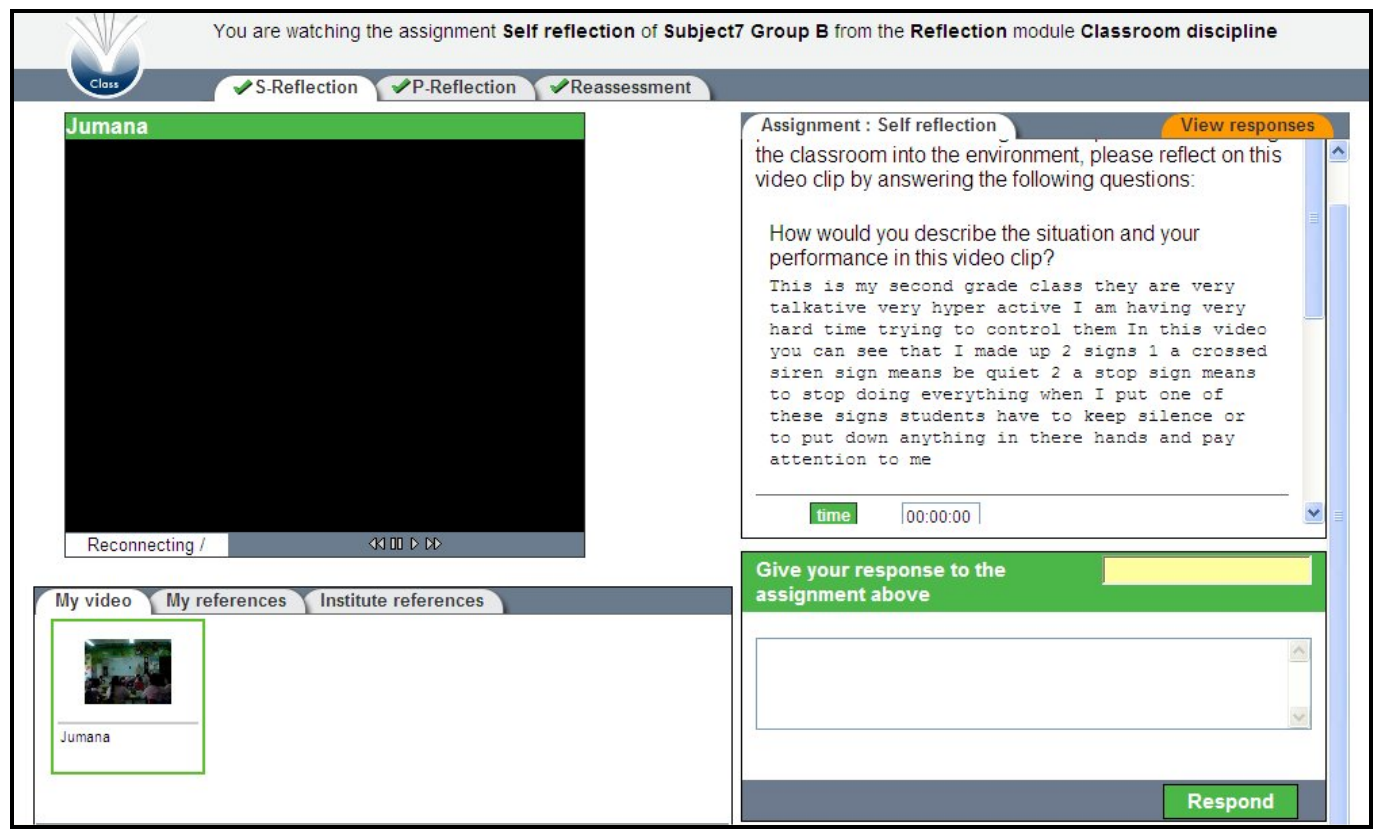

Figure 7 The peers' pages 
As shown in Figure 7, the top of the page presents information about this page including the name of the participant, the assignment, and the module. Furthermore, three tabs are provided to allow the visitors to switch between the published assignments of this participant. Even though this page is relatively similar to the assignments pages, different functionalities are provided here. In the self-reflection assignment, the visitors can view the video clips, the description, and the selfreflection of this participant. In addition, the visitors can use the text box at the right side of the page to reflect on the performance of this participant by adding their responses. They can also view the responses of their peers and supervisors about this performance by using the view responses tab. By switching into the peer-reflection assignment, the visitors can read the question that was formulated and submitted by the participant and give their answer and feedback. They can also see the answers of their peers and supervisors regarding this question.

\section{- Finding alternatives assignment}

The finding alternatives page organizes the third assignment in the V-class environment, which is the last activity in the introductory text in Figure 2. The participants can reach this page by using the reassessment tab in the top of the module page. Similar to the self-reflection and peerreflection page, this page allows the participants to review their video clips and to submit their new conception regarding the practice of the discussed competence. The supervisors provide also guidance for the participants to help them carry out this assignment. The guidance for the finding alternatives assignment is presented in Figure 8.

Using the reflection you made on your own performance and the reflection you received from your colleagues, you should be able to reassess your own performance and to develop alternative behaviors for practicing this competence in the future:

- How would you describe your future practice of maintaining discipline and controlling your classroom based on what you have learned in this assignment?

- Match all of the performances that you reviewed including your own performance into one of the following phrases (Excellent - Very good - Good - Complex). Note: Please use each phrase for one participant only. Example: Khalid complex - Dana good - Abdulaziz very good - Saud excellent

Figure 8 Directions for the finding alternatives activity

The first question in the supervisors' guidance stimulates participants' ability on constituting and developing a new behavior and practice that improves their performance regarding this competence. The second requirement in this guidance, however, aimed to trace participants' perspectives toward all performances in order to use these perspectives in the group reflection at the end of this investigation. 


\section{APPENDIX 6}

\section{Guidelines for supervisors's interview}

For the original data from this interview, please contact the researcher.

- What is your general impression of this experiment?

- In general, do you think the reflective practice method has an influence on the learning process?

- If so, how? Please give an example

- In general, do you think the reflective practice method has an influence on students' achievement?

- If so, how? Please give an example

- What do you think of the quality of the reflection students wrote?

- Please explain your answer and give an example

- Has the quality of reflection students wrote changed (increased/decreased) over time during the experiment?

- Why?

"Now I would like to discuss with you the differences between this field training and previous courses in relation to the reflection activities"

- In comparison with previous field training courses, which course requires more time and effort from the students?

- Why?

- In comparison with previous field training courses, which course requires more time and effort from the supervisor?

- Why?

- Do you think there is a difference in the performance of the students from this course in comparison with students from previous courses?

- If so, what and why?

- In comparison with previous field training courses, where do you find a stronger presence of theory?

- In this course, please explain

- In previous courses, please explain

- If you have been asked to choose for your students between practicing field training with or without the reflective practice method, what would you choose?

- Please explain why

"Now I would like to discuss with you the influence of practicing the reflection on the gap between theory and practice" 
Interviewer note: introduce all questions of this section to the supervisors and ask for their preference in how to handle this section.

- In general, do you think the reflective practice method has an influence on the gap between theory and practice?

- Please explain

- Do you think the description activities during the experiment have an influence on connecting theory with practice?

- If yes, how? Please give an example

- If no, how can it be used to enhance the theory/practice's relationship?

- Do you think the self-reflection activities during the experiment have an influence on connecting theory with practice?

- If yes, how? Please give an example

- If no, how can it be used to enhance the theory/practice's relationship?

- Do you think the peer reflection activities during the experiment have an influence on connecting theory with practice?

- If yes, how? Please give an example

- If no, how can it be used to enhance the theory/practice's relationship?

- Do you think the reassessment activities during the experiment have an influence on connecting theory with practice?

- If yes, how? Please give an example

- If no, How it can be used to enhance the theory/practice's relationship?

Is there something you wish to add about the experience you had with supervising students who practice the reflection activities in field training? 


\section{APPENDIX 7}

\section{Guidelines for students' interviews (G 2 \& 4)}

For the original data from this interview, please contact the researcher.

- What is your general impression of this experiment?

- How would you describe your experience with the reflective practice method in this field training course?

- At the end of the field training, do you feel that the reflection skills can help you later as a teacher?

- If so, how? Please give an example

"Now I would like to discuss with you the pedagogical influence of the reflective practice method on your achievement"

- What influence did the reflective practice have on your understanding of the imbedded theory behind the practiced skill?

- If positive, please explain how

- If negative, please explain how

- What influence did the reflective practice have on your ability to master the practiced skill?

- Positive, please explain how?

- Negative, please explain how?

"Now I would like to discuss with you the difficulties that you may have encountered with carting out the reflection activities"

- What were the difficulties that you may have encountered during the field training with relation to the reflection activities?

- Difficulties related to recording activities

- Difficulties related to description activities

- Difficulties related to self reflection activities

- Difficulties related to peer reflection activities

- Difficulties related to reassessment activities

"Now I would like to discuss with you the effectiveness of the online environment in facilitating the reflection activities" 
- How would you evaluate the usability of the environment in general?

- Accessing the environment

- Finding your way

- Submitting material

- Finding material

- Uploading and viewing video

- Communication

- How would you evaluate the usefulness of the environment in facilitating the different reflection activities?

- Facilitating the recording activities

- Facilitating the description activities

- Facilitating the self reflection activities

- Facilitating the peer reflection activities

- Facilitating the reassessment activities

- Is there anything you wish to add about the experience you had by practicing this field training course with the reflective practice method? 


\section{APPENDIX 8}

\section{Guidelines for students' interviews (G 1 \& 3)}

For the original data from this interview, please contact the researcher.

- What is your general impression of this experiment?

- How would you describe your experience with the reflective practice method at the first part of the field training course?

- At the end of the field training, do you feel that the reflection skills can help you later as a teacher?

- If so, how? Please give an example

- How would you describe your experience without the reflective practice method at the second part of the field training course? (G1 and 3)

- If you have been asked to choose between practicing field training with or without the reflective practice, what would you choose? (G 1 and 3)

- Please explain why

"Now I would like to discuss with you the pedagogical influence of the reflective practice method on your achievement"

- What influence did the reflective practice have on your understanding of the imbedded theory behind the practiced skill?

- If positive, please explain how

- If negative, please explain how

- What influence did the reflective practice have on your ability to master the practiced skill?

- If positive, please explain how

- If negative, please explain how

"Now I would like to discuss with you the difficulties that you may have encountered with carting out the reflection activities"

- What were the difficulties that you may have encountered during the field training with relation to the reflection activities?

- Difficulties related to recording activities

- Difficulties related to description activities

- Difficulties related to self reflection activities

- Difficulties related to peer reflection activities

- Difficulties related to reassessment activities

"Now I would like to discuss with you the effectiveness of the online environment in facilitating the reflection activities" 
- How would you evaluate the usability of the environment in general?

- Accessing the environment

- Finding your way

- Submitting material

- Finding material

- Uploading and viewing video

- Communication

- How would you evaluate the usefulness of the environment in facilitating the different reflection activities?

- Facilitating the recording activities

- Facilitating the description activities

- Facilitating the self reflection activities

- Facilitating the peer reflection activities

- Facilitating the reassessment activities

"Now I would like to discuss your experience of practicing field training with and without the reflective practice method"

- By experiencing both the practice of field training with and without the reflection activities, which method provided you more experience?

- How?

- By experiencing both the practice of field training with and without the reflection activities, which method required more time and effort from you?

- Why?

- In comparison between the period with the reflection (the first part of the semester) and the period without the reflection (the second part of the semester), where do you find a stronger presence of theory?

- If the first part, please explain

- If the second part, please explain

- During the practice of field training without the reflection at the second part of the semester, are there any reflection activities you continued to use?

- What and why?

- At the second part of the semester when you were practicing field training without reflection, are there any reflection activities you wish to continue using?

- What and why?

- Is there anything you wish to add about the experience you had by practicing field training with and without the reflective practice method? 


\section{APPENDIX 9}

\section{Results of the Difficulties Questionnaire}

\begin{tabular}{|c|c|c|c|c|c|c|c|}
\hline 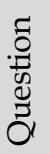 & $\begin{array}{c}\text { Not } \\
\text { applicable } \\
\text { at all }\end{array}$ & $\begin{array}{c}\text { Slightly } \\
\text { applicable }\end{array}$ & $\begin{array}{l}\text { Applicable } \\
\text { to a some } \\
\text { extend }\end{array}$ & Applicable & $\begin{array}{c}\text { Applicable } \\
\text { to a great } \\
\text { extend }\end{array}$ & Mean & $\begin{array}{l}\text { Standard } \\
\text { deviation }\end{array}$ \\
\hline \multicolumn{8}{|c|}{ Part 1: Difficulties related to recording } \\
\hline 11 & 11 & 2 & 1 & 1 & 1 & 1.68 & 1.25 \\
\hline 12 & 4 & & 2 & 7 & 3 & 3.31 & 1.49 \\
\hline 13 & 6 & 3 & 5 & 2 & & 2.18 & 1.10 \\
\hline 14 & 4 & 3 & 7 & 2 & & 2.43 & 1.03 \\
\hline 15 & & & & & & $=8$ & \\
\hline \multicolumn{8}{|c|}{ Part 2: Difficulties related to description } \\
\hline 16 & 1 & 2 & 8 & 4 & 1 & 3.12 & .95 \\
\hline 17 & 4 & & 10 & 2 & & 2.62 & 1.02 \\
\hline 18 & 2 & 2 & 5 & 6 & 1 & 3.12 & 1.14 \\
\hline 19 & 3 & 6 & 2 & 3 & 2 & 2.68 & 1.35 \\
\hline \multirow{2}{*}{\multicolumn{8}{|c|}{ Part 3: Difficulties related to self reflection }} \\
\hline & & & & & & & \\
\hline 21 & 3 & 2 & 5 & 4 & 2 & 3.00 & 1.31 \\
\hline 22 & 7 & 4 & 2 & 2 & 1 & 2.12 & 1.31 \\
\hline 23 & 1 & 2 & 8 & 1 & 4 & 3.31 & 1.19 \\
\hline 24 & 2 & 3 & 9 & 2 & & 2.68 & .87 \\
\hline 25 & & Yes $=0$ & & & & $=16$ & \\
\hline \multicolumn{8}{|c|}{ Part 4: Difficulties related to peer reflection } \\
\hline 26 & 7 & 2 & 2 & 3 & 5 & 2.43 & 1.54 \\
\hline 27 & 8 & 3 & 2 & 3 & & 2.00 & 1.21 \\
\hline 28 & 7 & 3 & 4 & & 2 & 2.18 & 1.37 \\
\hline 29 & 8 & 3 & 2 & 3 & & 2.00 & 1.21 \\
\hline 30 & & Yes $=0$ & & & & $=16$ & \\
\hline \multicolumn{8}{|c|}{ Part 5: Difficulties related to assessment } \\
\hline 31 & 5 & 6 & 4 & 1 & & 2.06 & .92 \\
\hline 32 & 7 & 3 & 4 & 1 & 1 & 2.12 & 1.25 \\
\hline 33 & 7 & 5 & 4 & & & 1.81 & .83 \\
\hline 34 & 8 & 5 & 3 & & & 1.68 & .79 \\
\hline 35 & Yes $=0$ & & & & & $=16$ & \\
\hline
\end{tabular}




\section{APPENDIX 10}

\section{Results of the Effectiveness Questionnaire}

\begin{tabular}{|c|c|c|c|c|c|c|c|}
\hline 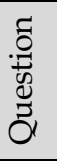 & $\begin{array}{l}\text { Not easy } \\
\text { at all }\end{array}$ & $\begin{array}{l}\text { Slightly } \\
\text { easy }\end{array}$ & $\begin{array}{l}\text { Easy to a } \\
\text { some } \\
\text { extend }\end{array}$ & Easy & $\begin{array}{c}\text { Easy to a } \\
\text { great } \\
\text { extend }\end{array}$ & Mean & $\begin{array}{l}\text { Standard } \\
\text { deviation }\end{array}$ \\
\hline \multicolumn{8}{|c|}{ Part 1: The usability of the environment } \\
\hline 36 & & 1 & 1 & 6 & 8 & 4.31 & .87 \\
\hline 37 & & 1 & 1 & 4 & 10 & 4.43 & .89 \\
\hline 38 & & & & 5 & 11 & 4.68 & .47 \\
\hline 39 & & 1 & 1 & 1 & 13 & 4.62 & .88 \\
\hline 40 & & 1 & 1 & 1 & 13 & 4.62 & .88 \\
\hline 41 & & & & 6 & 10 & 4.62 & .50 \\
\hline 42 & 2 & 2 & 3 & 4 & 5 & 3.50 & 1.41 \\
\hline 43 & 1 & & 1 & 4 & 10 & 4.37 & 1.08 \\
\hline 44 & & & & 3 & 13 & 4.81 & .40 \\
\hline 45 & & & & 2 & 14 & 4.87 & .34 \\
\hline
\end{tabular}

\begin{tabular}{|c|c|c|c|c|c|c|c|}
\hline 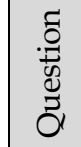 & $\begin{array}{l}\text { Not useful } \\
\text { at all }\end{array}$ & $\begin{array}{l}\text { Slightly } \\
\text { useful }\end{array}$ & $\begin{array}{l}\text { Useful to } \\
\text { a some } \\
\text { extend }\end{array}$ & Useful & $\begin{array}{l}\text { Useful to } \\
\text { a great } \\
\text { extend }\end{array}$ & Mean & $\begin{array}{l}\text { Standard } \\
\text { deviation }\end{array}$ \\
\hline
\end{tabular}

Part 2: The usefulness of the environment

\begin{tabular}{|l|l|l|l|l|l|r|}
\hline 46 & & 1 & 4 & 11 & 4.62 & .61 \\
\hline 47 & & 2 & 4 & 10 & 4.50 & .73 \\
\hline 48 & & 1 & 4 & 11 & 4.62 & .61 \\
\hline 49 & & 1 & 3 & 12 & 4.68 & .60 \\
\hline 50 & & 1 & 5 & 10 & 4.56 & .62 \\
\hline
\end{tabular}




\section{APPENDIX 11}

\section{Results of the Achievement Questionnaire}

\begin{tabular}{|c|c|c|c|c|c|c|c|}
\hline 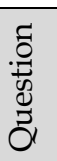 & $\begin{array}{c}\text { Not } \\
\text { effective } \\
\text { at all }\end{array}$ & $\begin{array}{l}\text { Slightly } \\
\text { effective }\end{array}$ & $\begin{array}{l}\text { Effective } \\
\text { to a some } \\
\text { extend }\end{array}$ & Effective & $\begin{array}{l}\text { Effective } \\
\text { to a great } \\
\text { extend }\end{array}$ & Mean & $\begin{array}{l}\text { Standard } \\
\text { deviation }\end{array}$ \\
\hline \multicolumn{8}{|c|}{ Part 1: The effect of reflection in connecting theory to practice } \\
\hline 1 & & & 1 & 8 & 7 & 4.37 & .61 \\
\hline 2 & & & 3 & 7 & 6 & 4.18 & .75 \\
\hline 3 & & & 4 & 6 & 6 & 4.12 & .80 \\
\hline 4 & & & 1 & 5 & 10 & 4.56 & .62 \\
\hline 5 & & & 3 & 4 & 11 & 4.62 & .61 \\
\hline
\end{tabular}

\begin{tabular}{|c|c|c|c|c|c|c|c|}
\hline \multirow{2}{\tilde{D}}{} & $\begin{array}{c}\text { Not } \\
\text { effective } \\
\text { at all }\end{array}$ & $\begin{array}{c}\text { Slightly } \\
\text { effective }\end{array}$ & $\begin{array}{c}\text { Effective } \\
\text { to a some } \\
\text { extend }\end{array}$ & Effective & $\begin{array}{c}\text { Effective } \\
\text { to a great } \\
\text { extend }\end{array}$ & Mean & $\begin{array}{c}\text { Standard } \\
\text { deviation }\end{array}$ \\
\hline
\end{tabular}

Part 2: The effect of reflection in mastering the required competences

\begin{tabular}{|c|c|c|c|c|c|c|}
\hline 6 & & 1 & 9 & 6 & 4.31 & .60 \\
\hline 7 & & 4 & 5 & 7 & 4.18 & .83 \\
\hline 8 & & 4 & 4 & 8 & 4.06 & 1.18 \\
\hline 9 & & 4 & 5 & 7 & 4.18 & .83 \\
\hline 10 & 3 & 3 & 3 & 7 & 3.87 & 1.20 \\
\hline
\end{tabular}


